\title{
Analysis on Combined Heat and Power, and Combined Heat and Power Hybrid Systems for Unconventional Drilling Operations
}

\author{
Diego G. Dranuta Ferrer \\ WVU, dgdranuta@mix.wvu.edu
}

Follow this and additional works at: https://researchrepository.wvu.edu/etd

Part of the Mechanical Engineering Commons

\section{Recommended Citation}

Dranuta Ferrer, Diego G., "Analysis on Combined Heat and Power, and Combined Heat and Power Hybrid Systems for Unconventional Drilling Operations" (2021). Graduate Theses, Dissertations, and Problem Reports. 8279.

https://researchrepository.wvu.edu/etd/8279

This Thesis is protected by copyright and/or related rights. It has been brought to you by the The Research Repository @ WVU with permission from the rights-holder(s). You are free to use this Thesis in any way that is permitted by the copyright and related rights legislation that applies to your use. For other uses you must obtain permission from the rights-holder(s) directly, unless additional rights are indicated by a Creative Commons license in the record and/ or on the work itself. This Thesis has been accepted for inclusion in WVU Graduate Theses, Dissertations, and Problem Reports collection by an authorized administrator of The Research Repository @ WVU. For more information, please contact researchrepository@mail.wvu.edu. 


\title{
Analysis on Combined Heat and Power, and Combined Heat and Power Hybrid Systems for Unconventional Drilling Operations
}

\author{
Diego G. Dranuta Ferrer
}

Thesis submitted to the Benjamin M. Statler College of Engineering and Mineral Resources At West Virginia University

In partial fulfillment of the requirements for the degree of

\author{
Master of Science \\ In \\ Mechanical Engineering \\ Derek Johnson, Ph.D. PE, Chair \\ Andrew Nix, Ph.D. \\ Scott Wayne, Ph.D. \\ Department of Mechanical and Aerospace Engineering \\ Morgantown, West Virginia \\ 2021
}

Keywords: Combined Heat Power, Hybrid Energy Management System, Energy Utilization Factor, Unconventional Well Development 


\title{
Abstract \\ Analysis on Combined Heat and Power, and Combined Heat and Power Hybrid Systems for Unconventional Drilling Operations
}

\author{
Diego G. Dranuta Ferrer
}

The United States (U.S.) has experienced a natural gas "boom" due to the development of unconventional shale plays, but well development is energy intensive. Operations use electric drilling rigs typically powered by either three high-horsepower diesel engines (HHPDE) or three dedicated natural gas engines (DNGE) and associated generators. From a first law analysis, HHPDEs peak at $42 \%$ efficiency at full load, while DNGE peak at about $30 \%$. Most of the fuel energy is lost as heat rejected by the exhaust and radiators. Concurrently, during cold seasons rigs utilize boilers to provide steam throughout the rig to prevent freezing and provide comfort. The U.S. Department of Energy (DOE) and the National Energy Technology Laboratory (NETL) recently granted West Virginia University (WVU) funding, under agreement DE-FE0024297, to "develop and validate new knowledge and technology to improve recovery efficiency and minimize environmental implications of unconventional resource development." As part of the funding, WVU was tasked with auditing the energy consumption during the horizontal drilling of an unconventional well, processing the data, and assessing methods to reduce fossil fuel consumption and associated emissions during the development phase.

My research analysis focused on a combined heat power (CHP) approach as a means to improve the utilization factor (UF) of fossil energy consumed during development. Engine activity, boiler fuel consumption, and exhaust gas temperatures were recorded during winter drilling of an entire well in the Marcellus shale. Four characteristic activity cycles were extracted from recorded engine and boiler activity to represent four energy consumption scenarios. Exhaust and jacket water heat exchangers (E-HEX, JW-HEX) were designed and simulated, and results were analyzed in 0-D models for the four case scenarios. A 584-kWh hybrid energy management system (HEMS) was also designed and simulated into the model as another method to reduce fossil fuel energy consumption during well development.

HHPDE UF improved on average from $35.7 \%$ to $55.7 \%$ if only E-HEXs were used and improved to $72.7 \%$ if JW-HEXs were also used. DNGEs were less efficient than HHPDE; therefore, more waste heat was available and at a higher quality (temperature). DNGE average UF increased from $19.0 \%$ to $34.9 \%$ using E-HEX only. HEMS utilization improved UF up to an average of $76.9 \%$ and $39.1 \%$ for HHPDE CHP and DNGE CHP systems, respectively 


\section{Acknowledgments}

I want to thank Dr. Derek Johnson for the opportunity to work with him and his team. His tutelage, experience, and guidance made it possible for me to grow as a student, as a researcher, as a worker, as a professional, and as an individual. Thanks, boss, for providing me with the opportunity to come back to school to continue with my academic career.

I would also like to thank the other members of my committee: Drs. Andrew Nix and Scott Wayne. Both of them were very important in my formation as a graduate student through taught courses and advising for my research project.

Recognition must also be given to the Department of Energy and the National Energy Technology Laboratory for the funding, which allowed me to complete this work.

I also have to thank my laboratory coworkers. Their willingness to assist me any time needed, the experience they shared with me, and the personal time shared with them made my research experience enjoyable.

Lastly, I would like to thank my parents, brother, and family for always being present throughout my academic experience. Although of being far away for so many years, they have always been supportive, and they have been vital in my academic and personal achievements. My friends and roommates also deserve a special thanks for helping me enjoy my college experience to the fullest. 


\section{Table of Contents}

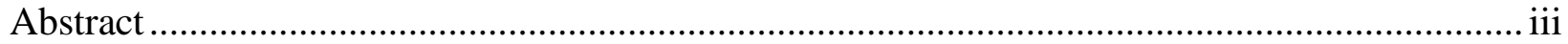

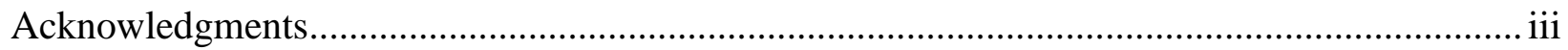

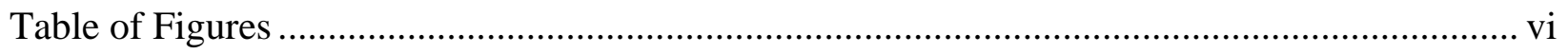

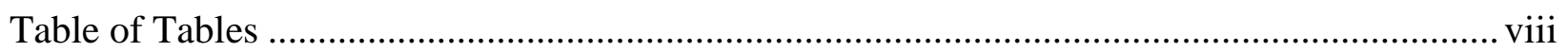

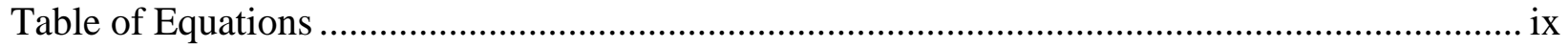

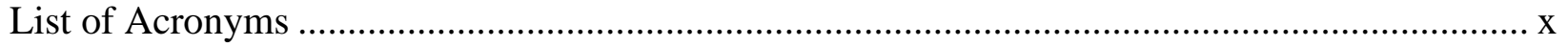

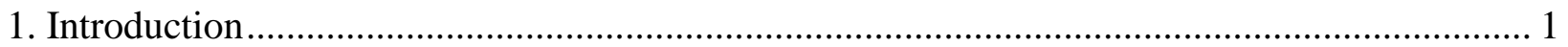

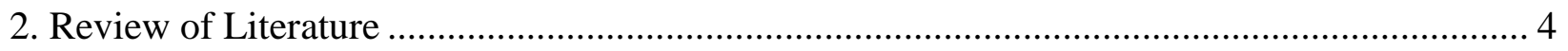

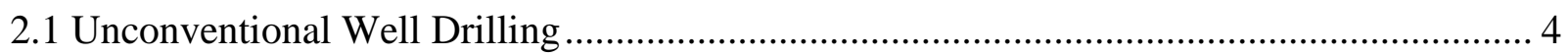

2.2 Energy Consumption During Well Development ............................................................ 6

2.3 Non-road Land Drilling Engines Emissions ……………................................................ 7

2.4 Waste Heat Recovery ………………...................................................................... 8

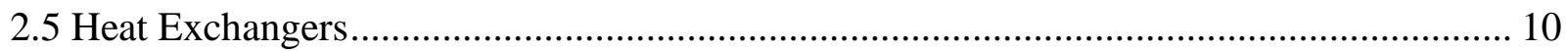

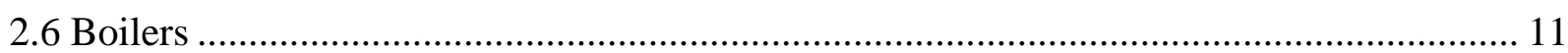

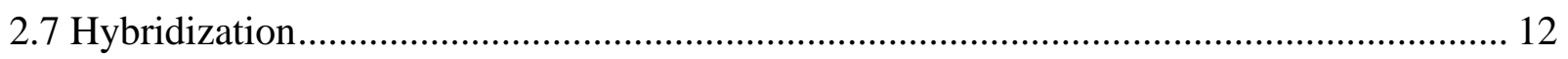

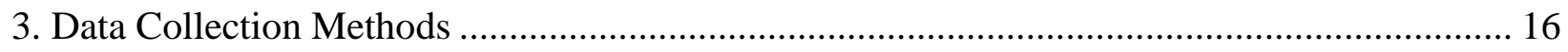

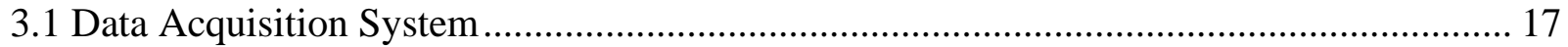

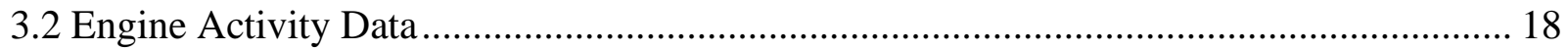

3.3 Diesel Fuel Consumption ......................................................................................... 20

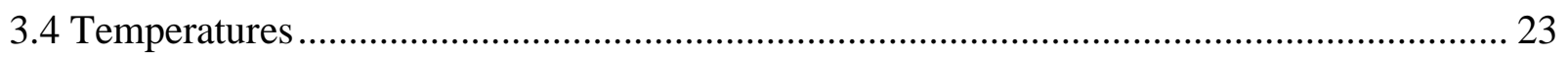

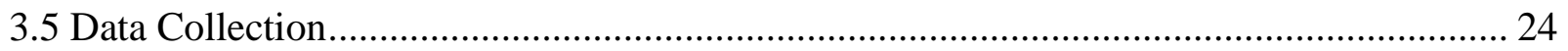

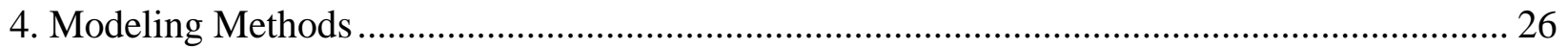

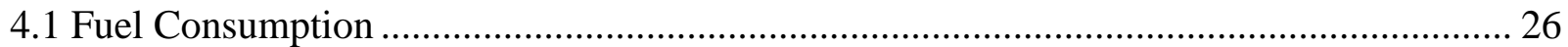

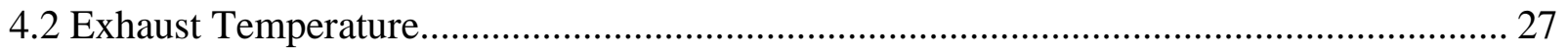

4.3 Exhaust Mass Flow and Exhaust Heat Rejection Models................................................. 28

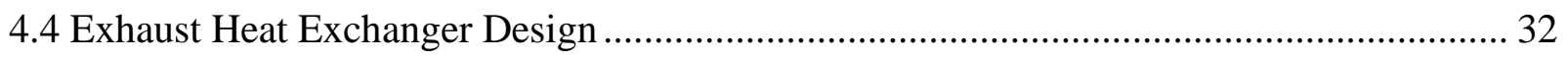

4.5 Hybrid System Battery Model........................................................................................... 37

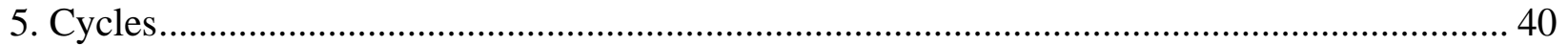

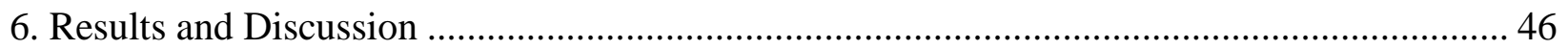

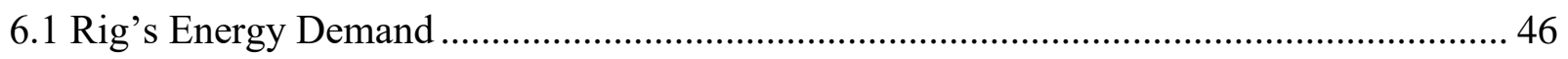

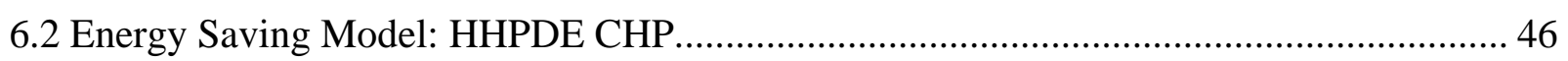




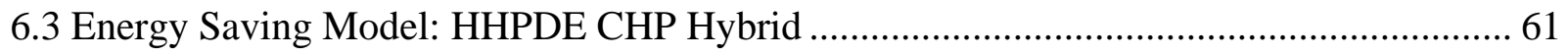

6.4 Energy Saving Model: DNGE CHP ................................................................... 70

6.5 Energy Saving Model: DNGE CHP Hybrid ......................................................... 77

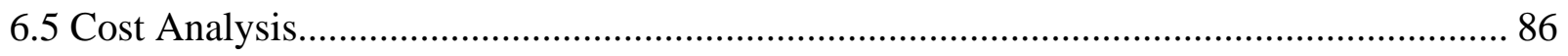

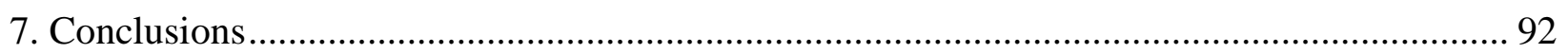

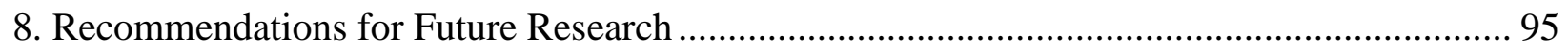

8.1Tier 4 Compression Ignition CHP and CHP hybrid system modeling ............................ 95

8.2 Waste Heat Recovery System On-site Validation..................................................... 95

8.3 Emissions Savings Through CHP and CHP Hybrid Systems ...................................... 95

8.4 Heat and Power Hybrid Energy Management System Integration ................................. 96

8.5 Waste Heat Recovery Analysis on Gas Turbine Powered Rigs ...................................... 97

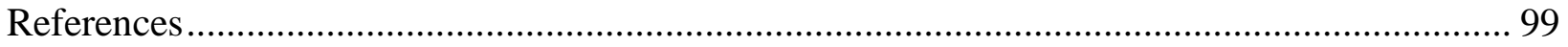

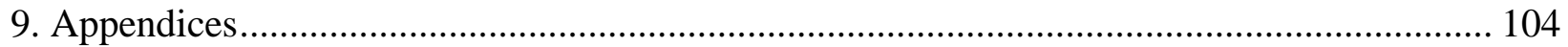

9.1 Appendix A: KRAL OEM 20 calibration test............................................................ 104

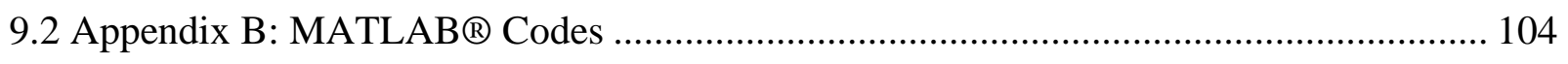

9.3 Appendix C: CHEMCAD Heat Exchangers TEMA Sheets ........................................ 120

9.4 Appendix D: Heat Exchanger Quotes ................................................................. 124

9.5 Appendix E: SIMULINK® 0-D Models.......................................................... 143

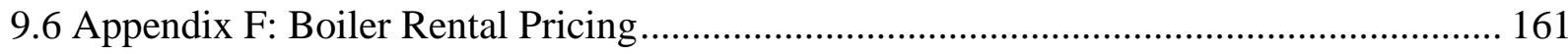




\section{Table of Figures}

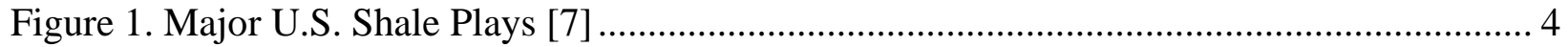

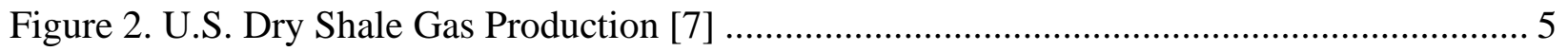

Figure 3. HHPDE-Powered Rig Equipped with a HEMS ....................................................... 14

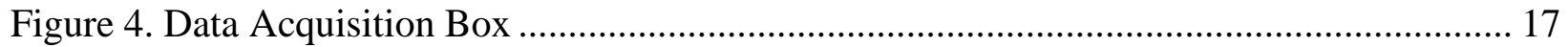

Figure 5. J1939 PGN And SPN IDs Used for Engine Data Collection (VDF) ............................ 19

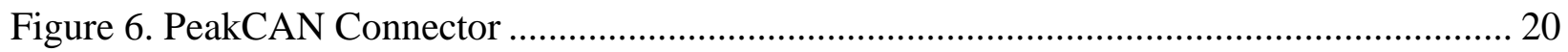

Figure 7. KRAL BEM 500 Display and KRAL OEM 20 Diesel Flow Meters ............................. 22

Figure 8. K=Type Thermocouple Installed in the Engine's Muffler ............................................ 24

Figure 9. HHPDE And DNGE Fuel Consumption Models ......................................................... 27

Figure 10. HHPDE And DNGE Exhaust Temperature Models ……………………….............. 28

Figure 11. Counterflow Shell and Tube Heat Exchanger Diagram Using the LMTD Method [52]

Figure 12. HHPDE E-HEX Sizing and Design Conditions in The CHEMCAD Environment.... 35

Figure 13. DNGE E-HEX Sizing and Design Conditions in the CHEMCAD Environment ....... 36

Figure 14. HHPDE ESG, HHPDE E-HEX, DNGE ESG, and DNGE E-HEX Heat Recovery as a

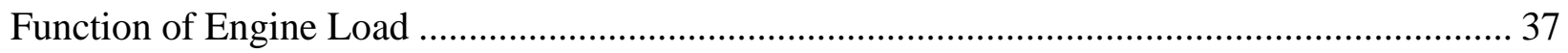

Figure 15. 2E1HR Cycle Genset Power Output ………............................................................. 42

Figure 16. 3E1HR Cycle Genset Power Output ......................................................................... 43

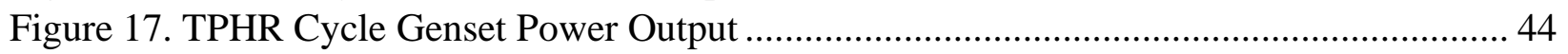

Figure 18. 24HR Cycle Genset Power Output .............................................................................. 45

Figure 19. HHPDE CHP 0-D SIMULINK Model ..................................................................... 48

Figure 20. HHPDE JW-HEX Mass Flow Rate Model ............................................................ 51

Figure 21. CAT G3512 Low-Speed Pressure Drop (B=1200 RPM) …………….................... 52

Figure 22. HHPDE JW-HEX Sizing and Design Conditions .................................................. 53

Figure 23. HHPDE JW-HEX Heat Recovery Model.................................................................. 54

Figure 24. HHPDE CHP System 0-D Model Equipped with HHPDE JW-HEX .......................... 55

Figure 25. HHPDE CHP System, 2E1HR Cycle Instant Heat Recovery ………......................... 56

Figure 26. HHPDE CHP System, 31HR Cycle Instant Heat Recovery .......................................... 56

Figure 27. HHPDE CHP System, TP1HR Cycle Instant Heat Recovery ……………................. 57

Figure 28. HHPDE CHP System, 24HR Cycle Instant Heat Recovery .......................................... 57

Figure 29. HHPDE CHP System, 24HR Cycle 30-Minute Heat Balance Moving Average........ 58

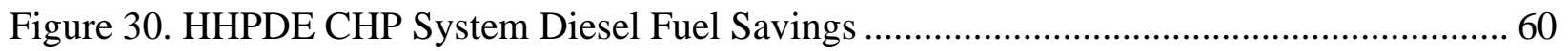

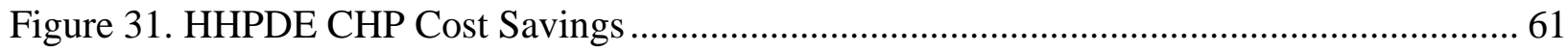

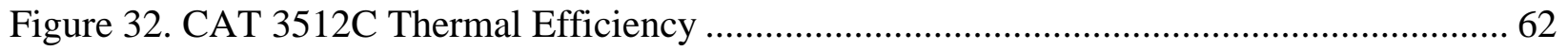

Figure 33. HHPDE CHP Hybrid System 0-D SIMULIK Model Diagram.................................... 63

Figure 34. HHPDE CHP Hybrid System, 2E1HR Cycle Instant Heat Recovery ............................ 64

Figure 35. HHPDE CHP Hybrid System, 3E1HR Cycle Instant Heat Recovery ........................... 65

Figure 36. HHPDE CHP Hybrid System, TP1HR Cycle Instant Heat Recovery.......................... 65

Figure 37. HHPDE CHP Hybrid System, 24HR Cycle Instant Heat Recovery ............................ 66

Figure 38. HHPDE CHP Hybrid System, 24HR Cycle 30-Minute Heat Balance Moving

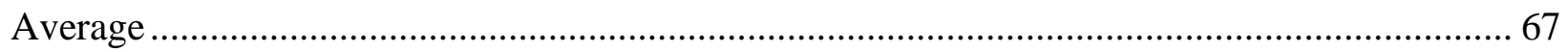

Figure 39. HHPDE CHP Hybrid System Diesel Fuel Savings ..................................................... 69 
Figure 40. HHPDE CHP Hybrid System Cost Savings..

Figure 41. HHPDE CHP Hybrid System, 24HR Cycle Instant Heat Recovery Utilizing Electric

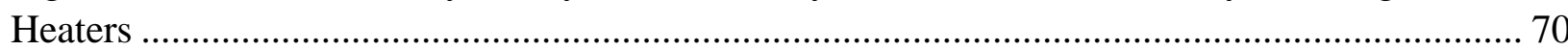

Figure 42. DNGE CHP System 0-D SIMULINK Model Diagram .............................................. 72

Figure 43. DNGE CHP System, 2E1HR Cycle Instant Heat Recovery …………………............ 73

Figure 44. DNGE CHP System, 3E1HR Cycle Instant Heat Recovery ....................................... 73

Figure 45. DNGE CHP System, TP1HR Cycle Instant Heat Recovery ......................................... 74

Figure 46. DNGE CHP System, 24HR Cycle Instant Heat Recovery …………………….......... 74

Figure 47. DNGE CHP System, 24HR Cycle 30-Minute Heat Balance Moving Average .......... 75

Figure 48. DNGE CHP System Natural Gas Savings............................................................... 76

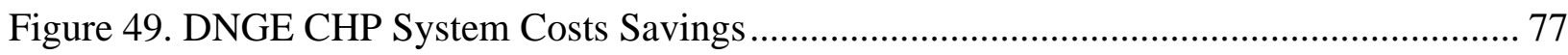

Figure 50. Waukesha L7044gsi Engine Thermal Efficiency ..................................................... 78

Figure 51. DNGE CHP Hybrid System 0-D SIMULINK Model Diagram ..................................... 79

Figure 52. DNGE CHP Hybrid System, 2E1HR Cycle Instant Heat Recovery .............................. 81

Figure 53. DNGE CHP Hybrid System, 3E1HR Cycle Instant Heat Recovery ……………......... 81

Figure 54. DNGE CHP Hybrid System, TP1HR Cycle Instant Heat Recovery ……………........ 82

Figure 55. DNGE CHP Hybrid System, 24HR Cycle Instant Heat Recovery ……….................. 82

Figure 56. DNGE CHP Hybrid System, 24HR Cycle 30-Minute Heat Balance Moving Average

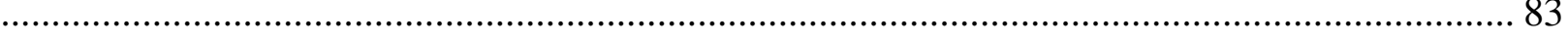

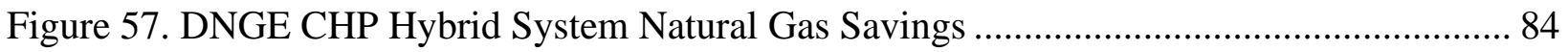

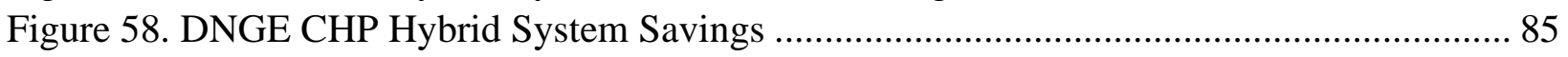

Figure 59. DNGE CHP Hybrid System, 24HR Cycle Instant Heat Recovery Equipped with

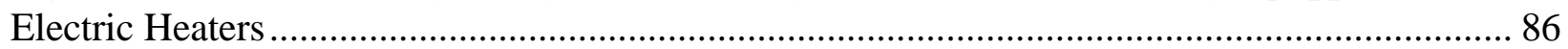

Figure 60. Gas Turbine Powered Drilling Rig SIMULINK Model............................................. 98 


\section{Table of Tables}

Table 1. Nonroad Compression-Ignition Engines: Exhaust Emissions Standards [23]................ 8

Table 2. Nonroad Large Spark-Ignition Engines: Exhaust Emissions Standards [24] ................ 8

Table 3. HHPDE And DNGE Engine Parameters [32,33] .................................................. 17

Table 4. KRAL OME 20 Diesel Flow Meters Technical Data .............................................. 21

Table 5. Exhaust Gas Temperature Data [32,33] ................................................................. 28

Table 6. CAT 3512C Exhaust Specifications [32] ................................................................. 29

Table 7. Specific Enthalpy of Dry Air And Water Vapor Used For HHPDE Exhaust Heat

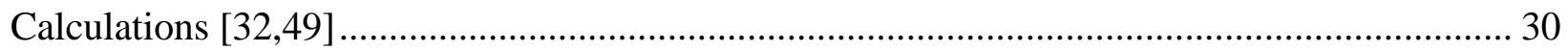

Table 8. CAT 3512C Mass Exhaust Flow Rate Model [32] ................................................... 30

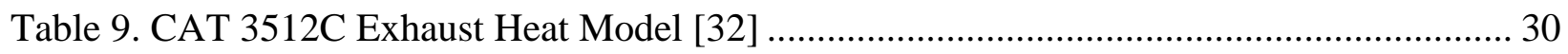

Table 10. Specific Enthalpy of Dry Air and Water Vapor Used For DNGE Exhaust Heat

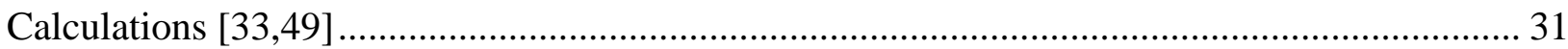

Table 11. Waukesha L7044GSI Mass Exhaust Flow Rate Model [33] ................................... 31

Table 12. Waukesha L7044GSI Exhaust Heat Model [33] .................................................. 32

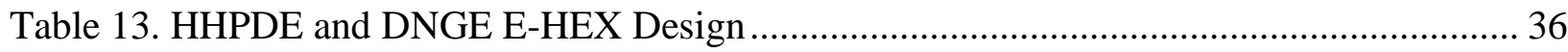

Table 14. HEMS Ideal Engine Load Controller ................................................................... 39

Table 15. Cycle Energy Demand Specifications ...................................................................... 46

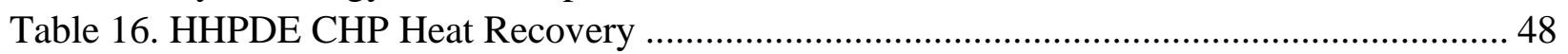

Table 17. HHPDE Heat Rejection Through the Radiator [32] ................................................ 49

Table 18. CAT 3512C Coolant Return Temperature Model .................................................... 49

Table 19. Coolant Mass Flow Model....................................................................................... 50

Table 20. CAT 3512C Coolant Model Error ............................................................................. 51

Table 21. HHPDE JW-HEX Design ................................................................................. 53

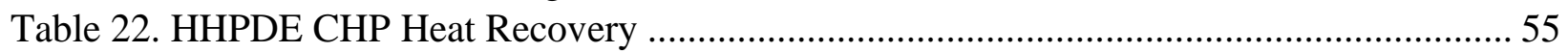

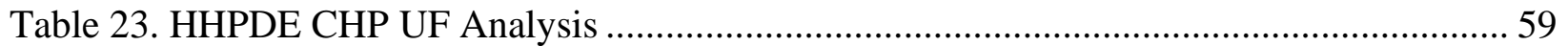

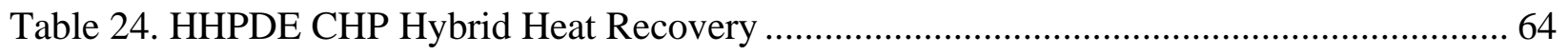

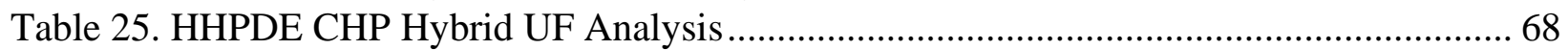

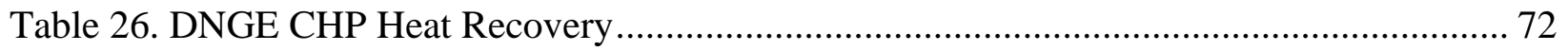

Table 27. DNGE CHP UF Analysis ............................................................................... 76

Table 28. DNGE CHP Hybrid System Heat Recovery ............................................................ 80

Table 29. DNGE CHP Hybrid System UF Analysis ......................................................... 84

Table 30. HHPDE CHP Return on Investment Analysis....................................................... 88

Table 31. HHPDE CHP Equipped with a HEMS Return on Investment Analysis .................... 89

Table 32. DNGE CHP System Return on Investment Analysis ............................................. 90

Table 33. DNGE CHP System Equipped with the HEMS Return on Investment Analysis........ 91

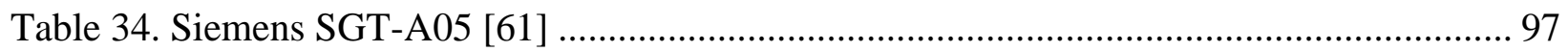




\section{Table of Equations}

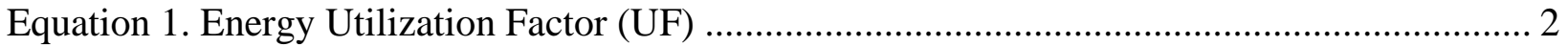

Equation 2. Boiler Fuel Consumption Energy Balance ....................................................... 23

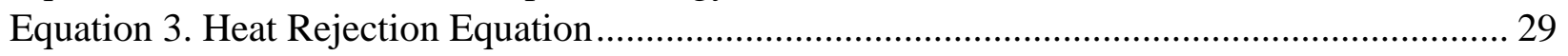

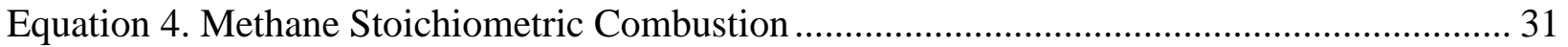

Equation 5. Heat Exchanger Heat Transfer ...................................................................... 33

Equation 6. Logarithmic Mean Temperature Difference .................................................... 33

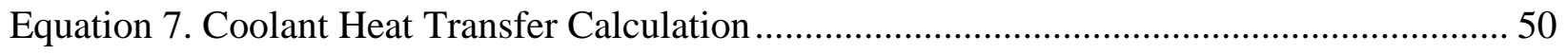

Equation 8. Coolant Mass Flow Rate Error ........................................................................ 51

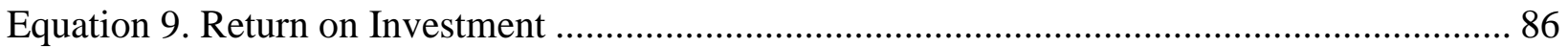




\section{List of Acronyms}

\section{Acronym}

${ }^{\circ} \mathrm{C}$

A

AFR

ASME

Bhp

bhp

BSFC

BTU

CAFEE

CAN

CARB

CAT

$\mathrm{CH}_{4}$

$\mathrm{CHP}$

$\mathrm{CO}_{2}$

DAQ

DNGE

DOE

DPF

ECU

EF

EIA

EPA

ESG

$\mathrm{Ft}^{3}$

FTIR

$\mathrm{g}$

gal

GE

genset

GHG

Gph

$\mathrm{h}$

$\mathrm{H}_{2} \mathrm{O}$

HEMS

HEX

HHPDE

HP

$\mathrm{Hr}$

HVAC

$\mathrm{Hz}$

ID

ISO

$\mathrm{kPa}$
Word or Phrase

Degrees Celsius

Surface Area

Air to Fuel Ratio

American Society of Mechanical Engineers

Boiler Horsepower

Brake Horsepower

Brake Specific Fuel Consumption

British Thermal Unit

Center for Alternative Fuels, Engines, and Emissions

Communication Area Network

California Air Resources Board

Caterpillar ${ }^{\circledR}$

Methane

Combined Heat Power

Carbon Dioxide

Data Acquisition

Dedicated Natural Gas Engine

Department of Energy

Diesel Particulate Filter

Engine Control Unit

Evaluation Function

Energy Information Administration

Environmental Protection Agency

Exhaust Steam Generator

Cubic Feet

Fourier-Transform Infrared Spectroscopy

Grams

Gallons

General Electric

Electric Generator Set

Greenhouse Gas

Gallons per Hour

Specific Enthalpy

Water

Hybrid Energy Management System

Heat Exchanger

High Horsepower Diesel Engine

Horsepower

Hour

Heating Ventilating and Air Conditioning

Hertz

Identification

International Organization for Standardization

Kilopascal 
$\mathrm{kW}$

kWe

Kwh

L

LA

Lbs

LHV

LMTD

$\mathrm{m}^{3}$

$\mathrm{MBH}$

Min

MJ

MW

$\mathrm{N}_{2}$

NETL

$\mathrm{NM}$

$\mathrm{NO}_{\mathrm{x}}$

NTU

$\mathrm{NY}$

$\mathrm{O}_{2}$

$\mathrm{OH}$

ORC

PA

PGN

PM

ppm

Psi

Psig

rpm

SAE

SCF

SI

$\mathrm{Sm}^{3}$

SOC

SPN

TE

TEG

TEMA

TX

U

UF

ULSD

US

$\mathrm{V}$

VDF

WHR
KiloWatt

Electric KiloWatt

Kilowatt per Hour

Liters

Louisiana

Pounds

Lower Heating Value

Logarithmic Mean Temperature Difference

Cubic Meter

Million BTU per Hour

Minute

Mega Joule

Mega Watt

Dinitrogen

National Energy Technology Laboratory

New Mexico

Oxides of Nitrogen

Number of Transfer Units

New York

Oxygen

Ohio

Organic Rankine Cycle

Pennsylvania

Parameter Group Number

Particulate Matter

Parts Per Million

Pounds per Square Inch

Pounds per Square Inch Gauge

Revolutions Per Minute

International Society of Automotive Engineers

Standard Cubic Feet

International System

Standard Cubic Meter

State of Charge

Suspect Parameter Number

Thermoelectric

Thermoelectric Generator

Tubular Exchanger Manufacturer Association

Texas

Heat Transfer Coefficient

Utilization Factor

Ultra-Low-Sulfur Diesel

United States

Volts

Vector Database File

Waste Hear Recovery 
WJ

Water Jacket

WV

West Virginia

WVU

West Virginia University 


\section{Introduction}

The United States (U.S.) has experienced a natural gas "boom" over the past few decades. Natural gas gross withdrawals have increased 52\% since 2010 from 27 million to 41 million cubic feet per year [1]. Projections indicate that natural gas consumption will keep growing as the energy industry phases towards green energy. Higher withdrawals are possible due to the implementation of new techniques such as unconventional drilling and hydraulic fracturing technologies that enable cost-effective extraction from shale gas reserves, but well development is energy intensive. Operations use electric drilling rigs typically powered by either three high horsepower diesel engines (HHPDE) or three dedicated natural gas engines (DNGE) and associated generators. From a first law analysis, HHPDEs peak at about $42 \%$ efficient at full load, while DNGEs peak at about $30 \%$. Most fuel energy is lost as heat rejected by the exhaust and radiators. Concurrently, during cold seasons rigs utilize boilers to provide steam throughout the rig to prevent freezing and provide comfort. Strategies are being studied to reduce associated fuel costs and emissions [2].

Government agencies, including the U.S. Environmental Protection Agency (EPA), the California Air Resources Board (CARB), and the U.S. Department of Energy (DOE), are tasked with determining new techniques to reduce greenhouse gas (GHG) engine emissions. The U.S. DOE and the National Energy Technology Laboratory (NETL) recently granted West Virginia University (WVU) funding, under agreement DE-FE0024297, to "develop and validate new knowledge and technology to improve efficiency and minimize environmental implications of unconventional resource development." As part of the funding, WVU was tasked with auditing the energy consumption during the horizontal drilling of an unconventional well, processing the data, and assessing methods to reduce fossil fuel consumption and associated emissions during the development phase.

Combined heat and power (CHP) models allow researchers to quantify and estimate possible waste energy recovery from the same engines as those that operate in the field. The engines are attached to electric generators that power drilling rigs. The engines and generators together are also known as gensets. Evaluating the true impact of the gensets deployed in the field can be accomplished using on-site genset activity data. In-field data were collected from the gensets and boiler during drilling of an unconventional well in the Marcellus shale play, so that representative fuel and energy-saving systems could be modeled. The energy-saving techniques examined with the 
models were CHP and a hybrid energy management system (HEMS). Exhaust heat exchangers (EHEX) and jacket water heat exchangers (JW-HEX) were designed, modeled, and simulated in the CHEMCAD® software environment, while the HEMS was modeled to meet 584-kW-hr battery technical specifications [2]. Four characteristic cycles were extracted from in-use genset activity to represent possible scenarios during the unconventional drilling. Cycles and energy recovery system models were combined into a SIMULINK software environment for system performance simulations.

Results were calculated in terms of energy utilization factor (UF). The UF was defined as the amount of work and heat produced by the gensets to the fuel's energy presented in Equation 1. Recovering enough heat from the gensets while powering the rig would allow operations to reduce the boiler utilization or eliminate it.

$$
\begin{aligned}
& \text { Equation 1. Energy Utilization Factor }(\mathbf{U F}) \\
& U F=\frac{\text { Genset Work }(k J)+\text { Genset Heat }(k J)}{\text { Fuel's Energy }(k J)}
\end{aligned}
$$

Research Hypothesis: Energy recovery methods deployed in other stationary or mobile applications (CHP and HEMS) could be deployed at unconventional well sites to reduce energy and fossil fuel consumption through possible elimination of boiler systems and overall improvement in energy UF.

To assess this hypothesis, I conducted the following main research tasks:

1) Conducted a literature review on well development and energy-saving technologies.

2) Developed a data acquisition system necessary to characterize the engine and boiler activity during unconventional well development.
a) Integration of engine ECU data within SCIMITAR Software
b) Deployed and monitored the system in the field.
c) Collected and analyzed the activity data.

3) Created multiple activity cycles to assess energy-saving technologies through reduced-order models. 
4) Used commercially available modeling software to design and evaluate various heat exchangers.

5) Developed 0-D models to assess potential energy savings - fuel, costs, emissions. 


\section{Review of Literature}

\subsection{Unconventional Well Drilling}

Estimated natural gas reserves rose to 2074 trillion cubic feet in 2008, from 1532 trillion cubic feet in 2006 [3]. Proved natural gas reserves rose from 213 trillion cubic feet in 2005 to 505 trillion cubic feet in 2018 [4]. Shale gas represented $68 \%$ of proved natural gas reserves in the U.S. in 2018 [5]. Estimations based on recoverable resources of dry natural gas in the U.S., assuming the production's annual rate to be similar to the production in 2018, show that the U.S. has enough natural gas to last about 92 years [6]. The U.S. has been importing natural gas to supply the country's demand since 1957; however, due to the growth in known reserves and extraction capabilities, production has overpassed local demand. The U.S. started exporting natural gas in 2017 [7]. Natural gas is found in shale plays formations located in about 30 states: Texas (TX) and Pennsylvania (PA) being the most relevant natural gas producers. Shale plays are areas in which pockets of natural gas are available deep below the surface in tight shale formations. Figure 1 shows a map of the lower 48 major shale plays in the U.S., including Marcellus, Bakken, Barnett, Fayetteville, Eagle Ford, Haynesville, and Utica.

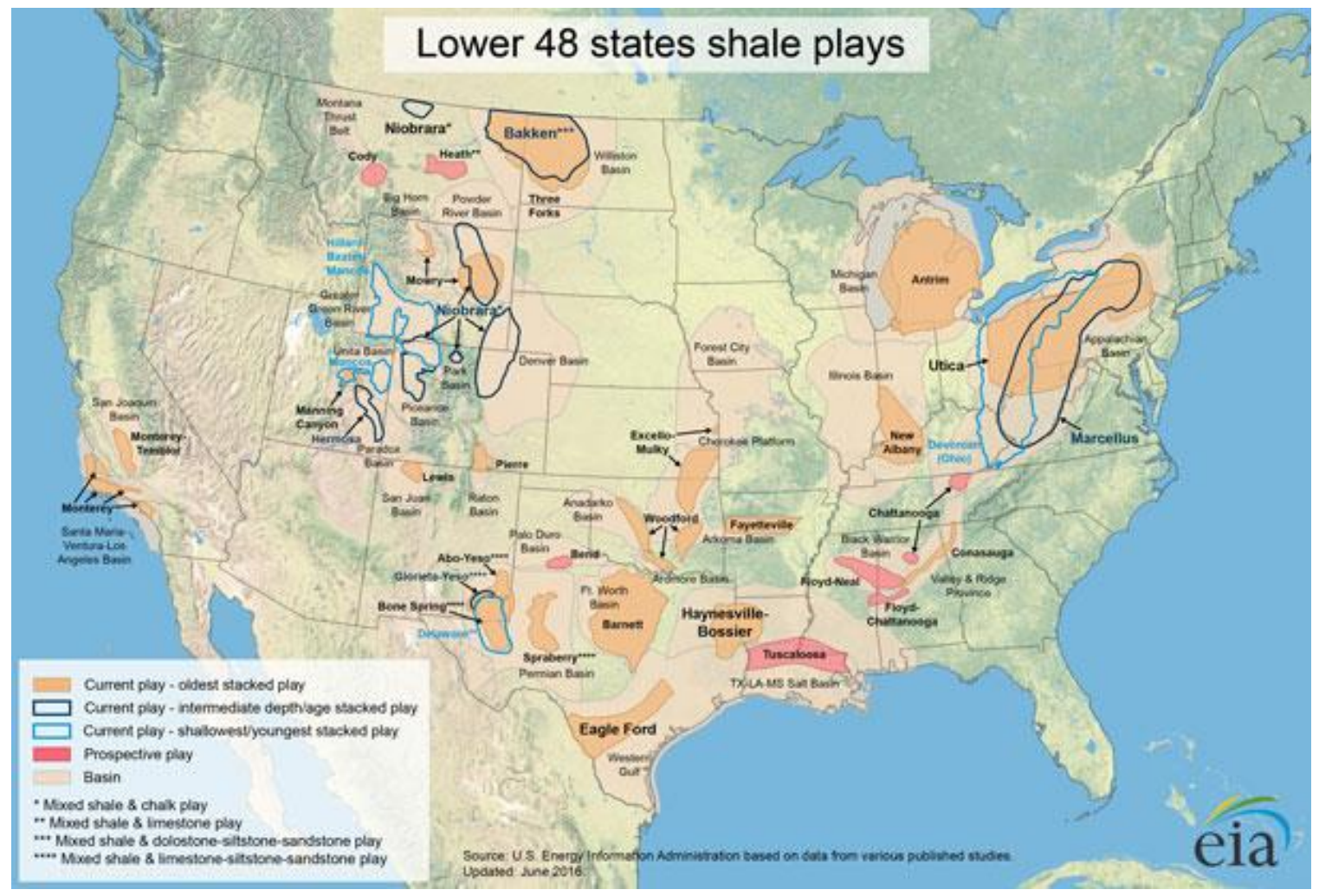

Figure 1. Major U.S. Shale Plays [7] 
In 2019, 23.9\% of the natural gas production was obtained from TX, while $20 \%$ was obtained from PA [7]. The Marcellus shale (PA, WV, OH, and NY) is the most productive play, followed by Permian (TX and NM), Utica (OH, PA, and WV), and Haynesville (LA and TX). Figure 2 presents productions for the major gas shale plays.

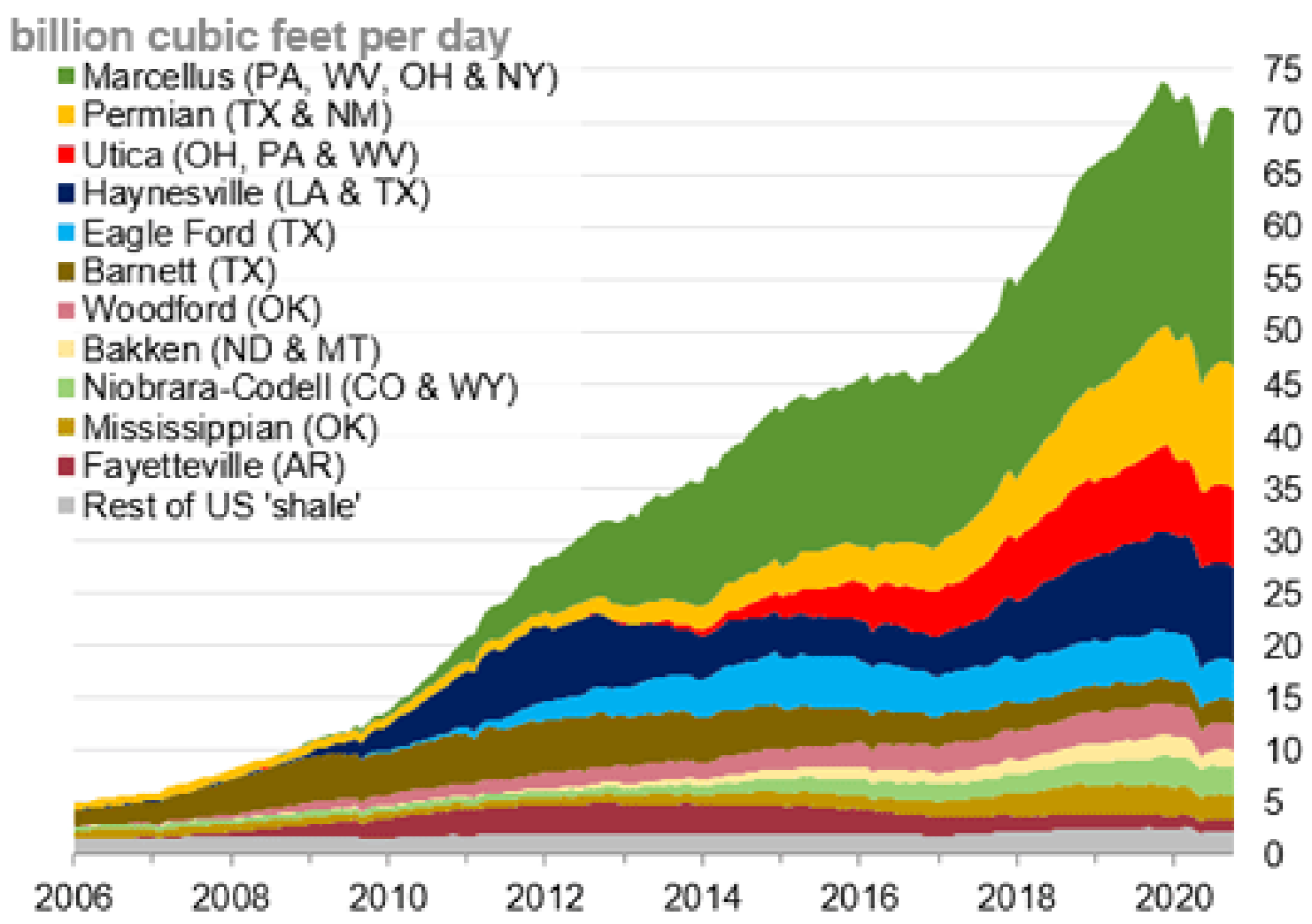

Figure 2. U.S. Dry Shale Gas Production [7]

Conventional (vertical) drilling on shale gas plays proved to have limited effectiveness due to the limited access to the reservoir. Directional drilling provided the opportunity to drill across the play (laterally), enabling access to a larger percentage of the product by drilling longer wells. Natural gas is highly dispersed in rock formations, and because shales have insufficient permeability to allow fluid to flow to a wellbore, hydraulic fracturing must be used. Hydraulic fracturing is a stimulation technique where water, sand, and chemicals are pumped under high pressure into the bedrock formation via the well. This process creates new fractures and extends and connects existing ones, allowing the gas to flow. A typical directional well has around 16 hydraulic fracturing stages [8]. 


\subsection{Energy Consumption During Well Development}

Well development is an energy-intensive process. There are multiple stages in unconventional well development that have high energy demands. This energy is provided by HHPDEs or DNGEs depending on natural gas availability and drilling companies' equipment. There are three different common configurations for powering rigs: HHPDE, DNGE, and dual-fuel-kit-adapted diesel gensets. The industry is dominated by either HHPDE or DNGE due to their cost performance. Dual-fuel kits represent a high upfront expense that is not cost-effective given current diesel prices. Diesel gensets are reliable at any site regardless of natural gas availability.

Unconventional wells consist of two stages of drilling: vertical and horizontal. The total length drilled can vary depending on the region in which the well is located and the shale gas's depth. Barnett region wells generally require up to 8000 feet of vertical drilling, but Haynesville region wells can require up to 13,500 feet of vertical drilling [9]. Average lateral lengths have grown from about 2000 feet in 2005 to about 6000 feet in 2015, at a near linear rate, with an average length of about 4000 feet over the entire sample period [10]. Drilling longer horizontals allow the potential for more natural gas to be extracted from a single well. However, horizontal drilling requires more energy and time. This increases the costs of unconventional well development compared to a conventional well. Most current drilling rigs are electric and use three stationary engines coupled to electric generators to produce on-site electricity. The engines and generators together are known as gensets. On average, drilling rigs utilize 2.15 operating gensets, with $1030 \mathrm{~kW}$ (1381 HP) per genset. These gensets are estimated to operate 62.6 hours per 1000 feet drilled at an average load of $48.5 \%$ [11]. A model developed by the WVU Center of Alternative Fuels, Engines, and Emissions (CAFEE) estimated that, on average, drilling gensets fueled by diesel consumed $6.06 \times 10^{6} \mathrm{MJ}$ per well [12]. Using the same model, it was estimated that the amount of energy needed for drilling a well using natural gas was $1.08 \times 10^{7} \mathrm{MJ}$ [12].

The three gensets combined working in a closed loop are called the on-site power plant. The power plant operates using its own control system, independent from the control system of the rig. The rig control system uses engine load data from the gensets to dynamically limit the load to prevent overload requests. However, the power plant does not receive a demand signal from the rig control system. Rather, the gensets operate on a closed-loop system that uses voltage and frequency to recognize adequate load to meet the power demand. Since there is no stored energy, the gensets must increase or decrease load in an attempt to match the amount of electrical power that the rig 
requires. When the system is balanced at $60 \mathrm{Hertz}(\mathrm{Hz})$ and 600 Volts $(\mathrm{V})$, power production matches rig demand [13]. The total power demand is evenly divided across all online gensets (generally three). Having an excess number of gensets online to be able to handle potential spikes in power demand results in a lower average load on each engine. Therefore, they may operate at lower efficiency and produce higher levels of emissions. Gensets may remain online and running even when fewer gensets could meet power demand because each genset takes several minutes to start up. The gensets need time to warm up and synchronize to the communication area network (CAN) bus. Genset warmup time is a critical consideration in automating engine start and stop decisions while avoiding power limits that interfere with rig operations [13].

\subsection{Non-road Land Drilling Engines Emissions}

In-use engines vary in age, power, activity, and emissions compliance certification level. Numerous studies have suggested that emissions from unconventional resource development can affect local and regional air quality [14-22]. WVU's model estimated emissions from in-use data. Diesel powered land drilling engines are the primary sources of carbon dioxide $\left(\mathrm{CO}_{2}\right)$, carbon monoxide $(\mathrm{CO})$, and methane $\left(\mathrm{CH}_{4}\right)$ emissions throughout the unconventional natural gas well development process. If land drilling engines are natural gas-powered, model estimation implies they are the primary $\mathrm{CO}_{2}$ emitting source compared to the other prime movers (fracking pumps and on-road trucks) [12].

The EPA regulates non-road engine exhaust emissions categorized by rated power and ignition system. In general, compression-ignition drilling engines fall within the highest power rating $(\mathrm{kW}>900)$. There have been three tiers of emissions compliance since 2000. Tier 1 (2000-2005), Tier 2 (2006-2010), and Tier 4 (2011-Present) [23]. Large-spark-ignition drilling engines are categorized into two tiers, Tier 1 (2004-2006) and Tier 2 (2007-Present) [24]. Tier 2 compression ignition and Tier 2 spark-ignited engines dominate the unconventional natural gas well industry, and compression ignition engines are slowly shifting towards Tier 4 engines. Tables 1 and 2 present the exhaust emissions standards for compression ignition and spark ignited large bore engine respectively. 
Table 1. Nonroad Compression-Ignition Engines: Exhaust Emissions Standards [23]

\begin{tabular}{|c|c|c|c|c|c|c|c|}
\hline $\begin{array}{l}\text { Rated } \\
\text { Power }\end{array}$ & Tier & $\begin{array}{l}\text { Model } \\
\text { Year }\end{array}$ & $\begin{array}{l}\text { NMHC } \\
\text { (g/kW-hr) }\end{array}$ & $\begin{array}{c}\text { NMHC + NOx } \\
(\mathrm{g} / \mathrm{kW}-\mathrm{hr})\end{array}$ & $\begin{array}{c}\text { NOx } \\
\text { (g/kW-hr) }\end{array}$ & $\begin{array}{c}\text { PM } \\
\text { (g/kW-hr) }\end{array}$ & $\begin{array}{c}\text { CO } \\
\text { (g/kW-hr) }\end{array}$ \\
\hline \multirow{4}{*}{$k W>900$} & 1 & $\begin{array}{l}2000- \\
2005\end{array}$ & 1.3 & - & 9.2 & 0.54 & 11.4 \\
\hline & 2 & $\begin{array}{l}2006- \\
2010\end{array}$ & - & 6.4 & - & 0.20 & 3.5 \\
\hline & 4 & $\begin{array}{l}2011- \\
2014\end{array}$ & 0.40 & - & 3.5 & 0.10 & 3.5 \\
\hline & & $2015+$ & 0.19 & - & 3.5 & 0.04 & 3.5 \\
\hline
\end{tabular}

Table 2. Nonroad Large Spark-Ignition Engines: Exhaust Emissions Standards [24]

\begin{tabular}{|c|c|c|c|c|c|c|c|}
\hline \multirow{2}{*}{ Tier } & \multirow{2}{*}{$\begin{array}{l}\text { Model } \\
\text { Year }\end{array}$} & \multicolumn{2}{|c|}{$\begin{array}{c}\text { General Duty-Cycle } \\
\text { Standards }\end{array}$} & \multicolumn{2}{|c|}{$\begin{array}{c}\text { Alternative } \\
\text { Standards for } \\
\text { Severe-Duty Engines }\end{array}$} & \multicolumn{2}{|c|}{$\begin{array}{l}\text { Field Testing } \\
\text { Standards }\end{array}$} \\
\hline & & $\begin{array}{l}\mathrm{HC}+\mathrm{NOx} \\
\text { (g/kW-hr) }\end{array}$ & $\begin{array}{c}\text { CO } \\
(\mathrm{g} / \mathrm{kW}-\mathrm{hr}) \\
\end{array}$ & $\begin{array}{l}\text { HC+NOx } \\
(\mathrm{g} / \mathrm{kW}-\mathrm{hr})\end{array}$ & $\begin{array}{c}\text { CO } \\
\text { (g/kW-hr) }\end{array}$ & $\begin{array}{l}\text { HC+NOx } \\
(\mathrm{g} / \mathrm{kW}-\mathrm{hr})\end{array}$ & $\begin{array}{c}\mathrm{CO} \\
(\mathrm{g} / \mathrm{kW}-\mathrm{hr}) \\
\end{array}$ \\
\hline 1 & 2004-2006 & 4.0 & 50.0 & 4.0 & 130.0 & - & - \\
\hline 2 & $2007+$ & 2.7 & 4.4 & 2.7 & 130.0 & 3.8 & 6.5 \\
\hline
\end{tabular}

Gensets operate more efficiently when running at higher loads. Exhaust gas emissions are also lower relative to power at higher loads [13]. The industry is attempting to optimize rig and power plant communication, so engines run at the most efficient point, reducing both fuel consumption and regulated emissions.

\subsection{Waste Heat Recovery}

The growing energy demand has led to increases in GHG production. With the continuous tightening of emissions regulations, GHGs and wasted energy are being curbed but with an economic disadvantage. Multiple industries face losing their competitive edge due to the restrictions currently in place. For the industry to reduce both reliance on fossil fuels and environmental impact, there are two basic options: using renewable energy systems or reducing overall energy consumption. Incorporating renewable energy technologies is an increasingly attractive option as prices fall. However, renewable energy technologies are not suitable for all locations, all industries, and investment costs can still be prohibitive. The alternative, reducing energy demand, can be divided into three further options: reducing total activity, better energy 
management, and recovery of otherwise wasted energy [25]. With developments of thermal and physical waste management technologies, multiple companies are utilizing waste heat technologies to recapture previously lost energy to be used in other applications [26].

The EPA has ambitious targets for reducing GHGs and the effects of global warming. Globally, industrial energy use is responsible for $33 \%$ of GHGs, and approximately $70 \%$ of the industrial sector's energy demand is for heat. All heating processes result in waste heat, up to $50 \%$ in some cases, and heat recovery potential is widely acknowledged [26]. Improving system designs will reduce fossil fuel consumption and emissions, allowing industries to comply with regulations and remain competitive financially.

Internal combustion engine waste heat recovery (WHR) has recently garnered interest due to its potential to contribute to the phasing towards green energy and less fossil fuel dependency. There are many WHR systems either being researched or already in production. Some of the most popular are CHP systems, bottoming cycles, or thermoelectric generators (TEG). A TEG is formed by series of thermoelectric (TE) modules. These modules consist of many TE elements connected in series. TEs are made of semiconductor materials. The temperature difference between two dissimilar semiconductors produces a voltage difference [27]. Hawawasam, et al. simulated an internal combustion exhaust TE generator recovery system. It was found that TEGs can recover up to $16.5 \%$ of the exhaust heat [27]. Bottoming cycles involve thermodynamic cycles such as the Rankine or Brayton cycle, which involves heat recovery and rejection via a working fluid to drive a turbine and produce mechanical or electrical energy [28]. Shekh and Saiful, at the University of South Australia, designed an experiment on a 40 kilowatt $(\mathrm{kW})$ diesel generator where they found they could recover up to $10 \%$ extra power by using an organic Rankine cycle (ORC) with the exhaust heat recovered [29]. Other studies have shown that utilizing ORC on a heavy-duty diesel engine can recover up to $20 \%$ of its exhaust heat, improving the system's efficiency by over $50 \%$ [30]. CAIN industries is an exhaust heat recovery systems manufacturer which has sold and installed exhaust steam generators (ESG) in multiple locations and industries using natural gas generators. They have installed an ESG recovering exhaust heat from a Jenbacher JMS-320-900 $\mathrm{kW}$ natural gas engine, claiming heat recoveries from exhaust up to over $300 \mathrm{~kW}$, using the recovered heat for heating, ventilating, and air conditioning (HVAC) purposes in a hospital, and decreasing wasted heat [31]. 
The unconventional natural gas well development industry usually powers an electric rig with a set of Caterpillar (CAT) 3512C diesel engines, or Waukesha L7044GSI dedicated natural gas engines accompanied by electric generators. CAT 3512C engines peak at about $42 \%$ efficiency, rejecting $58 \%$ of the fuel's energy as waste heat and other minor losses [32]. Waukesha's L7044GSI engine peak at about 33\% efficiency, rejecting 67\% of the energy consumed as waste heat [33]. Internal combustion engines have room for waste heat recovery improvement, given their large waste heat rate at the exhaust flue and cooling system (radiators). About $34 \%$ of the fuel energy consumed by a CAT $3512 \mathrm{C}$ is rejected through the exhaust gas, and an additional 16\% is lost to the engine coolant [32]. Approximately 30\% of the energy consumed on an L7044GSI engine is rejected through the exhaust flue and about the same amount through the radiator [33].

\subsection{Heat Exchangers}

Heat exchangers (HEX) are devices used to transfer heat between two or more fluids. A solid wall may separate the fluids to prevent mixing, or they may be in direct contact. They are widely used in heating, refrigeration, air conditioning, power stations, engines, chemical plants, petrochemical plants, petroleum refineries, natural-gas processing, and sewage treatment. The heat transfer effectiveness depends on both the HEX's design and the working fluid's properties. Some critical design parameters include the pitch ratio, tube length, tube number, tube layer, and baffle spacing [34].

During engine run time, there are several locations in the engine's configuration where heat is dissipated to the environment. The engine's highest heat rejection areas are exhaust gas and radiator. This heat may be recovered with a heat exchanger's assistance, although it requires upfront equipment costs, installation, and maintenance. In the past, fossil fuel was cheap, and a WHR system was not cost-efficient. Furthermore, high sulfur concentrations in diesel fuel resulted in corrosive exhaust gas, requiring expensive alloys to manufacture E-HEXs.

The EPA has instituted more stringent off-road engine emissions and diesel fuel quality standards to reduce environmental and health impacts. In 1993, the EPA began regulating diesel fuel sulfur levels. Before any EPA diesel fuel sulfur concentration regulations, diesel fuel contained as much as 5000 ppm of sulfur. In 2006, the EPA began to phase in more stringent regulations to lower the amount of sulfur in diesel fuel to $15 \mathrm{ppm}$. This fuel is known as ultra-low sulfur diesel (ULSD). From 2007 to 2014, low sulfur diesel fuel (500 ppm) and ULSD were phased in for non-road. After 
2014, the EPA required ULSD fuel for all non-road operations [35]. Alongside the implementation of oxidation catalysts and diesel particulate filter (DPF) on Tier 2 and 4 engines to comply with the EPA's non-road emissions standards, diesel-fuel sulfur concentration regulations have reduced sulfur oxides and particulate matter (PM). For non-road stationary diesel engine WHR systems, the reduction in sulfur and PM may allow E-HEX to be more practical. The exhaust will be less corrosive and produce less soot, both of which have prevented economic heat recovery in the past.

Another source of waste heat is the engine cooling system. An engine cooling system relies on a HEX where the working fluids absorb heat from the engine via JW to prevent overheating. That heat is later released into the atmosphere. Capturing JW heat from the engine would increase system performance. CAIN Industries offers pre-engineered standardized HEXs for engine exhaust and JW. Their experiments have shown that their systems recover up to $782.2 \mathrm{~kW}$ from a $1700 \mathrm{~kW}$ natural gas engine in the form of steam vapor at $150 \mathrm{psig}$ [31]. They also offer ebullient steam generators from engine JW, a JW-HEX which produces low-pressure steam. They can be added to the exhaust heat steam generator to improve overall system efficiency.

Current unconventional drilling rigs do not utilize these WHR systems. Their heat sources are industrial boilers fueled by diesel or natural gas. Boilers operate when weather conditions require large amounts of energy for heating - either seasonally or regionally.

\subsection{Boilers}

A boiler is a steam generator device that combusts fuel to heat and convert water to steam at variable pressures. Boilers are used in multiple industries such as food processing, power generation, and heat production. The boiler's main components are fuel supply, combustion air system, feedwater system, pressurized heat exchanger, and exhaust gas venting system. There are two basic boiler configurations: firetube and water tube. In firetube boilers, exhaust gases pass inside boiler tubes, and heat is transferred to water between the tubes and the shell. In water tube boilers, water passes through the tubes, and exhaust gasses remain on the shell side. Because tubes can typically withstand higher internal pressure than the large chamber shell in a firetube, water tube boilers are used where high steam pressures [over 3,000 pounds per square inch (psi)] are required [36].

Unconventional natural gas wells being developed at cold weather locations often require a boiler to ensure reliable and efficient heat supply for the crew, drilling, and safety equipment. An 
industry standard is the HURST series 300 model, rated at 200 boiler horsepower (Bhp) at a maximum heat output of 6695 million British thermal units per hour (MBH) or $1962 \mathrm{~kW}$ [37]. These boilers are generally diesel fuel and/or natural gas-powered, depending on natural gas fuel availability on-site. A HURST 300 Series model $200 \mathrm{Bhp}$ is about $81 \%$ efficient. At $100 \%$ load, the boiler outputs 6900 pounds per hour (lbs./hr.) of saturated vapor at $110 \mathrm{psi}$ (758 kPa) [37]. Maximum boiler fuel consumption is 8400 cubic feet per hour for natural gas and 60 gallons per hour for diesel fuel.

Once saturated steam exits the boiler, it is directed through a system of insulated hoses connected to multiple-sized heaters in offices, drilling fluid tanks, and other accessory locations. Heaters may vary between 320,000 BTU/hr to 1.7 million BTU/hr (94 kW to $498 \mathrm{~kW}$ ), and they are operated manually by the crew in the rig. Manual operation of heating sources introduces human inefficiencies into the system. Heaters are not automated to maintain a working temperature; thus, rig crew members determine when to power the heaters on or off. On average, a rig operates between 11 to 15 steam heaters, and it is recommended not to use heaters over one million BTU/hr $(293 \mathrm{~kW})$ to keep heat demand low [38]. Steam lines are equipped with steam traps. Steam traps are an essential part of any steam heating system. They help keep steam pressure inside the heater cores, allowing the heater to maximize heat usage. They also allow condensate to return to the preheated tank, reducing the amount of water consumed. Steam traps are built-in with a thermostat that opens at high temperatures. When the temperature drops below a specified temperature, it closes, capturing condensate water. This water is then redirected towards a preheated tank, also known as a day tank, usually attached to the boiler as a feedwater recovery system.

\subsection{Hybridization}

The continuous need for emissions reduction and fuel efficiency improvements has led to multiple research approaches to achieve those goals. With improved energy storage technologies and electrically driven motor equipment, hybrid engines are gaining popularity. In the light vehicle industry, hybrid vehicle sales began in 1999 and have become more popular since. In 2019, the U.S. market share reached $2.4 \%$ of the total fleet of light-duty vehicles [39]. Hybridization technology is also penetrating the heavy-duty vehicle industry due to the tight emissions regulations, especially those of the CARB. In order to advance towards low emissions engines, Cummins released PowerDrive in 2018, an advanced hybrid system offering both parallel and series capabilities [40]. 
North America occupies the most extensive electricity consumption market globally. Large-scale energy projects are growing exponentially. Through December 2016, 1227 electricity energy storage projects had been carried out worldwide, and the total installed capacity reached $1930 \mathrm{MW}$ [41]. The electricity storage techniques being used are led by lithium-ion batteries. This type of battery has a year-on-year growth of approximately 55\% [41]. Other energy storage technologies are lead-acid batteries, supercapacitors, sodium-sulfur batteries, lithium iron phosphate, and flow batteries.

On July $1^{\text {st }}, 2018$, a HEMS was introduced to the land drilling industry for commercial operations [13]. The HEMS used battery energy storage and engine automation to reduce the number of gensets operating, increase the efficiency of each genset, and reduce emissions. The power bank (battery system) is connected to the rig's control system in order to maximize engine operation and reduce fuel consumption. Gensets are automatically turned on or off depending on the rig's power demand and the battery state of charge (SOC). In addition to fuel savings, downtime due to issues with generators is avoided. Furthermore, the battery energy storage system can temporarily provide power when an engine fails or requires maintenance. The system was developed over two years and tested at a rig construction facility before being placed into operation on a rig working in the Marcellus shale [13].

Patterson-UTI Drilling Company (Patterson) is starting to use the ECO-CELL. An energy management system that leverages stored energy to optimize fuel efficiency and reduce emissions. This power bank utilizes lithium-ion batteries due to their cycle life, energy and power ratings, and safety characteristics. The power bank acts as a fourth generator and can provide 1.5 times more power at full load. The power bank stores up to $584 \mathrm{kWh}$ of energy and communicates with the rig's operation system for optimal synchronization [42]. Figure 3 presents an experimental HEMSequipped rig power plant. Three CAT 3512C gensets, the HEMS, and the diesel fuel tank are the major components of the on-site power plant. 


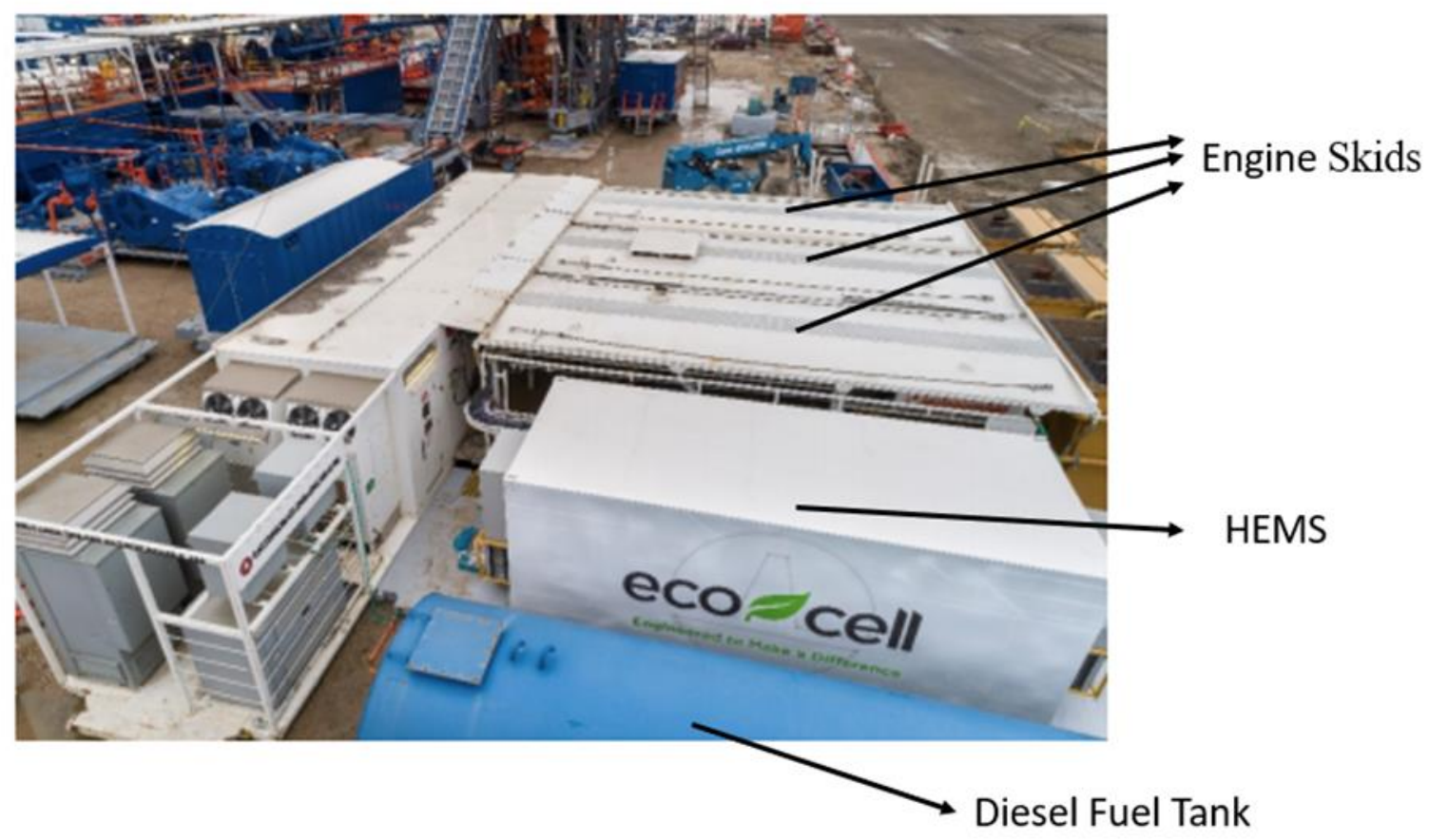

Figure 3. HHPDE-Powered Rig Equipped with a HEMS

For testing purposes, Patterson recorded approximately 600 days of operational data from 7 rigs working in the Marcellus shale over one year. Data analysis established the baseline average number of gensets used in each type of operation. Data recorded from December 2018 was used for normalizing engine activity [13]. During testing, it was found that the HEMS reduced fuel consumption by $13.6 \%$ [13]. Total costs savings were $\$ 18,284$, with an average saving of $\$ 659$ per day of operation in diesel costs (Based on Standardized \$2.17/gal. Fuel Cost [ $\$ 2.00$ plus $\$ 0.17$ delivery]) [13]. The most savings were detected during tripping and casing operations (transient operations), saving over $\$ 11,000$ during this operation alone [13]. Similar calculations were performed to estimate emissions reduction. The system resulted in reductions of $\mathrm{NO}_{\mathrm{x}}$ by $3 \%, \mathrm{CO}$ by $31 \%$, and PM by $43 \%$ [13]. Also, by reducing active engine time, maintenance intervals were extended, saving expenses and engine availability. Calculations showed that genset usage might be reduced from 1808 hours to 1229 hours with the HEMS in operation versus baseline operation.

Operating a diesel generator set at loads lower than $30 \%$ of rated power for extended periods might negatively impact the unit [43]. Diesel gensets are designed to operate between 50 and $85 \%$ load [43]. If the engines are operated at low loads for extended periods, the most prevalent consequence 
is a phenomenon known as exhaust slobber or wet stack. Running at high idle with little or no load reduces the heat in the cylinder, allowing unburned fuel and oil deposits to leak through the exhaust slip joints [43]. The engine slobber itself will not harm the engine. However, it indicates underload operations that may be accompanied by other underloading effects such as deposit build-up behind piston rings, deposits developing inside the cylinders, and in extreme cases, cylinder liner polishing may occur [43]. During the HEMS testing, the amount of time the gensets operated below a load of $30 \%$ was reduced [13]. The total engine operation time under $30 \%$ load was 331 hours with the HEMS, compared to 996 hours in the baseline, a 66\% reduction [13]. With less time under the $30 \%$ load mark, engines will be more efficient, emit fewer pollutants, extend their lifespan, and require less maintenance.

Optimal operation conditions are between $50 \%$ to $100 \%$ of the rated load for natural gas generator sets. It is recommended not to load the engines below 50\% load for any duration in time, and the ideal range is $70 \%$ load and above [43]. Natural gas powered engines do not have enough cylinder pressure to maintain oil control in the cylinder at low loads, letting the oil pass the oil rings into the cylinders, leading to ash deposits. These deposits alter the compression ratio, which can diminish the detonation margin. If the detonation margin is reduced sufficiently, unintended detonation may occur. Detonation will decrease the engine's lifespan, harm components, and cause unexpected shutdowns or failures. Like diesel generator sets, the extended operation of gas generator sets at low loads may lead to deposit build-up on the valves, spark plugs, and behind the piston rings [43]. In extreme cases, deposits in the cylinder can develop, causing cylinder liner polishing.

Additionally, many natural gas engines operate at an air to fuel ratio (AFR) below 1 (i.e., rich) at low loads to sustain combustion and guarantee that the engine does not misfire. A rich AFR causes the engine to deviate from the expected emissions levels, potentially leading to non-compliance with required emissions regulations. Also, a rich AFR increases temperatures and can accelerate component wear [43]. 


\section{Data Collection Methods}

In order to analyze scenarios that represent the energy utilization of an unconventional drilling rig, it was necessary to collect data from three CAT 3512C engines and a HURST 300 series 200 Bhp in the Marcellus shale region. The gensets and the boilers are the primary fuel consumers during this energy intensive phase. Reducing fuel consumption by recovering waste heat from the engines to assist or eliminate the boiler would reduce operating costs. Other relevant information was obtained from the engine's specification sheets. A dedicated, natural gas powered rig was also modeled and analyzed. Data used for this model was previously obtained by WVU's researchers as part of another DOE funded research program. Data were collected from multiple Waukesha L7044GSI engines during the drilling of wells in two different shale plays. Table 3 presents major engine specifications.Boiler rental expenses were based on a daily fee of $\$ 240$ and one freight charge fee of $\$ 3950$ (Appendix F).

Natural gas fuel costs to be recovered with the UFs of $30.3 \%$ and $34.9 \%$.

Table 32 shows the return on investment analysis for the DNGE CHP system.

Table 32. DNGE CHP System Return on Investment Analysis

\begin{tabular}{ccc}
\hline \hline \multirow{2}{*}{ Equipment } & \multicolumn{2}{c}{ DNGE CHP } \\
\cline { 2 - 3 } E-HEX & Expenses (+) and Savings (-) \\
\hline Boiler Rental & \multicolumn{2}{c}{$\$ 408,102$} \\
Natural Gas Costs to Be Saved & \multicolumn{2}{c}{$-\$ 108,756$} \\
UF & $\mathbf{3 0 . 3 \%}$ & $\mathbf{3 4 . 9 \%}$ \\
Time (hrs. of replaced boiler activity) & 10,061 & 8236 \\
Days (replaced boiler activity) & 419 & 343 \\
\hline
\end{tabular}

If normalizing savings per day of replaced boiler activity, the HHPDE CHP system would save approximately $\$ 974$ per day. If the UF was increased to $34.9 \%$, savings would be estimated at $\$ 1190$ per day. 
Table 3. HHPDE And DNGE Engine Parameters [32,33]

\begin{tabular}{ccc}
\hline \hline Parameter & CAT 3512C & Waukesha L7044GSI \\
\hline Rated Brake Power & $1101 \mathrm{~kW}$ & $1253 \mathrm{~kW}$ \\
Piston Displacement & $52 \mathrm{~L}$ & $115 \mathrm{~L}$ \\
Exhaust Stack Temperature & $397.6^{\circ} \mathrm{C}$ & $637{ }^{\circ} \mathrm{C}$ \\
Heat Rejected to Exhaust & $902 \mathrm{~kW}$ & $1143 \mathrm{~kW}$ \\
Heat Rejected to Jacket Water & $412 \mathrm{~kW}$ & $1128 \mathrm{~kW}$ \\
Generator Efficiency & $95 \%$ & $95 \%$ \\
Reference LHV & $62,780 \mathrm{~kJ} / \mathrm{kg}$ & $35,533 \mathrm{MJ} / \mathrm{nm}^{3}$ \\
\hline
\end{tabular}

\subsection{Data Acquisition System}

A data acquisition (DAQ) system containing three computers equipped with WVU CAFEE's DAQ software SCIMITAR was developed. These computers recorded engine activity, exhaust temperatures, and boiler fuel consumption. Figure 4 presents the DAQ system.

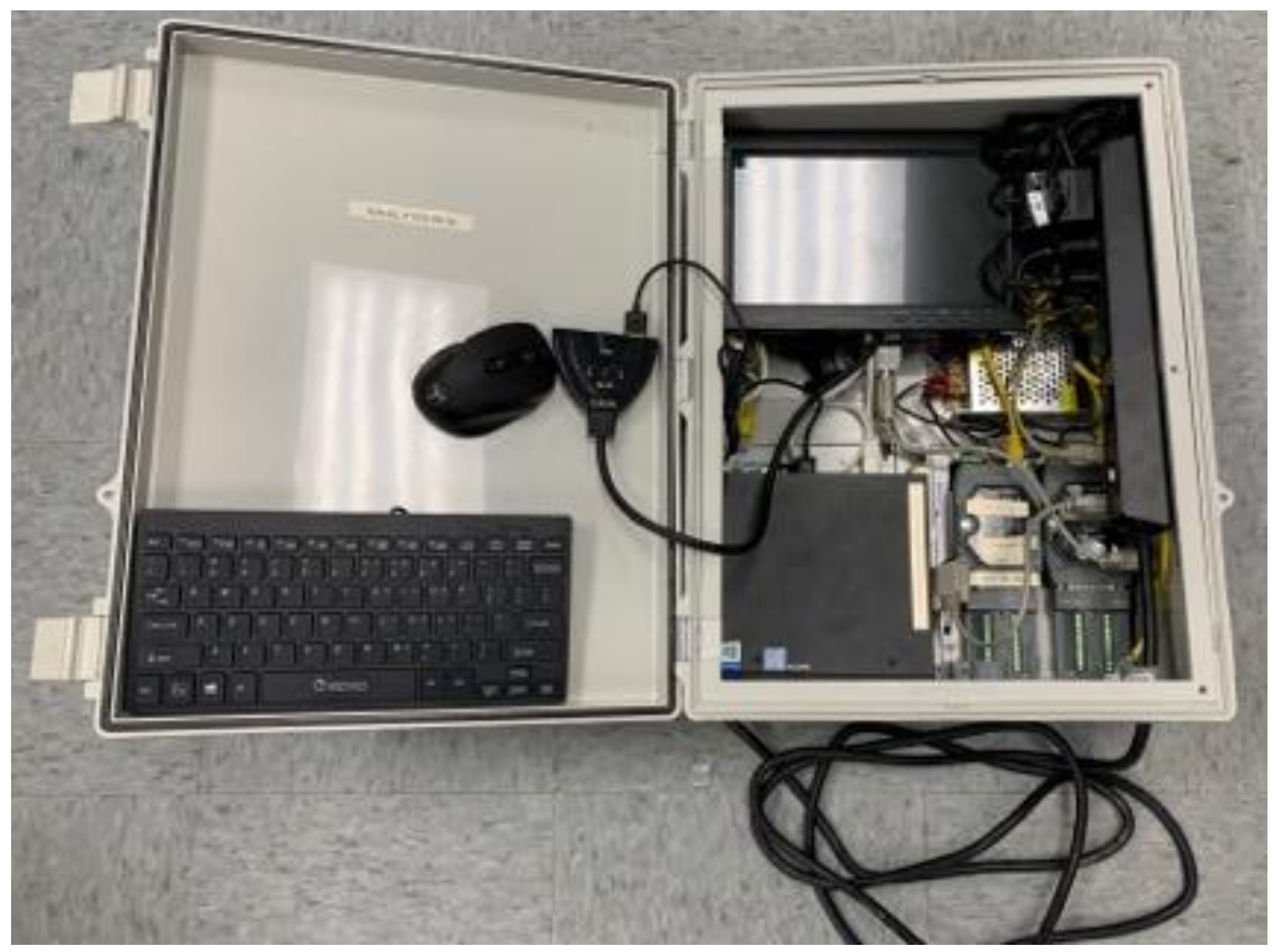

Figure 4. Data Acquisition Box 


\subsection{Engine Activity Data}

The engine control unit (ECU) streams a set of public and private channels where multiple engine parameters are broadcasted. Public data generally includes parameters such as engine load, coolant temperature, and fuel consumption. ECU data were obtained via the CAN by connecting the SAEJ1939 engine port from the control panel with a PCAN-USB device to the DAQ box. CAN outputs were indexed using a hexadecimal format. A vector database file (VDF) (.dbc file) was created and adapted to CAT's network IDs to translate data from hexadecimal format to traditional numerical format using CAN-ID-to-PGN public cloud-based files published by CSS Electronics [44]. Figure 5 presents the $\mathrm{CDF}$ showing the main engine public channels recorded via CAN communication. 


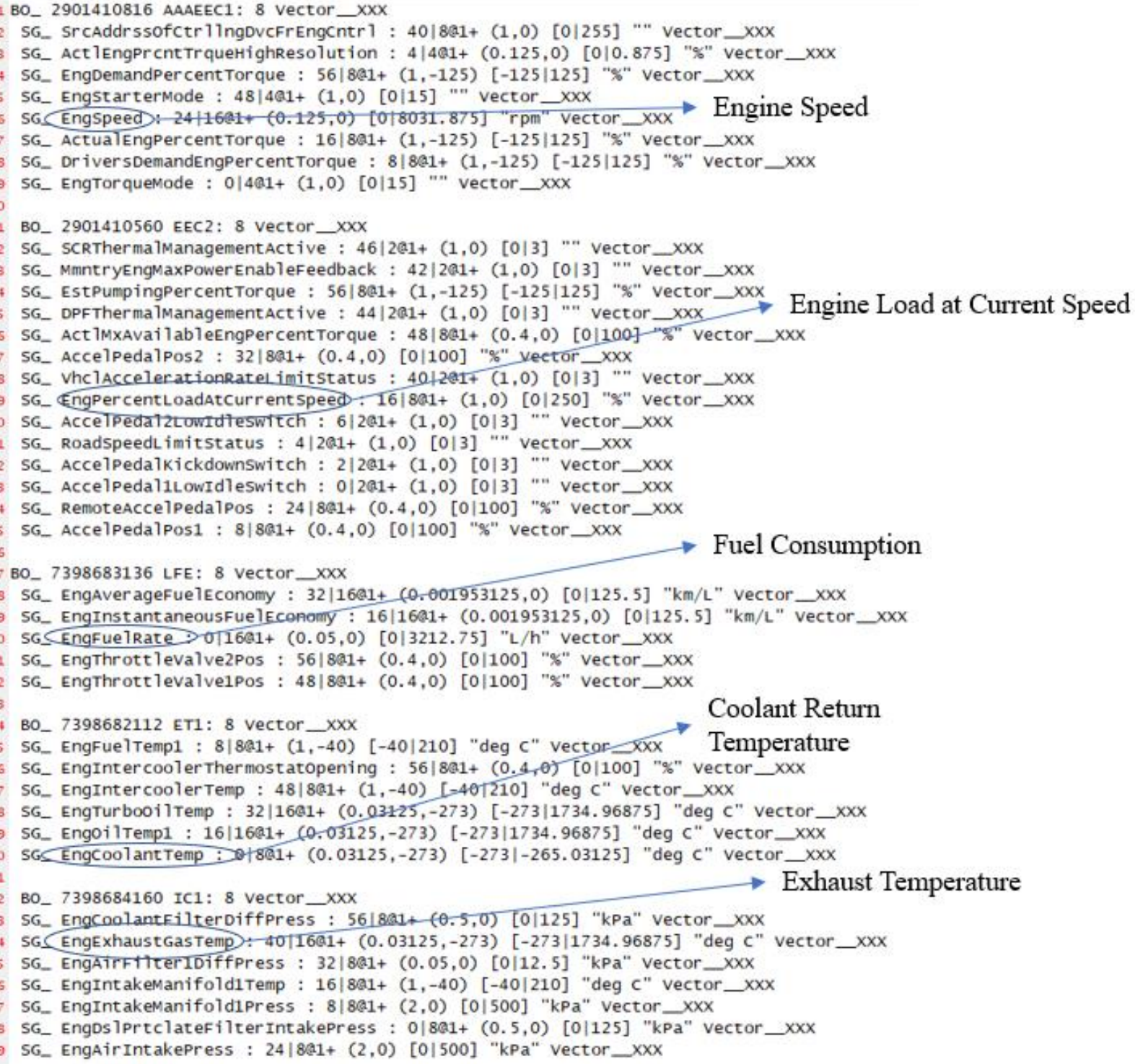

Figure 5. J1939 PGN And SPN IDs Used for Engine Data Collection (VDF)

SCIMITAR's built-in, CAN-Interface, was used to record ECU parameters specified on the VDF.

Only parameters relevant to energy efficiency were recorded to reduce the risk of data loss and maintain manageable file size for post-processing purposes. Once the DAQ box was installed and connected to the PCANs, SCIMITAR automatically recorded engine parameters when the engines were started. Figure 6 presents the PCAN device utilized for CAN communication. 


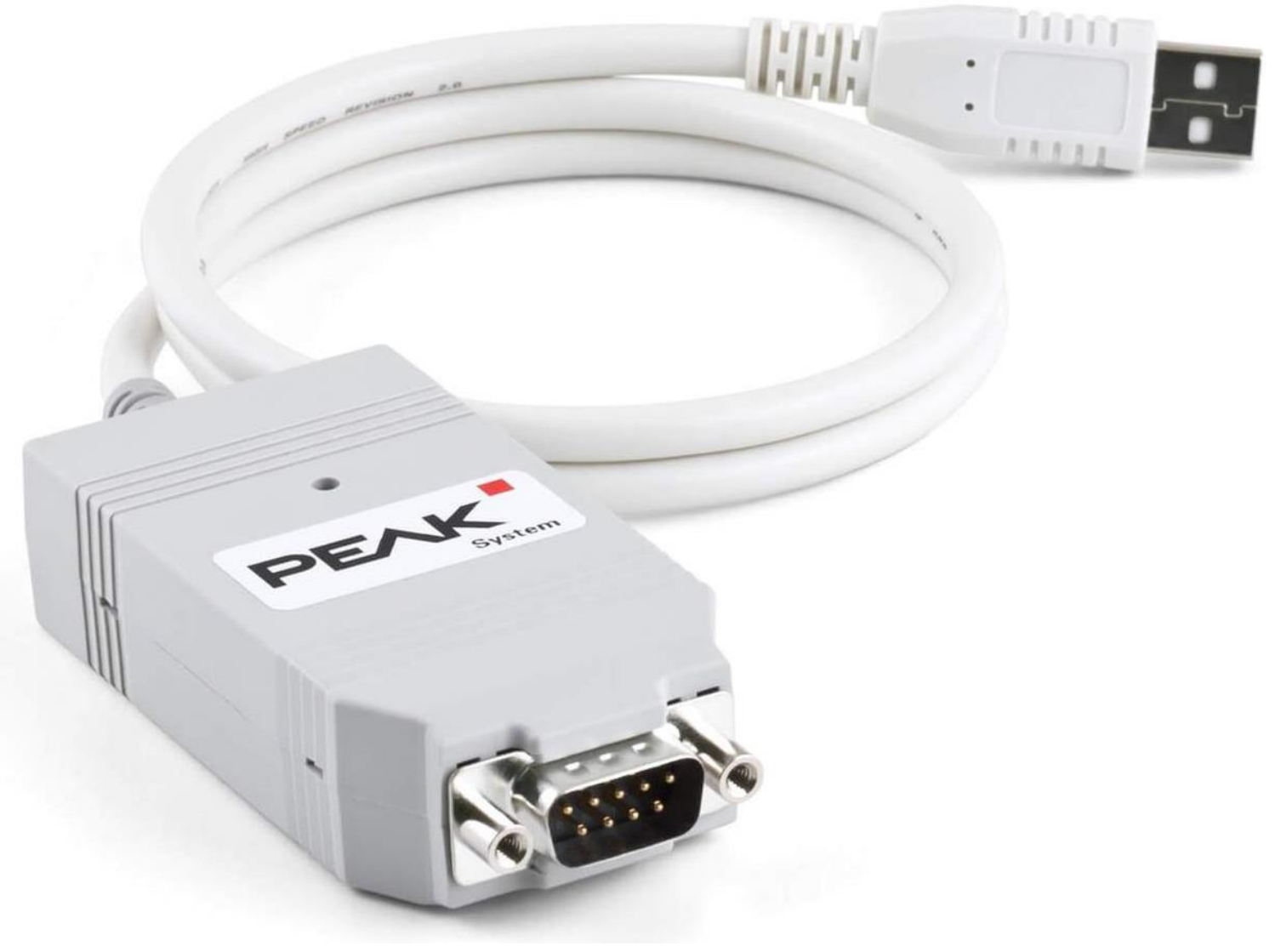

Figure 6. PeakCAN Connector

\subsection{Diesel Fuel Consumption}

Although diesel fuel consumption from the three engines was recorded through ECU communication, the HURST boiler was not equipped with a control unit. Two KRAL diesel fuel flow meters were used to record boiler diesel fuel consumption by measuring fuel flow rate and temperature. KRAL OME 20 diesel fuel flow meters were selected due to their measurement range and compact size [45]. Previous research programs conducted by WVU used these flow meters. Researchers determined that KRAL OME 20 accuracy was $\pm 2 \%$ of the measured value [46]. Table 4 presents the KRAL flowmeters' technical specifications. 
Table 4. KRAL OME 20 Diesel Flow Meters Technical Data

\begin{tabular}{ccc}
\hline \hline Parameter & & OME-20 \\
\hline Nominal Diameter & $\mathrm{DN}(\mathrm{mm})$ & 20 \\
Total Length with DIN flange & $\mathrm{DN}(\mathrm{in})$ & $3 / 4$ \\
Flow rate L/hr & $(\mathrm{mm})$ & 135 \\
& $\mathrm{Q}_{\max }$ & 2700 \\
& $\mathrm{Q}_{\mathrm{nom}}$ & 1800 \\
Flow rate L/min & $\mathrm{Q}_{\min }$ & 18 \\
& $\mathrm{Q}_{\max }$ & 45 \\
& $\mathrm{Q}_{\text {nom }}$ & 30 \\
Max. Pressure & $\mathrm{Q}_{\min }$ & 0.3 \\
Temperature & $(\mathrm{bar})$ & 40 \\
& $\left({ }^{\circ} \mathrm{C}\right)$ & -20 to \\
Viscosity & $\left(\mathrm{mm}{ }^{2} / \mathrm{s}\right)$ & 125 \\
& to & $1 \mathrm{x} 10^{6}$ \\
Precision & Of measurement & $\pm 0.1 \%$ \\
Repeatibility & value & $\pm 0.01 \%$ \\
K-factor & $\mathrm{K}(\mathrm{P} / \mathrm{L})$ & 321 \\
Frequency & $\mathrm{F}$ at $\mathrm{Q}_{\text {nom }} \mathrm{Hz}$ & 161 \\
\hline & &
\end{tabular}

KRAL flow meters were attached to a KRAL BEM 500 display where the instantaneous reading could be observed. The BEM 500 converted voltage signals into readable data and sent it to the DAQ system via ethernet for SCIMITAR logging. Figure 7 shows the flow meters accompanied by the display used for on-field data collection. 


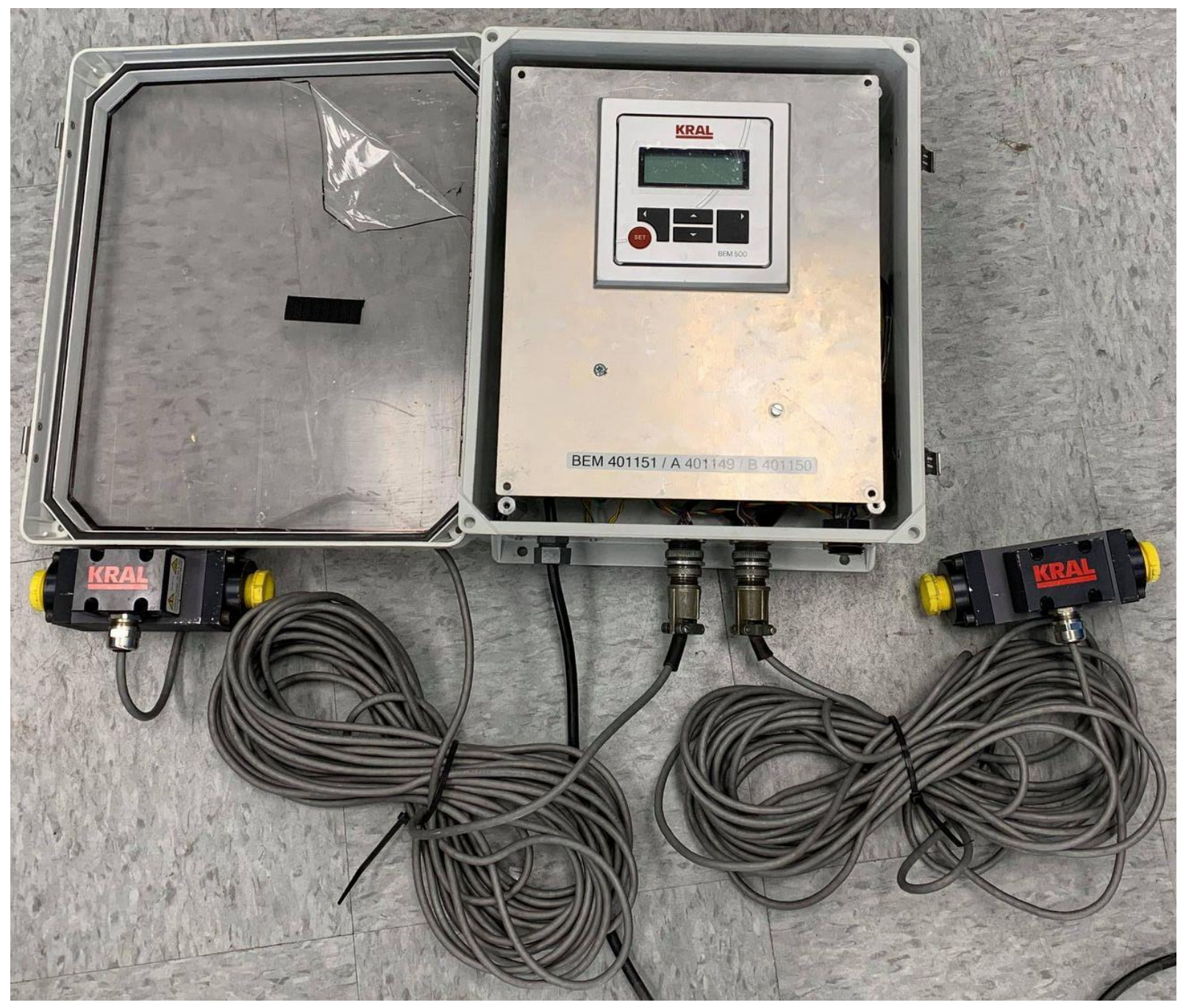

Figure 7. KRAL BEM 500 Display and KRAL OEM 20 Diesel Flow Meters

Before installation, flow meters were calibrated and tested at WVU's engine laboratory. Tests showed that flow meters operated with errors less than 3\%, as presented in Appendix A. Each of these flow meters has a turbine meter and a temperature sensor for density correction. One of the flow meters was installed in the boiler diesel fuel supply line, while the other was located on its return. Fuel consumed by the boiler was calculated by measuring fuel flow difference. Boilers are usually fueled by diesel or natural gas, depending on the fuel's availability. Data recorded referred to a diesel fueled boiler; therefore, an energy balance was performed to model a natural gas fueled boiler based on recorded heat demand and assuming constant thermal efficiency of $81 \%$ [37]. Boiler heat output was not measured directly. Rather, fuel consumption served as a surrogate along with the assumed constant efficiency as heat output estimations. The lower heating value (LHV) for diesel fuel was assumed to be $42,780 \mathrm{~kJ} / \mathrm{kg}$ with a density of $838.9 \mathrm{~g} / \mathrm{L}$, while $\mathrm{LHV}$ for natural 
gas was assumed to be $33,533 \mathrm{~kJ} / \mathrm{m}^{3}$ with a density of $0.68 \mathrm{~kg} / \mathrm{Sm}^{3}$ being consistent with values used by CAT and Waukesha in their respective engine specification literature [32,33]. Equation 2 shows the energy balance used for the boiler natural gas fuel consumption model.

\section{Equation 2. Boiler Fuel Consumption Energy Balance}

$$
\frac{42,780 \frac{\mathrm{kJ}}{\mathrm{kg}} \times 0.8389 \frac{\mathrm{kg}}{\mathrm{L}} \times \text { Diesel Fuel }(\mathrm{L})}{0.81 \%}=\frac{\frac{33,533 \frac{\mathrm{kJ}}{\mathrm{m}^{3}}}{0.68 \frac{\mathrm{kg}}{\mathrm{Sm}^{3}}} x(\text { Natural Gas }(\mathrm{kg})}{0.81 \%}
$$

\subsection{Temperatures}

Temperatures from the three engine exhausts, boiler water feed, and boiler steam output were measured using K-type thermocouples connected to two 10-channel thermocouple input modules (ICP CONs) located in the DAQ system and connected to the SCIMITAR software. HHPDE exhaust temperature was directly measured with K-type thermocouples installed in the muffler, as shown in Figure 88 . These temperature sensors have an uncertainty of $\pm 2.2^{\circ} \mathrm{C}$ [47]. Temperatures were later used for heat loss detection and addressing efficient heat recovery systems possibilities throughout the rig's energy source configuration. 


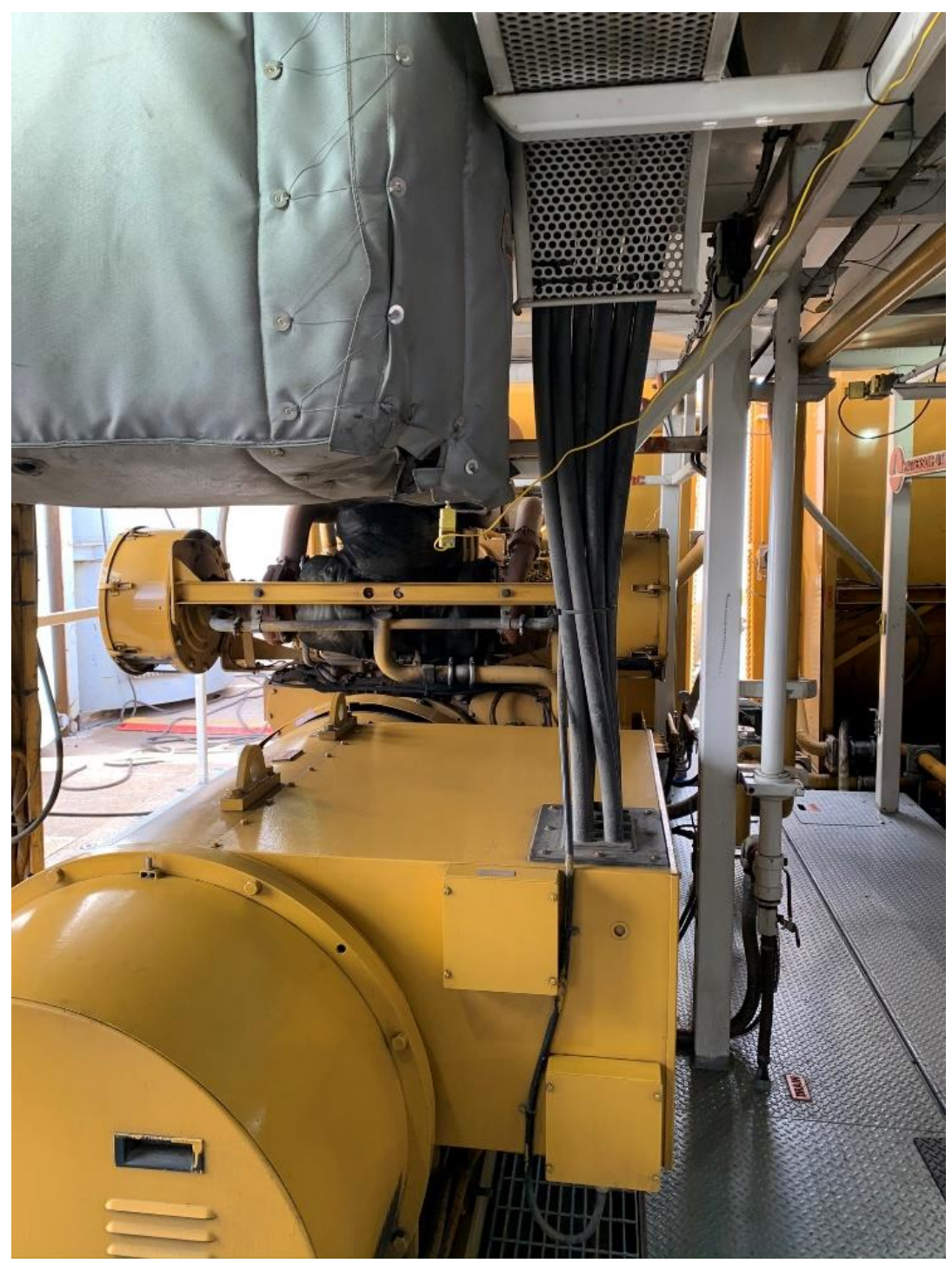

Figure 8. K=Type Thermocouple Installed in the Engine's Muffler

\subsection{Data Collection}

Instrumentation occurred on February $17^{\text {th }}, 2020$, and the engines were fired for powering accessory equipment the following day. Drilling activities were not detected until February $21^{\text {st }}$, and data collection continued with minimal disruptions until the well was completed. The equipment was removed on March $20^{\text {th }}$ during rig downtime. Therefore, the data collected included all processes from engine start up through the completion of drilling.

The boiler was fired on February $21^{\text {st }}$ and remained in operation until March $5^{\text {th }}$. Boiler activity was detected on 14 days but was only active continuously with no disruptions for six of those days. The boiler operated intermittently during the remaining eight days, supplying smaller amounts of 
heat based on varying weather conditions. Boiler activity depends exclusively on weather temperatures, the crew's tolerance to cold, and liquid temperatures to prevent freezing.

Engine data collection referred to Tier 2 engines for both HHPDE and DNGE. Therefore, the modeling methods include Tier 2 engine performance only. Newer HHPDEs are certified under tighter emissions standards, which involved aftertreatment systems and additional control. These could contribute to different exhaust gas conditions than the engines analyzed in this paper. The unconventional well development industry has not yet shifted towards Tier 4 engines, being still dominated by Tier 2 engines. 


\section{Modeling Methods}

\subsection{Fuel Consumption}

HHPDE fuel consumption was measured through ECU data streamed by each of the engines' CAN systems. Therefore, diesel fuel consumption for the cycles extracted from engine activity was not modeled. However, when analyzing other possible scenarios, such as the HHPDE CHP hybrid model, fuel consumption was estimated as a function of engine load. Brake specific fuel consumption (BSFC) information was publicly available on the CAT 3512C specification sheet for laboratory conditions at 25\%,50\%,75\%, and 100\% engine loads [32]. Performance published on this specification sheet complied with the SAEJ1995 standard reference conditions. Diesel fuel density was assumed to be $838.9 \mathrm{~g} / \mathrm{L}$ as calculated by CAT in their engine specification sheet [32].

The DNGE fuel model was developed using engine activity recorded by previous campaigns in Midland, TX, and Knight Fork, WV in 2016. The BSFC at 100\% engine load specified on the Waukesha L7044GSI engine specification sheet was also utilized [33]. Fuel consumption from the specification sheet was based on ISO3046/1-1996 with a tolerance for commercial quality natural gas having a 33,533 kJ/m³ (900 BTU/ft $\left.{ }^{3}\right)$ LHV [33]. Field gas LHV varied due to composition, which impacted the standard fuel curve.

Fuel consumption data recorded from both sites were concatenated and binned in 15 groups. The first group contained any fuel consumption for engine loads between $0-20 \%$, and $5 \%$ increments binned the remaining groups. Low engine loads were rare and can induce unnecessary error; therefore, all fuel consumption values indexed to engine loads under $20 \%$ were averaged into the first bin. Fuel consumption for the DNGE at 100\% load was extracted from the specification sheet and added to the model. Natural gas density was assumed to be $0.68 \mathrm{~kg} / \mathrm{Sm}^{3}$. Figure 9 presents both engine fuel consumption models used for the simulations. The MATLAB® script used to calculate DNGE fuel consumption is available in Appendix B. 


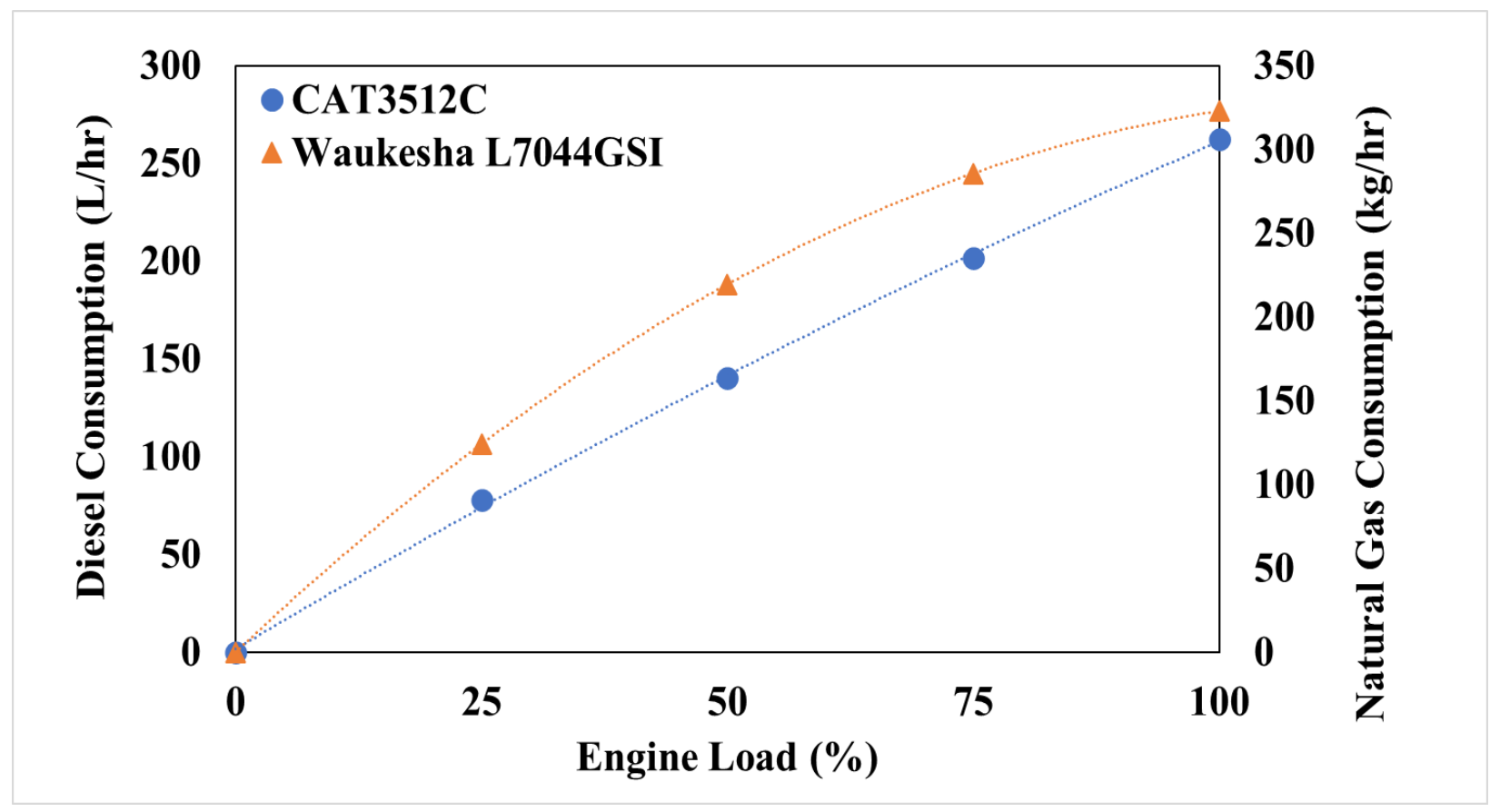

Figure 9. HHPDE And DNGE Fuel Consumption Models

\subsection{Exhaust Temperature}

An exhaust temperature model for each engine (HHPDE and DNGE) was modeled so simulations of different scenarios could be analyzed. Engine manufacturers generally provide exhaust temperature at full load. CAT also provided exhaust temperatures at $50 \%$ and $75 \%$ loads. However, no available data addressed low engine loads. To model lower engine loads, exhaust on-site temperature behavior, a quasi-steady engine operation at low load was identified during a transient operation portion for about a minute. All three engines averaged 20\% engine load, and exhaust temperatures averaged $306{ }^{\circ} \mathrm{C}$. This data point was added to the exhaust temperatures at $50 \%$, $75 \%$, and $100 \%$ engine load specified by the manufacturer, and a polynomial regression was constructed for the HHPDE exhaust temperature model.

DNGE exhaust stack temperature was also modeled based on a regression analysis from data previously recorded from DNGE engines at two other well sites. This data was concatenated and binned into 12 bins with two unique bins (0-10\% load and 60\%-100\% load). The remaining data were binned in 5\% increments between $10 \%$ and $60 \%$ load. Data points in the lowest and highest engine load ranges were averaged in wider bins due to transient operations over these loads. Also, $100 \%$ engine load stack temperature was obtained from Waukesha's specification sheet and included in the regression. Table 5 presents exhaust temperatures specified by the manufacturers 
at laboratory conditions [32,33]. Figure 10 presents the HHPDE and the DNGE exhaust gas temperature model constructed. The MATLAB® script used for the DNGE exhaust temperature model is included in Appendix B.

Table 5. Exhaust Gas Temperature Data [32,33]

\begin{tabular}{ccc}
\hline \hline Engine Load & $\begin{array}{c}\text { CAT 3512C Exhaust } \\
\text { Temperature }\end{array}$ & $\begin{array}{c}\text { Waukesha L7044GSI } \\
\text { Exhaust Temperature }\end{array}$ \\
\hline$\%$ & ${ }^{\circ} \mathbf{C}$ & ${ }^{\circ} \mathbf{C}$ \\
\hline $\mathbf{5 0}$ & 394 & \\
$\mathbf{7 5}$ & 391 & 637 \\
$\mathbf{1 0 0}$ & 398 & 637 \\
\hline
\end{tabular}

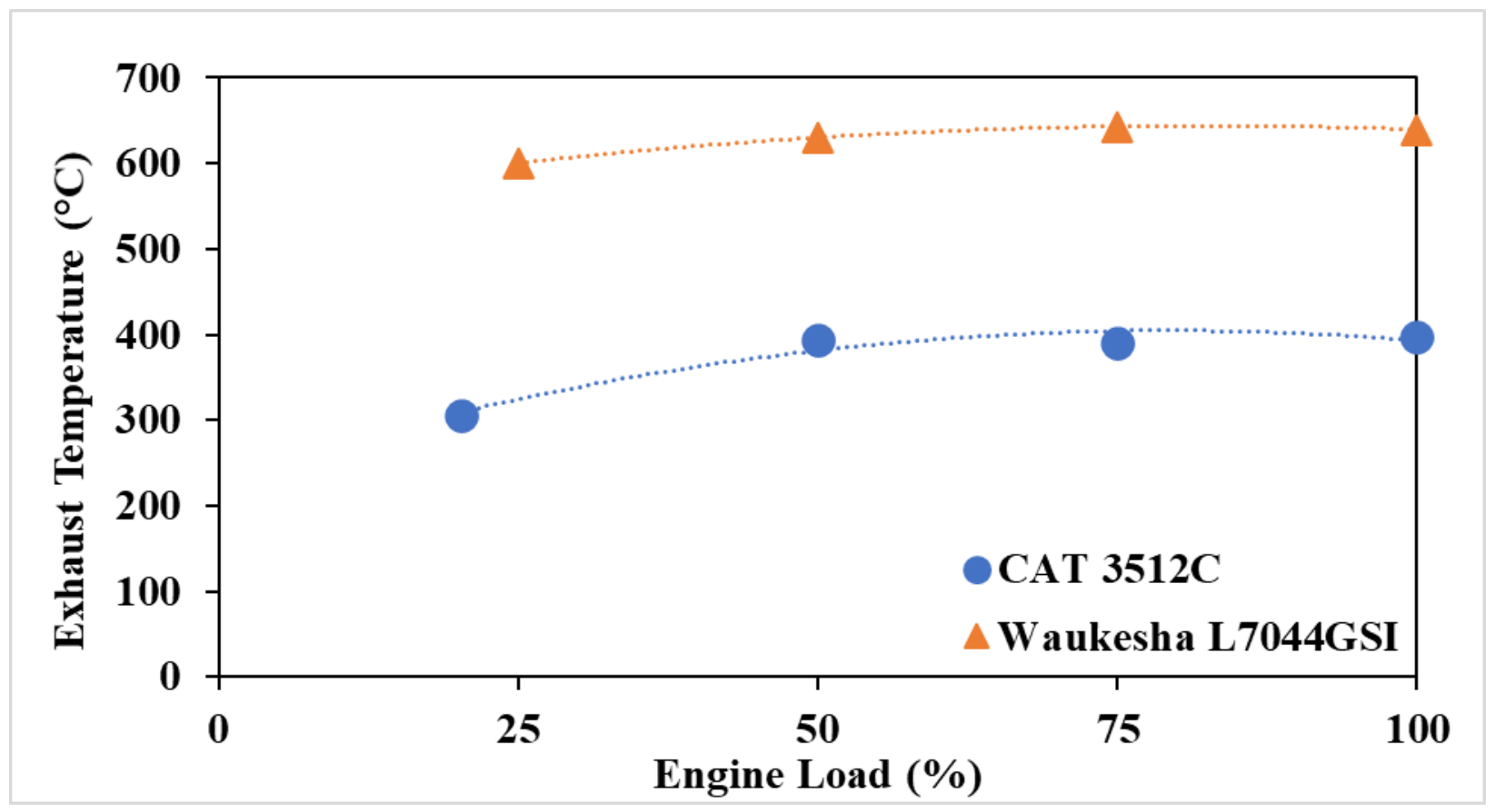

Figure 10. HHPDE And DNGE Exhaust Temperature Models

\subsection{Exhaust Mass Flow and Exhaust Heat Rejection Models}

Diesel exhaust gas is mainly composed of nitrogen $\left(\mathrm{N}_{2}\right)$, water $\left(\mathrm{H}_{2} \mathrm{O}\right)$, carbon dioxide $\left(\mathrm{CO}_{2}\right)$, and oxygen $\left(\mathrm{O}_{2}\right)$ [48]. For simplicity, exhaust flow was assumed to be dry air $\left(78 \% \mathrm{~N}_{2}, 21 \% \mathrm{O}_{2}, 1 \%\right.$ other components) and water vapor only. Dry air and water vapor were treated independently for heat rejection calculation purposes. The same assumption was used for the DNGEs where exhaust 
composition is mostly $\mathrm{N}_{2}, \mathrm{CO}_{2}$, and $\mathrm{H}_{2} \mathrm{O}$. Waukesha L44GSI engines run on a slightly rich airfuel mixture ( $\lambda=0.98$ on average); therebefore, there was no excess oxygen in the exhaust gas.

CAT provides volumetric exhaust flow rates for 50\%, 75\%, and 100\% engine loads and a mass flow rate for $100 \%$ engine load. They also report exhaust heat rejection at these three engine loads. An HHPDE exhaust flow model was constructed using these data points. Table 6 presents engine exhaust information provided by the manufacturer.

Table 6. CAT 3512C Exhaust Specifications [32]

\begin{tabular}{cccc}
\hline \hline $\begin{array}{c}\text { Engine } \\
\text { Load }\end{array}$ & $\begin{array}{c}\text { Volumetric } \\
\text { Exhaust Flow Rate }\end{array}$ & $\begin{array}{c}\text { Mass Exhaust } \\
\text { Flow Rate }\end{array}$ & $\begin{array}{c}\text { Exhaust } \\
\text { Heat }\end{array}$ \\
\hline $\mathbf{\%}$ & $\mathbf{\mathbf { m } ^ { 3 } / \mathbf { m i n }}$ & $\mathbf{K g} / \mathbf{h r}$ & $\mathbf{k W}$ \\
\hline $\mathbf{5 0}$ & 125.9 & & 501 \\
$\mathbf{7 5}$ & 173.5 & & 707 \\
$\mathbf{1 0 0}$ & 218.0 & 6979 & 902 \\
\hline
\end{tabular}

The exhaust gas composition of a CAT 3512C engine operating on the Marcellus Shale Energy and Environment Laboratory (MSEEL) was measured during a previous WVU campaign [46]. A Fourier-transform infrared spectroscopy (FTIR) device was used to measure exhaust water vapor concentration. The average water vapor concentration was found to be $7.4 \%$. Thus, HHPDE exhaust flow was assumed to be around $7.4 \%$ water vapor and $92.6 \%$ dry air. Using this ratio of dry air to water vapor in the exhaust, the molar exhaust flow rate was iteratively calculated to estimate exhaust mass flow and heat rejection. Values converged when the minimal error was achieved at 50\%, 75\%, and 100\% engine loads. Iterations were dominated by Equation 3 based on thermal properties for dry air and water vapor which are presented in Table 7. Calculated mass flow rate and calculated heat rejection were compared to data provided on the engine specification sheet. Tables 8 and 9 present estimated exhaust flow rates and heat rejections with their respective errors.

\section{Equation 3. Heat Rejection Equation}

$$
\dot{Q}=m_{\mathrm{H}_{2} \mathrm{O}}\left(h_{\text {exhaust } \mathrm{H}_{2} \mathrm{O}}-h_{\text {ambient }, \mathrm{H}_{2} \mathrm{O}}\right)+m_{\text {Alr }}\left(h_{\text {exhaust,Air }}-h_{\text {ambient,Air }}\right)
$$


Table 7. Specific Enthalpy of Dry Air and Water Vapor Used for HHPDE Exhaust Heat Calculations [32,49]

\begin{tabular}{cccc}
\hline \hline Engine Load & Temperature & $\mathbf{h ~ H} \mathbf{2}_{\mathbf{O}}$ & $\mathbf{h}$ Air \\
\hline \% & ${ }^{\circ} \mathbf{C}$ & $\mathbf{k J} / \mathbf{k g}$ & $\mathbf{k J} / \mathbf{k g}$ \\
\hline Ambient & 25 & 418 (Sat. Liquid) & 298 \\
$\mathbf{5 0}$ & 394 & 3265 & 668 \\
$\mathbf{7 5}$ & 391 & 3260 & 675 \\
$\mathbf{1 0 0}$ & 398 & 3273 & 682 \\
\hline
\end{tabular}

Table 8. CAT 3512C Mass Exhaust Flow Rate Model [32]

\begin{tabular}{cccc}
\hline \hline $\begin{array}{c}\text { Engine } \\
\text { Load }\end{array}$ & $\begin{array}{c}\text { Total Mass } \\
\text { Exhaust Flow }\end{array}$ & $\begin{array}{c}\text { Total Mass Exhaust } \\
\text { Flow Rate by CAT }\end{array}$ & Error \\
\hline $\mathbf{\%}$ & $\mathbf{k g} / \mathbf{h r}$ & $\mathbf{k g} / \mathbf{h r}$ & \% \\
\hline $\mathbf{5 0}$ & 3632 & & \\
$\mathbf{7 5}$ & 5157 & & \\
$\mathbf{1 0 0}$ & 6637 & 6797 & 2.4 \\
\hline
\end{tabular}

Table 9. CAT 3512C Exhaust Heat Model [32]

\begin{tabular}{cccc}
\hline \hline \multirow{2}{*}{ Engine Load } & Heat Release Calculated & Heat Release Specified by CAT & Error \\
\hline $\boldsymbol{\%}$ & $\mathbf{k W}$ & $\mathbf{k W}$ & $\mathbf{\%}$ \\
\hline $\mathbf{5 0}$ & 501 & 501 & 0.0 \\
$\mathbf{7 5}$ & 707 & 707 & 0.0 \\
$\mathbf{1 0 0}$ & 924 & 902 & 2.3 \\
\hline
\end{tabular}

A DNGE exhaust flow model was built based on the manufacturer's specification sheet information, ECU data, and emissions data recorded during previous projects. Natural gas fuel consumption was converted to SI units by converting standard cubic feet (SCF) to $\mathrm{Sm}^{3}$ and using a natural gas density of $0.68 \mathrm{~kg} / \mathrm{Sm}^{3}$. Equation 3 was also used for heat rejection calculations. Natural gas LHV was assumed to be $33,533 \mathrm{MJ} / \mathrm{m}^{3}$ as specified by Waukesha's engine specification sheet [33]. 
According to data previously recorded, the DNGE AFR is 16.86 [37]. Note that the stoichiometric AFR for natural gas combustion is 17.2 when approximated as methane. With a modeled fuel consumption curve and a fixed AFR assumption, the mass air intake was calculated. It was determined from previous data that DNGE water vapor exhaust concentration was $17.94 \%$ on average [37]. Therefore, the exhaust flow of the DNGE was assumed to be $17.94 \%$ water vapor and $82.1 \%$ dry air. If pure methane was considered for stoichiometric combustion, Equation 4 presents the stoichiometric water vapor concentration in exhaust.

\section{Equation 4. Methane Stoichiometric Combustion}

$$
\mathrm{CH}_{4}+2\left(\mathrm{O}_{2}+3.76 \mathrm{~N}_{2}\right) \rightarrow \mathrm{CO}_{2}+2 \mathrm{H}_{2} \mathrm{O}+7.52 \mathrm{~N}_{2}
$$

Methane complete combustion products indicate a water vapor exhaust concentration of $19 \%$. Onsite data collected referred to field gas composition that differed from pure methane, dropping water vapor concentration to $17.9 \%$ of its exhaust composition. Table 10 presents the thermal properties for dry air and water vapor used for the DNGE exhaust heat rejection calculations. Like the HHPDE exhaust heat model, the DNGE model was calculated via iterations until converging to the minimum error governed by Equation 3. Tables 11 and 12 present the DNGE exhaust flow and heat model errors.

\section{Table 10. Specific Enthalpy of Dry Air and Water Vapor Used for DNGE Exhaust Heat} Calculations [33,49]

\begin{tabular}{cccc}
\hline \hline Engine Load & Temperature & h $\mathbf{H}_{2} \mathbf{O}$ & h Dry Air \\
\hline \% & ${ }^{\circ} \mathbf{C}$ & $\mathbf{k J} / \mathbf{k g}$ & $\mathbf{k J} / \mathbf{k g}$ \\
\hline Ambient & 25 & 419 & 298 \\
$\mathbf{1 0 0}$ & 637 & 3787 & 944 \\
\hline
\end{tabular}

Table 11. Waukesha L7044GSI Mass Exhaust Flow Rate Model [33]

\begin{tabular}{cccc}
\hline \hline $\begin{array}{c}\text { Engine } \\
\text { Load }\end{array}$ & $\begin{array}{c}\text { Calculated Mass } \\
\text { Exhaust Flow }\end{array}$ & $\begin{array}{c}\text { Total Exhaust Mass Flow } \\
\text { Specified by Waukesha }\end{array}$ & Error \\
\hline$\%$ & Kg/hr & Kg/hr & $\%$ \\
\hline $\mathbf{1 0 0}$ & 4653 & 5113 & 9.0 \\
\hline
\end{tabular}


Table 12. Waukesha L7044GSI Exhaust Heat Model [33]

\begin{tabular}{cccc}
\hline \hline $\begin{array}{c}\text { Engine } \\
\text { Load }\end{array}$ & $\begin{array}{c}\text { Calculated } \\
\text { Heat Rejected }\end{array}$ & $\begin{array}{c}\text { Heat Rejection } \\
\text { Specified by Waukesha }\end{array}$ & Error \\
\hline $\boldsymbol{\%}$ & $\mathrm{kW}$ & $\mathrm{kW}$ & $\%$ \\
\hline $\mathbf{1 0 0}$ & 1256 & 1143 & 9.0 \\
\hline
\end{tabular}

\subsection{Exhaust Heat Exchanger Design}

HEX design was performed using CC-THERM software, a sub-program to the CHEMCAD ${ }^{\circledR}$ suite developed by Chemstations [50]. CC-THERM software allows the user to design HEXs and performs calculations of hypothetical conditions. This program supports shell-and-tube, aircooled, plate-and-frame, and double-pipe exchangers. Its integration with CHEMCAD software makes it possible to calculate HEX exit conditions from simulations [50]. This software bundle was used for the design of the E-HEXs and JW-HEXs. These exchangers' physical design was outside of this project's scope, but the focus was to estimate potential heat recovery. HEXs were selected to be automatically sized and designed complying with the American Society of Mechanical Engineers (ASME) and Tubular Exchanger Manufacturers Association (TEMA) standards [51]. Size constraints were implemented so that the HEX could be placed in a standard 20 ' $\times 8$ ' 6' ' $\times 8$ ' $(6.1 \times 2.6 \times 2.4 \mathrm{~m})$ container frame for simple handling and transportation, typical in the industry. Pressure drop was also limited and constituted the primary constraint to avoid exhaust backpressures that would negatively impact engine efficiency [28]. Most diesel generator manufacturers set their maximum allowed backpressure limits ranging from 6.7 to $10.2 \mathrm{kPa}(0.97$ to $1.48 \mathrm{psi}$ ) [28].

Boilers usually provide saturated steam at pressures around $110 \mathrm{psi}$; therefore, the E-HEX design was intended to match the boiler's pressure and temperature output. Water inlet was selected to be variable while steam output conditions were set to be fixed at saturated steam at $110 \mathrm{psi}$. Saturated steam distribution lines are equipped with steam traps that redirect saturated and condensed water to a day tank that functions as a recovery feedwater system that feeds the boiler. The goal was not to redesign the heat distribution system but to assist/replace the boiler with a set of HEXs. Therefore, steam distribution system design and specifications had to integrate into the design. Day tank water was selected as the water inlet for the designs. Since the boiler steam output has a fixed pressure, the temperature of the water returned to the day tank was nearly constant, only 
affected by ambient temperature. Water inlet temperature (day tank temperature) was assumed to be constant at the average temperature recorded during boiler usage $\left(70{ }^{\circ} \mathrm{C}\right)$.

E-HEX and JW-HEX types were selected to be shell-and-tube due to their popularity in steam generation applications in industries such as combined cycle power plants. These configurations also have the ability to handle high pressures and flows.

CC-THERM used the logarithmic mean temperature difference (LMTD) method instead of the number of transfer units (NTU) method. The NTU method predicted the outlet fluid temperature if the heat transfer coefficient and inlet temperatures were known. The LMTD method was convenient for determining the overall HEX coefficient based on the measured inlet and outlet fluid temperatures. Therefore, the HEX designs were based on the exhaust flow and temperature and water inlet temperature. The software neglects any heat losses to the environment. Exhaust and other higher temperature lines at drilling sites tended to be insulated. HEX designs could be implemented to match well with the externally insulated boundary conditions. Using the LMTD method and software package, an iterative process was performed to find the best HEX design for the required heat transfer coefficient (U) and the surface area (A) while also meeting necessary constraints. Equation 5 was utilized for LMTD calculations.

\section{Equation 5. Heat Exchanger Heat Transfer}

$$
Q=U \times A \times L M T D
$$

Where LMTD is the logarithmic mean temperature difference defined as:

Equation 6. Logarithmic Mean Temperature Difference

$$
L M T D=\frac{\Delta T_{A}-\Delta T_{B}}{\ln \frac{\Delta T_{A}}{\Delta T_{B}}}
$$

Where $\Delta \mathrm{T}_{\mathrm{A}}$ is the temperature difference between the two streams at end $\mathrm{A}$ and $\Delta \mathrm{T}_{\mathrm{B}}$ is the temperature difference between the two streams at B. Figure 11 presents a counterflow shell and tube HEX diagram using the LMTD method. 


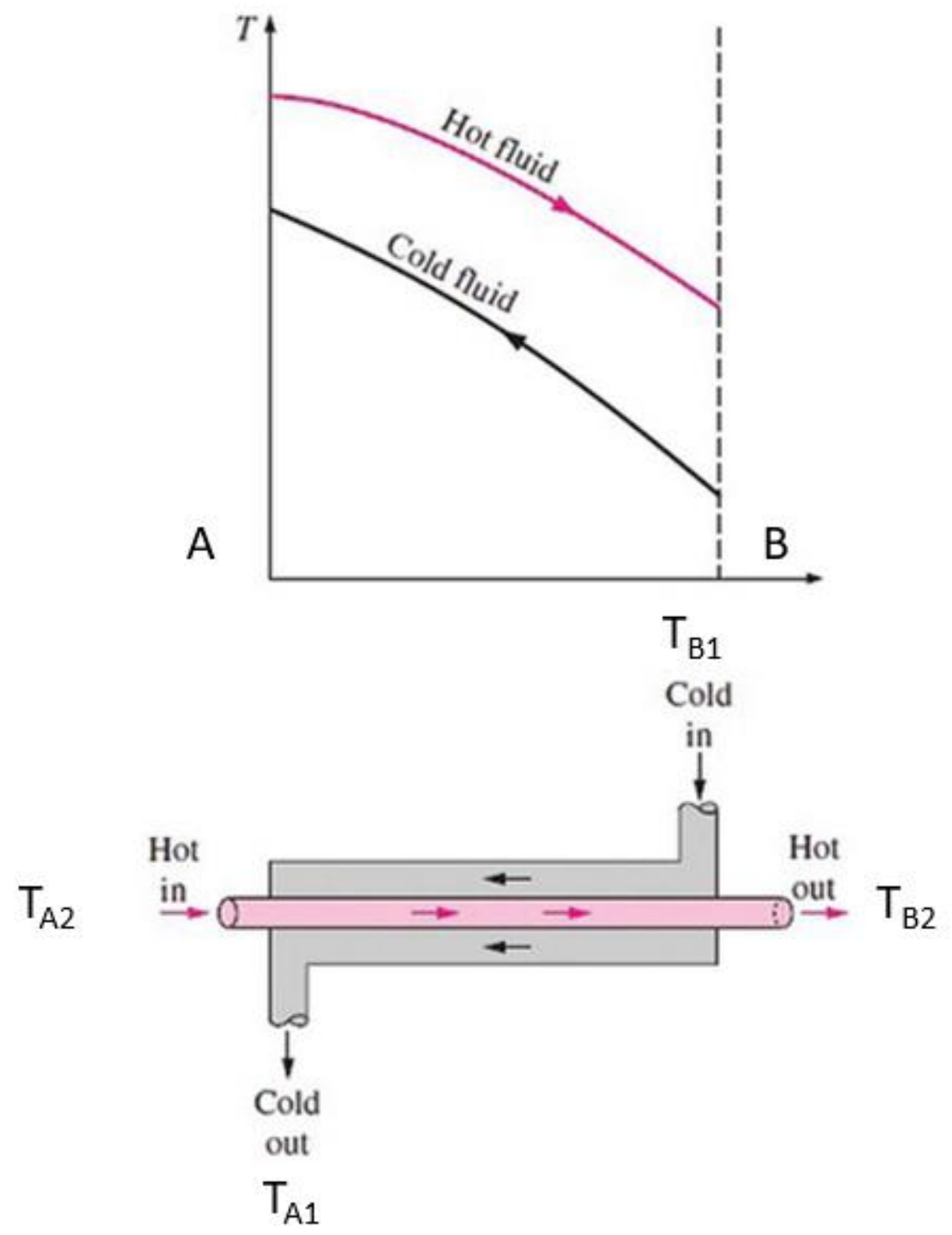

Figure 11. Counterflow Shell and Tube Heat Exchanger Diagram Using the LMTD Method [52]

The HHPDE E-HEX was sized to recover the most heat possible by utilizing engine conditions at $100 \%$ load. The water inlet rate was iterated until it converged to the maximum water flow maintaining steam outlet conditions. The system uses a reversible pump to pressurize the water and meet steam pressure requirements to imitate heat output rates. Pump energy consumption was not considered in this first energy analysis for simplicity. In the current rig configuration, water is pumped from the day tank into the boiler. Pump work was small and negligible compared to the other energy demands of the system. The software automatically calculated enthalpy for each fluid 
inlet and outlet. The difference in enthalpy at constant pressure represents the energy transfer rate. Therefore, the enthalpy difference between the steam outlet and the water inlet represented the recovered heat in the exchanger. Various combinations of exhaust flow and exhaust temperatures were rated in the software. Their respective heat recovery values were saved to develop a twoentry table. Values that did not fall at the exhaust flow and temperatures simulated were linearly interpolated. Figure 12 presents the HHPDE sizing conditions extracted from the software. The HHPDE E-HEX TEMA sheet is included in Appendix C.

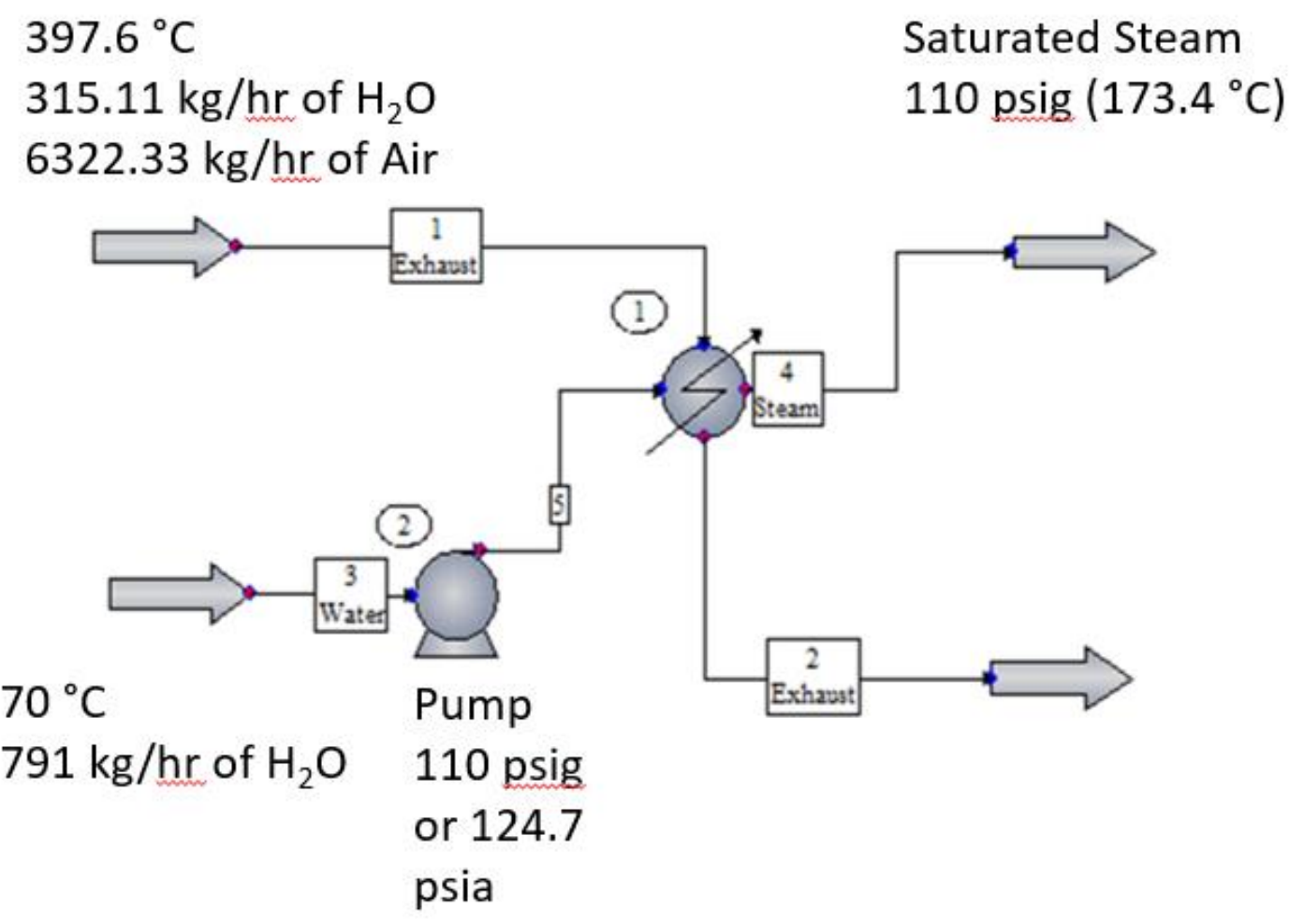

Figure 12. HHPDE E-HEX Sizing and Design Conditions in The CHEMCAD Environment

Similarly, a DNGE E-HEX was designed and sized for the engine's operating conditions at full engine load with the exhaust temperature provided by the specification sheet and exhaust flow calculated by the DNGE exhaust flow model. Allowable pressure drop was assumed to be 10.2 $\mathrm{kPa}$ as determined for HHPDE E-HEX. Figure 13 presents the DNGE E-HEX design conditions in the software environment. The DNGE exhaust heat rejection depended only on engine load; thus, DNGE E-HEX heat recovery also depended on engine load. Table 13 presents HHPDE and 
DNGE E-HEX main design parameters. The DNGE E-HEX TEMA sheet is included in Appendix C.

$637{ }^{\circ} \mathrm{C}$

$917.3 \mathrm{~kg} / \mathrm{hr}$ of $\mathrm{H}_{2} \mathrm{O}$

$4195.7 \mathrm{~kg} / \mathrm{hr}$ of Air

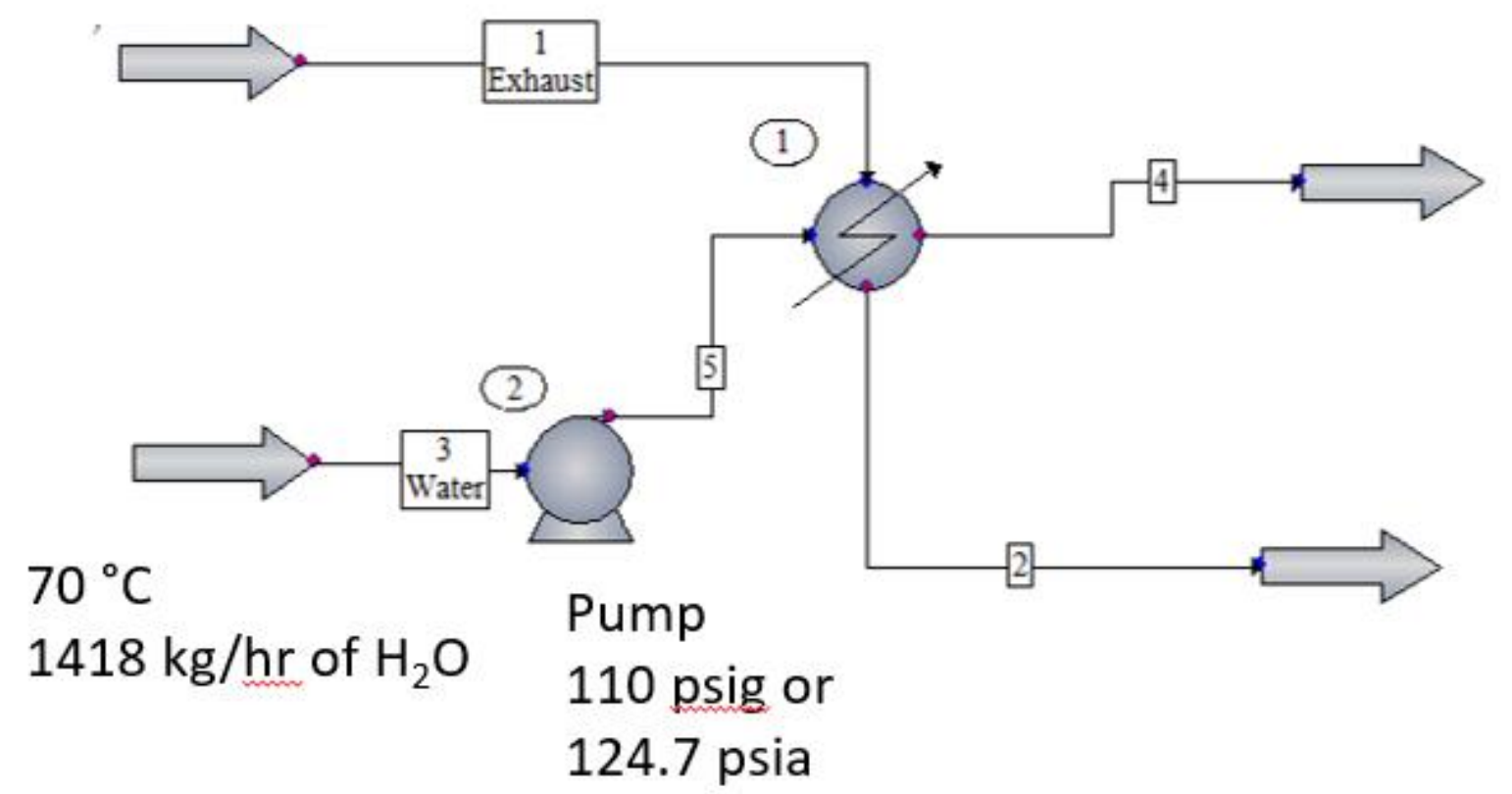

Figure 13. DNGE E-HEX Sizing and Design Conditions in the CHEMCAD Environment

Table 13. HHPDE and DNGE E-HEX Design

\begin{tabular}{ccc}
\hline \hline E-HEX & HHPDE E-HEX & DNGE E-HEX \\
\hline Shell Diameter $(\mathbf{m})$ & 2.1 & 2.4 \\
Tube Length $(\mathbf{m})$ & 2.4 & 3.0 \\
Number of Tubes & 5557 & 7508 \\
Effective Transfer Area $\left(\mathbf{m}^{\mathbf{2}}\right)$ & 798.3 & 1352.4 \\
U (W/m2 $\left.\mathbf{2}^{\circ} \mathbf{C}\right)$ & 30.2 & 21.5 \\
Tube $\mathbf{O . D .}(\mathbf{c m})$ & 1.91 & 1.91 \\
Tube I.D. $(\mathbf{c m})$ & 1.56 & 1.56 \\
\hline
\end{tabular}


A commercially available E-HEX was compared with the CHEMCAD designed E-HEX. CAIN industries is an exhaust heat recovery and steam generator system manufacturer. They usually work with large diesel and/or natural gas-powered engines. The best fit unit was selected from their exhaust steam generator (ESG) catalog. The ESG1-B30B14.5CSS unit equipped with an internal economizer was recommended for optimal effectiveness. The ESG performance was simulated by the company's software given exhaust flow and temperatures provided by CAT's engine specification sheet [32]. A regression analysis was performed from the exchanger company's three data points to compare results and validate simulations. Note that ESG heat recovery estimation is only a function of engine load from data recorded in CAT's laboratory at steady loads. The CAIN ESG1-824B16CSS was selected as the best fit for the DNGE engine. Figure 14 presents HHPDE E-HEX, DNGE E-HEX, HHPDE ESG, and DNGE ESG performance as a function of engine load. Both HHPDE ESG and DNGE ESG design and quote can be found in Appendix D.

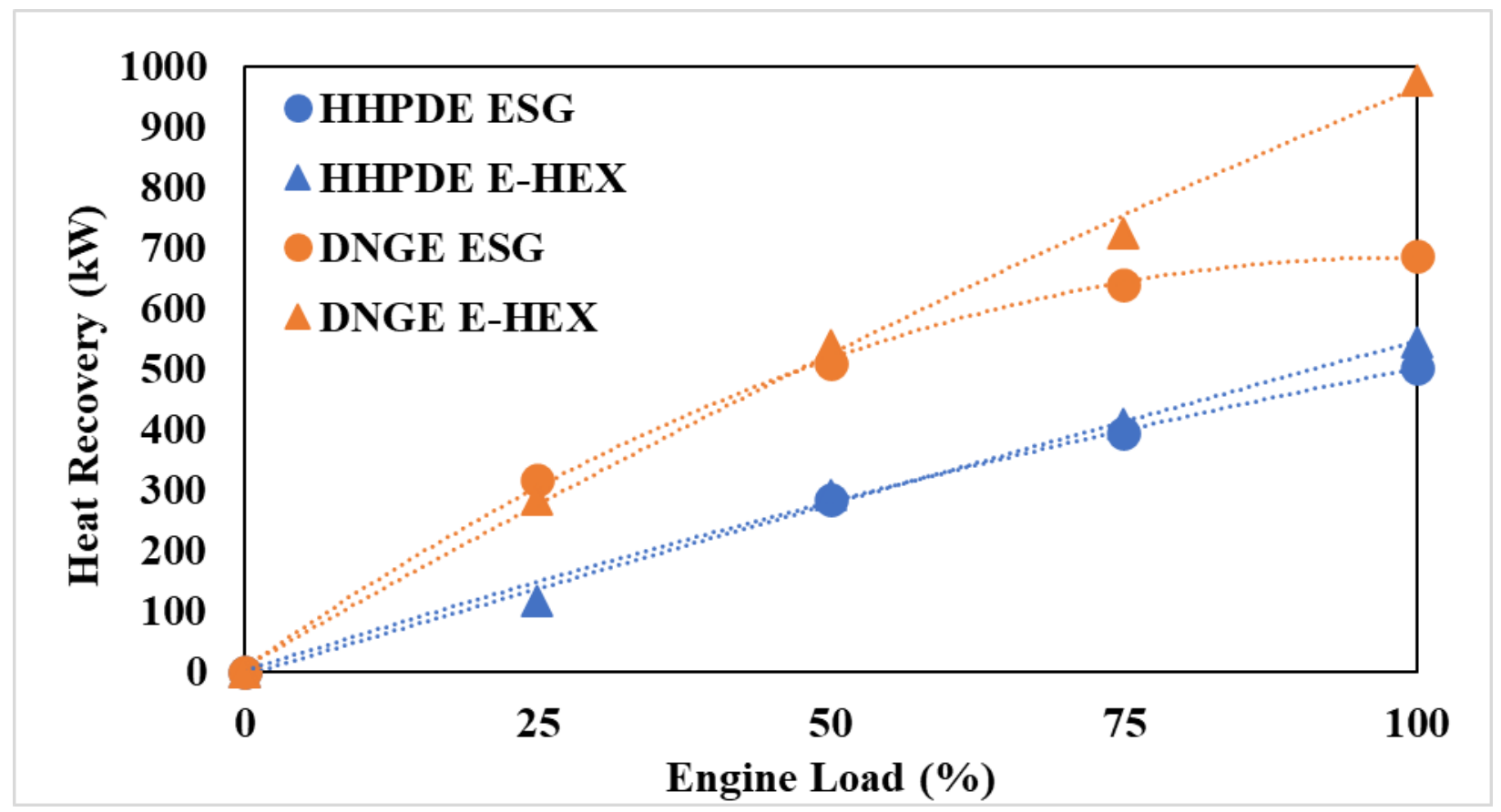

Figure 14. HHPDE ESG, HHPDE E-HEX, DNGE ESG, and DNGE E-HEX Heat Recovery as a Function of Engine Load

\subsection{Hybrid System Battery Model}

A basic battery design was created based on a hybrid system reported in the literature [13]. The system used a 584-kW-hr battery pack. Only the rate of charge/discharge and usable SOC range 
were considered in the design for simplicity. The SOC is the charge of a battery relative to its capacity. The rate of charge/discharge is the amount of energy being supplied or extracted from the battery per unit of time. Coulomb's C-rate is a measure of the rate at which a battery is being charged or discharged. It determined the maximum rate of charge and discharge. The HEMS was designed with a $3 \mathrm{C}$ discharge and $1 \mathrm{C}$ charging rates, meaning the battery can be fully charged in one hour while it can be discharged in 20 minutes. The allowable range of the SOC was assumed to be between $40 \%$ and $100 \%$ capacity. Considering the SOC restrictions, the battery could discharge from $100 \%$ to $40 \%$ in 12 minutes at the maximum discharge rate. Coulombic efficiency is a measure of charging and discharging efficiency that accounts for heat losses through internal impedances. Lithium-ion cells have high coulombic efficiency estimated at around 80\% and 90\% for charging and discharging, respectively [52]. Coulombic efficiencies were also integrated into the HEMS model. The power output limit of the system was rated at $1752 \mathrm{~kW}$, larger than any of the analyzed individual engines.

The HEMS was designed to enable the operation of fewer engines, requiring those in operation to operate at higher loads near peak efficiency. This reduced transient operations and emissions. The initial battery SOC was assumed to be $70 \%$ for scenarios analyzed, and the number of online gensets was calculated given average and maximum power output. The goal was to have as few online gensets as possible at any given time. Initial engine load was assumed to be $75 \%$, and engine load is automatically adjusted based on the last 60 seconds of SOC. Table 14 presents the HEMS ideal engine load controller commands. Also, the HEMS was designed to maintain instant heat recovery at higher rates than the system's instant heat demand when possible 
Table 14. HEMS Ideal Engine Load Controller

\begin{tabular}{cccc}
\hline \hline Previous 60 Seconds of Activity & SOC & $\begin{array}{c}\text { Load } \\
\text { Adjustment }\end{array}$ & $\begin{array}{c}\text { Ideal Load } \\
\text { Output }\end{array}$ \\
\hline \multirow{3}{*}{ SOC Continous Increment } & SOC $\geq 90$ & -0.03 & \\
& $S O C \geq 80$ & -0.02 & Decreased \\
& SOC $\geq 60$ & -0.01 & \\
SOC Continous Reduction & $S O C \leq 50$ & +0.03 & \\
& $S O C \leq 60$ & +0.02 & Increased \\
Non-continuous SOC Activity Detected & $40 \geq S O C \geq 100$ & 0.00 & Maintained \\
\hline
\end{tabular}

The HEMS load controller worked on a two-level decision-making unit. The top-level was the limitations due to the HEMS restrictions. These helped the HEMS stay within the allowable SOC working range and its respective charging/discharging limits. The second level included the ideal load controller presented in Table 14 and the heat balance controller.

HEMS top-level load control unit:

- If SOC approached $100 \%$, engine load was decreased to its minimum possible

- If SOC approached $40 \%$, engine load was increased to its maximum possible

- If the rate of charge approached $1 \mathrm{C}$, engine load was decreased to its minimum possible

- If the rate of discharge approached $3 \mathrm{C}$, engine load was increased to its maximum possible

HEMS second-level load control unit:

- Ideal engine load controller as presented in Table 14

- If instant heat demand exceeded instant heat recovery, engine load was increased by $1 \%$ load increments, and excess energy was stored in the HEMS battery 
In order to compare hybrid to non-hybrid systems, fuel consumption was corrected for battery SOC differences for each cycle. Both HHPDE and DNGE HEMS MATLAB ${ }^{\circ}$ scripts can be found in Appendix B.

\section{Cycles}

A set of four activity cycles was extracted from on-site recorded data to study the energy UF during varying timespans that were representative of unconventional well development. These cycles were selected to represent various drilling operations and conditions. These cycles included three short duration cycles (each an hour in length) where drilling operations were powered by either two engines (2E1HR), three engines $(3 \mathrm{E} 1 \mathrm{HR})$, and transient tripping pipe/casing operations powered by three engines (TP1HR) (high transient loads). The final cycle was a longer duration (representative of an entire day) that combined all operations (24HR).

Since DNGE activity was not directly recorded, the same cycles recorded on HHPDEs were utilized. The same number of online gensets were used, and the engine load was adjusted to the DNGE power (1253 bkW), assuming a constant generator efficiency of $95 \%$. Generator efficiencies might vary, especially at low loads. However, a constant efficiency reported by manufacturers was utilized for simplicity [32,33]. Figures 15 through 18 present the genset power output for each of the analyzed cycles.

Cycles were characterized by a name, the number of online gensets, average power output, drilling operation, and timespan. Each of these cycle characteristics are specified below:

- 2E1HR Cycle

○ Two online gensets

○ Average Power Output was 1360 kWe

- The average engine load CAT3 512C was $65.0 \%$

- The average engine load Waukesha L7044GSI was 57.1\%

○ Steady drilling operation

○ One hour long

- 3E1HR Cycle

○ Three online gensets

○ The average power output was $1455 \mathrm{kWe}$ 
- The average engine load CAT3 512C was $46.4 \%$

- The average engine load Waukesha L7044GSI was 40.7\%

○ Steady drilling operation

○ One hour long

- $\quad$ TP1HR Cycle

○ Three online gensets

○ Average Power Output was $801 \mathrm{kWe}$

- The average engine load CAT3 $512 \mathrm{C}$ was $25.5 \%$

- The average engine load Waukesha L7044GSI was $22.4 \%$

○ Tripping pipe/casing operation (highly transient)

○ One hour long

- 24HR Cycle

○ Two and three online gensets

- Average Power Output was 1209 kWe

- The average engine load CAT3 512C was $38.5 \%$

- The average engine load Waukesha L7044GSI was $33.9 \%$

○ Steady drilling and tripping pipe/ casing operations

○ 24 hours long

Figure 15 presents the 2E1HR cycle, which represents low load steady drilling operations with two engines online for one hour. 

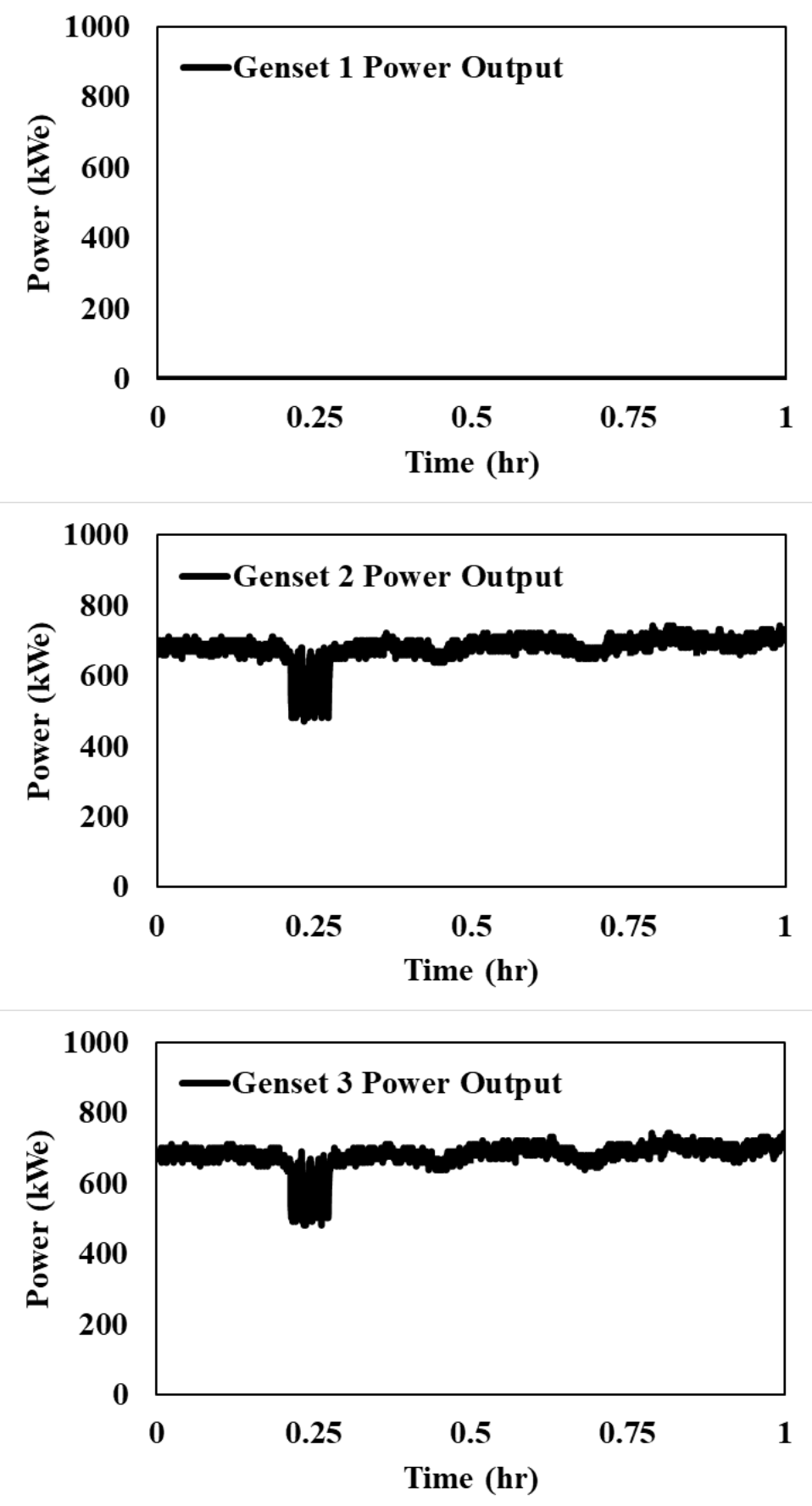

Figure 15. 2E1HR Cycle Genset Power Output

Figure 16 presents the 3E1HR cycle, which is characteristic of a high load drilling operation. The differentiation to the $2 \mathrm{E} 1 \mathrm{HR}$ cycle is that it had three engines online and higher electric power outputs. 

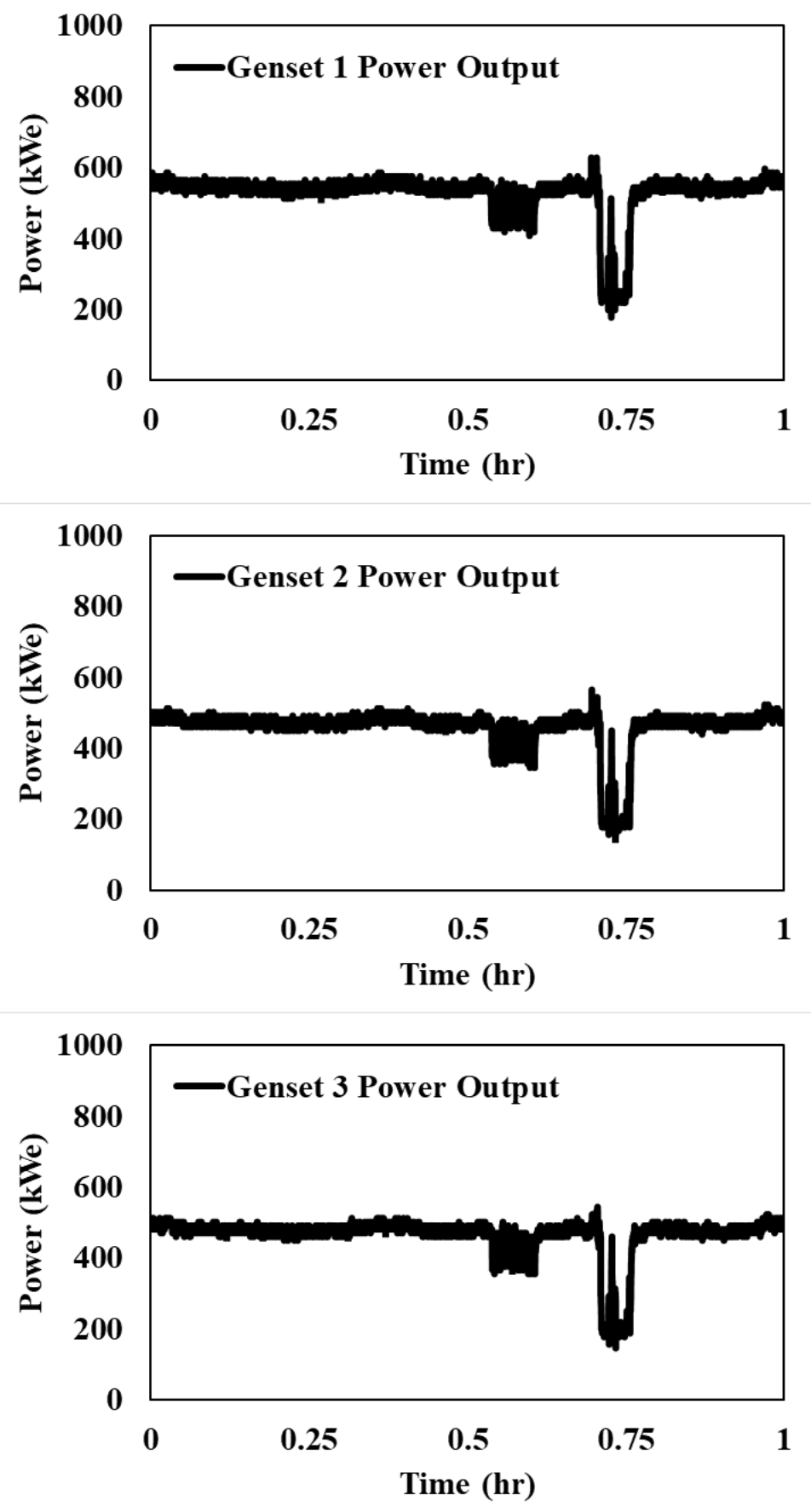

Figure 16. 3E1HR Cycle Genset Power Output

Figure 17 presents the TP1HR cycle, which represents transient activity during tripping pipe/casing operations of the rig where high loads are required after low loads or idling operations causing transient engine operation. This cycle demanded three engines online for one hour. 

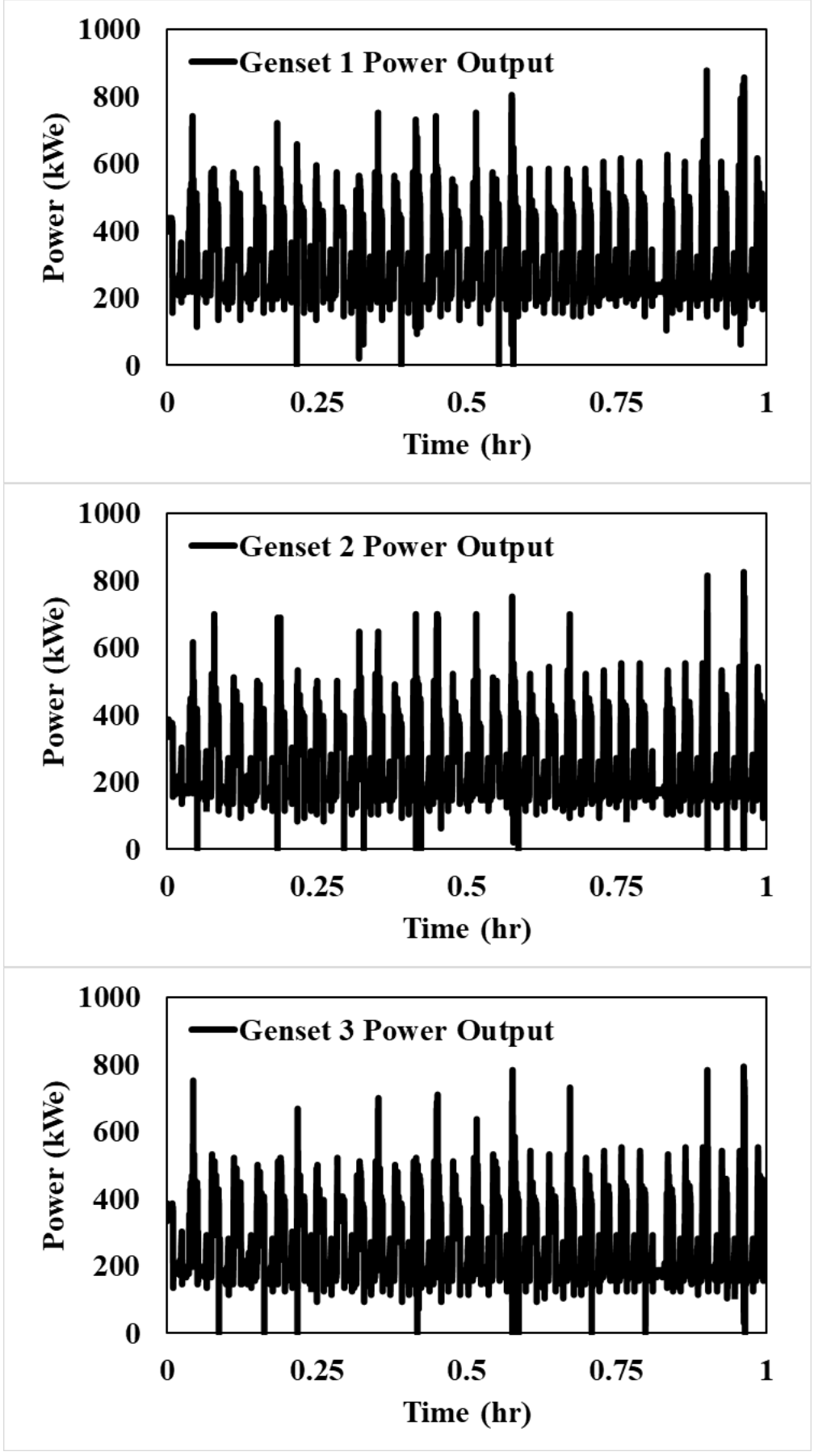

Figure 17. TPHR Cycle Genset Power Output

Figure 18 presents the 24HR cycle, which combined all engine operations on a well pad. This engine operation profile was extracted from 24 hours. It was characterized by having two and three engines online, steady drilling operation, and tripping pipe/casing operations. 

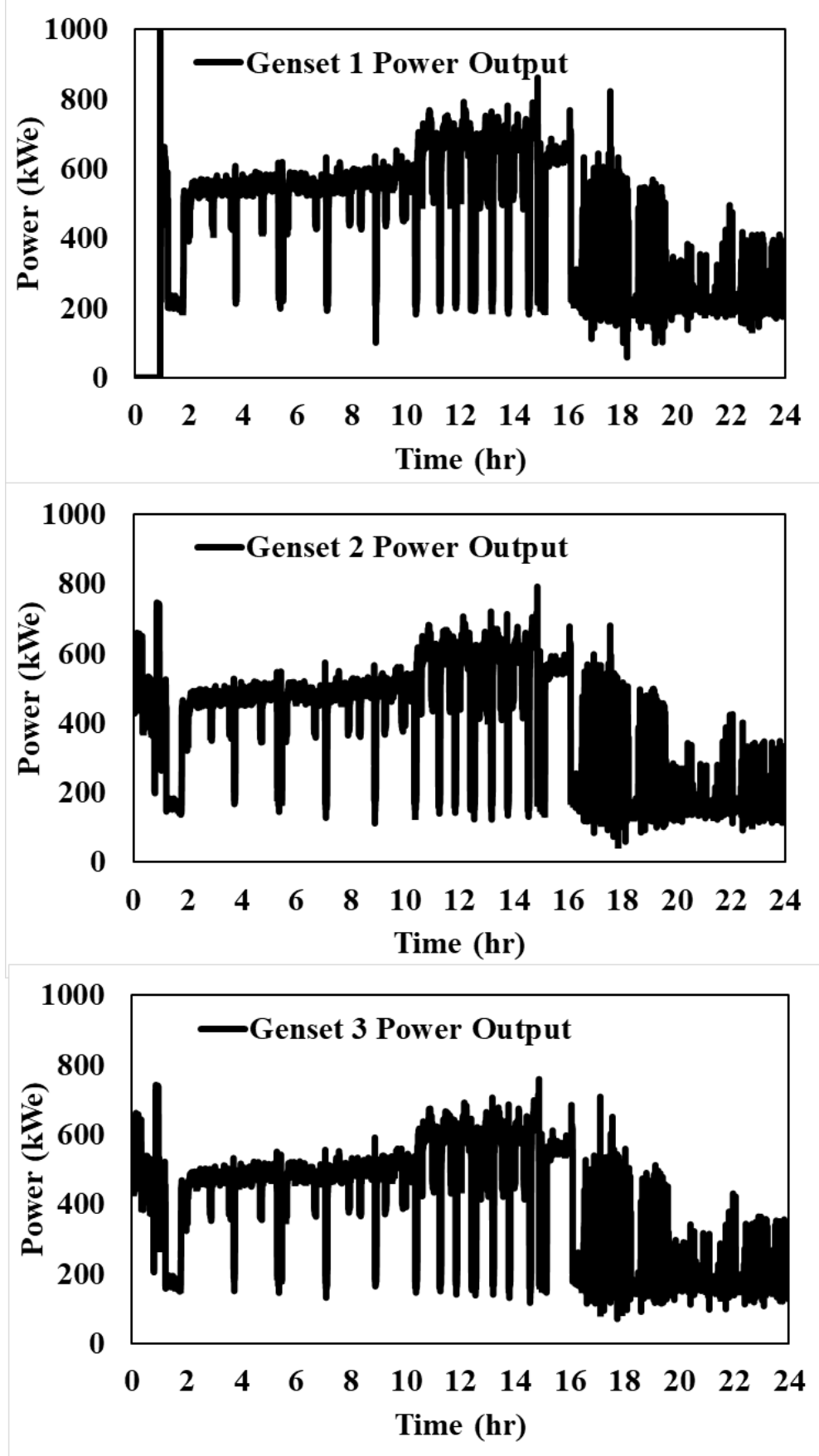

Figure 18. 24HR Cycle Genset Power Output 


\section{Results and Discussion}

\subsection{Rig's Energy Demand}

Four different scenarios were analyzed over the four characteristic cycles previously defined.

These scenarios were:

- High horsepower diesel engine combined heat and power system (HHPDE CHP)

- High horsepower diesel engine combined heat and power hybrid system (HHPDE CHP hybrid)

- Dedicated natural gas engine combined heat and power system (DNGE CHP)

- Dedicated natural gas engine combined heat and power hybrid system (DNGE CHP hybrid)

Table 15 presents the total rig energy demand for the duration of each cycle as well as the average boiler heat demand.

Table 15. Cycle Energy Demand Specifications

\begin{tabular}{cccc}
\hline \hline Cycle & $\begin{array}{c}\text { Rig's Energy } \\
\text { Demand }\end{array}$ & $\begin{array}{c}\text { Boiler's Energy } \\
\text { Demand }\end{array}$ & $\begin{array}{c}\text { Boiler's Average } \\
\text { Instant Demand }\end{array}$ \\
\hline Name & MJ & MJ & kW \\
\hline 2E1HR & 4895 & 2619 & 727.5 \\
3E1HR & 5238 & 2339 & 649.7 \\
TP1HR & 2884 & 2388 & 663.3 \\
24HR & 104,437 & 60,760 & 703.2 \\
\hline
\end{tabular}

\subsection{Energy Saving Model: HHPDE CHP}

The HHPDE CHP system was simulated in a 0-D model in a SIMULINK environment presented in Figure 19, and results are presented in Table 16. The HHPDE E-HEX is the CHEMCAD designed exhaust heat exchanger and HHPDE ESG is the industrial exhaust heat exchanger being compared in this analysis. UF is the ratio of the energy used (heat or work) to the fuel energy (LHV). 
The SIMULINK model for the HHPDE CHP system model specifications is attached in Appendix E and included:

- CAT 3512C engine subsystem

- Calculated exhaust heat rejection utilizing Equation 3

- Exhaust mass flow rate modeled as a function of engine load

- Dry air mass flow rate

- Water vapor mass flow rate

- Exhaust temperature recorded by the thermocouples installed in the exhaust muffler

○ Fuel consumption from ECU

○ Power output calculated assuming constant generator efficiency of $95 \%$

- HHPDE E-HEX subsystem

- Calculated exhaust heat recovery from CHEMCAD developed two-entry table, dry air, and water vapor mass exhaust flow rate from CAT 3512C engine subsystem and exhaust temperature

- HHPDE ESG subsystem

- Calculated exhaust heat recovery from the exchanger performance provided by the manufacturer and available in Appendix D.

- Boiler subsystem

○ Fuel consumption (diesel) recorded by the KRAL flow meters

- Calculated heat supplied to the system from fuel consumption assuming constant efficiency of $81 \%$ 


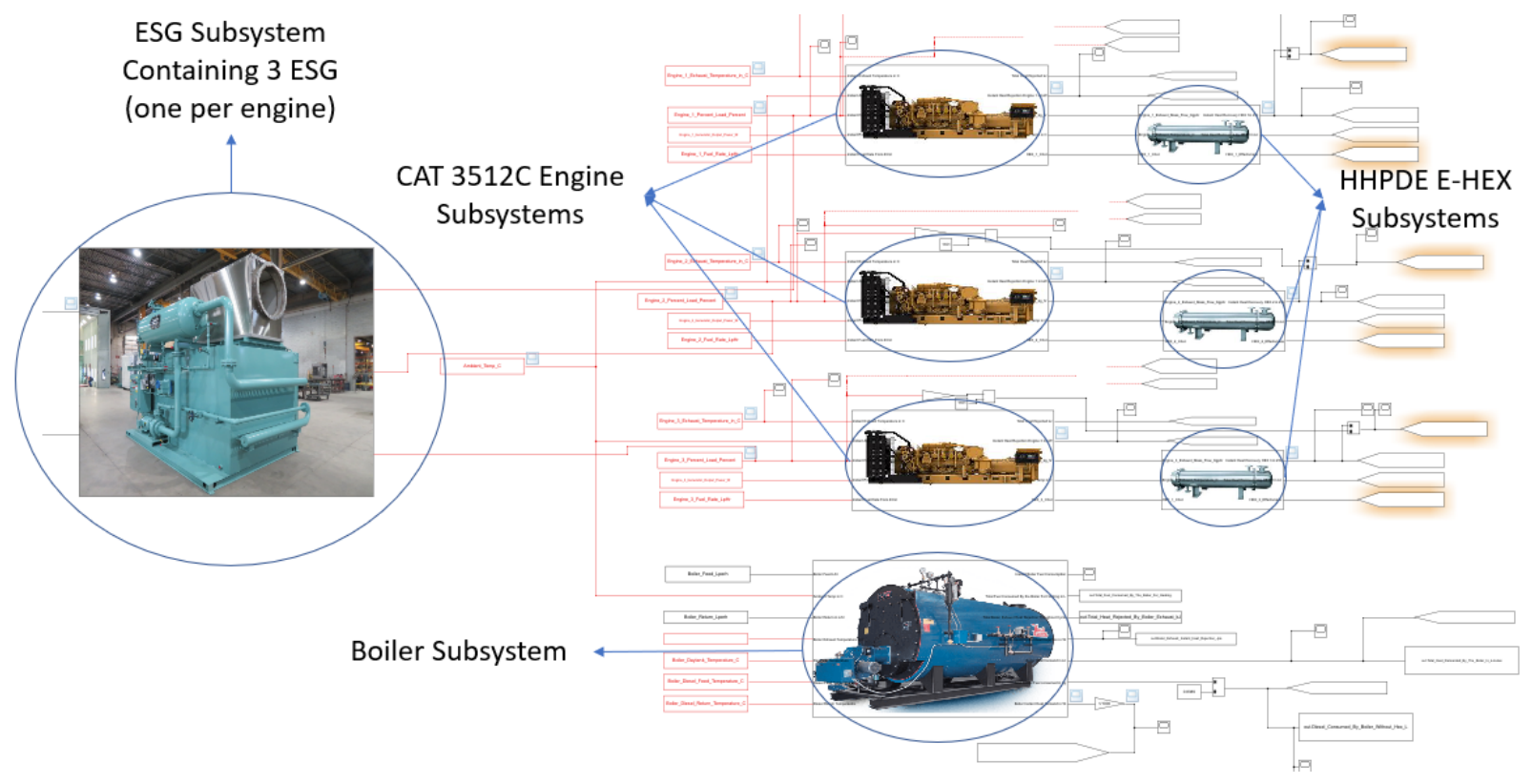

Figure 19. HHPDE CHP 0-D SIMULINK Model

Table 16. HHPDE CHP Heat Recovery

\begin{tabular}{ccccc}
\hline \hline Cycle & $\begin{array}{c}\text { HHPDE E- } \\
\text { HEX Heat } \\
\text { Recovered }\end{array}$ & $\begin{array}{c}\text { HHPDE E-HEX } \\
\text { Heat Recovered- } \\
\text { Demanded }\end{array}$ & $\begin{array}{c}\text { HHPDE } \\
\text { ESG Heat } \\
\text { Recovered }\end{array}$ & $\begin{array}{c}\text { HHPDE ESG } \\
\text { Heat Recovered- } \\
\text { Demanded }\end{array}$ \\
\hline Name & MJ & \% & MJ & \% \\
\hline 2E1HR & 3226 & 123 & 2517 & 96 \\
3E1HR & 3072 & 131 & 2894 & 124 \\
TP1HR & 1220 & 51 & 1907 & 80 \\
24HR & 57,070 & 94 & 60,326 & 99 \\
\hline
\end{tabular}

E-HEX heat recovery was sufficient to meet and exceed boiler heat demand for 2E1HR and $3 \mathrm{E} 1 \mathrm{HR}$ cycles. However, only $94 \%$ and $51 \%$ of the required heat was recovered for the $24 \mathrm{HR}$ and TP1HR cycles, respectively. For the commercial unit (HHPDE ESG), only the 3E1HR cycle exceeded the boiler heat output required. The other three cycles did not recover enough heat to meet boiler heat demand. The 2E1HR cycle recovered $96 \%$ of the boiler heat demanded, the TP1HR cycle recovered $80 \%$ of the boiler heat demanded, and the $24 \mathrm{HR}$ cycle recovered $99 \%$ of the boiler heat demanded. 
Although HHPDE E-HEX proved to reduce diesel fuel consumption by supplementing heat, the boiler would still be needed to meet the rig's steam demand. Therefore, the second source of potential heat recovery was assessed. CAT $3512 \mathrm{C}$ engines reject up to $412 \mathrm{~kW}$ of heat to the environment through their radiator [32]. Table 17 presents JW heat rejection specified in the technical engine sheet.

Table 17. HHPDE Heat Rejection Through the Radiator [32]

Engine Load Heat Rejection Through Radiator

\begin{tabular}{cc}
\hline$\%$ & $\mathbf{k W}$ \\
\hline $\mathbf{5 0}$ & 263 \\
$\mathbf{7 5}$ & 340 \\
$\mathbf{1 0 0}$ & 412 \\
\hline
\end{tabular}

Coolant return temperature was recorded via CAN. Data from the three engines were combined into a single dataset and binned based on engine load. The bins were distributed as follows: 0\%$40 \%, 40 \%-50 \%, 50 \%-60 \%, 60 \%-70 \%$, and 70\%-100\%. Bins were defined this way due to limited data at low and high engine loads. Also, these engine loads were generally only observed during transient operations. Engine load and coolant return temperature were averaged for each bin, and results are presented in Table 18. The MATLAB $®$ script used to model coolant temperature is available in Appendix B.

Table 18. CAT 3512C Coolant Return Temperature Model

\begin{tabular}{cc}
\hline \hline Engine Load & Coolant Return Temperature \\
\hline$\%$ & ${ }^{\circ} \mathbf{C}$ \\
\hline $\mathbf{2 5}$ & 74.9 \\
$\mathbf{5 0}$ & 78.7 \\
$\mathbf{7 5}$ & 82.5 \\
$\mathbf{1 0 0}$ & 86.3 \\
\hline
\end{tabular}


If a heat exchanger replaced the radiator, the working fluid is the coolant that goes through the radiator rather than the coolant that goes through the bypass back into the engine block. Therefore, coolant mass flowrate is variable depending on engine load. The coolant mass flow rate through the heat exchanger was modeled using Equation 7.

\section{Equation 7. Coolant Heat Transfer Calculation}

$$
\dot{Q}=\dot{m} c_{p} \Delta T
$$

Where $c_{p}$ is the coolant's heat capacity (approximated as water) at $99^{\circ} \mathrm{C}(4.14 \mathrm{~kJ} / \mathrm{kgK})$. Using Equation 7, with the heat rejected presented at Table 17, and a modeled coolant return temperature, a coolant mass flow rate model was developed. Table 19 presents coolant mass flow rates through the radiator as a function of engine load. Figure 20 presents the coolant flow rate through the JWHEX model.

Table 19. Coolant Mass Flow Model

\begin{tabular}{cccccc}
\hline $\begin{array}{c}\text { Engine } \\
\text { Load }\end{array}$ & $\dot{\mathbf{Q}}$ & $\begin{array}{c}\text { JW Outlet } \\
\text { Temperature }\end{array}$ & $\begin{array}{c}\text { JW Inlet } \\
\text { Temperature }\end{array}$ & ${ }^{\mathbf{\Delta}}$ & $\begin{array}{c}\dot{\mathbf{m}} \\
\text { Calculated }\end{array}$ \\
\hline $\boldsymbol{\%}$ & $\mathbf{k W}$ & ${ }^{\circ} \mathbf{C}$ & ${ }^{\circ} \mathbf{C}$ & ${ }^{\circ} \mathbf{C}$ & $\mathbf{k g} / \mathbf{s}$ \\
\hline $\mathbf{5 0}$ & 263 & 99 & 78.7 & 20.3 & 3.1 \\
$\mathbf{7 5}$ & 340 & 99 & 82.5 & 16.5 & 4.9 \\
$\mathbf{1 0 0}$ & 412 & 99 & 86.3 & 12.7 & 7.7 \\
\hline
\end{tabular}




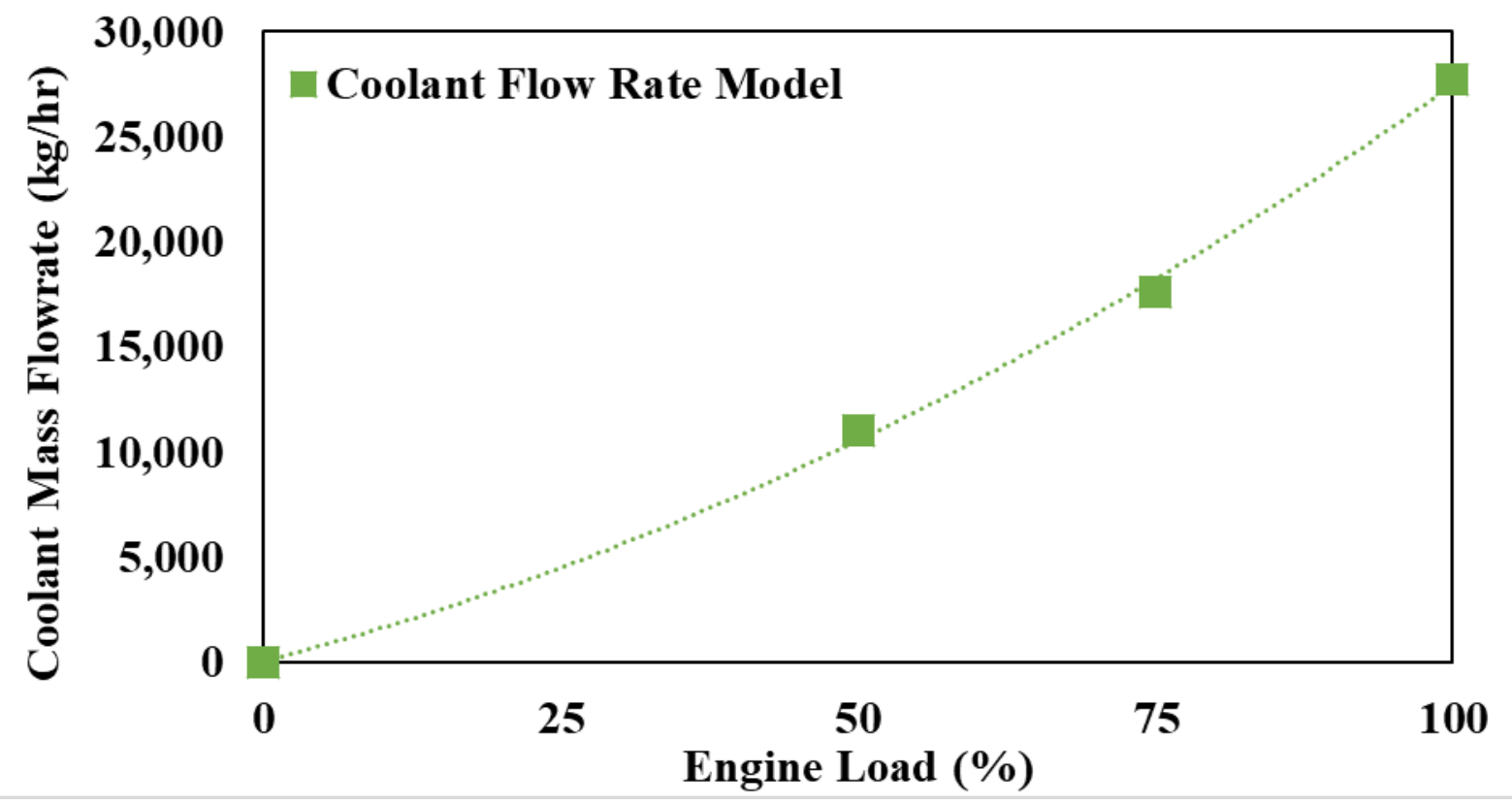

Figure 20. HHPDE JW-HEX Mass Flow Rate Model

Equation 8. Coolant Mass Flow Rate Error

$$
\text { Error }=\left|\frac{\text { Calculated }- \text { Actual }}{\text { Actual }}\right| \times 100
$$

Table 20. CAT 3512C Coolant Model Error

\begin{tabular}{cccc}
\hline \hline \multirow{2}{*}{ Engine Load } & $\dot{\text { Q Modeled }}$ & $\dot{\text { Q Specified By CAT }}$ & Error \\
\hline \% & $\mathbf{k W}$ & $\mathbf{k W}$ & $\mathbf{\%}$ \\
\hline $\mathbf{5 0}$ & 251.6 & 263 & 4.3 \\
$\mathbf{7 5}$ & 352.4 & 340 & 3.6 \\
$\mathbf{1 0 0}$ & 408.4 & 412 & 0.9 \\
\hline
\end{tabular}

CHEMCAD software was also used for HHPDE JW-HEX design. The HHPDE JW-HEX was sized and designed for full load engine operation to recover the most heat possible. The only restriction on the JW-HEX design was the allowable pressure drop. Allowable pressure drop on the radiator information was not available for the CAT 3512C engine; therefore, information from a CAT G3512 natural gas engine was used for estimating maximum allowable pressure drop. 
Interpolation was used to estimate the maximum modeled coolant mass flow rate into the natural gas G3512 engine. It was estimated that the maximum allowable pressure drop for CAT 3512C engine was 30.3 psi or $208.9 \mathrm{kPa}$. Figure 21 shows the JW pressure drop on the CAT G3512 engine.

\section{G3512 Low Speed}

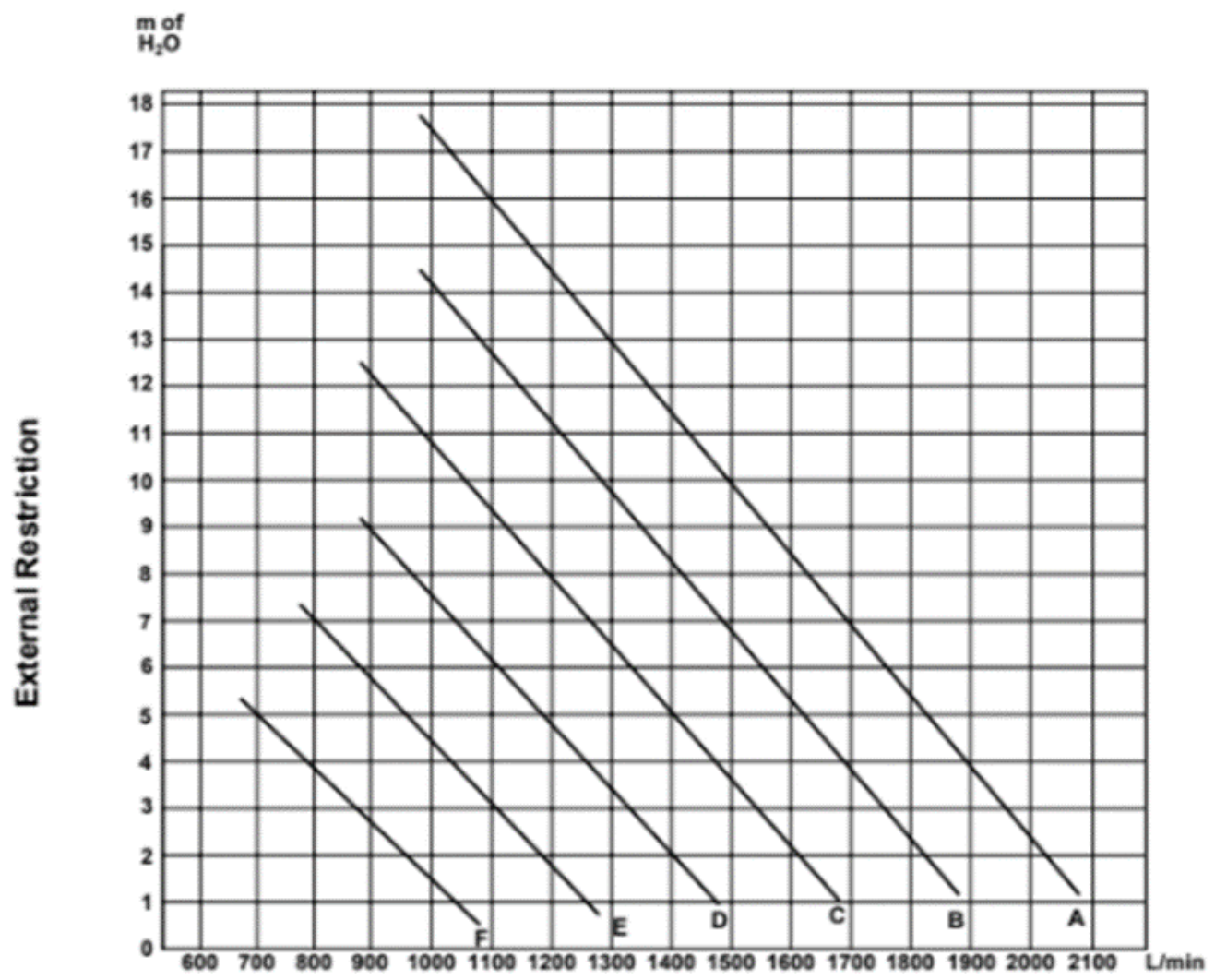

External Water Flow

Figure 21. CAT G3512 Low-Speed Pressure Drop (B=1200 RPM)

Size was not a constraint for HHPDE JW-HEX since this exchanger would have to be located by the engine where the radiator is placed in current rig configuration. The JW-HEX could be installed on the genset skid. The JW-HEX was designed in the CHEMCAD software environment for full load engine operating conditions, and the water flow rate was automatically calculated to have an exit temperature matching the conventional coolant return temperature from the in-use operation. Figure 22 presents the HHPDE JW-HEX design diagram. Table 21 summarizes the HHPDE JW- 
HEX design main parameters. Figure 23 presents heat recovery as a function of engine load. The HHPDE JW-HEX TEMA sheet is included in Appendix C.
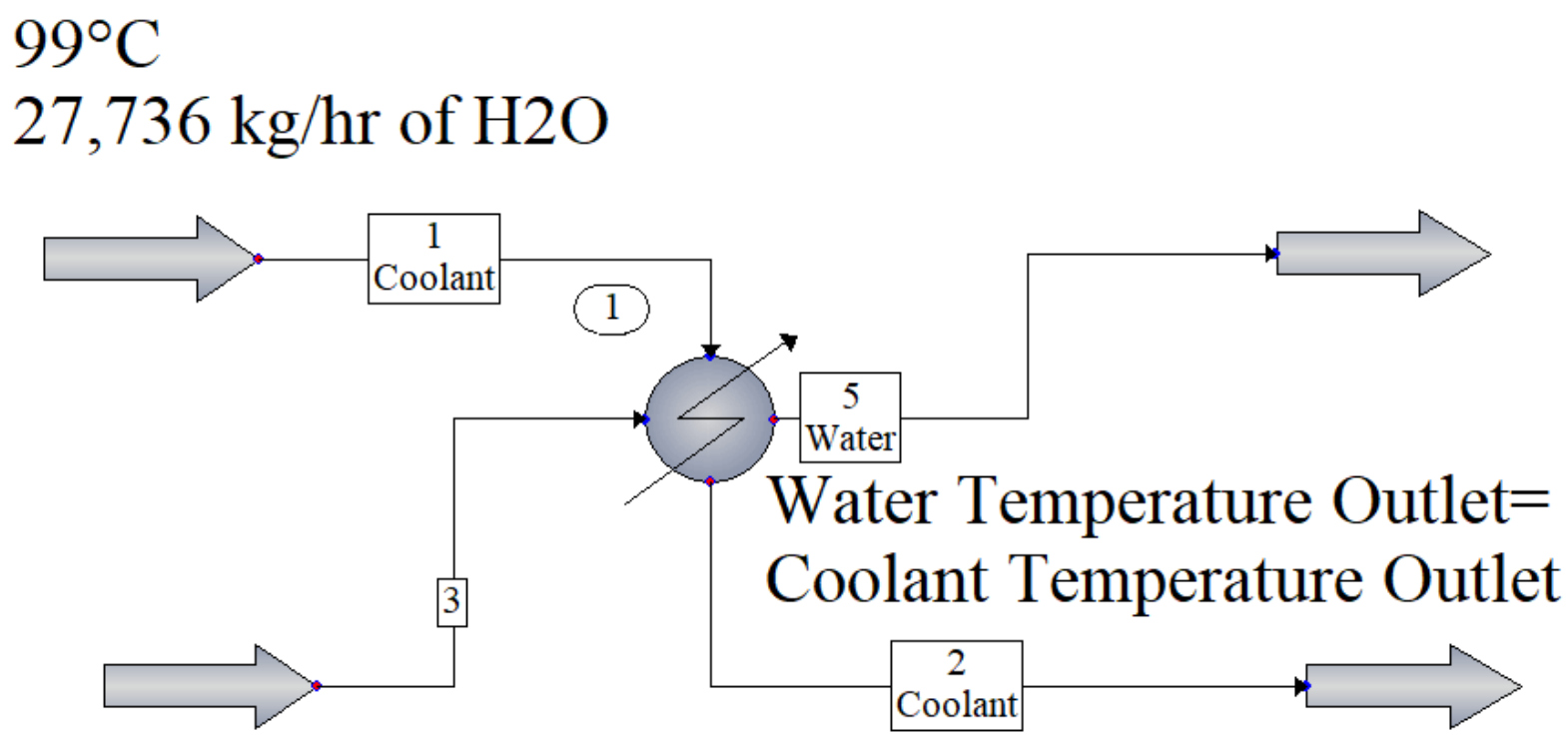

Figure 22. HHPDE JW-HEX Sizing and Design Conditions

Table 21. HHPDE JW-HEX Design

\begin{tabular}{cc}
\hline \hline HHPDE JW-HEX & HHPDE JW-HEX \\
\hline Shell Diameter $(\mathbf{m})$ & 0.4 \\
Tube Length $(\mathbf{m})$ & 4.9 \\
Number of Tubes & 192 \\
Effective Transfer Area $\left(\mathbf{m}^{\mathbf{2}}\right)$ & 52.5 \\
U $\left(\right.$ W/m ${ }^{2}$ C) & 394.3 \\
Tube O.D. $(\mathbf{c m})$ & 1.91 \\
Tube I.D. $(\mathbf{c m})$ & 1.56 \\
\hline
\end{tabular}




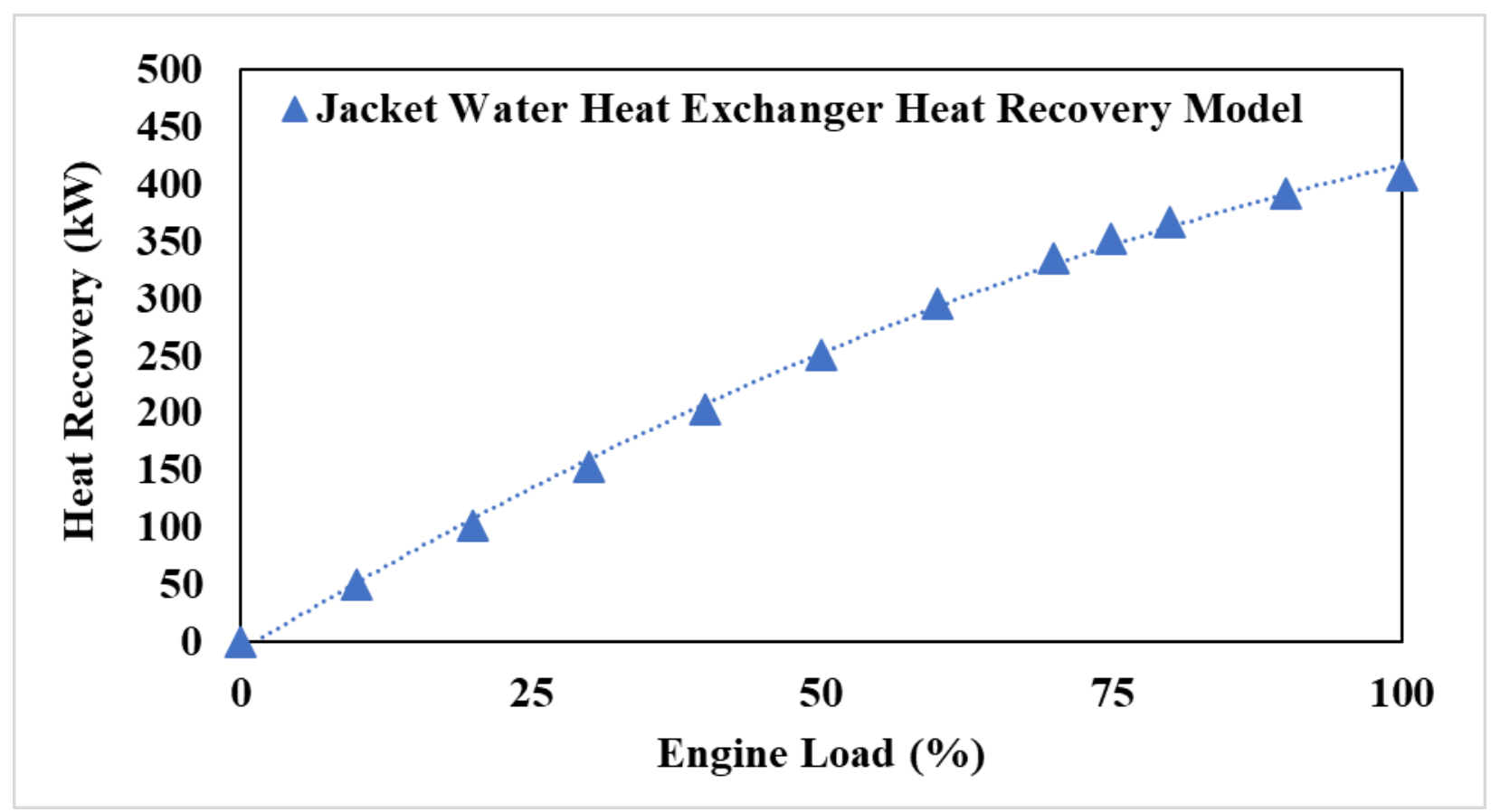

Figure 23. HHPDE JW-HEX Heat Recovery Model

The HHPDE CHP system was simulated again, including both the HHPDE E-HEX and the HHPDE JW-HEX. The HHDE JW-HEX subsystem contains the JW-HEX heat recovery model shown in Figure 23. Figure 24 presents the 0-D HHPDE CHP model with the HHPDE JW-HEX subsystem. Table 22 shows HHPDE CHP system results. Heat recovery over all four analyzed cycles was exceeded by utilizing both E-HEX and JW-HEX designed, where the lowest percentage of heat recovered was $109 \%$ of the heat demanded by the rig during the TP1HR cycle using both HHPDE E-HEX and HHPDE JW-HEX. Therefore, enough heat could be captured to eliminate the boiler. Figures 25 through 28 present the instant heat recovery and instant heat demanded by the system throughout the four analyzed cycles. 


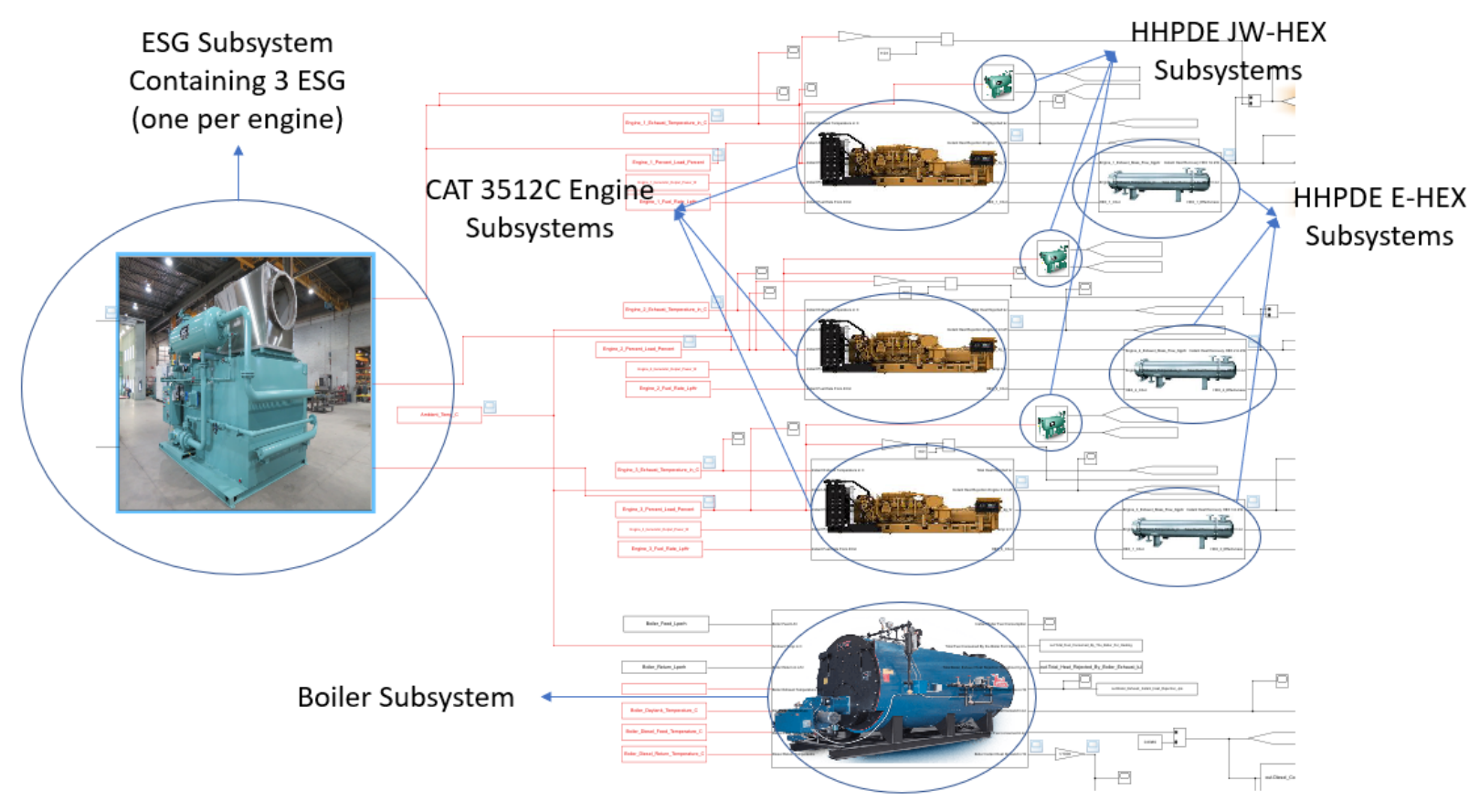

Figure 24. HHPDE CHP System 0-D Model Equipped with HHPDE JW-HEX

Table 22. HHPDE CHP Heat Recovery

\begin{tabular}{ccccc}
\hline \hline Cycle & $\begin{array}{c}\text { HHPDE E- } \\
\text { HEX+JW-HEX } \\
\text { Heat Recovered }\end{array}$ & $\begin{array}{c}\text { HHPDE E-HEX+JW- } \\
\text { HEX Heat Recovered- } \\
\text { Demanded }\end{array}$ & $\begin{array}{c}\text { HHPDE } \\
\text { ESG+JW-HEX } \\
\text { Heat Recovered }\end{array}$ & $\begin{array}{c}\text { HHPDE ESG +JW- } \\
\text { HEX Heat Recovered } \\
\text { Demanded }\end{array}$ \\
\hline Name & MJ & $\%$ & MJ & $\%$ \\
\hline 2E1HR & 5494 & 210 & 4785 & 183 \\
3E1HR & 5589 & 239 & 5411 & 231 \\
TP1HR & 2612 & 109 & 3299 & 138 \\
24HR & 106,919 & 176 & 110,175 & 181 \\
\hline
\end{tabular}




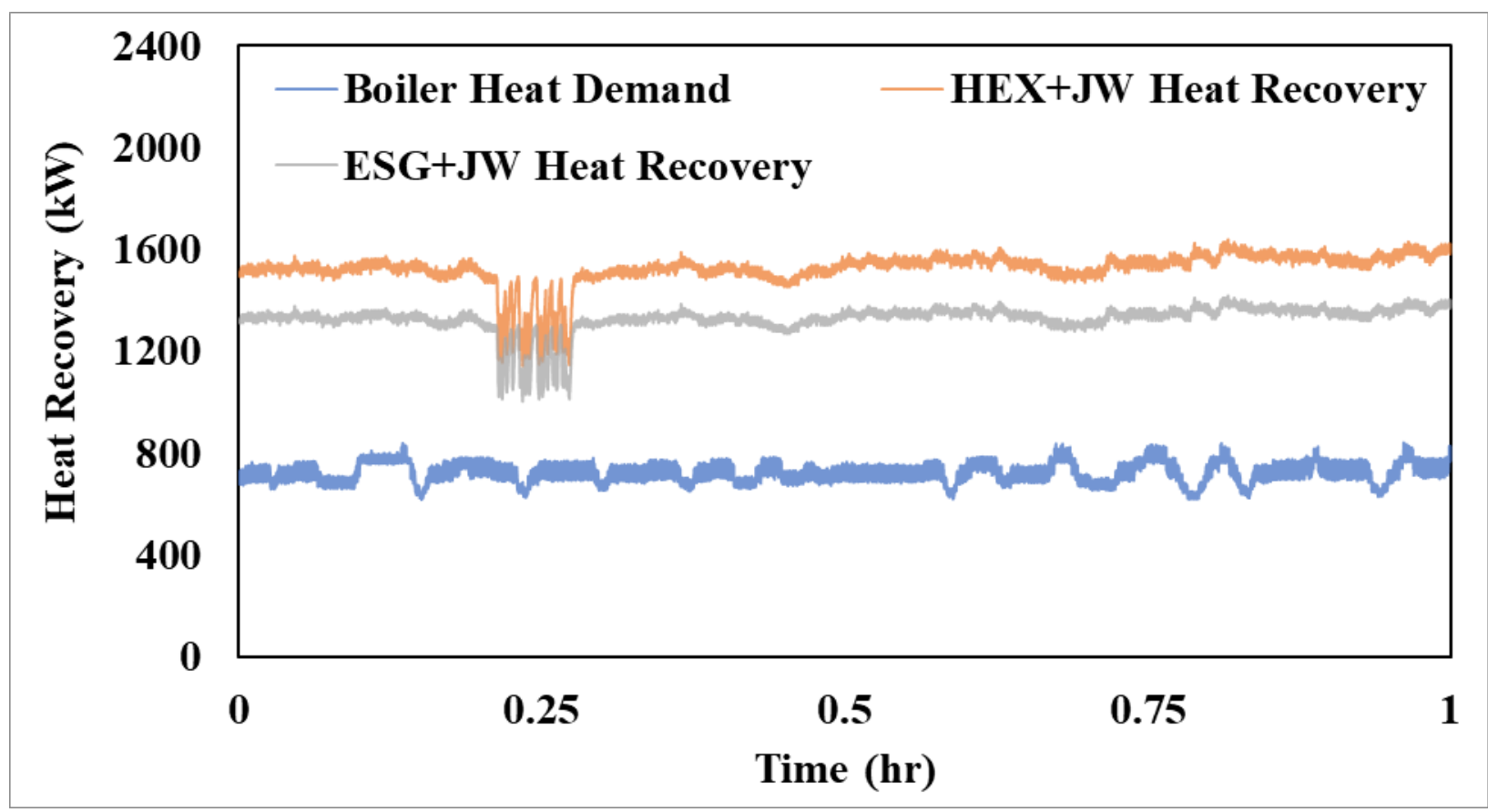

Figure 25. HHPDE CHP System, 2E1HR Cycle Instant Heat Recovery

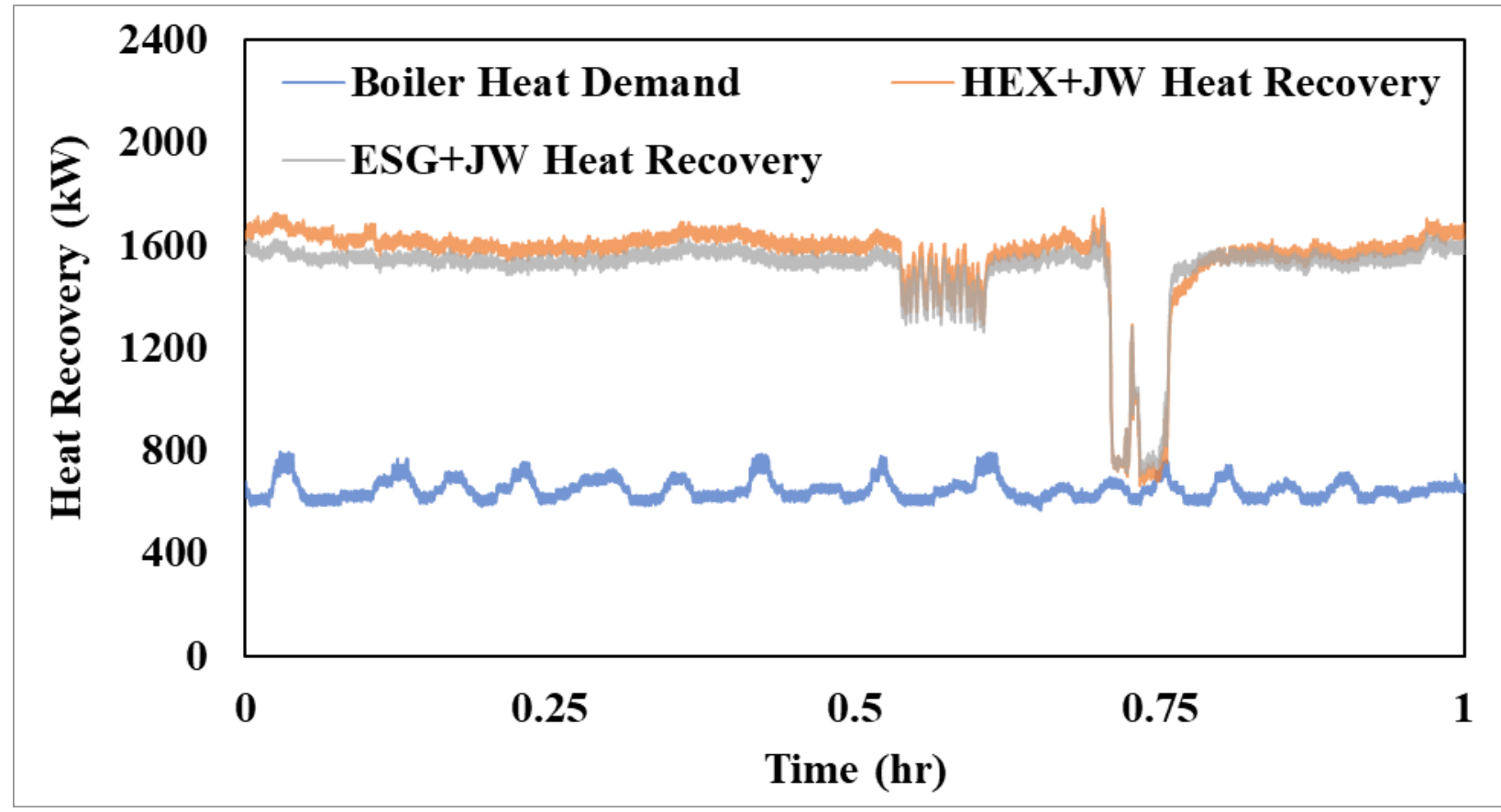

Figure 26. HHPDE CHP System, 31HR Cycle Instant Heat Recovery 


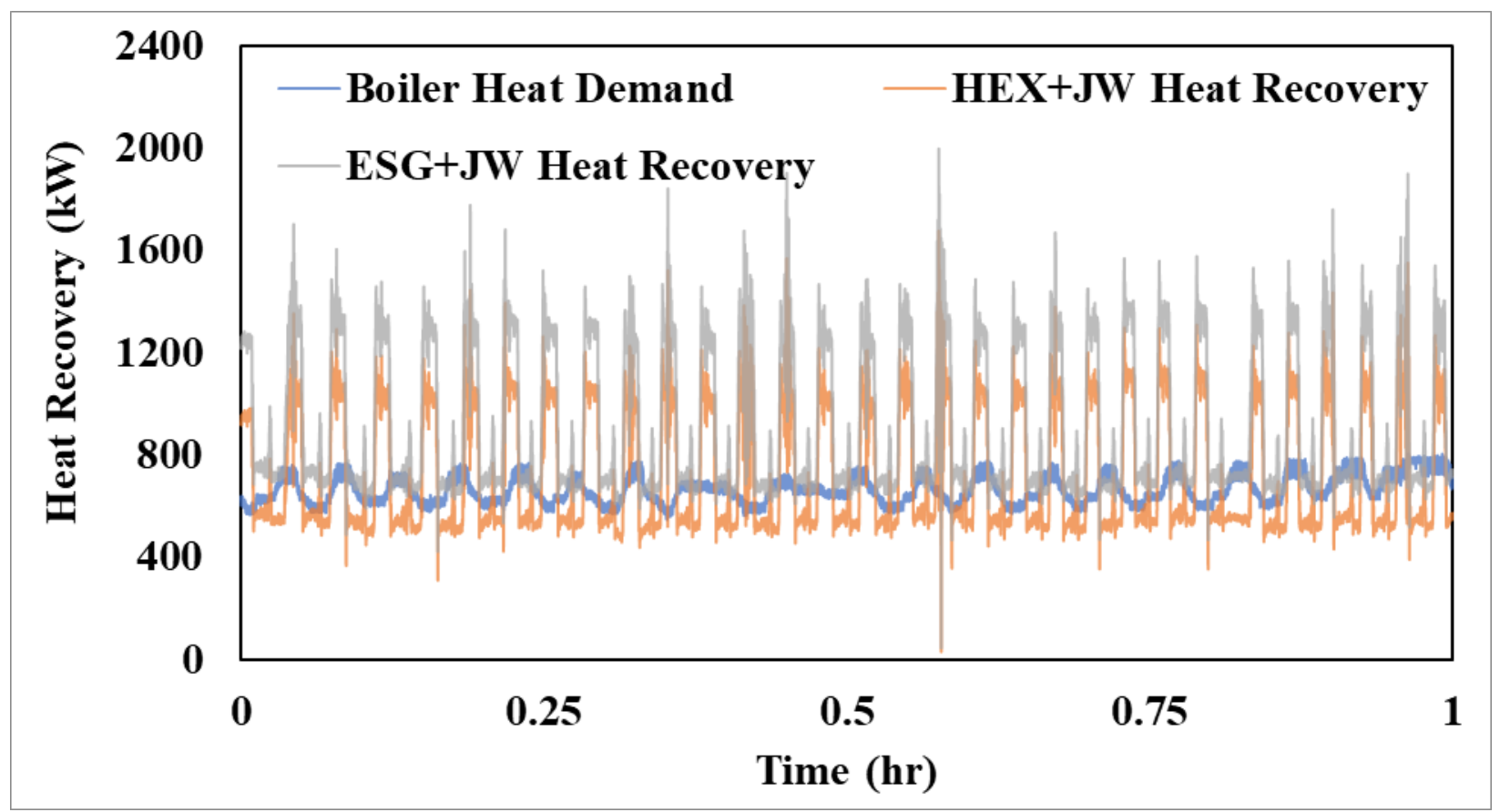

Figure 27. HHPDE CHP System, TP1HR Cycle Instant Heat Recovery

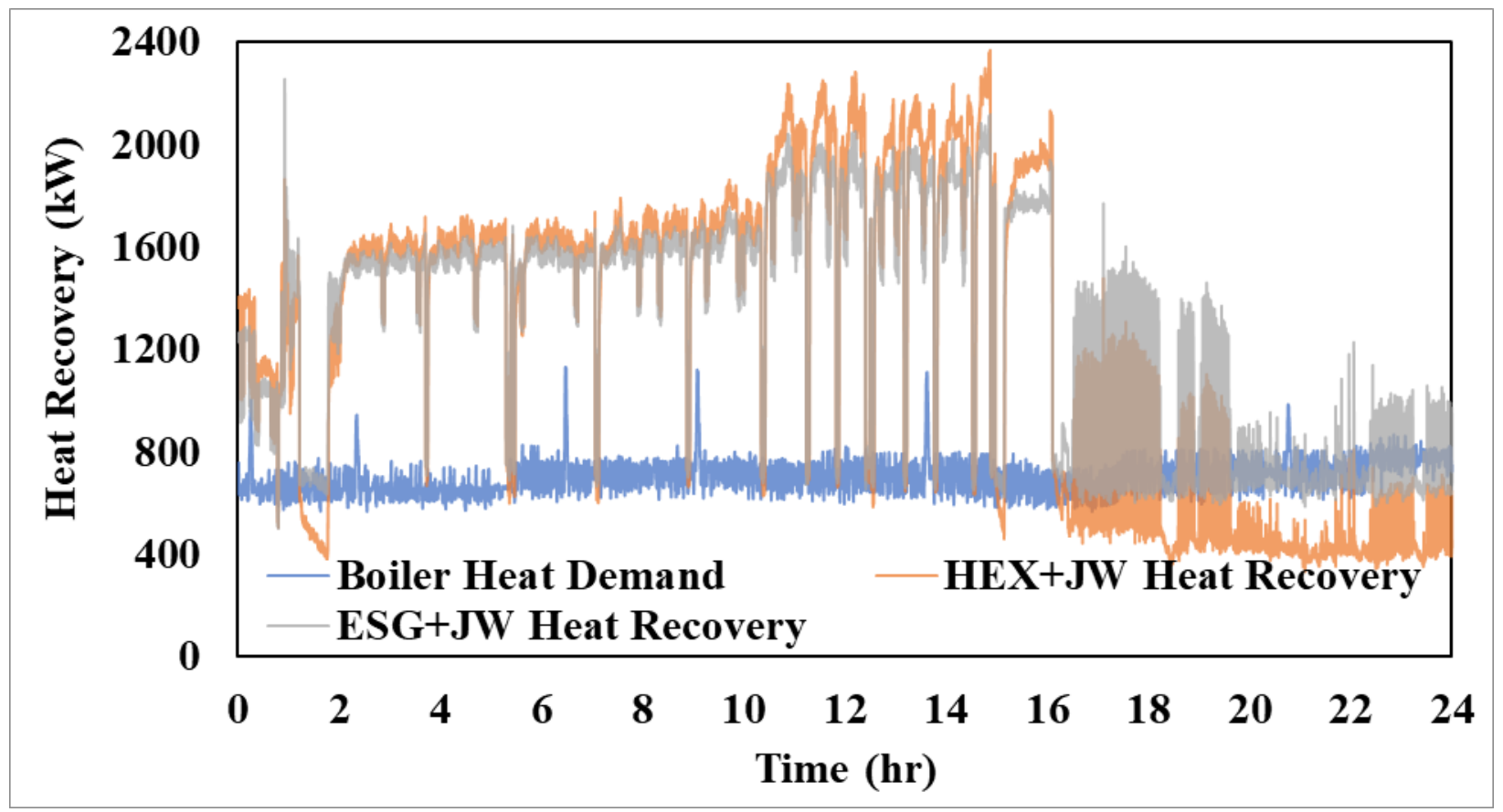

Figure 28. HHPDE CHP System, 24HR Cycle Instant Heat Recovery

Both steady drilling cycles (2E1HR and 3E1HR) recovered enough heat at all times to meet the system's heat demand. However, the TP1HR and the 24HR cycles have periods when instantaneous heat demand was higher than heat recovered. The TP1HR cycle was characterized 
by transient engine operation and thus produced transient heat recovery rates, resulting in insufficient heat demanded for short periods. Average heat demand during the TP1HR cycle was $663 \mathrm{~kW}$, while heat recovered was $726 \mathrm{~kW}$ and $916 \mathrm{~kW}$ for HHPDE CHP equipped with EHEX+JW-HEX and ESG+JW-HEX, respectively. The 24HR cycle had a long transient engine operation period at the end of the cycle (from 16 to $24 \mathrm{hrs}$.). During this section of the cycle, heat recovery failed to recover enough instantaneous heat. However, this portion was highly transient at $1 \mathrm{~Hz}$. Therefore, a 30-minute instant heat recovery moving average over the transient operation of the $24 \mathrm{HR}$ cycle was created to examine a more appropriate timeframe for the heat analysis. Figure 29 presents that both WHR systems failed to recover enough heat during the last eight hours of engine transient operation of the 24HR cycle. However, this analysis showed that the ESG system would likely yield acceptable operation through hour 20. In this scenario, utilization of the boiler or electric heaters would be necessary to meet heat demands. If electric heaters were used to supply the system with the required heat, engine load would increase, recovering more heat. Another approach to the problem would be to utilize thermal reservoirs to store thermal energy for later usage. An example device could be a steam accumulator. They could help save some of the extra heat recovered from the exchangers to be used when heat demand exceeded heat recovery.

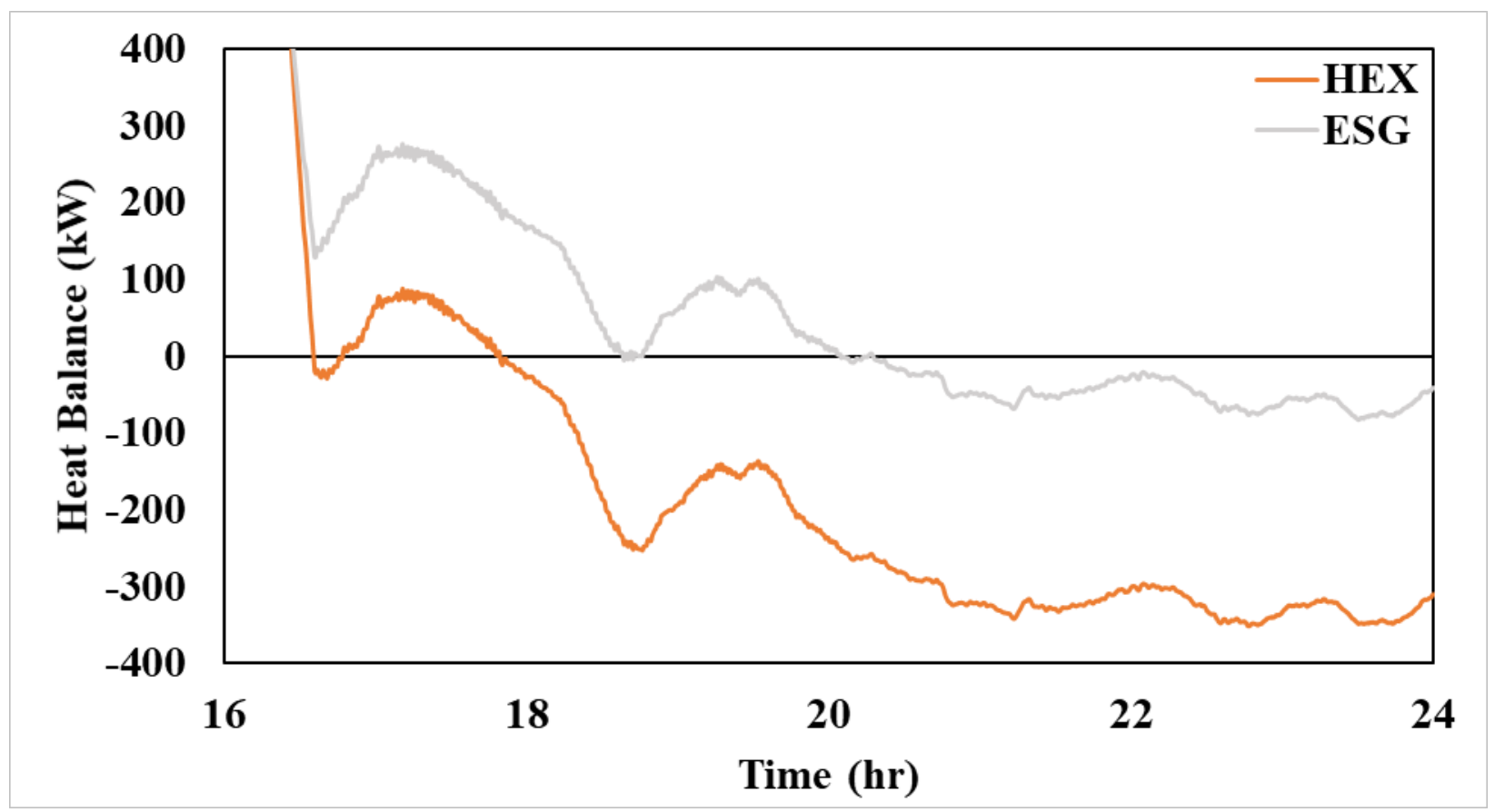

Figure 29. HHPDE CHP System, 24HR Cycle 30-Minute Heat Balance Moving Average 
UF was defined as the amount of engine work and recovered heat by the system divided by the fuel's energy throughout the cycle. Table 23 presents a comparison of UFs for the various cycles and HEX combinations. Recovered heat can only be used if the system requires it; otherwise, it is considered lost or potential heat. Note that my data collection did not encompass all cold weather conditions. The highest values presented could be used to estimate performance in colder applications than those that occurred during these data collection efforts.

Table 23. HHPDE CHP UF Analysis

\begin{tabular}{|c|c|c|c|c|c|}
\hline \multirow{2}{*}{ Cycle } & \multirow{2}{*}{$\begin{array}{c}\text { HHPDE } \\
\text { Without CHP } \\
\text { System UF }\end{array}$} & \multicolumn{2}{|c|}{$\begin{array}{l}\text { HHPDE-CHP System UF } \\
\text { limited by Heat Required }\end{array}$} & \multicolumn{2}{|c|}{$\begin{array}{c}\text { HHPDE-CHP System } \\
\text { Potential UF }\end{array}$} \\
\hline & & $\begin{array}{c}\text { E-HEX+JW- } \\
\text { HEX }\end{array}$ & $\begin{array}{c}\text { ESG+JW } \\
\text {-HEX } \\
\end{array}$ & $\begin{array}{c}\text { E-HEX+JW- } \\
\text { HEX } \\
\end{array}$ & $\begin{array}{l}\text { ESG+J } \\
\text { W-HEX }\end{array}$ \\
\hline Name & $\%$ & $\%$ & $\%$ & $\%$ & $\%$ \\
\hline 2E1HR & 38.3 & 58.8 & 58.8 & 81.3 & 75.7 \\
\hline 3E1HR & 37.1 & 53.7 & 53.7 & 76.8 & 75.7 \\
\hline TP1HR & 31.8 & 58.1 & 58.1 & 60.6 & 68.2 \\
\hline 24HR & 35.7 & 56.5 & 56.5 & 72.3 & 73.4 \\
\hline Average & 35.7 & 56.8 & 56.8 & 72.7 & 73.2 \\
\hline
\end{tabular}

On average, for the four cycles analyzed, energy's UF could be improved from $35.7 \%$ to $56.8 \%$. If potential heat was considered, the UF increased to $72.7 \%$ and $73.2 \%$ for E-HEX+JW-HEX and ESG+JW-HEX, respectively. Higher UFs translate to less fuel being consumed. Figure 30 shows the HHPDE CHP system diesel fuel savings. 


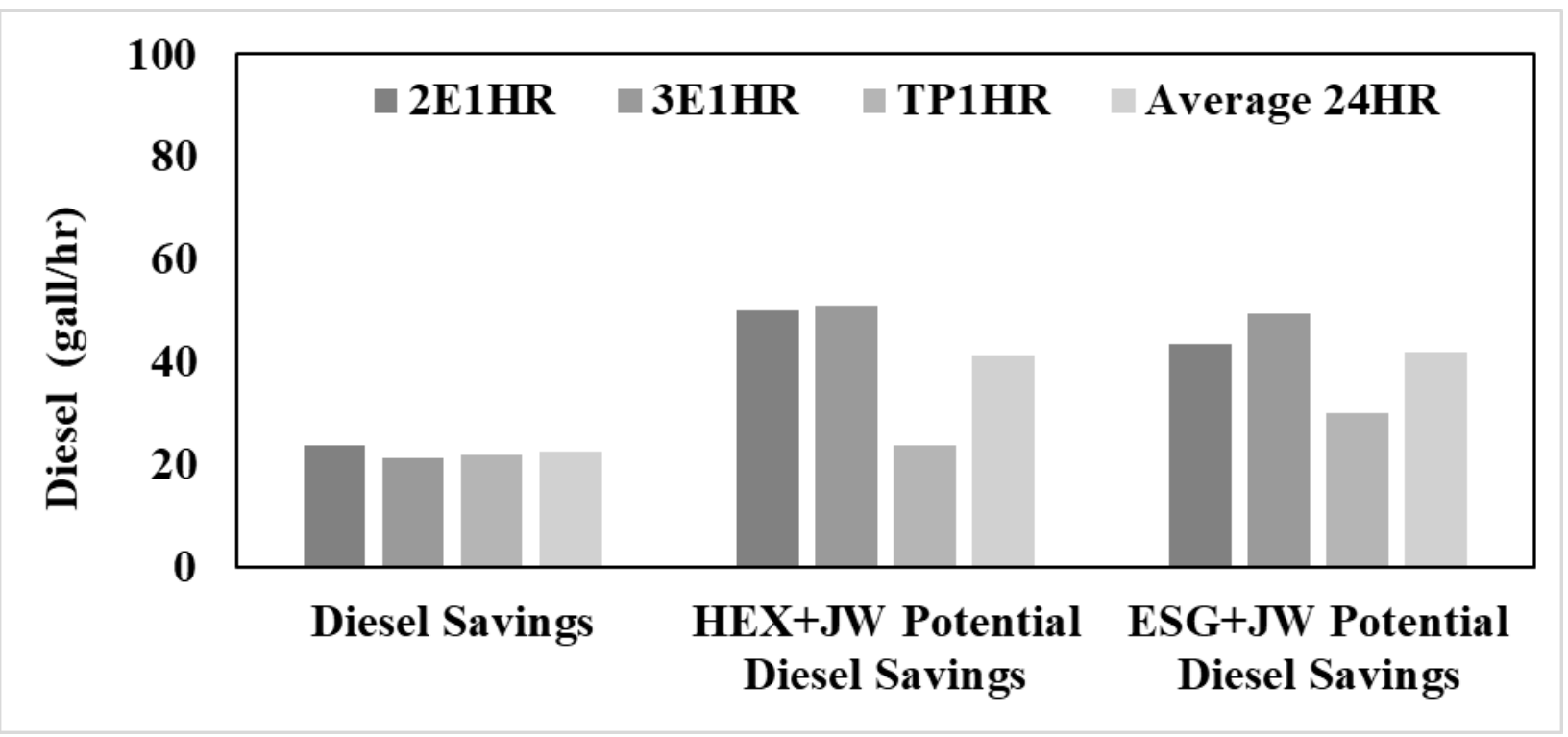

Figure 30. HHPDE CHP System Diesel Fuel Savings

Fuel savings were consistent since the average cycle boiler heat demand ranged between 649.7 $\mathrm{kW}$ and $727.5 \mathrm{~kW}$, as presented in Table 15. As shown in Figure 30, potential heat recovery peaked at the two steady drilling cycles (2E1HR and 3E1HR). This is due to their high engine loads, which resulted in large amounts of heat rejection that the E-HEX and JW-HEX recovered. The TP1HR cycle was dominated by low and unsteady engine loads causing a smaller heat recovery potential. Average diesel fuel saved was calculated at $22.5 \mathrm{gph}(84.9 \mathrm{~L} / \mathrm{hr})$, and potential diesel fuel savings averaged $41.3 \mathrm{gph}(156.1 \mathrm{~L} / \mathrm{hr})$. Associated $\mathrm{CO} 2$ emissions reductions were estimated at 226.2 $\mathrm{kg} / \mathrm{hr}$, and potential emissions savings averaged $418 \mathrm{~kg} / \mathrm{hr}$. Assuming a cost of $\$ 2.973 / \mathrm{gal}$ of diesel fuel, Figure 31 shows the costs savings in U.S. dollars. Average cost savings were estimated at $\$ 66.4 / \mathrm{hr}$ (20.5\% fuel expenses) with potential up to an average of $\$ 122.8 / \mathrm{hr}$ (36.4\% of total diesel fuel expenses). 


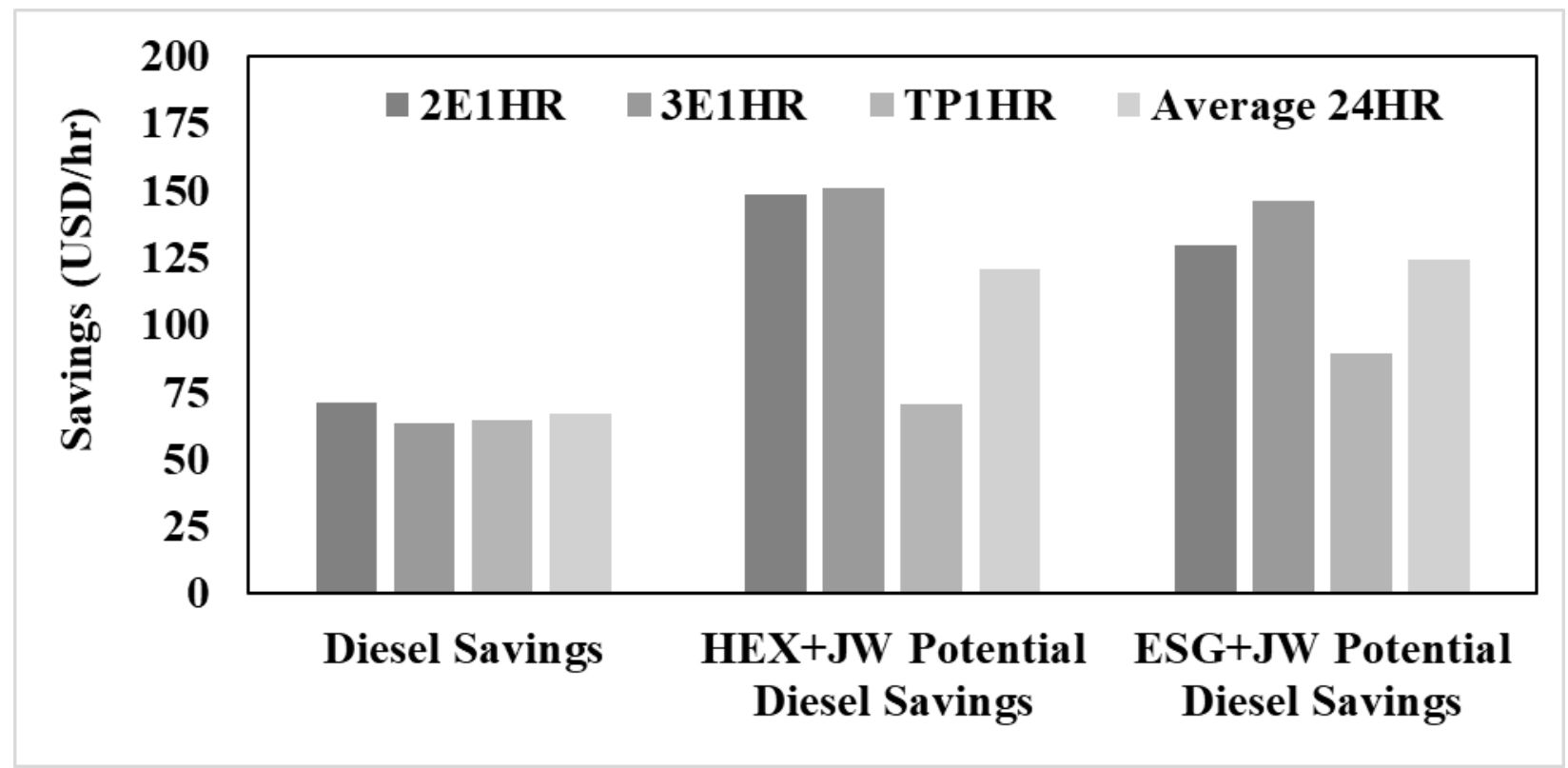

Figure 31. HHPDE CHP Cost Savings

\subsection{Energy Saving Model: HHPDE CHP Hybrid}

As another method to reduce fossil fuel energy consumption during well development, a HHPDE CHP hybrid model was developed. The HHPDE CHP hybrid system was equipped with the HEMS. This system was intended to reduce the number of required gensets by increasing the average load of those operating, causing them to have a higher thermal efficiency. Figure 32 shows CAT 3512C engine thermal efficiency as specified by the manufacturer [32]. 


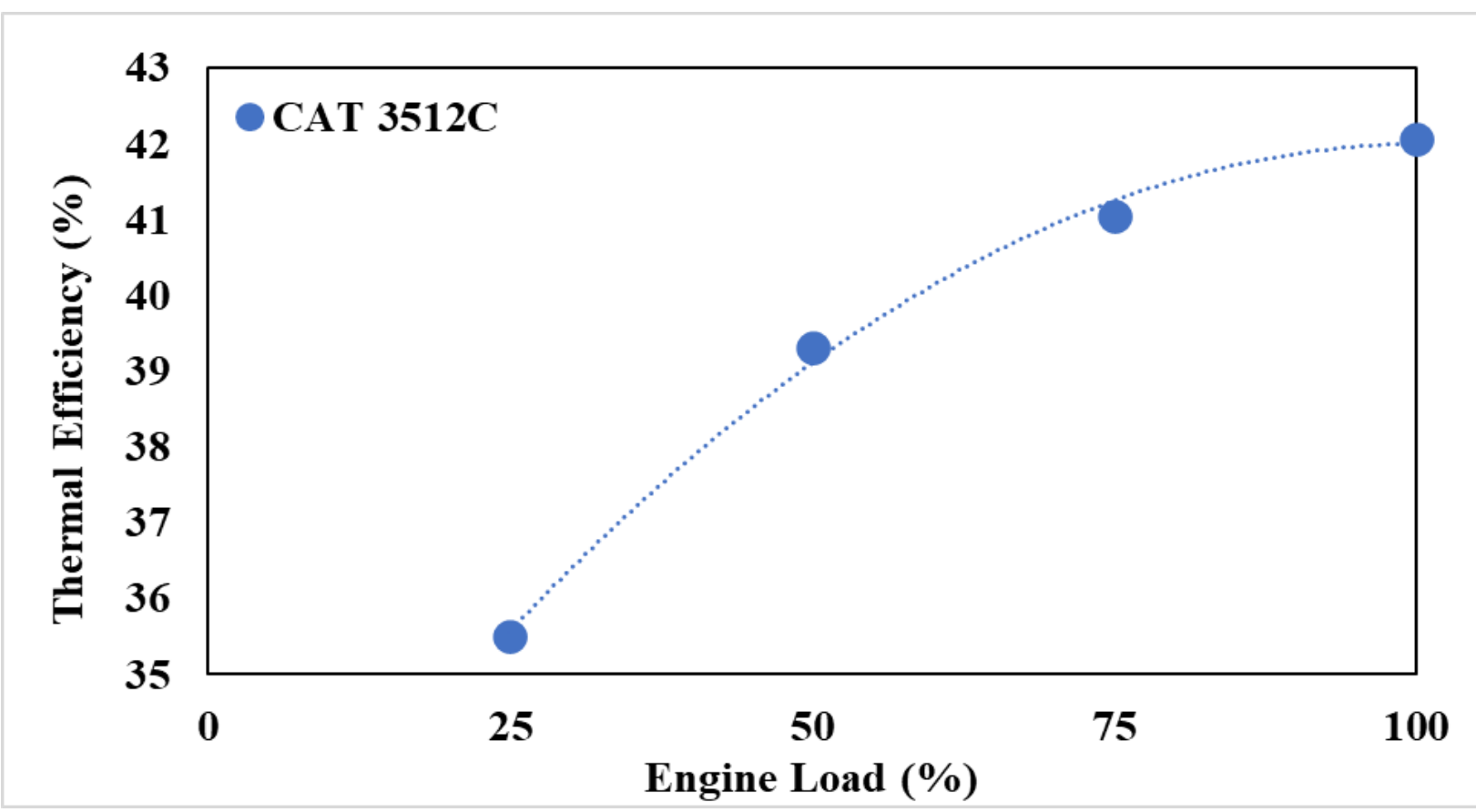

Figure 32. CAT 3512C Thermal Efficiency

A 0-D SIMULINK model was designed for this configuration, and it is presented in Figure 33. The SIMULINK model for the HHPDE CHP hybrid system model specifications is attached in Appendix E and included:

- CAT 3512C engine subsystem

- Calculated exhaust heat rejection utilizing Equation 3

- Exhaust mass flow rate model as a function of engine load

- Dry air mass flow rate

- Water vapor flow rate

- Exhaust gas temperature modeled as a function of engine load

○ Fuel consumption modeled as a function of engine load

- Power output assuming constant generator efficiency of $95 \%$

- HHPDE E-HEX subsystem

- Calculated exhaust heat recovery from CHEMCAD developed two-entry table, dry air, and water vapor mass exhaust flow rate from CAT 3512C engine subsystem and exhaust temperature models

- HHPDE JW-HEX

- HHPDE JW-HEX heat recovery model as a function of engine load 
- HHPDE ESG subsystem

- Calculated exhaust heat recovery from the exchanger performance provided by the manufacturer and available in Appendix D.

- HEMS subsystem

○ $70 \%$ initial SOC assumption

○ Minimum number of online gensets possible

○ Instant heat feedback control

○ Genset load control system

$\circ$ Charging and discharging coulombic efficiency of $80 \%$ and $90 \%$, respectively

- Boiler subsystem

- Fuel consumption (diesel) recorded by the KRAL flow meters

- Calculated heat supplied to the system from fuel consumption assuming constant efficiency of $81 \%$

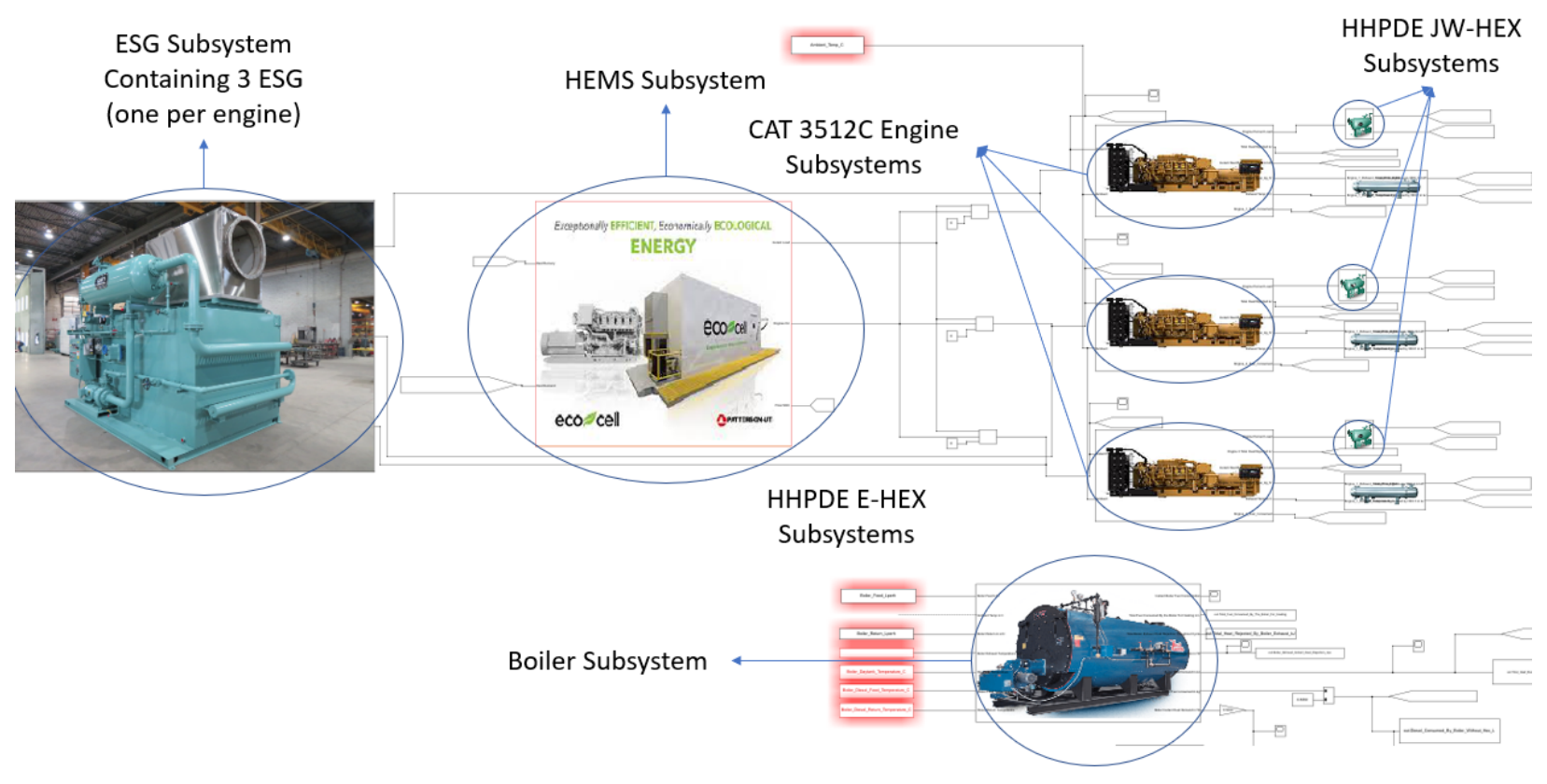

Figure 33. HHPDE CHP Hybrid System 0-D SIMULIK Model Diagram

By running fewer gensets at higher loads, it was expected to obtain higher UF and possibly a tradeoff with potential heat recovery. Table 24 presents the heat recovery results for the HHPDE CHP model equipped with the HEMS. Heat recovery for the HHPDE CHP equipped with the HEMS was sufficient to supply the system's heat demand for all cycles. Figures 34 through 37 
show instant heat recovery for the HHPDE CHP hybrid system for the four cycles examined in this paper.

Table 24. HHPDE CHP Hybrid Heat Recovery

\begin{tabular}{ccccc}
\hline \hline Cycle & $\begin{array}{c}\text { HHPDE Hybrid } \\
\text { E-HEX+JW- } \\
\text { HEX Heat } \\
\text { Recovered }\end{array}$ & $\begin{array}{c}\text { HHPDE Hybrid } \\
\text { E-HEX+JW-HEX } \\
\text { Heat Recovered- } \\
\text { Demanded }\end{array}$ & $\begin{array}{c}\text { HHPDE Hybrid } \\
\text { ESG+JW-HEX } \\
\text { Heat Recovered }\end{array}$ & $\begin{array}{c}\text { HHPDE Hybrid } \\
\text { ESG +JW-HEX } \\
\text { Heat Recovered- } \\
\text { Demanded }\end{array}$ \\
\hline Name & MJ & $\%$ & MJ & $\%$ \\
\hline 2E1HR & 5175 & 198 & 4899 & 187 \\
3E1HR & 5209 & 223 & 4931 & 211 \\
TP1HR & 2834 & 119 & 2650 & 111 \\
24HR & 105,344 & 173 & 103,337 & 170 \\
\hline
\end{tabular}

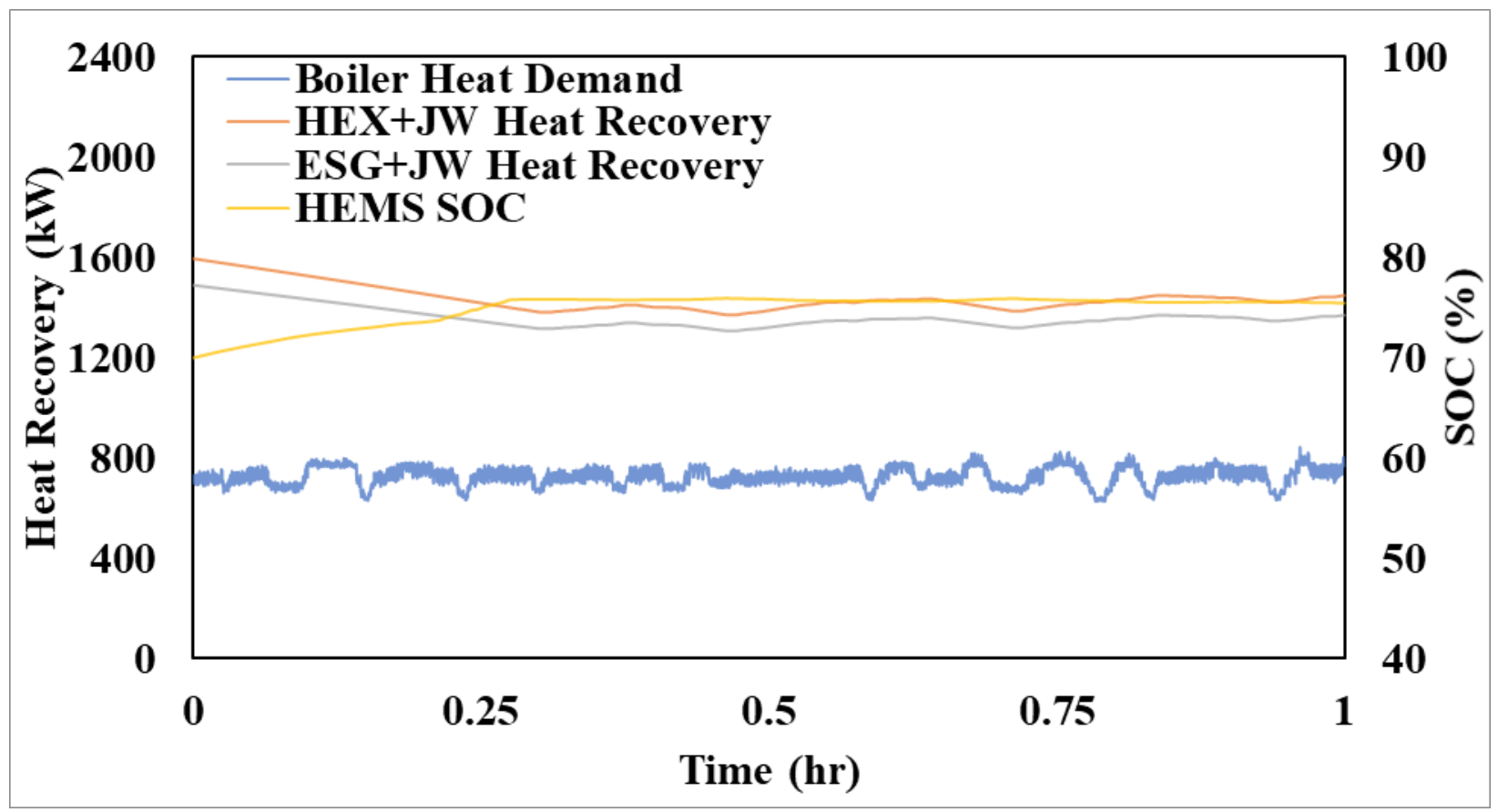

Figure 34. HHPDE CHP Hybrid System, 2E1HR Cycle Instant Heat Recovery 


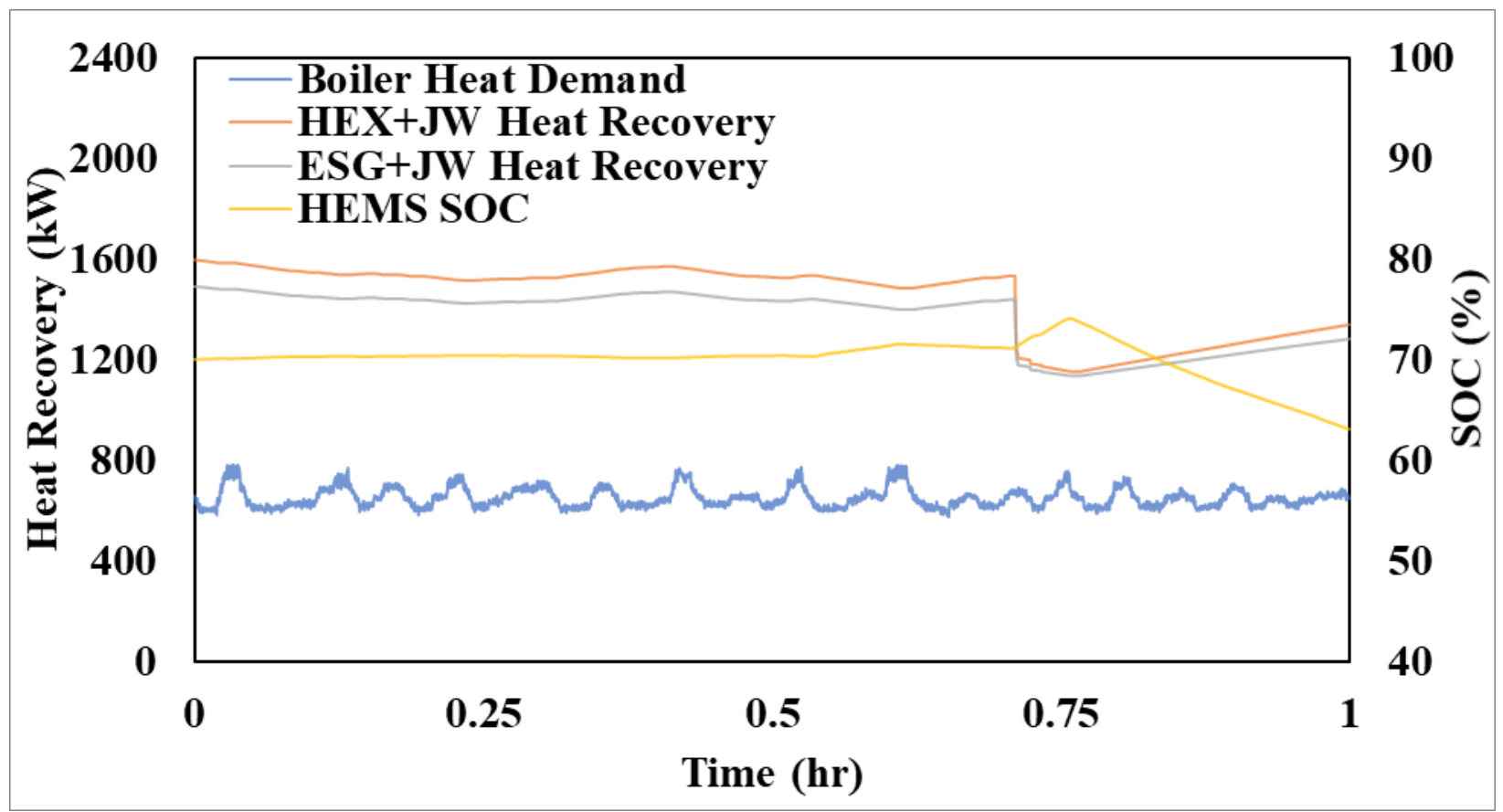

Figure 35. HHPDE CHP Hybrid System, 3E1HR Cycle Instant Heat Recovery

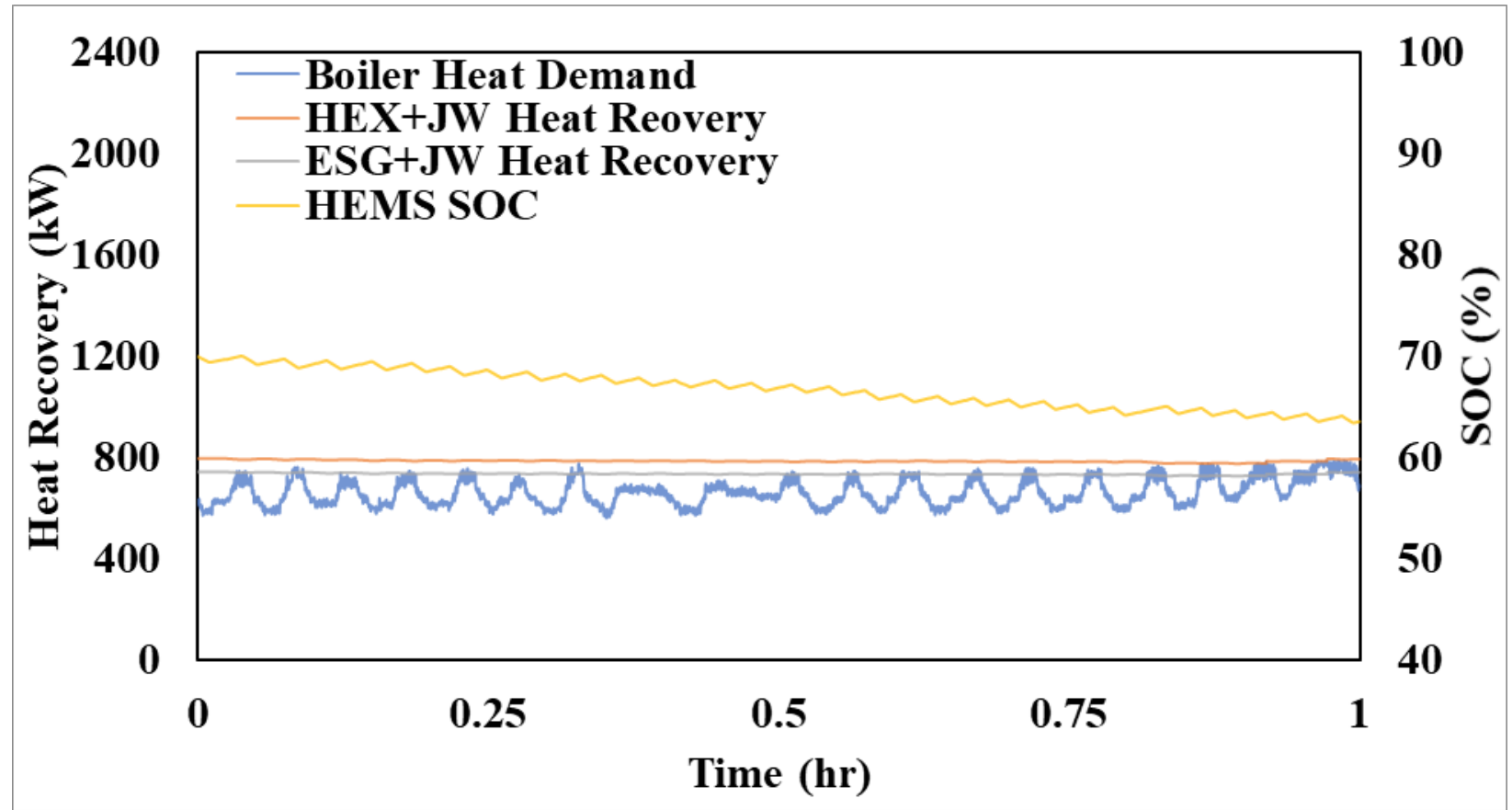

Figure 36. HHPDE CHP Hybrid System, TP1HR Cycle Instant Heat Recovery 


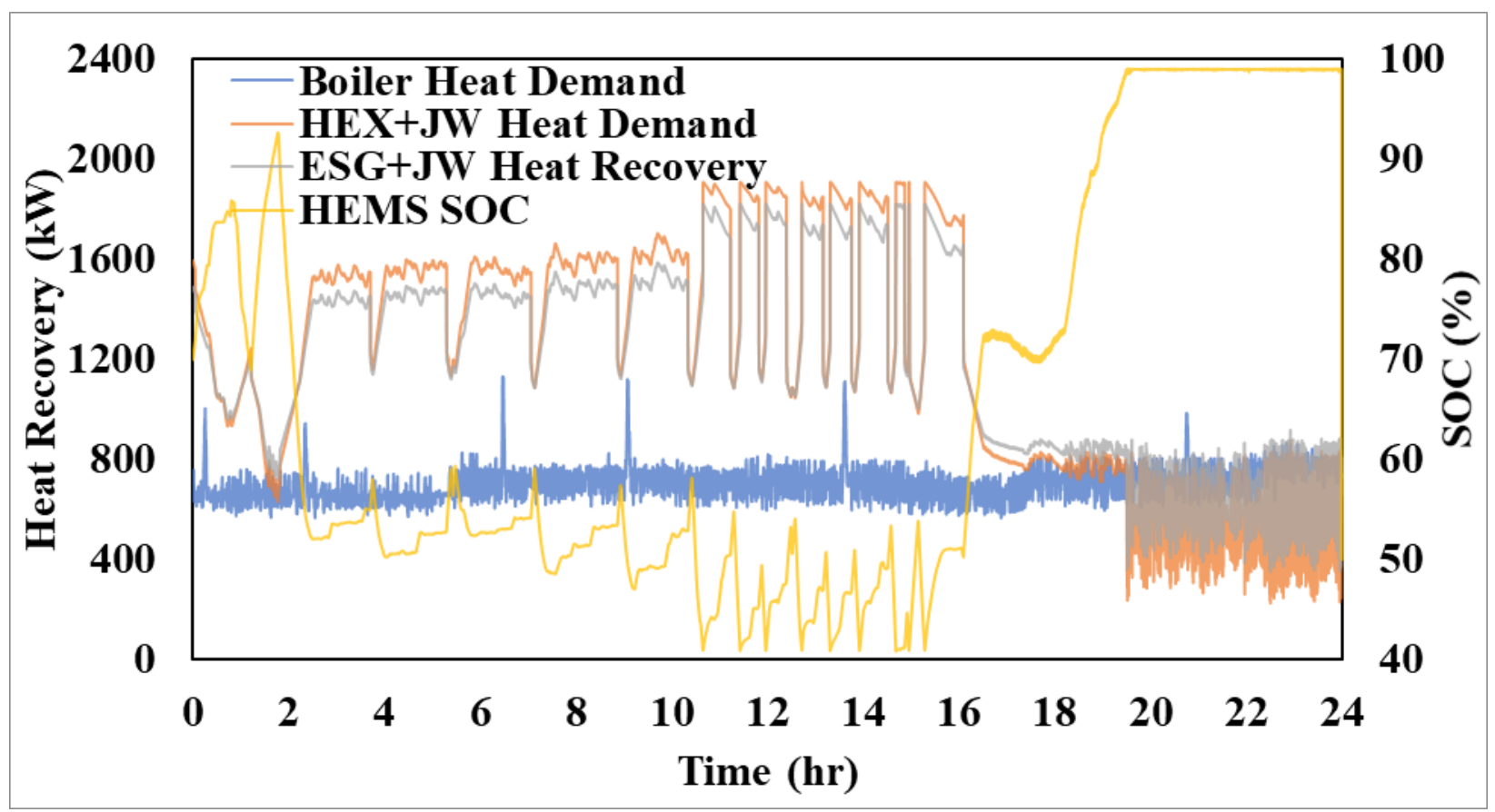

Figure 37. HHPDE CHP Hybrid System, 24HR Cycle Instant Heat Recovery

Instant heat recovered by the HHPDE CHP equipped with the HEMS was sufficient to meet demands through the 2E1HR, 3E1HR, and TP1HR cycles. However, as observed for the nonhybrid system, instant heat recovered for the transient section of the $24 \mathrm{HR}$ cycle was not enough to surpass the heat demanded. Figure 38 presents the HHPDE CHP system equipped with the HEMS 30-minute instant heat recovery moving average for the last eight hours of the 24HR cycle. In this case, both systems failed to meet the heat demand during the last $\sim 4$ hours. 


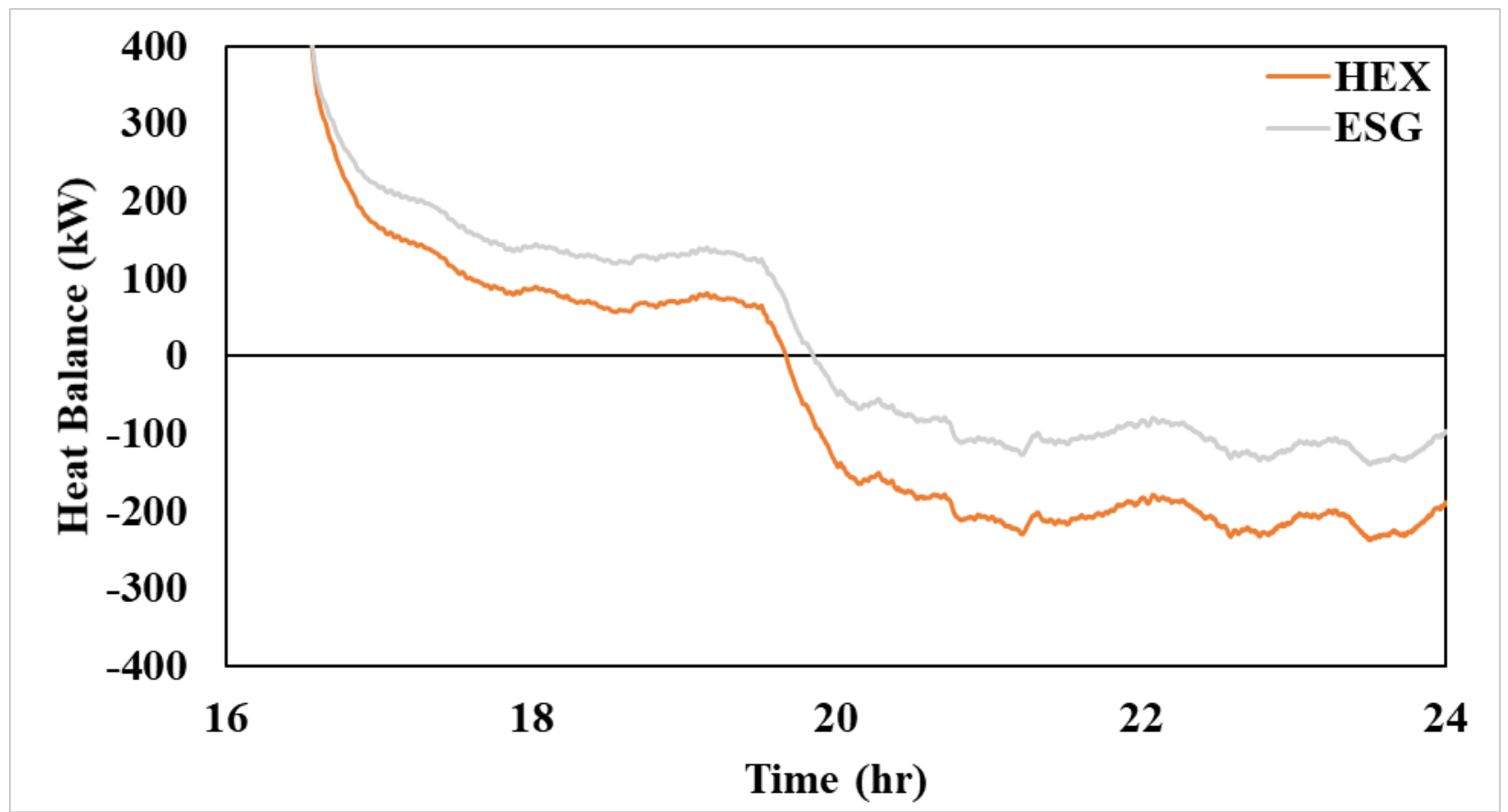

Figure 38. HHPDE CHP Hybrid System, 24HR Cycle 30-Minute Heat Balance Moving Average

During the eight-hour transient section of the 24HR cycle, heat recovery did not meet instant heat demand. However, compared to the non-hybrid system (Figure 29), the HHPDE CHP equipped with a HEMS recovered sufficient heat for approximately two hours longer than the non-hybrid system. Therefore, a more complex heat feedback control could further improve instant heat recovery. The goal of this paper was to assess potential energy utilization in terms of UF and not design a HEMS, but it proves that an energy management system could be a fuel-saving accessory for land drilling engines. Table 25 presents the UF analysis for this system configuration. 


\begin{tabular}{|c|c|c|c|c|c|}
\hline \multirow{2}{*}{ Cycle } & \multirow{2}{*}{$\begin{array}{c}\text { HHPDE } \\
\text { Hybrid } \\
\text { Without CHP } \\
\text { System UF }\end{array}$} & \multicolumn{2}{|c|}{$\begin{array}{l}\text { HHPDE-CHP Hybrid System } \\
\text { UF limited by Heat Required }\end{array}$} & \multicolumn{2}{|c|}{$\begin{array}{l}\text { HHPDE-CHP Hybrid } \\
\text { System Potential UF }\end{array}$} \\
\hline & & $\begin{array}{l}\text { E-HEX+JW- } \\
\text { HEX }\end{array}$ & $\begin{array}{l}\text { ESG+JW- } \\
\text { HEX }\end{array}$ & $\begin{array}{l}\text { E-HEX+JW- } \\
\text { HEX }\end{array}$ & $\begin{array}{l}\text { ESG+J } \\
\text { W-HEX }\end{array}$ \\
\hline Name & $\%$ & $\%$ & $\%$ & $\%$ & $\%$ \\
\hline 2E1HR & 37.3 & 57.2 & 57.2 & 76.7 & 74.6 \\
\hline 3E1HR & 38.8 & 56.2 & 56.2 & 77.5 & 75.4 \\
\hline TP1HR & 39.2 & 71.6 & 71.6 & 77.7 & 75.2 \\
\hline 24HR & 37.6 & 59.5 & 59.5 & 75.6 & 74.8 \\
\hline Average & 38.2 & 61.1 & 61.1 & 76.9 & 75.0 \\
\hline
\end{tabular}

Average UF on the engines only was increased from $35.7 \%$ to $38.2 \%$ by using the HEMS, where the cycle that experienced the most significant improvement was the TP1HR cycle. The hybrid system reduced the number of gensets required for three of the four cases analyzed in this research. The number of active engines for the TP1HR cycle, reduced from three online gensets to one. The cycles 3E1HR and 24HR reduced from three online gensets to two. Lastly, the 2E1HR cycle did not reduce the number of engines online. The objective of the HEMS was to have the fewer possible gensets online at a high steady load. The cycles characterized by a high-steady-load did not provide a significant improvement; however, highly transient cycles showed an improvement in UF terms. The TP1HR cycle had the most significant improvement, from $31.8 \%$ to $39.2 \%$. The UF of the HHPDE CHP system from $56.8 \%$ to $61.1 \%$ on average when equipped with the HEMS. The average potential was improved from $72.7 \%$ and $73.2 \%$ without the HEMS to $76.9 \%$ and $75.0 \%$ for HHPDE E-HEX+JW-HEX and HHPDE ESG+JW-HEX configurations when equipped with the HEMS. Higher UFs with the same energy demand resulted in higher fuel savings. Average diesel fuel saved was calculated at $27.3 \mathrm{gph}(103.1 \mathrm{~L} / \mathrm{hr})$, and potential diesel fuel savings averaged $44.9 \mathrm{gph}(169.6 \mathrm{~L} / \mathrm{hr})$. Associated CO2 emissions reductions were estimated at $276.2 \mathrm{~kg} / \mathrm{hr}$, and potential emissions savings averaged $454 \mathrm{~kg} / \mathrm{hr}$. Figure 39 presents the HHPDE CHP hybrid system diesel fuel savings. Savings were estimated on an average of $\$ 81.1$ per hour (27.3\% of total fuel expenses) and potential of $\$ 133.4$ an hour (42.9\% of fuel expenses). Figure 40 shows savings per cycle in an hourly rate. 


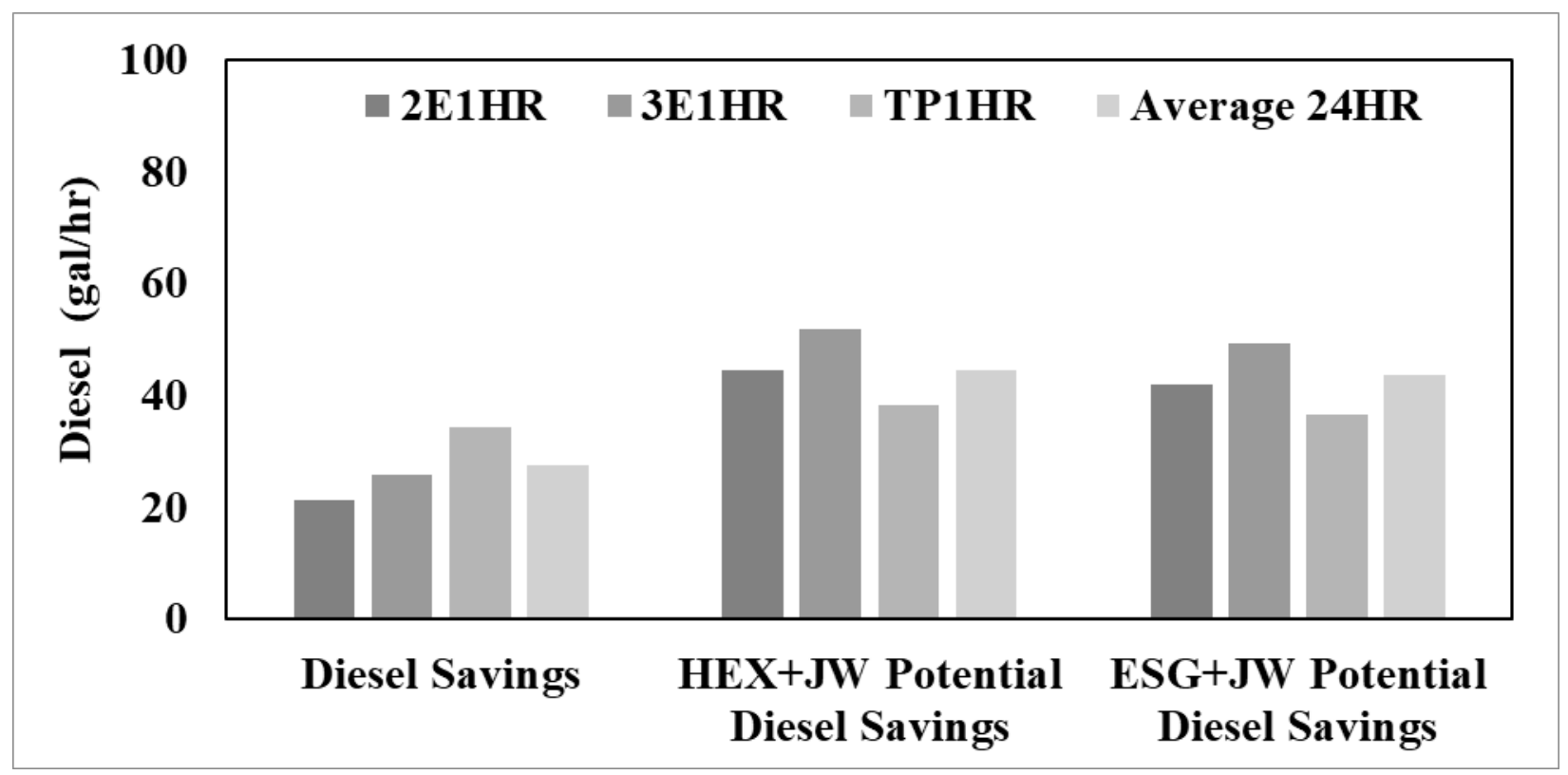

Figure 39. HHPDE CHP Hybrid System Diesel Fuel Savings

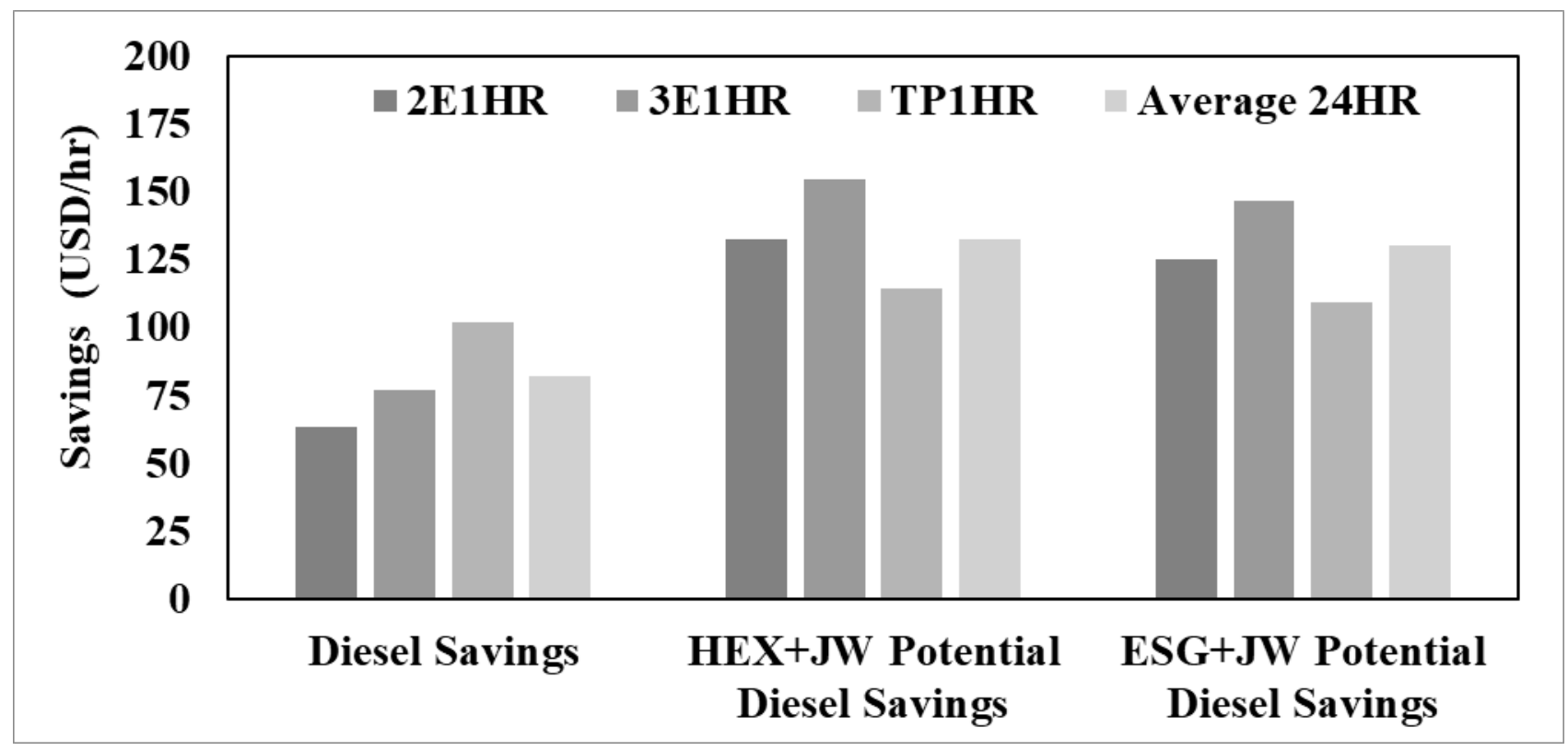

Figure 40. HHPDE CHP Hybrid System Cost Savings

A potential solution to the lack of recovered heat during the last section of the $24 \mathrm{HR}$ cycle could be the utilization of electric heaters throughout the rig using stored energy in the HEMS. In order to estimate the feasibility of such a configuration, a simple heater module was developed and implemented in the SIMULINK HHPDE CHP hybrid model. For the simulation, it was assumed that the electric heaters are $100 \%$ efficient. The electric heater load control was developed to increase its load when the heat balance (heat demanded - heat recovered) approached zero over the 
period of a minute. Figure 41 shows the instant heat recovery over the 24HR cycle for the HHPDE CHP hybrid model using electric heaters powered by the HEMS. Note that the electric heater load control was a simple model with the only objective of testing its feasibility. A more advanced control system could be developed obtaining higher UF simulations. The potential UF decreased from $76.9 \%$ using the E-HEX and JW-HEX to $73.7 \%$ with the same configuration and utilizing the electric heaters. For the ESG and JW-HEX configuration the potential UF decreased from 75\% to $72.7 \%$. While the UF decreased, this approach highlights that HEMs as currently configured had stored more than enough energy to meet the total energy demand (heat + generator power + stored electrical energy). Another possible approach for HEMS stored energy utilization could be the usage of air conditioners when rigs are located in warm weather conditions.

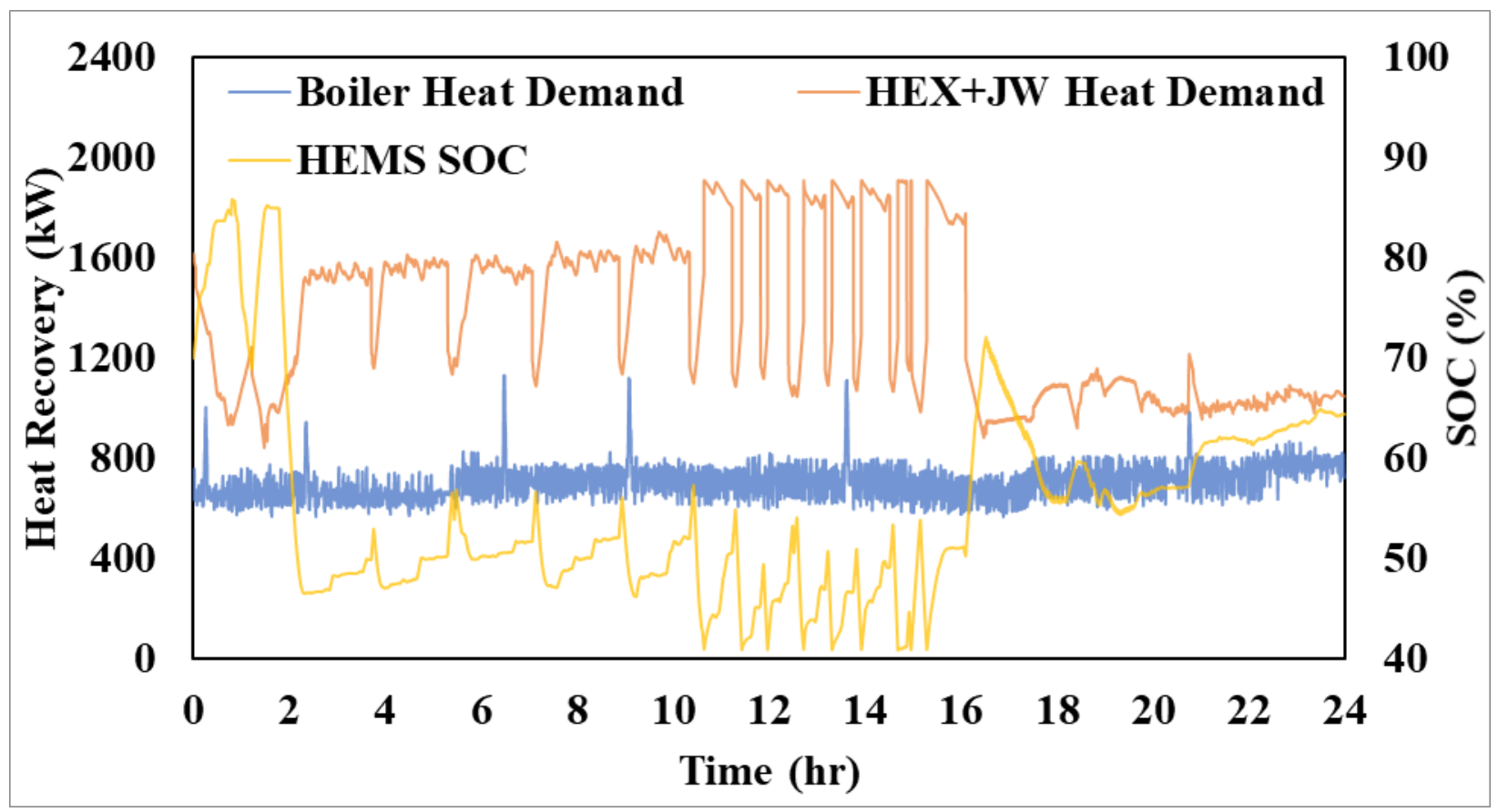

Figure 41. HHPDE CHP Hybrid System, 24HR Cycle Instant Heat Recovery Utilizing Electric Heaters

\subsection{Energy Saving Model: DNGE CHP}

To assess possible fuel savings on natural gas powered rigs, a DNGE CHP system was also modeled and simulated. The same four cycles were used, and the number of DNGE online gensets was selected to match the HHPDE online gensets amount, although DNGE is rated at higher brake power. A DNGE CHP 0-D SIMULINK model was constructed, and it is presented in Figure 42. 
Table 26 presents the DNGE CHP heat recovery rates. The SIMULINK model for the DNGE CHP system model specifications is attached in Appendix E and included:

- Waukesha L7044GSI engine subsystem

- Calculated exhaust heat rejection utilizing Equation 3

- Exhaust mass flow rate from the model as a function of engine load

- Dry air mass flow rate

- Water vapor mass flow rate

- Exhaust temperature model as a function of engine load

○ Fuel consumption as a function of engine load

- Power output assuming constant generator efficiency of $95 \%$

- DNGE E-HEX subsystem

- Calculated exhaust heat recovery as a function of engine load

- DNGE ESG subsystem

- Calculated exhaust heat recovery from ESG manufacturer data provided and available in Appendix D

- Boiler subsystem

○ Fuel consumption (natural gas)

- Converted from diesel to natural gas utilizing Equation 2

- Calculated heat supplied to the system from fuel consumption assuming constant efficiency of $81 \%$ 


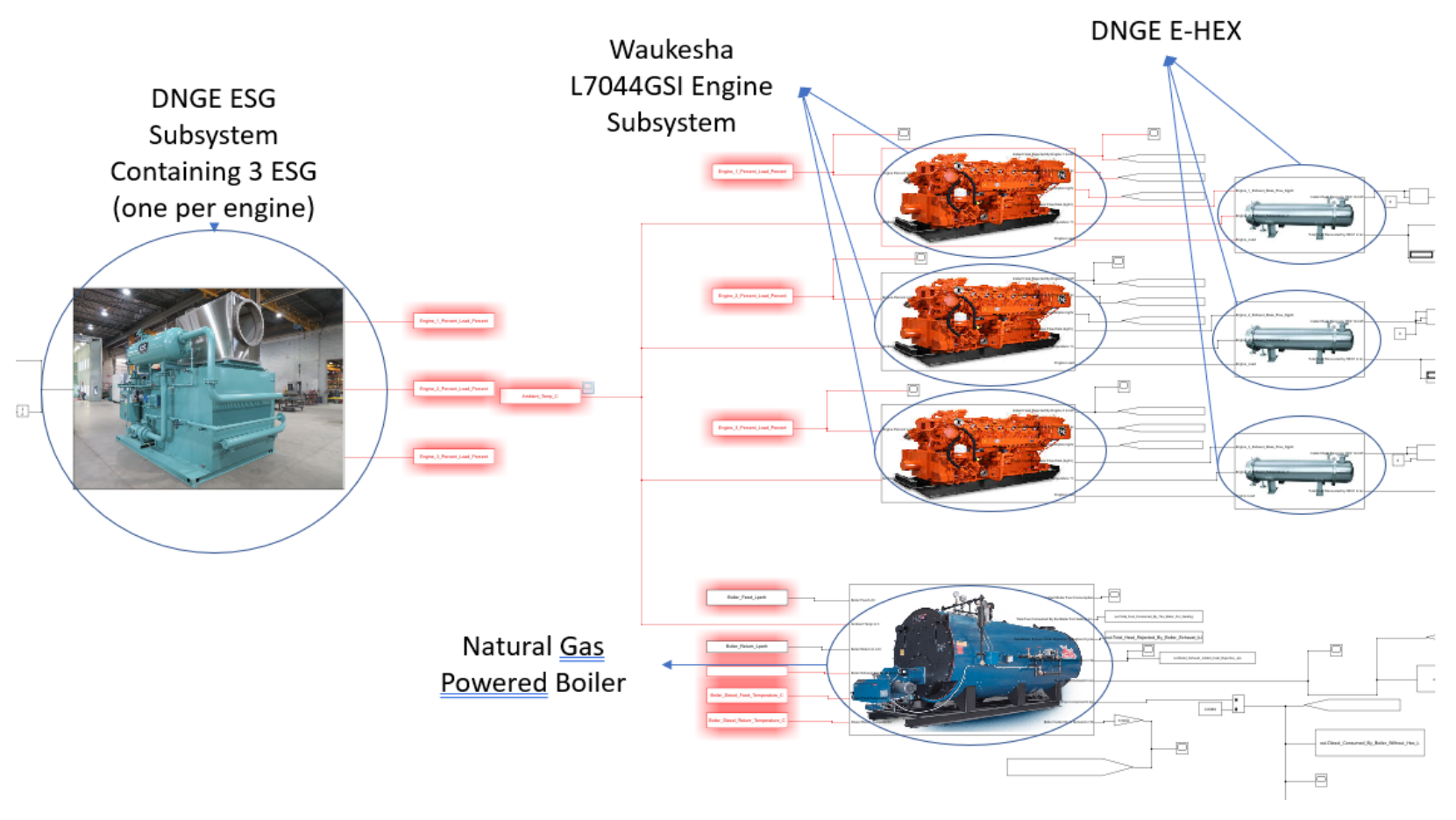

Figure 42. DNGE CHP System 0-D SIMULINK Model Diagram

Table 26. DNGE CHP Heat Recovery

\begin{tabular}{ccccc}
\hline \hline Cycle & $\begin{array}{c}\text { DNGE E- } \\
\text { HEX Heat } \\
\text { Recovered }\end{array}$ & $\begin{array}{c}\text { DNGE E-HEX } \\
\text { Heat Recovered- } \\
\text { Demanded }\end{array}$ & $\begin{array}{c}\text { DNGE } \\
\text { ESG Heat } \\
\text { Recovered }\end{array}$ & $\begin{array}{c}\text { DNGE ESG } \\
\text { Heat Recovered- } \\
\text { Demanded }\end{array}$ \\
\hline Name & MJ & \% & MJ & \% \\
\hline 2E1HR & 4081 & 156 & 4047 & 155 \\
3E1HR & 4368 & 187 & 4816 & 206 \\
TP1HR & 2404 & 101 & 2905 & 122 \\
24HR & 87,079 & 143 & 96,413 & 159 \\
\hline
\end{tabular}

Heat recovery for the DNGE CHP system exceeded the heat required by the system with exhaust HEX only. Both DNGE E-HEX and DNGE ESG performance were simulated. Enough heat was recovered to replace the boiler; therefore, no DNGE JW-HEX was designed and simulated for the DNGE CHP system. The lowest amount of heat recovered occurred during the TP1HR cycle, where $101 \%$ of the heat demanded by the rig was recovered by the DNGE E-HEX. For the DNGE ESG configuration, the TP1HR cycle was also the cycle that recovered the least heat (122\% of the 
heat demanded). On the other end, the 3E1HR cycle recovered $187 \%$ and $206 \%$ of the heat demanded for the DNGE E-HEX and DNGE ESG configurations, respectively. Figures 43 through 46 present DNGE CHP instant heat recovery.

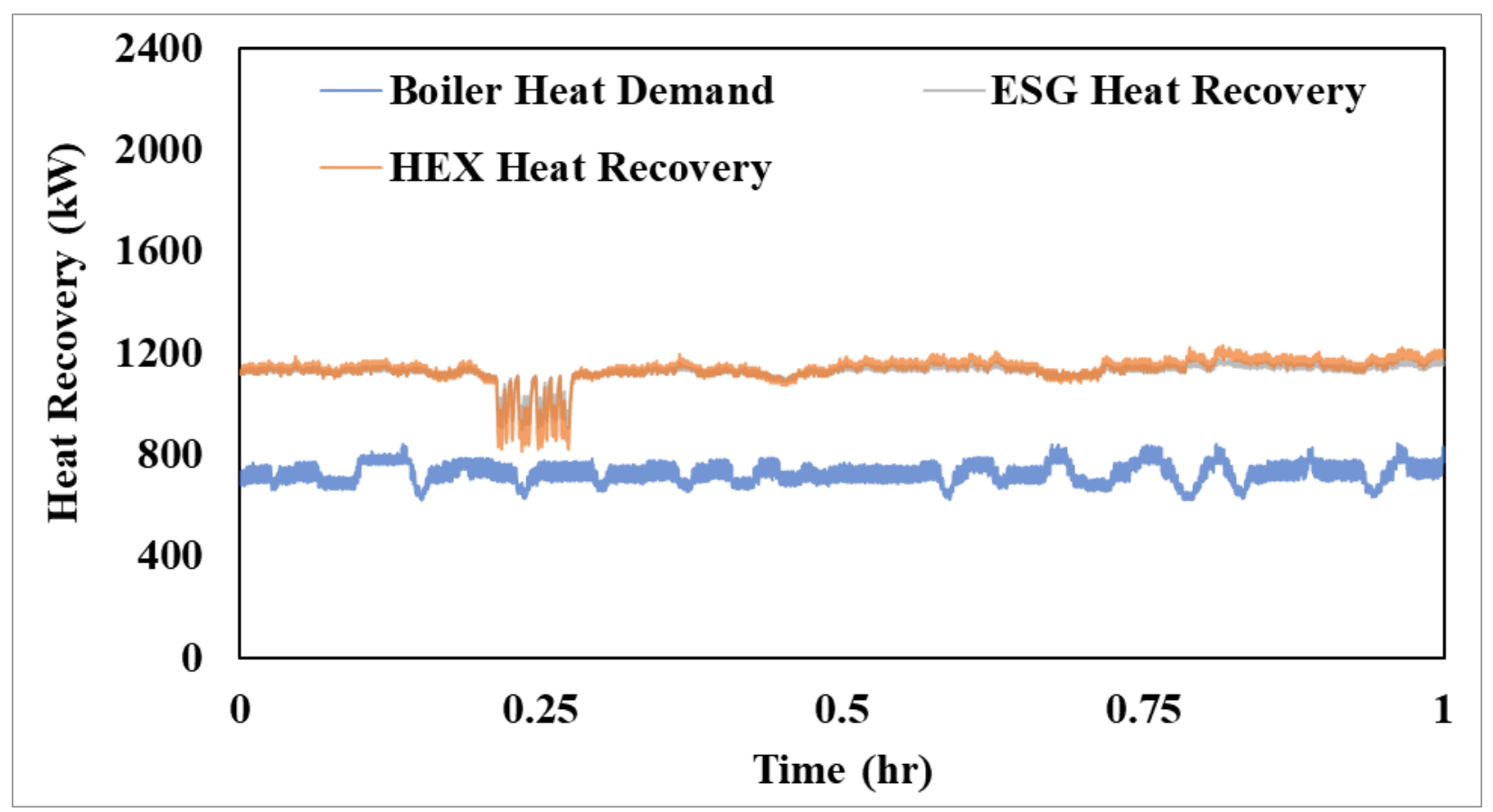

Figure 43. DNGE CHP System, 2E1HR Cycle Instant Heat Recovery

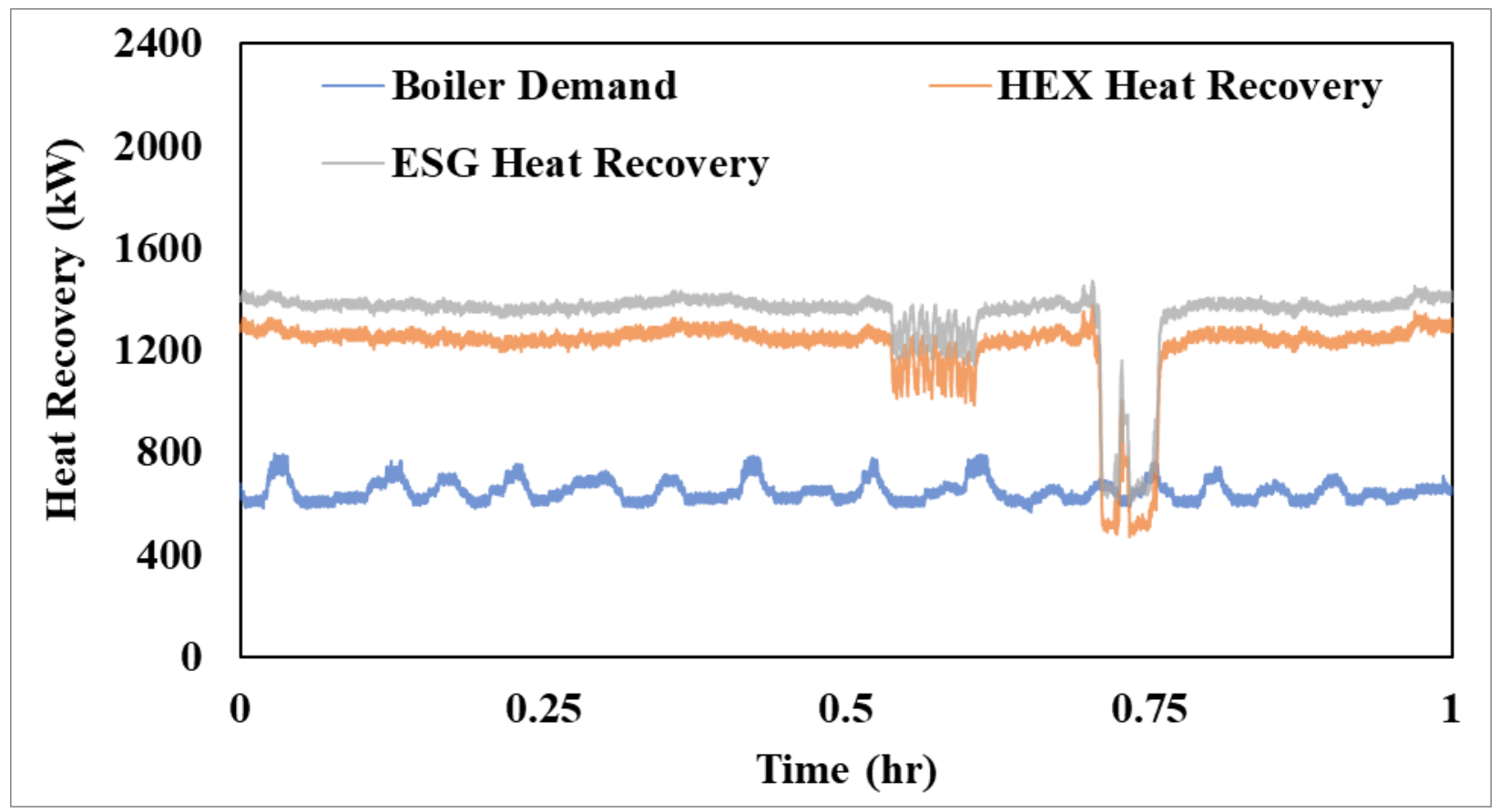

Figure 44. DNGE CHP System, 3E1HR Cycle Instant Heat Recovery 


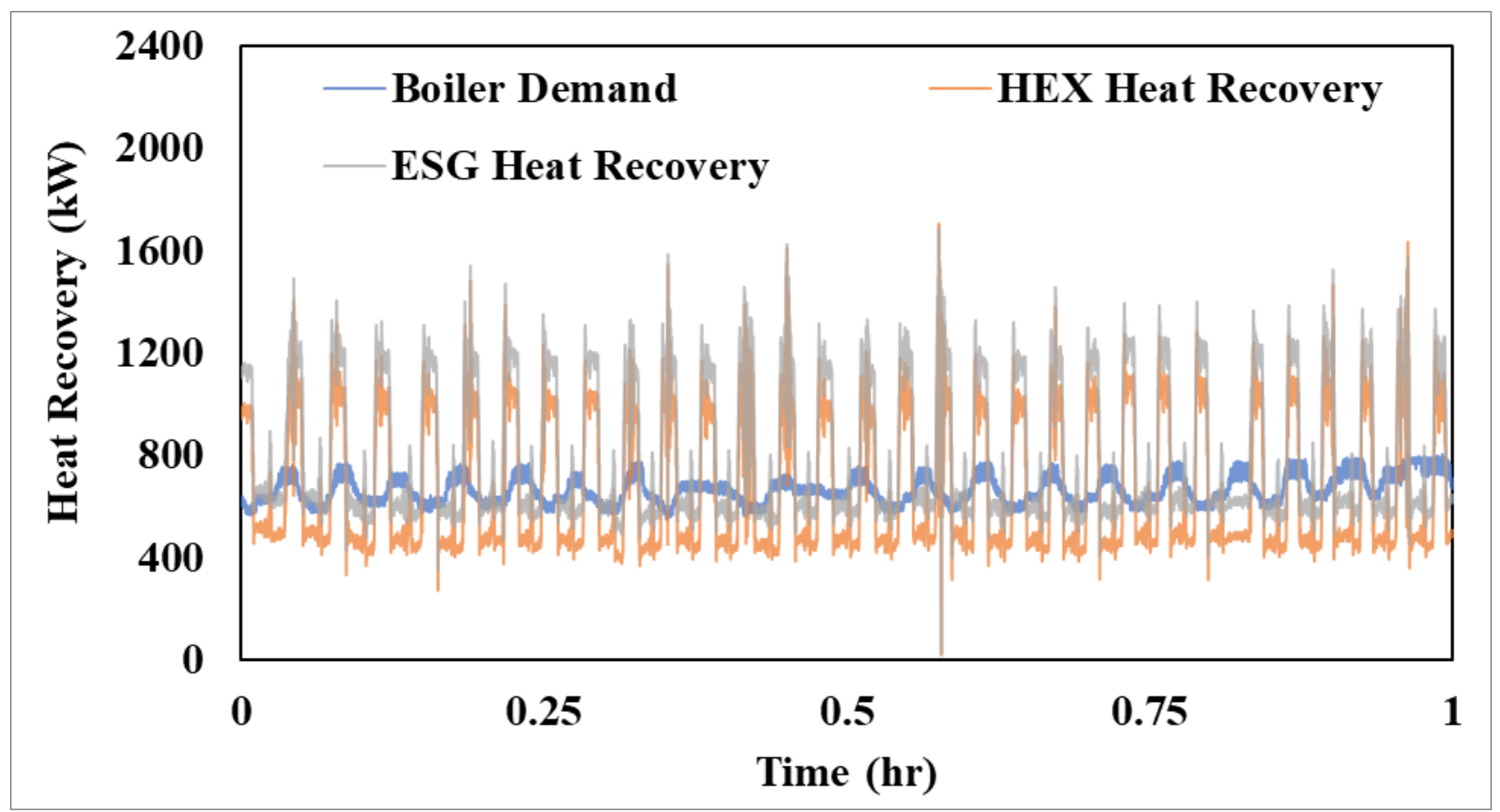

Figure 45. DNGE CHP System, TP1HR Cycle Instant Heat Recovery

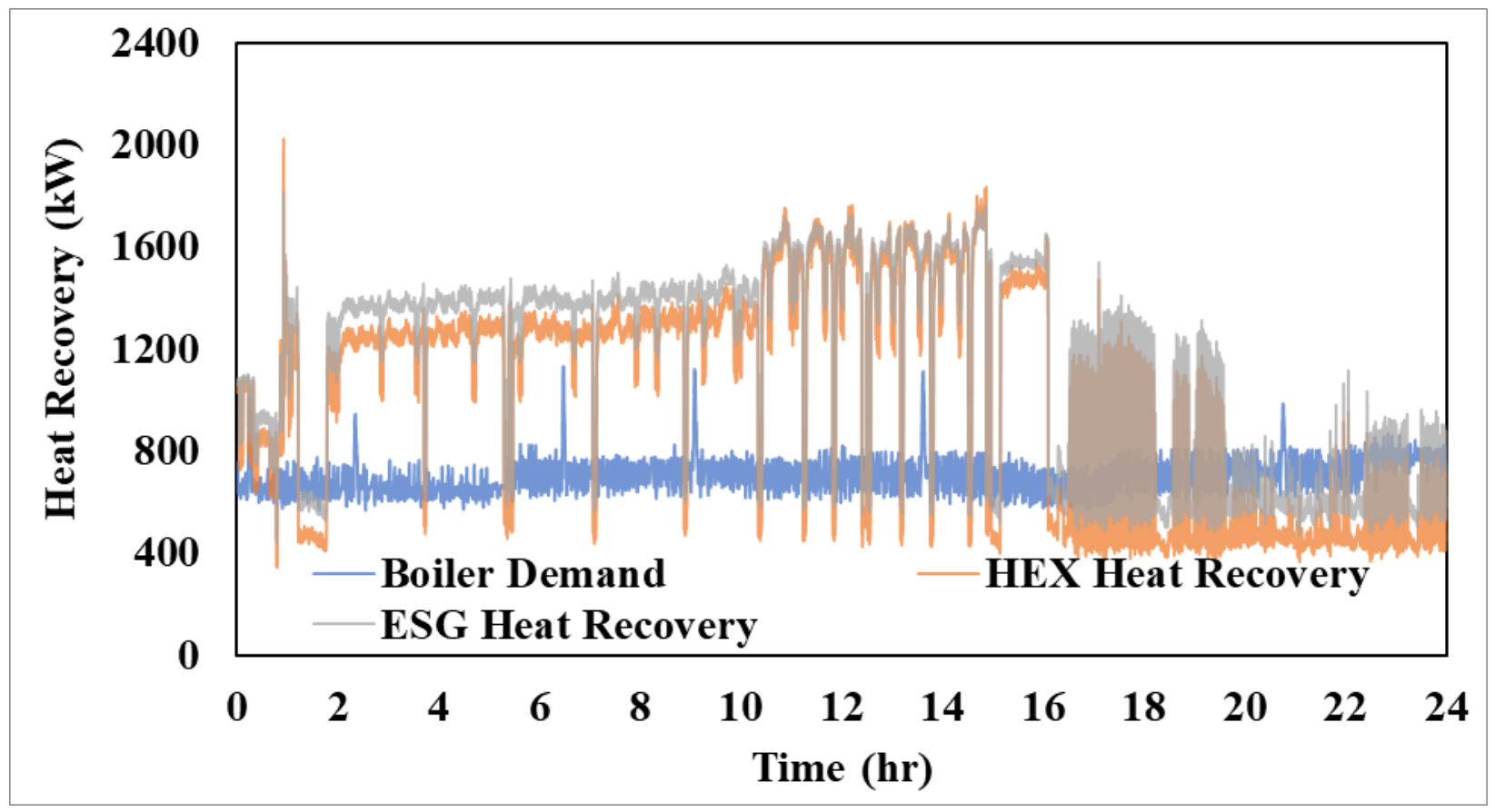

Figure 46. DNGE CHP System, 24HR Cycle Instant Heat Recovery

The DNGE CHP system recovered sufficient heat during the 2E1HR and 3E1HR cycles to surpass the heat demanded throughout the entire cycle. The TP1HR cycle recovered heat at unsteady rates due to transient engine operation, resulting in periods where it did not recover demanded heat. However, the average demanded heat was estimated to be $663 \mathrm{~kW}$, while heat recovery averaged 
$668 \mathrm{~kW}$ and $807 \mathrm{~kW}$ for the DNGE E-HEX and DNGE ESG WHR systems. Neither the E-HEX nor ESG systems could recover enough instant heat to meet the heat demanded during the transient section of the $24 \mathrm{HR}$ cycle. To better present heat balance over this period in the cycle, a 30-minute instant heat balance moving average was used. Figure 47 presents this curve for the DNGE CHP system. The ESG system behaved similar as in the HHPDE CHP system but was unable to meet heat demand during the last $\sim 6$ hours as opposed to the last $\sim 4$ hours.

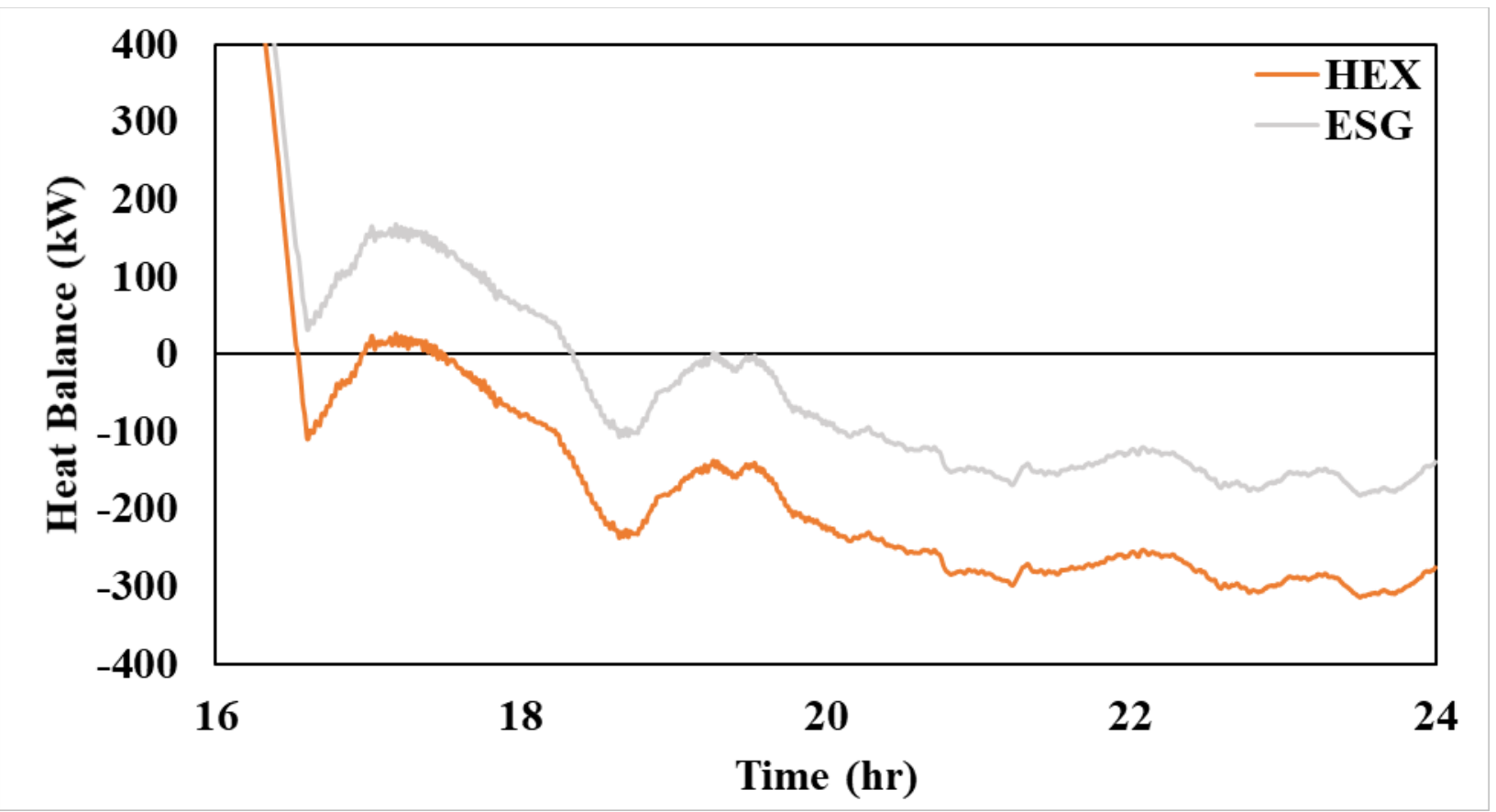

Figure 47. DNGE CHP System, 24HR Cycle 30-Minute Heat Balance Moving Average

As occurred for the HHPDE CHP system, heat recovered over the last eight-hour period of the 24HR cycle was insufficient. Other sources of heat would be necessary to meet the heat demand of the rig. On average, UF was improved from $19.0 \%$ to $30.3 \%$. Potential average UF could increase to $34.9 \%$ and $36.4 \%$ for DNGE E-HEX and DNGE ESG, respectively. Table 27 shows the UF analysis. Figure 48 shows the DNGE CHP system fuel savings. Fuel savings were measured in diesel gallon equivalent (dge) for consistency. Assuming diesel fuel LHV used by CAT in their technical sheet for the 3512C engine, a gallon of diesel gallon equivalent was calculated in 9494 $\mathrm{kJ} / \mathrm{dge}$. 
Table 27. DNGE CHP UF Analysis

\begin{tabular}{cccccc}
\hline \hline \multirow{2}{*}{ Cycle } & $\begin{array}{c}\text { DNGE } \\
\text { Without } \\
\text { CHP }\end{array}$ & \multicolumn{2}{c}{$\begin{array}{c}\text { DNGE-CHP System UF } \\
\text { Limited by Heat Required }\end{array}$} & \multicolumn{2}{c}{$\begin{array}{c}\text { DNGE-CHP System } \\
\text { Potential UF }\end{array}$} \\
\cline { 3 - 7 } Name & \begin{tabular}{c} 
\% UF \\
\cline { 5 - 7 } Name
\end{tabular} & E-HEX & ESG & E-HEX & ESG \\
\hline 2E1HR & 20.6 & 31.6 & 31.6 & 37.8 & 37.6 \\
3E1HR & 19.0 & 27.4 & 27.4 & 34.8 & 36.4 \\
TP1HR & 17.6 & 32.2 & 32.2 & 32.3 & 35.4 \\
24HR & 18.9 & 29.9 & 29.9 & 34.6 & 36.3 \\
Average & 19.0 & 30.3 & 30.3 & 34.9 & 36.4 \\
\hline
\end{tabular}

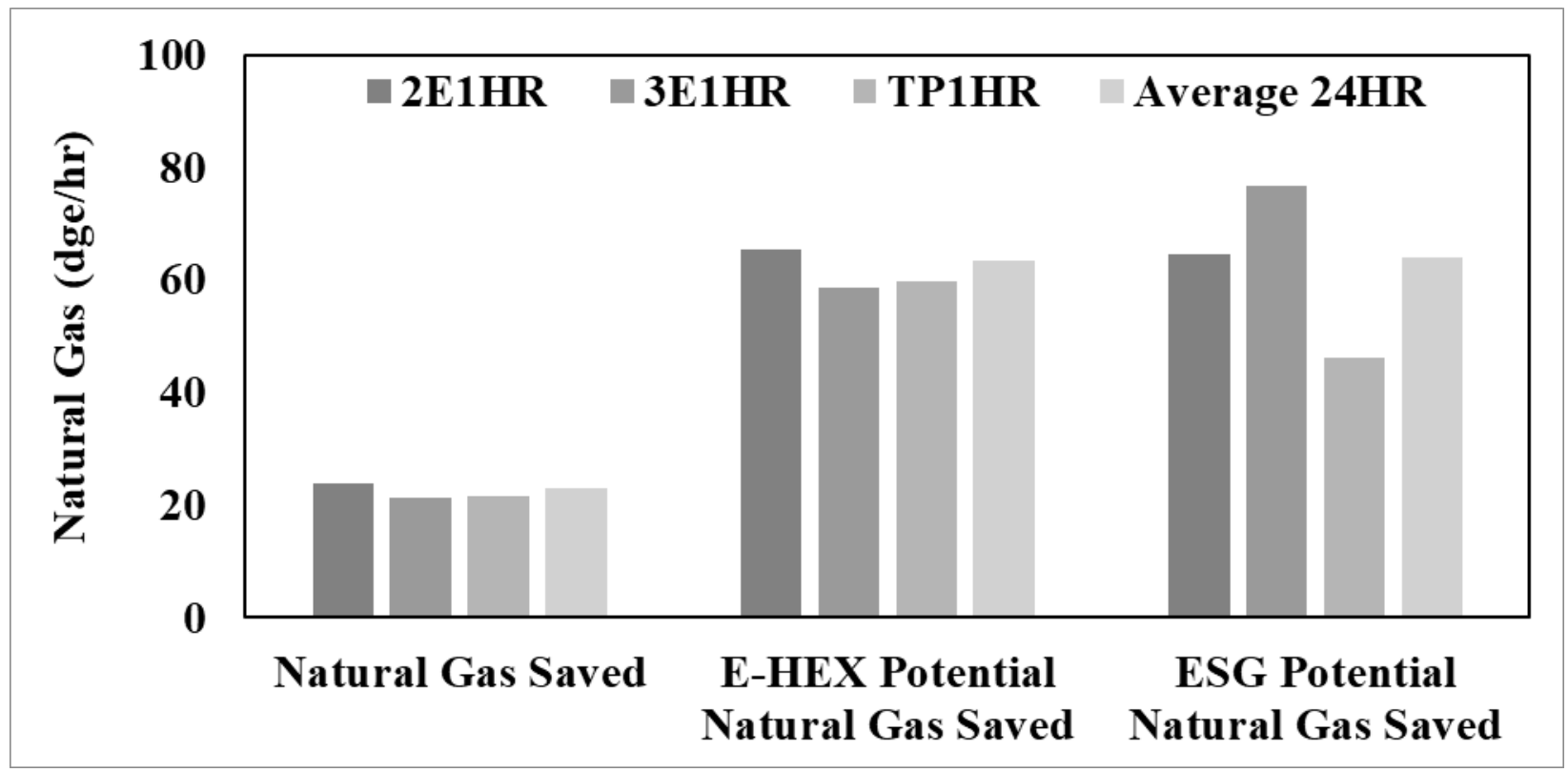

Figure 48. DNGE CHP System Natural Gas Savings

Like the HHPDE CHP system, fuel savings were obtained by eliminating the boiler use. Potential heat recovery peaked during the 2E1HR and 3E1HR cycles, where loads were high and steady throughout the cycle. The lowest heat recovery potential was found on the TP1HR cycle, where low and transient loads dominated engine activities. Average natural gas fuel saved was calculated at $22.5 \mathrm{dge} / \mathrm{hr}(61.8 \mathrm{~kg} / \mathrm{hr})$, and potential diesel fuel savings averaged $61.8 \mathrm{dge} / \mathrm{hr}(158.9) \mathrm{kg} / \mathrm{hr}$. Associated $\mathrm{CO} 2$ emissions reductions were estimated at $170 \mathrm{~kg} / \mathrm{hr}$, and potential emissions savings 
averaged $437 \mathrm{~kg} / \mathrm{hr}$. Figure 49 shows costs savings assuming a cost of $\$ 0.17$ per $\mathrm{kg}$ of natural gas. Average fuel costs savings were estimated at $\$ 10.5 / \mathrm{hr}$ (12.2\% of fuel costs) with a potential average of $\$ 27.0 / \mathrm{hr}$ (30.2\% of total fuel costs).

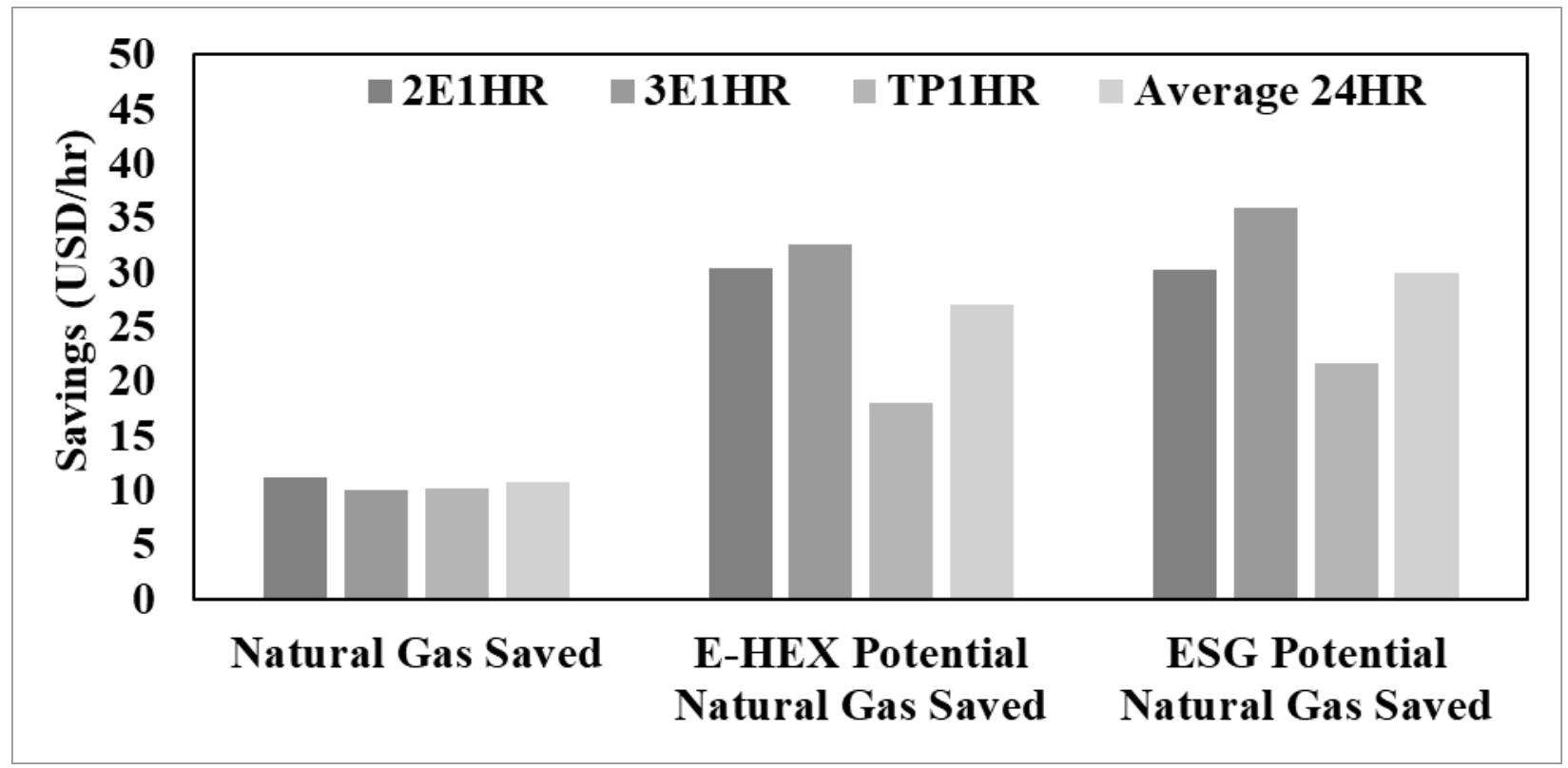

Figure 49. DNGE CHP System Costs Savings

\subsection{Energy Saving Model: DNGE CHP Hybrid}

The DNGE CHP hybrid system with the specified HEMS was also simulated and analyzed for the four cycles to further improvement in potential fuel savings. The HEMS can output electrical power up to $1752 \mathrm{kWe}$. Higher loads represent higher thermal efficiency for the DNGEs. Figure 50 shows Waukesha L7044GSI natural gas engine thermal efficiency as a function of engine load. However, previously recorded data showed that on-site thermal efficiency was lower [46]. The same HEMS, parameters, and assumptions as the HHPDE CHP hybrid system were used for the DNGE CHP hybrid system. 


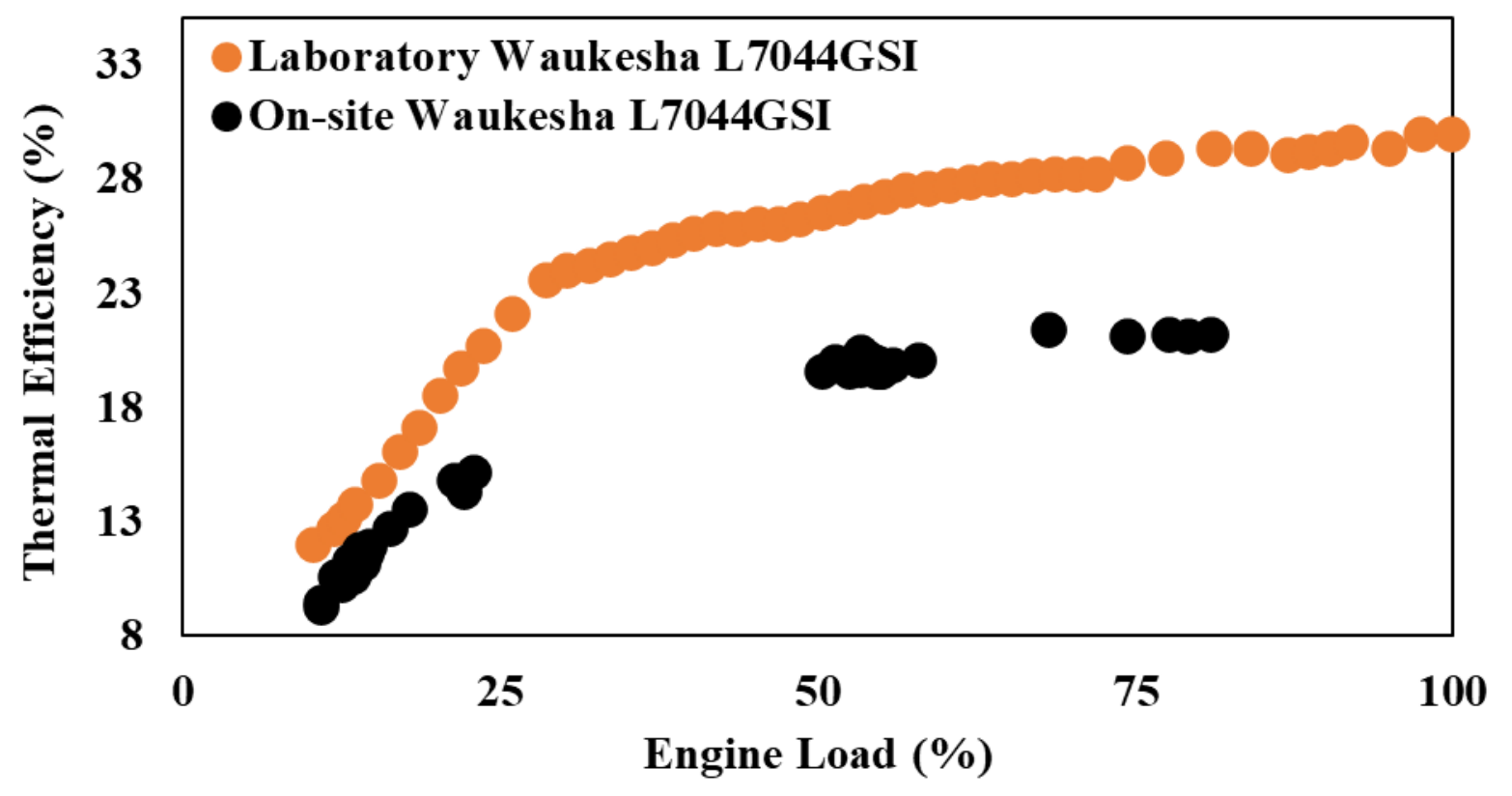

Figure 50. Waukesha L7044gsi Engine Thermal Efficiency

A 0-D SIMULINK model was designed for this configuration, and it is presented in Figure 51. Table 28 shows the heat recovery results for the DNGE CHP system equipped with the HEMS. The SIMULINK model for the DNGE CHP hybrid system model specifications is attached in Appendix E and included:

- Waukesha L7044GSI engine subsystem

- Calculated exhaust heat rejection utilizing Equation 3

- Exhaust mass flow rate from the model as a function of engine load

- Dry air mass flow rate

- Water vapor mass flow rate

- Exhaust temperature model as a function of engine load

- Fuel consumption as a function of engine load

- Power output assuming constant generator efficiency of $95 \%$

- DNGE E-HEX subsystem

- Calculated exhaust heat recovery as a function of engine load

- DNGE ESG subsystem

- Calculated exhaust heat recovery from ESG manufacturer data provided and available in Appendix D 
○ $70 \%$ initial SOC assumption

- Minimum number of online gensets possible

- Instant heat feedback control

- Genset load control system

$\circ$ Charging and discharging coulombic efficiency of $80 \%$ and $90 \%$, respectively

- Boiler subsystem

- Fuel consumption (natural gas)

- Converted from diesel to natural gas utilizing Equation 2

- Calculated heat supplied to the system from fuel consumption assuming constant efficiency of $81 \%$

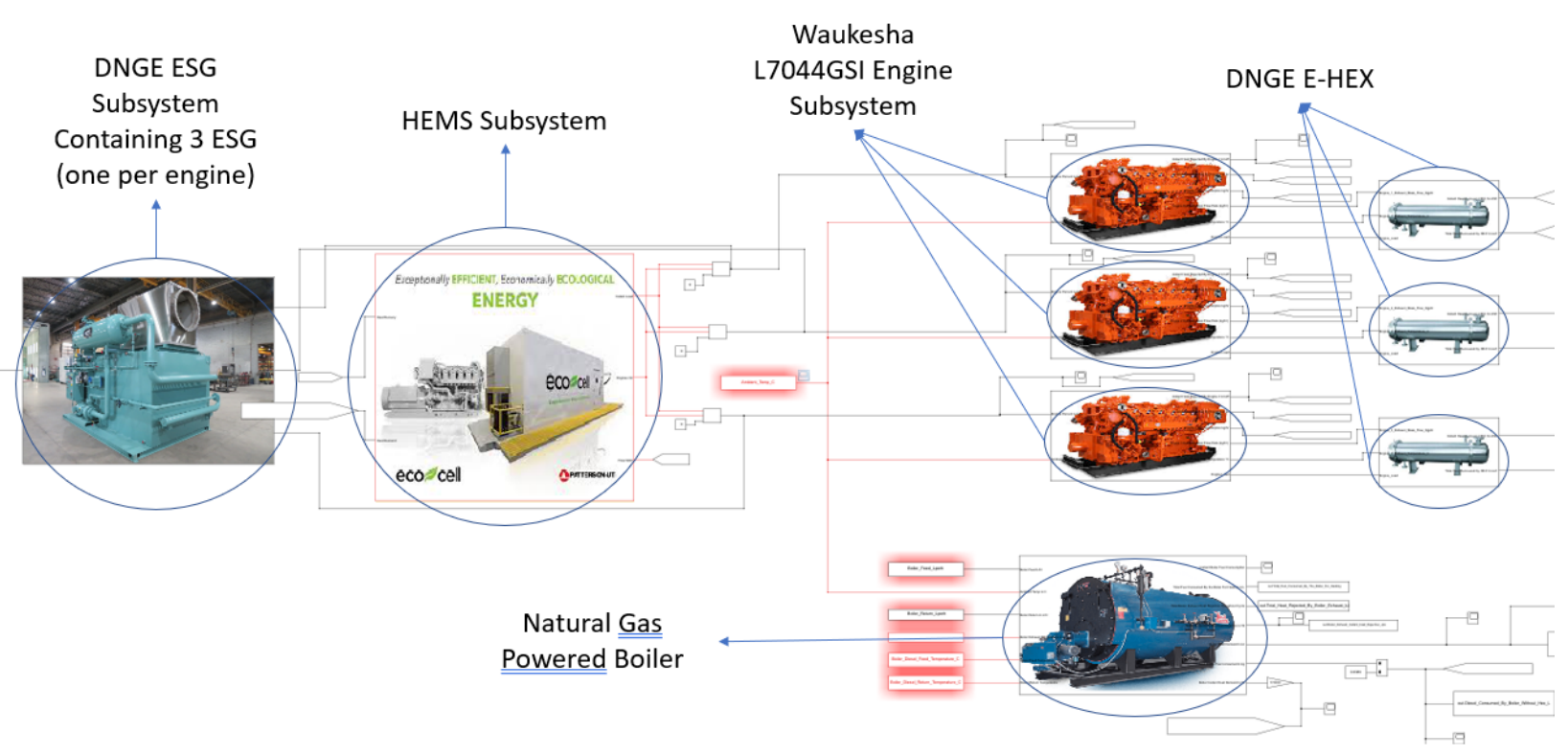

Figure 51. DNGE CHP Hybrid System 0-D SIMULINK Model Diagram 
Table 28. DNGE CHP Hybrid System Heat Recovery

\begin{tabular}{ccccc}
\hline \hline Cycle & $\begin{array}{c}\text { DNGE CHP } \\
\text { Hybrid System } \\
\text { E-HEX Heat } \\
\text { Recovered }\end{array}$ & $\begin{array}{c}\text { DNGE CHP Hybrid } \\
\text { System E-HEX } \\
\text { Heat Recovered- } \\
\text { Demanded }\end{array}$ & $\begin{array}{c}\text { DNGE CHP } \\
\text { Hybrid } \\
\text { ESG Heat } \\
\text { Recovered }\end{array}$ & $\begin{array}{c}\text { DNGE CHP } \\
\text { Hybrid ESG } \\
\text { Heat Recovered- } \\
\text { Demanded }\end{array}$ \\
\hline Name & MJ & $\mathbf{\%}$ & MJ & \% \\
\hline 2E1HR & 4366 & 167 & 4194 & 160 \\
3E1HR & 4378 & 187 & 4186 & 179 \\
TP1HR & 2735 & 115 & 2338 & 98 \\
24HR & 88,474 & 146 & 85,772 & 141 \\
\hline
\end{tabular}

Reducing the number of gensets online leads to a reduction in fuel consumption; however, it can also reduce heat recovery in some cases. Cycle TP1HR for DNGE CHP hybrid system equipped with the DNGE ESG was not able to recover $100 \%$ of the heat required by the system (98\%). However, this exchanger was used to compare the designed exchanger (DNGE E-HEX), which exceeded heat demands. In scenarios where the required heat was not able to be recovered, there are two possible solutions. A second engine can be fired to contribute with heat and power cogeneration, or electric heaters can be used in offices. Figures 52 through 55 present the instant heat recovery for each of the four cycles analyzed. 


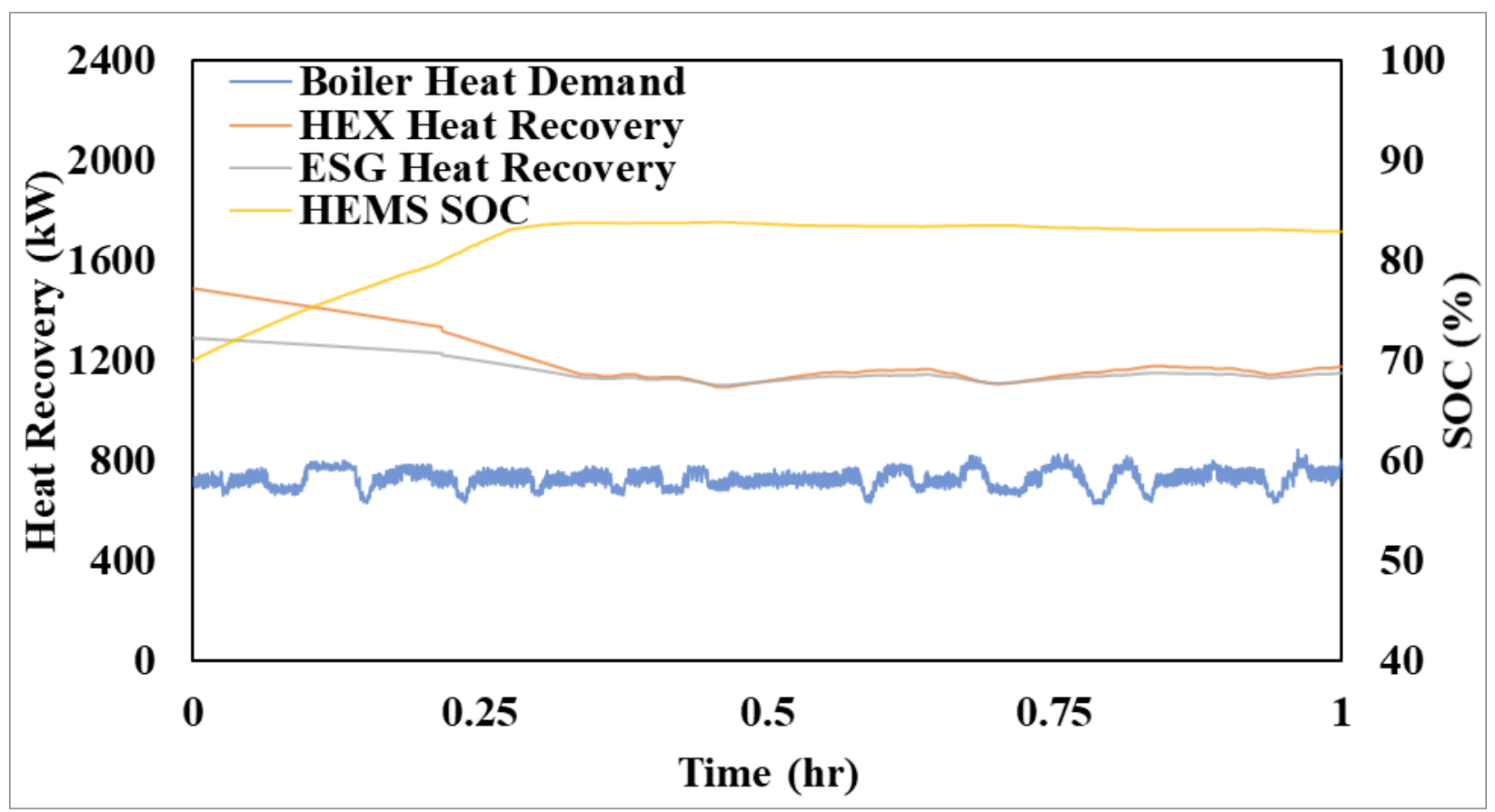

Figure 52. DNGE CHP Hybrid System, 2E1HR Cycle Instant Heat Recovery

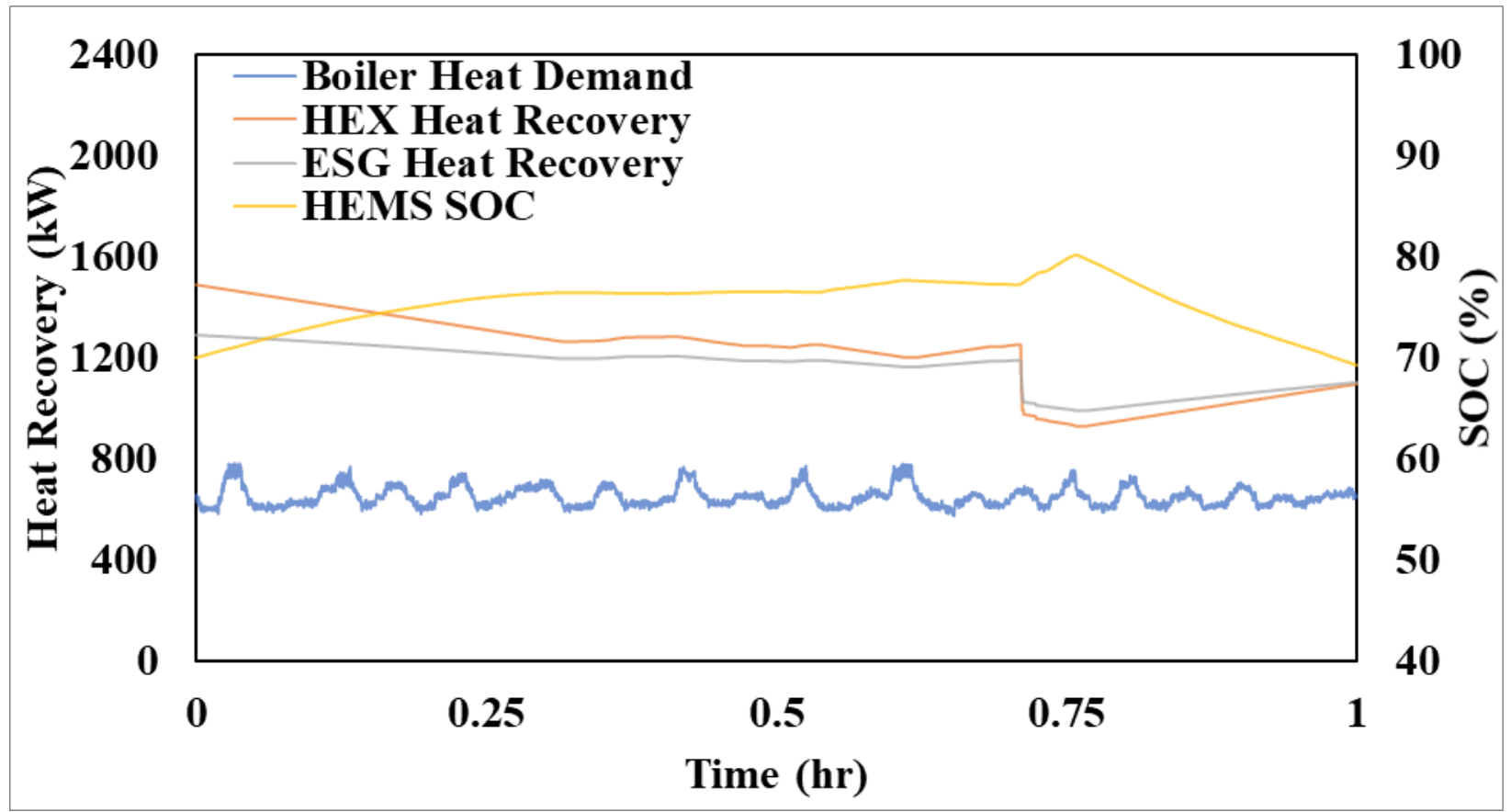

Figure 53. DNGE CHP Hybrid System, 3E1HR Cycle Instant Heat Recovery 


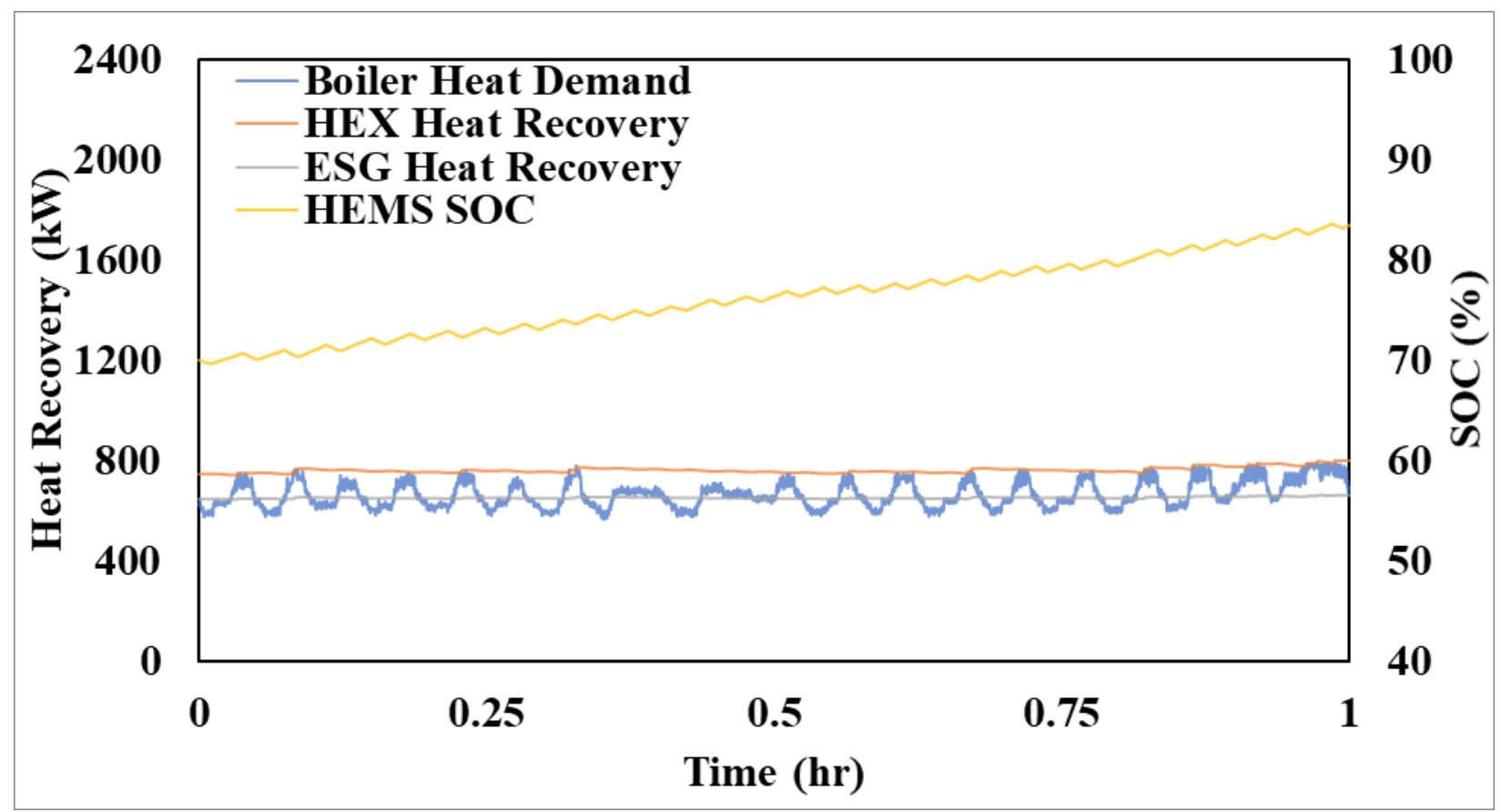

Figure 54. DNGE CHP Hybrid System, TP1HR Cycle Instant Heat Recovery

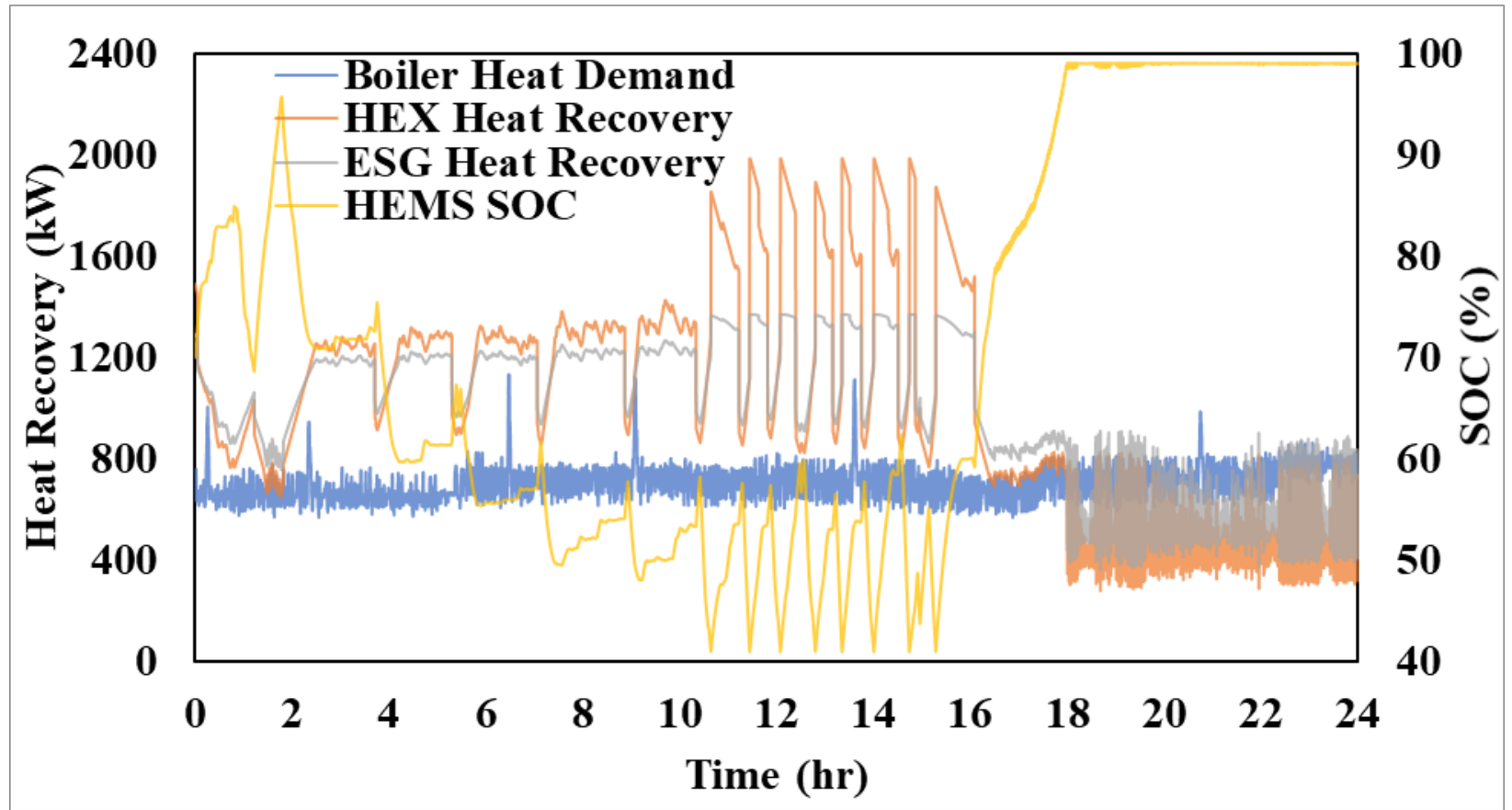

Figure 55. DNGE CHP Hybrid System, 24HR Cycle Instant Heat Recovery

The DNGE CHP system equipped with the HEMS recovered sufficient heat to meet the demands of the rig throughout the entire 2E1HR, 3E1HR, and TP1HR cycles. However, during the transient section of the $24 \mathrm{HR}$ cycle, the system did not recover sufficient instant heat. A 30-minute heat balance curve was created to observe heat recovery performance during that period of the $24 \mathrm{HR}$ 
cycle. Figure 56 presents the DNGE CHP hybrid system instant heat balance 30-minute moving average for the last eight hours of the $24 \mathrm{HR}$ cycle. With the addition of the hybrid systems, both the modeled HEX and ESG were able to meet heat demand until just after the $18^{\text {th }}$ hour of the 24 hour cycle.

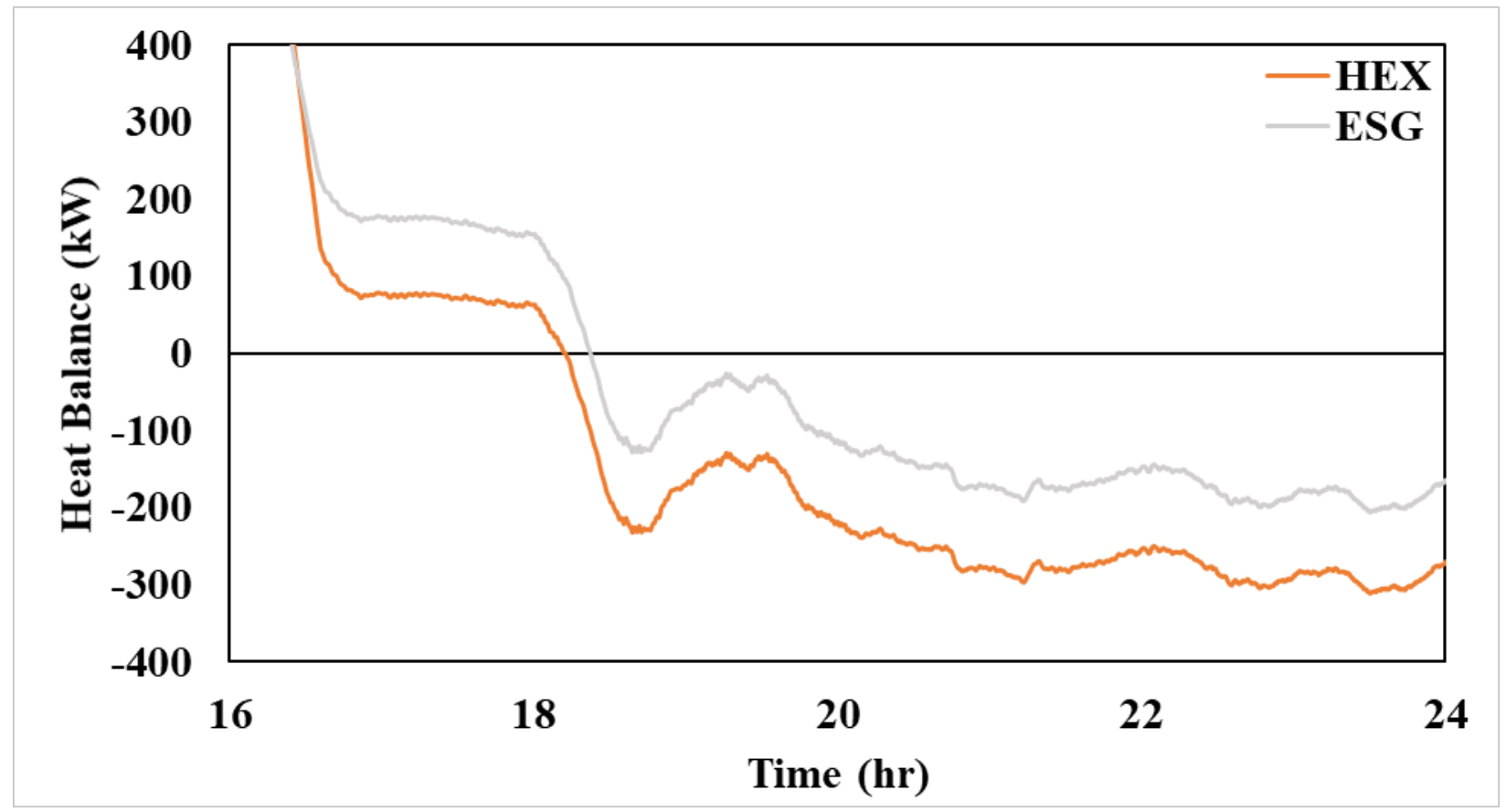

Figure 56. DNGE CHP Hybrid System, 24HR Cycle 30-Minute Heat Balance Moving Average

The DNGE CHP system equipped with the HEMS was able to supply sufficient heat for a more extended period during the $24 \mathrm{HR}$ cycle. However, by the conclusion of the cycle, the heat demanded was higher than the heat recovered.

Hybridization provided higher engine efficiency while generating enough heat to keep the rig's equipment functional and provide comfort to its crew. Table 29 shows DNGE CHP hybrid system performance in terms of UF. On average, the UF for the gensets only was improved from 19.0\% to $20.8 \%$, and CHP UF increased from 30.3 to $33.2 \%$ and $33.1 \%$ for the DNGE E-HEX and DNGE ESG units, respectively. Potential UFs reached $39.1 \%$ and $37.8 \%$ for the E-HEX and ESG configurations, respectively. 
Higher UF translates into a more efficient system; therefore, less fuel must be burned for the same amount of energy to be used. Figure 57 shows natural gas fuel savings for the DNGE CHP hybrid system for the four cycles.

Table 29. DNGE CHP Hybrid System UF Analysis

\begin{tabular}{cccccc}
\hline \hline \multirow{2}{*}{ Cycle } & $\begin{array}{c}\text { DNGE Hybrid } \\
\text { System } \\
\text { Without CHP } \\
\text { System UF }\end{array}$ & $\begin{array}{c}\text { DNGE-CHP Hybrid System } \\
\text { Name }\end{array}$ & UF Limited by Heat Required & \multicolumn{2}{c}{$\begin{array}{c}\text { DNGE-CHP Hybrid } \\
\text { System Potential UF }\end{array}$} \\
\cline { 3 - 6 } & \% & E-HEX & ESG & E-HEX & ESG \\
\hline 2E1HR & 20.2 & 31.0 & 31.0 & 38.2 & 37.5 \\
3E1HR & 21.1 & 30.5 & 30.5 & 38.7 & 37.9 \\
TP1HR & 21.2 & 38.7 & 38.3 & 41.2 & 38.3 \\
24HR & 20.7 & 32.7 & 32.7 & 38.2 & 37.7 \\
Average & 20.8 & 33.2 & 33.1 & 39.1 & 37.8 \\
\hline
\end{tabular}

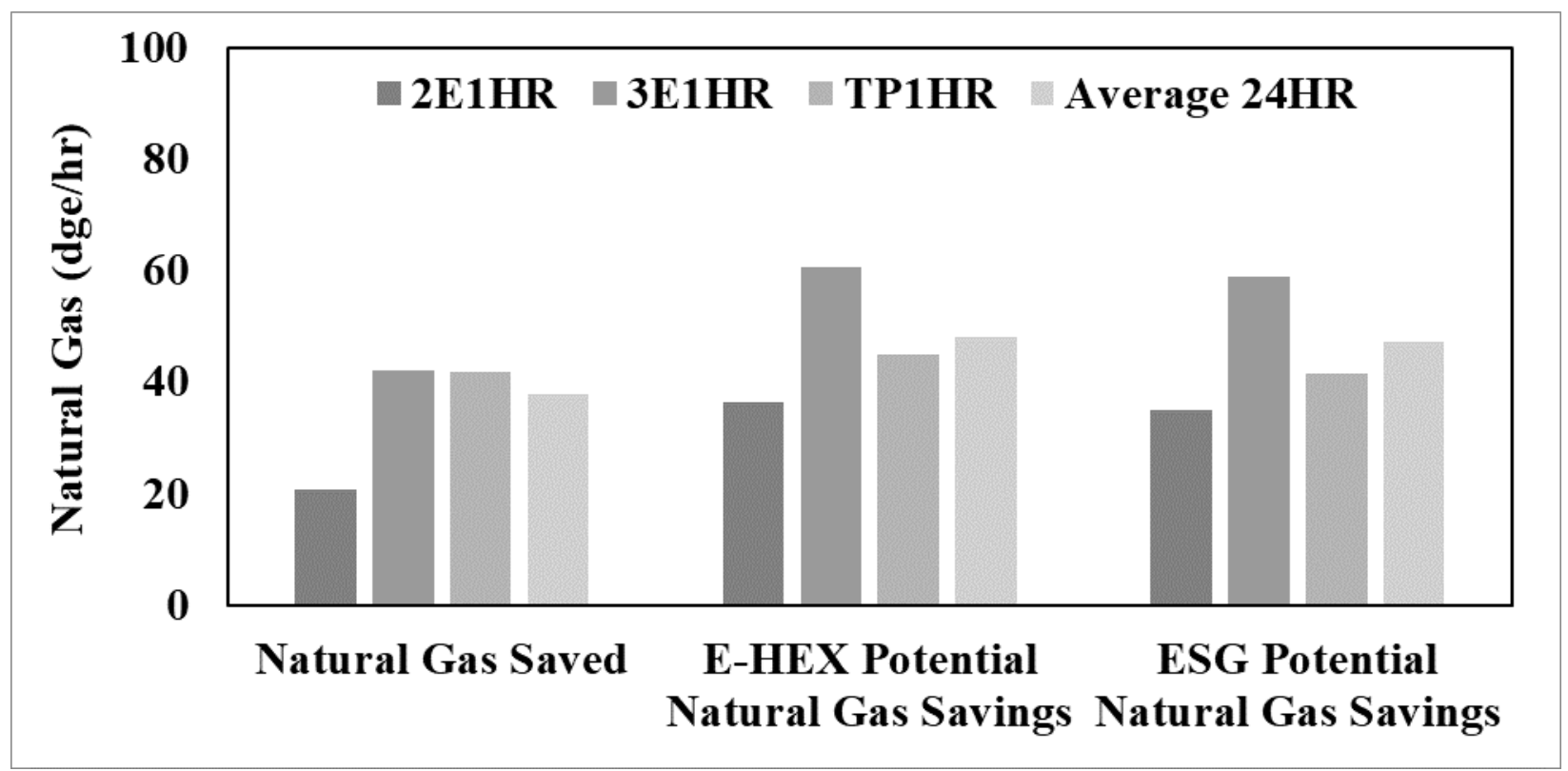

Figure 57. DNGE CHP Hybrid System Natural Gas Savings

Natural gas savings increased compared to the DNGE non-hybrid system due to running fewer engines at higher loads. Note that fuel savings for the 2E1HR cycle were lower than the non-hybrid system by $3.24 \mathrm{dge} / \mathrm{hr}(8.9 \mathrm{~kg} / \mathrm{hr})$. This cycle was characterized by running two engines at high- 
steady loads. The objective of the HEMS was to convert any cycle into a high load, steady-state cycle. Therefore, no significant changes were implemented for the hybrid system on this cycle. The TP1HR cycle resulted in the highest fuel savings reducing the online gensets from three to one accompanied by the HEMS. Average natural gas fuel saved was calculated at $35.5 \mathrm{dge} / \mathrm{hr}$ (97.7 $\mathrm{kg} / \mathrm{hr}$ ), and potential natural gas fuel savings averaged $47.6 \mathrm{dge} / \mathrm{hr}(130.8 \mathrm{~kg} / \mathrm{hr})$. Associated CO2 emissions reductions were estimated at $265 \mathrm{~kg} / \mathrm{hr}$, and potential emissions savings averaged 360 $\mathrm{kg} / \mathrm{hr}$. Figure 58 shows natural gas fuel costs savings for the system which averaged $\$ 16.1 / \mathrm{hr}$ (21.5\% of natural gas fuel expenses) with potential of reaching an average of $\$ 22.2 / \mathrm{hr}$ (27.9\% of natural gas fuel expenses).

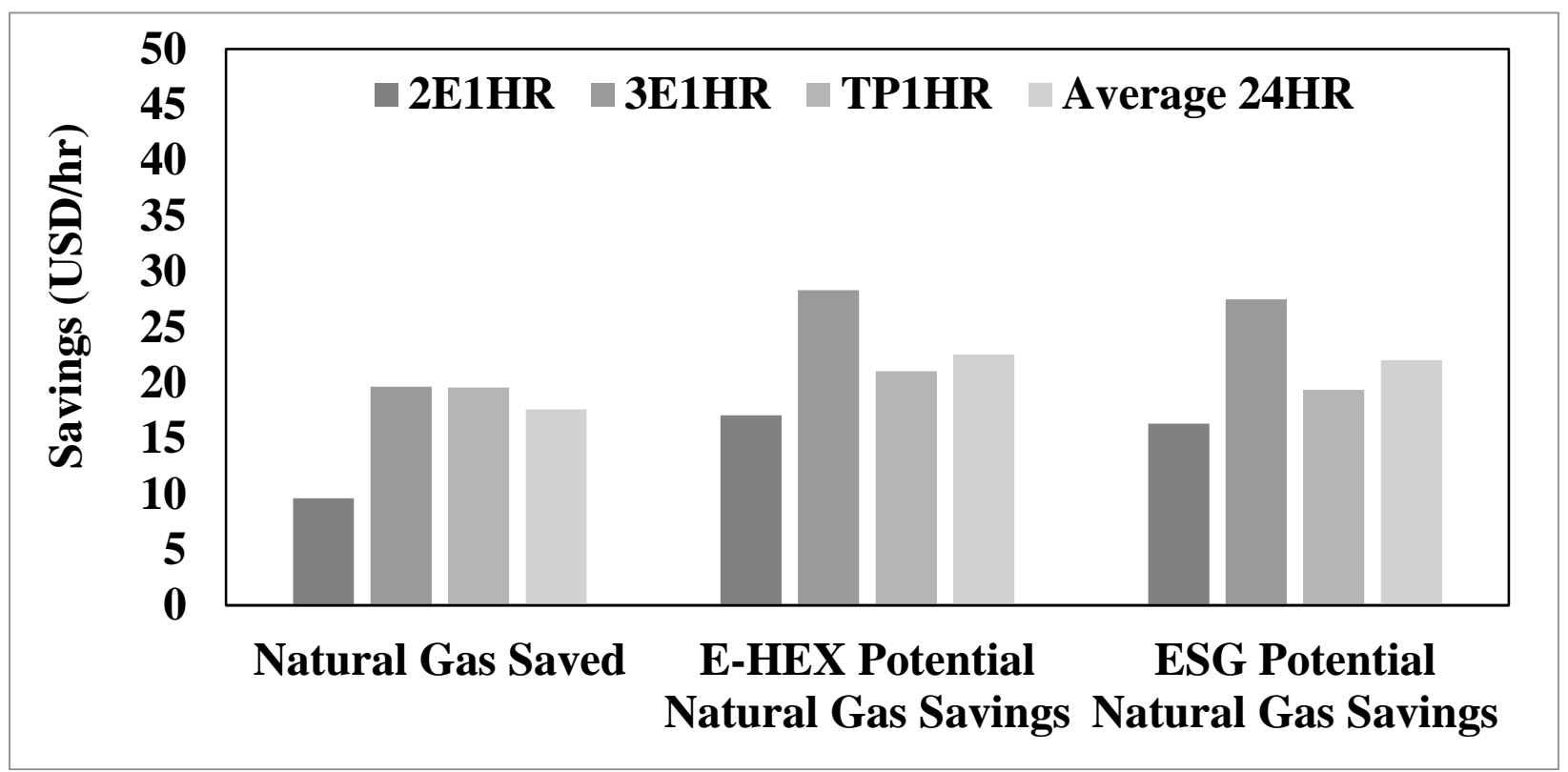

Figure 58. DNGE CHP Hybrid System Savings

In order to assess a solution for the instant heat recovery during the transient section of the $24 \mathrm{HR}$ cycle, the same electric heater module was included in the DNGE CHP hybrid model to investigate the feasibility of the system. It was found that using this approach, instant heat recovery exceeded instant heat demand throughout the cycle using electric heaters with a maximum output of 346 $\mathrm{kW}$. Similar to the analysis for HHPDE, this analysis highlights that the total energy demand can be met. The potential UF of the system equipped with the E-HEX and JW-HEX decreased from $38.2 \%$ to $36.6 \%$ when utilizing the electric heaters. For the system equipped with the ESG and the 
JW-HEX, the potential UF decreased from 37.8 to $35.9 \%$. Figure 59 shows the instant heat balance for the DNGE CHP hybrid system equipped with the electric heater system.

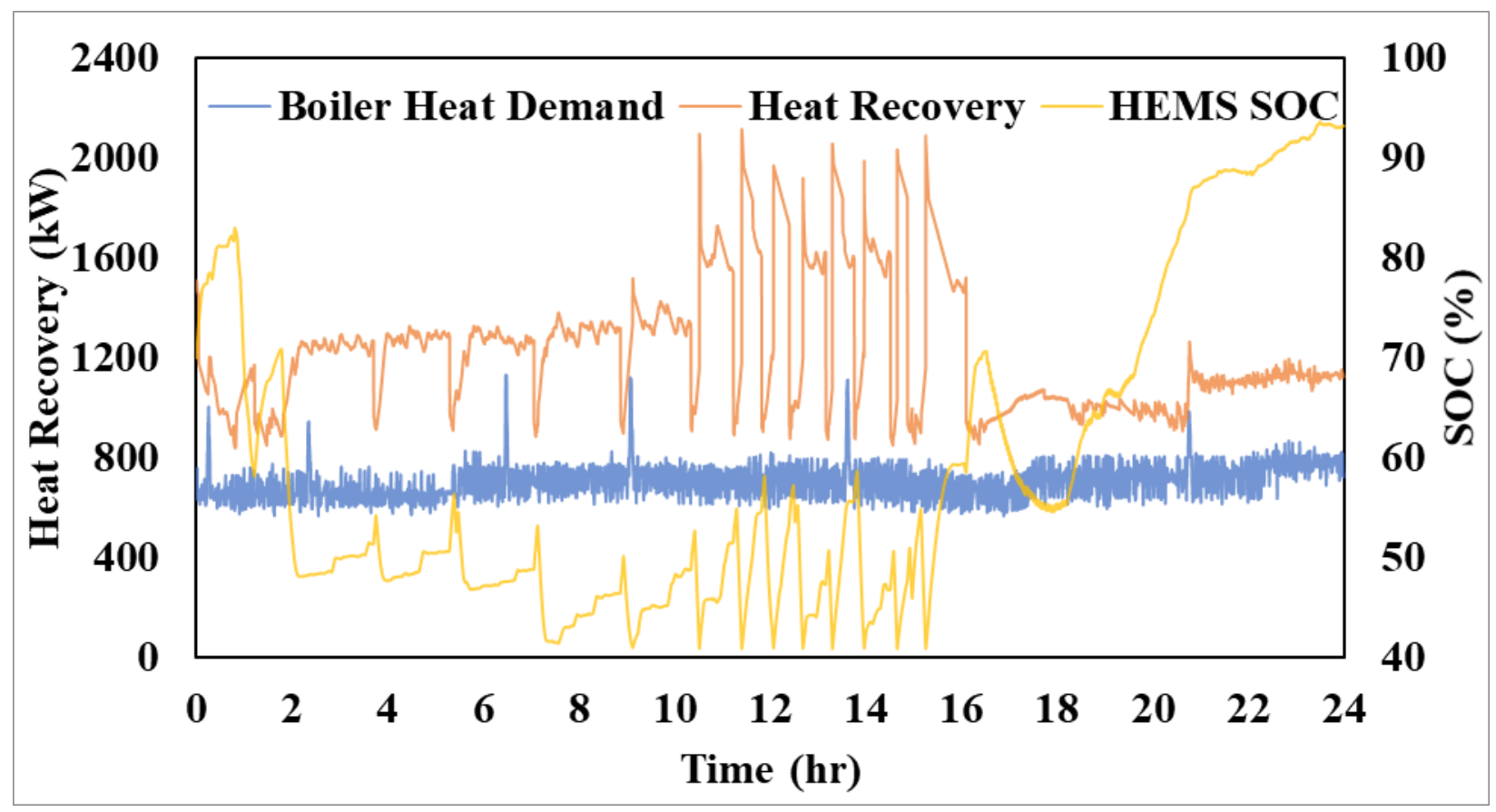

Figure 59. DNGE CHP Hybrid System, 24HR Cycle Instant Heat Recovery Equipped with Electric Heaters

\subsection{Cost Analysis}

Fuel consumption and emissions reductions may reduce operating costs, improve overall efficiency, and comply with future emissions regulations. However, to achieve these goals, a considerable amount of money must be invested. Rigs equipped with boilers are generally used in cold weather conditions, which vary by location, season, and rig activity frequency. Therefore, as a general cost-efficiency approach, time for investment recovery was calculated based on prices available in the U.S markets and U.S. dollars as a function of replaced boiler activity hours. Equation 9 shows the cost balance equation used.

\section{Equation 9. Return on Investment}

Expenses (hrs of replanced boiler activity) = Savings(hrs of replaced boiler activity)

Where expenses include the equipment needed to be acquired, and savings include equipment no longer required and fuel savings. 
Fuel prices vary throughout the U.S., and both diesel and natural gas fluctuate due to several factors that exceed the scope of this research. Therefore, fuel prices were standardized for calculating economic savings according to the models developed. As a reference, the average national diesel price as of 2/22/21, according to the U.S. Energy Information Administration (EIA), was considered ( $\$ 2.973 /$ gal or $\$ 0.787 / \mathrm{L}$ ) [53]. The last publicly available EIA natural gas prices information established that the industrial price as of November 2020 averaged $\$ 3.93$ per $1000 \mathrm{ft}^{3}$ [54]. The U.S. natural gas heat content in 2019 averaged $1038 \mathrm{BTU} / \mathrm{ft}^{3}$ or $49.7 \mathrm{MJ} / \mathrm{kg}$ [55]. The average natural gas price per $\mathrm{kg}$ was calculated at $\$ 0.17$.

For this analysis, the shipping and handling costs of the equipment were not calculated since each company has its own logistics regarding equipment management. The main components that may incur relevant costs were the E-HEXs, the JW-HEXs, the HEMS, the boiler, and the fuel consumed. Both HHPDE E-HEX and DNGE E-HEX were compared in price to the CAIN industries' ESG. Their respective price estimations are included in Appendix D. The HEMS cost was estimated by the price per kWh as reported by the EIA. The last U.S. average installed utilityscale battery storage cost in 2018 was estimated at $\$ 625$ per $\mathrm{kWh}$ [56]. Therefore, the cost for meeting $584 \mathrm{~kW}-\mathrm{hr}$ capacity could be estimated at $\$ 365,000$.

For the HHPDE CHP system, the expenses included:

Three E-HEX at $\$ 179,354$ each with a multiplying factor of 0.93 when purchasing more than one exchanger (Appendix D).

Three JW-HEXs at an estimated price of \$27,367 per unit (Appendix D).

The savings for this configuration included:

Boiler rental expenses were based on a daily fee of $\$ 240$ and one freight charge fee of $\$ 3950$ (Appendix F).

Diesel fuel costs to be recovered with the UFs of $56.8 \%$ and $72.7 \%$.

Table 30 shows the return on investment analysis based on the information provided above for the HHPDE CHP rig configuration. 
Table 30. HHPDE CHP Return on Investment Analysis

\begin{tabular}{ccc}
\hline \hline \multirow{2}{*}{ Equipment } & \multicolumn{2}{c}{ HHPDE CHP } \\
\cline { 2 - 3 } & \multicolumn{2}{c}{ Expenses (+) and Savings (-) } \\
\hline E-HEX & \multicolumn{2}{c}{$\$ 500,398$} \\
JW-HEX & \multicolumn{2}{c}{$\$ 82,100$} \\
Boiler Rental & \multicolumn{2}{c}{$-\$ 58,989$} \\
Diesel Costs to Be Saved & \multicolumn{2}{c}{$-\$ 523,509$} \\
UF & $\mathbf{5 6 . 8 \%}$ & $\mathbf{7 2 . 7 \%}$ \\
Time (hrs. of replaced boiler activity) & 5254 & 3857 \\
Days (replaced boiler activity) & 220 & 161 \\
\hline
\end{tabular}

If normalizing savings per day of replaced boiler activity, the HHPDE CHP system would save approximately $\$ 2648$ per day. If the UF was increased to $72.7 \%$, savings would be estimated at $\$ 3618$ per day.

For the HHPDE CHP system equipped with the HEMS, the expenses included:

Two E-HEX at $\$ 179,354$ each with a multiplying factor of 0.93 when purchasing more than one exchanger (Appendix D).

Two JW-HEXs with an estimated price of $\$ 27,367$ per unit (Appendix D).

A HEMS estimated at $\$ 365,000$.

The savings for this configuration included:

Boiler rental expenses were based on a daily fee of $\$ 240$ and one freight charge fee of $\$ 3950$ (Appendix F).

Diesel fuel costs to be recovered with the UFs of $61.1 \%$ and $76.9 \%$.

Table 31 shows the return of investment analysis for the HHPDE CHP system equipped with the HEMS. 
Table 31. HHPDE CHP Equipped with a HEMS Return on Investment Analysis

\begin{tabular}{ccc}
\hline \hline \multirow{2}{*}{ Equipment } & \multicolumn{2}{c}{ HHPDE CHP Hybrid } \\
\cline { 2 - 3 } & Expenses (+) and Savings (-) \\
\hline E-HEX & \multicolumn{2}{c}{$\$ 333,598$} \\
JW-HEX & \multicolumn{2}{c}{$\$ 54,733$} \\
Boiler Rental & \multicolumn{2}{c}{$-\$ 68,307$} \\
HEMS & \multicolumn{2}{c}{$\$ 365,000$} \\
Diesel Costs to Be Saved & \multicolumn{2}{c}{$\$ 685,024$} \\
UF & $\mathbf{6 1 . 1 \%}$ & $\mathbf{7 6 . 9 \%}$ \\
Time (hrs. of replaced boiler activity) & 6178 & 4794 \\
Days (replaced boiler activity) & 257 & 200 \\
\hline
\end{tabular}

If normalizing savings per day of replaced boiler activity, the HHPDE CHP hybrid system would save approximately $\$ 2931$ per day. If the UF was increased to $76.9 \%$, savings would be estimated at $\$ 3767$ per day.

For the DNGE CHP system, the investments include:

- Three E-HEX, each of their cost was $\$ 146,273$ with a multiplying factor of 0.93 when purchasing more than one unit (Appendix D).

On the savings side, the DNGE CHP system saved in:

Boiler rental expenses were based on a daily fee of $\$ 240$ and one freight charge fee of $\$ 3950$ (Appendix F).

Natural gas fuel costs to be recovered with the UFs of $30.3 \%$ and $34.9 \%$.

Table 32 shows the return on investment analysis for the DNGE CHP system. 
Table 32. DNGE CHP System Return on Investment Analysis

\begin{tabular}{ccc}
\hline \hline \multirow{2}{*}{ Equipment } & \multicolumn{2}{c}{ DNGE CHP } \\
\cline { 2 - 3 } & \multicolumn{2}{c}{ Expenses (+) and Savings (-) } \\
\hline E-HEX & \multicolumn{2}{c}{$\$ 408,102$} \\
Boiler Rental & \multicolumn{2}{c}{$\$ 108,756$} \\
UF & \multicolumn{2}{c}{$\$ 299,346$} \\
Natural Gas Costs to Be Saved & $\mathbf{3 0 . 3 \%}$ & $\mathbf{3 4 . 9 \%}$ \\
Time (hrs. of replaced boiler activity) & 10,061 & 8236 \\
Days (replaced boiler activity) & 419 & 343 \\
\hline
\end{tabular}

If normalizing savings per day of replaced boiler activity, the HHPDE CHP system would save approximately $\$ 974$ per day. If the UF was increased to $34.9 \%$, savings would be estimated at \$1190per day.

For the DNGE CHP system, equipped with the HEMS, expenses included:

- Two E-HEX, each of their cost was $\$ 146,273$ with a multiplying factor of 0.93 when purchasing more than one unit (Appendix D).

- One HEMS estimated at $\$ 365,000$.

The savings for this configuration included:

Boiler rental expenses were based on a daily fee of $\$ 240$ and one freight charge fee of $\$ 3950$ (Appendix F).

Natural gas fuel costs to be recovered with the UFs of $33.2 \%$ and $39.1 \%$.

Table 33 shows the return of investment analysis for the DNGE CHP system equipped with the HEMS. 
Table 33. DNGE CHP System Equipped with the HEMS Return on Investment Analysis

\begin{tabular}{ccc}
\hline \hline \multirow{2}{*}{ Equipment } & \multicolumn{2}{c}{ HHPDE CHP Hybrid } \\
\cline { 2 - 3 } & Expenses (+) and Savings (-) \\
\hline E-HEX & \multicolumn{2}{c}{$\$ 272,068$} \\
Boiler Rental & \multicolumn{2}{c}{$\$ 152,024$} \\
HEMS & \multicolumn{2}{c}{$\$ 365,000$} \\
UF & \multicolumn{2}{c}{$\$ 485,044$} \\
Natural Gas Costs to Be Saved & $\mathbf{3 3 . 2 \%}$ & $\mathbf{3 9 . 1 \%}$ \\
Time (hrs. of replaced boiler activity) & 14,215 & 11,827 \\
Days (replaced boiler activity) & 592 & 493 \\
\hline
\end{tabular}

The cost-efficiency analysis relied on the overall system running time, which includes the boiler being fully active. Boilers on well pads are only active at locations where cold weather occurs at cold seasons, varying throughout the country. To make this analysis applicable to all locations, expenses covered by savings were calculated in terms of hours of replaced boiler activity. Average annual boiler activity time at specific locations can be divided by time (hrs) to find the approximate time needed to amortize the potentially acquired assets.

For the weather activity recorded throughout the month of February and March in WV, it was estimated that using the HHPDE CHP system, including three E-HEXs and three JW-HEXs, 220 days of boiler activity would be needed to cover the system investment. For the same case scenario powered by the DNGE CHP system, 419 days would be required to amortize the investment. When optimizing the system with the HEMS, it was proven that two engines and the HEMS could handle any load, saving the third exchanger's costs. Moreover, the cost of the third engine could be categorized as savings. For the purpose of this analysis, the cost of the third engine was not removed from the total costs. It was estimated that approximately 257 days of boiler activity must be replaced to match investments on the system acquisition for the HHPDE CHP system equipped with the HEMS. If DNGE powered the hybrid system, 592 days of replaced boiler activity on average would be needed to pay off initial system investments. 


\section{Conclusions}

The unconventional well development industry has been growing in the U.S. Exploration and production companies are attempting to utilize energy-saving techniques to save on costs and reduce fuel consumption and emissions. In the unconventional well completion industry, the primary consumers, or prime movers, of diesel fuel or natural gas are HHP drilling engines and boilers. Combining both power and heat cogeneration would result in fuel savings and emissions reductions. This has led government agencies such as the U.S. DOE to seek information on these potential solutions. As part of a funding opportunity from the U.S. DOE, WVU was tasked to develop and validate new knowledge and technology to improve efficiency and minimize the environmental implications of unconventional resource development. An energy consumption audit was performed on HHP drilling engines during the horizontal drilling of an unconventional well. Data from the audit were used to assess methods for reducing fossil fuel consumption and associated emissions during the development phase.

In order to complete this task, in-field engine data were collected from the three CAT 3512C diesel gensets. The main data parameters were engine load, coolant temperature, fuel consumption, and exhaust temperature. The engine data were filtered and binned to create engine performance models that included exhaust temperature, fuel consumption, exhaust flow, and coolant temperature, as functions of engine load. Previously recorded emissions data from these engines were used to estimate water concentration in the exhaust flow. Exhaust gas was assumed to be water vapor and dry air only, and heat rejection calculations were based on this exhaust composition. Boiler activity was also recorded to determine fuel consumption and heat output, assuming a constant efficiency of $81 \%$. Four cycles representing different stages in the development of an unconventional well were extracted from recorded on-site data and used for comparisons. These included a steady drilling cycle powered by two engines, a steady drilling cycle powered by three engines, a tripping pipe/casing cycle (transient operation) powered by three engines, and a 24 hour cycle with variable engines online and variable power demand profile. A natural gas powered rig was also modeled based on engine data previously recorded by another research project conducted by WVU.

The heat recovery system was developed using an engine exhaust flow model, engine coolant model, and CHEMCAD software. Exhaust and jacket water heat exchangers were sized, designed, 
and simulated for both HHPDE and DNGE powered rigs. A simple HEMS model was developed on a SIMULINK subsystem based on literature. An overall SIMULINK model was created for each system configuration, including HHPDE and DNGE with no WHR system, HHPDE and DNGE with CHP system, and HHPDE DNGE CHP system equipped with HEMS. SIMULINK models were run using the four cycles extracted from on-site recorded data. Potential heat recovery was calculated and compared to the heat demand provided by the boiler. System efficiency was calculated in terms of the UF of the fuel (diesel or natural gas). The goal was to improve UF by recovering wasted heat rejected from the engines and utilizing the HEMS. This would reduce fuel consumption while providing the same amount of work and heat for the four cycles.

Results based on the cycles analyzed indicated that it would be possible to improve the UF utilization for both CHP and hybrid systems. Each of the cycles analyzed represents a characteristic operation of the rig. It was found that the HHPDE CHP system could increase UF from an average of 35.7 to an average of 56.8 and had the potential to use up to 72.7 of the fuel's energy. This would represent a potential diesel fuel savings of $156.1 \mathrm{~L} / \mathrm{hr}(\$ 122.9$ per hour) and an emissions reduction of $418 \mathrm{~kg} / \mathrm{hr}$ of $\mathrm{CO}_{2}$. An investment of $\$ 582,498$ would be required to acquire the equipment. This investment would be recouped after 220 days of replaced boiler operation. When the hybrid system was added to the HHPDE CHP system, the average UF was increased from 35.7 to 38.2 utilizing the HEMS alone. If equipped with the HHPDE E-HEXs and HHPDE JW-HEXs, the UF averaged about 61.1 and had the potential to reach 76.9, representing $169.6 \mathrm{~L} / \mathrm{hr}$ of diesel fuel savings ( $\$ 133.5$ per hour) and $454 \mathrm{~kg} / \mathrm{hr}$ of associated $\mathrm{CO}_{2}$ emissions. Investment for this scenario was estimated at $\$ 753,331$. This investment would be recouped after 257 days of replaced boiler operation to cover the cost. The DNGE CHP system increased the UF from an average of 19.0 to an average of 30.3 and the potential to use up to 34.9 , representing potential fuel savings of $158.9 \mathrm{~kg} / \mathrm{hr}$ of natural gas and associated emissions reduction of $437 \mathrm{~kg} / \mathrm{hr}$ of $\mathrm{CO}_{2}$. An investment of $\$ 408,102$ would be required for acquiring the equipment. This investment would be recouped after 419 days of replaced boiler operation. When the hybrid system was added to the DNGE CHP system, the average UF was increased from 19.0 to 20.8 using the HEMS only. When utilizing the DNGE E-HEX and the HEMS, the average UF increased to 33.2 and had the potential to reach 39.1 , representing $130.8 \mathrm{~kg} / \mathrm{hr}$ of natural gas and $360 \mathrm{~kg} / \mathrm{hr}$ of associated $\mathrm{CO}_{2}$ emissions. Investment for this scenario was estimated at $\$ 637,068$. This investment would be recouped after 592 days of replaced boiler operation. 
Results showed that instant heat recovery was insufficient for extended periods of transient engine operation. Therefore, other sources of heat had to be utilized in those circumstances. If electric heaters were used to supply the system with the required heat, engine load would increase, recovering more heat. Analysis also demonstrated that the stored electrical energy of the HEMS combined with other energy could meet total rig energy demands. Another approach to the problem would be to utilize thermal reservoirs to store thermal energy for later usage. A possible solution would be the installation of a steam accumulator. They could help save some of the extra heat recovered from the exchangers to be used when heat demand exceeded heat recovery. Such an analysis was not performed in this research, but it could be addressed in further investigation. 


\section{Recommendations for Future Research}

\subsection{Tier 4 Compression Ignition CHP and CHP hybrid system modeling}

The models developed on this analysis were based on Tier 2 engines due to the broad use of these engines within the industry. However, it is expected for the near future, that Tier 2 engines will be replaced with Tier 4 engines as older engines are taken off duty. To assess energy saving potential of CHP and HEMS, a Tier 4 engine data collection campaign should be completed. New models could be developed, and the Tier 4 engine sub models could be implemented into the 0-D models developed in this project and results for future industry prime movers could be obtained.

\subsection{Waste Heat Recovery System On-site Validation}

Simulations obtained through models developed in this paper suggested the waste heat recovered from unconventional well completion gensets may be able to reduce or eliminate boiler utilization during the drilling phase of wells during cold weather conditions or in cold regions. A cost analysis was performed, showing that such an investment would pay off between 161 and 592 days of boiler activity, depending on the configuration and fuel used. Validation of the system is critical for future industrial applications. It was calculated that the DNGE powered rigs have more room than HHPDE for heat recovery due to lower thermal efficiencies. The next step in the process would be to manufacture or purchase an E-HEX for a DNGE and obtain on-site heat recovery data from the physical design. To be achieved, it would be necessary to develop a control feedwater system for water inlet regulation based on engine activity. It would also be necessary to connect the E-HEX into a working steam line equipped with mass flow meters, k-type thermocouples, and pressure gauges to calculate heat supply. It would also be necessary to add a pump to pressurize the water inlet into the exchanger. Once data is recorded from this experiment, results can be extrapolated into a fully equipped rig power plant (three or four engines).

If data collected during the DNGE CHP system (one genset and one E-HEX) on-site validates the results presented in this paper, the next step would be to do the same with the HHPDE CHP system.

\subsection{Emissions Savings Through CHP and CHP Hybrid Systems}

Results obtained in this paper suggest that there is potential for fuel savings and reduced GHGs emissions with the use of CHP and CHP hybrid systems. Only $\mathrm{CO}_{2}$ emissions were estimated through models developed. However, DNGE and HHPDE emissions also include other products regulated pollutants. These include $\mathrm{CO}, \mathrm{HC}, \mathrm{PM}, \mathrm{NO}_{\mathrm{x}}$, and other GHGs such as $\mathrm{CH}_{4}$. 
A model for each engine type can be constructed based on data utilized in this project. Controlled emissions could be estimated to understand the system's impact on regulated emissions. Moreover, previously recorded emissions data from these engines could be used to build an emissions model.

Another critical aspect that has not been approached in this research is the E-HEX exhaust emissions. Temperature drops may affect the chemical composition of exhaust gases when passing through the E-HEX. Suppose the WHR system on-site validation step is taken. In that case, emissions sensors could be instrumented into the exchangers' exhaust for comparison to the engine's emissions with no CHP system to evaluate its impact.

\subsection{Heat and Power Hybrid Energy Management System Integration}

The power plant (composed of the three HHPDEs or DNGEs) operates using its own control system, independent from the rig's control system. The rig control system uses engine load data to prevent overload requests. However, the power plant does not receive a demand signal from the rig control system. Rather, the gensets operate on a closed-loop system that uses voltage and frequency to recognize adequate load to meet power demand. Since there is no stored energy, the gensets must increase or decrease load in an attempt to match the amount of power that the rig requires. When the system is balanced at $60 \mathrm{~Hz}$ and $600 \mathrm{~V}$, power production matches rig demand [13]. The total power demand is evenly divided across all the online gensets. Having an excess number of gensets online to be able to handle potential spikes in power demand results in a lower average load on each engine, causing them to operate at lower efficiency and produce higher brake specific emissions. Engines remain online and running when fewer engines could meet power demand because each genset takes several minutes to start up. The gensets need time to warm up and synchronize to the CAN bus. Genset warmup time is a critical consideration in automating engine start and stop decisions while avoiding power limits that interfere with rig operations [13].

The boiler is not equipped with a control unit system; therefore, the rig's crew is responsible for turning heaters on and off, and the boiler adjusts to the demand accordingly. An automated control system for the boiler could be developed to provide enough heat based on the weather without human intervention. Current technology allows accurate weather prediction in all locations to autoadjust heat supply and predict future demands. A smart control could be developed, allowing communication with weather report websites for predicted heat demand. 
The hybrid system advantage is its control system, allowing the engines to run in a more efficient load, reducing the required number of in-use engines while maintaining the capability to meet unpredictable spikes in power demand. The CHP hybrid integrated control system could consider both heat and power demands to increase the UF by adjusting engine load to produce enough power for the rig and its accessories while outputting enough heat through its exhaust to substitute the boiler's use more effectively. Such an integrated control system could be developed in MATLAB ${ }^{\circledR}$ and run on the already developed SIMULINK models. However, more boiler activity data would be needed to develop a more robust heat demand model as a function of ambient temperature that includes colder scenarios.

\subsection{Waste Heat Recovery Analysis on Gas Turbine Powered Rigs}

With continuous efforts of the industry to reduce diesel dependency, natural gas-powered drilling rigs could be an alternative for cheaper power generation on-site. In 2017, Siemens developed the SGT-A35 RB gas turbine for the oil and gas industry. The smallest current available gas turbine designed by Siemens for the oil and gas industry is the DGT-A05. Table 34 shows basic performance data published by the manufacturer.

Table 34. Siemens SGT-A05 [61]

\begin{tabular}{cc}
\hline \hline Parameter & DGT-A05 \\
\hline Gross Output & $4 \mathrm{MW}$ \\
Functionality & $50 / 60 \mathrm{~Hz}$ \\
Heat Rate & $12,137 \mathrm{~kJ} / \mathrm{kWh}$ \\
Gross Efficiency & $29.7 \%$ \\
Shaft Speed & $14,200 \mathrm{rpm}$ \\
Pressure Ratio & 10.3 \\
Exhaust Mass Flow & $15.4 \mathrm{~kg} / \mathrm{s}$ \\
Exhaust Temperature & $560^{\circ} \mathrm{C}$ \\
\hline
\end{tabular}

Using data provided by the manufacturer and using the same fuel composition assumptions used for the previous analysis, a simple SIMULINK model was developed to estimate potential heat rejection. A CHP system minimum effectiveness to recover heat demands for the four cycles analyzed in this paper was analyzed. Figure 60 shows the gas turbine rig powered SIMULINK model developed for estimating feasibility of turbine driven power generation on well development. 


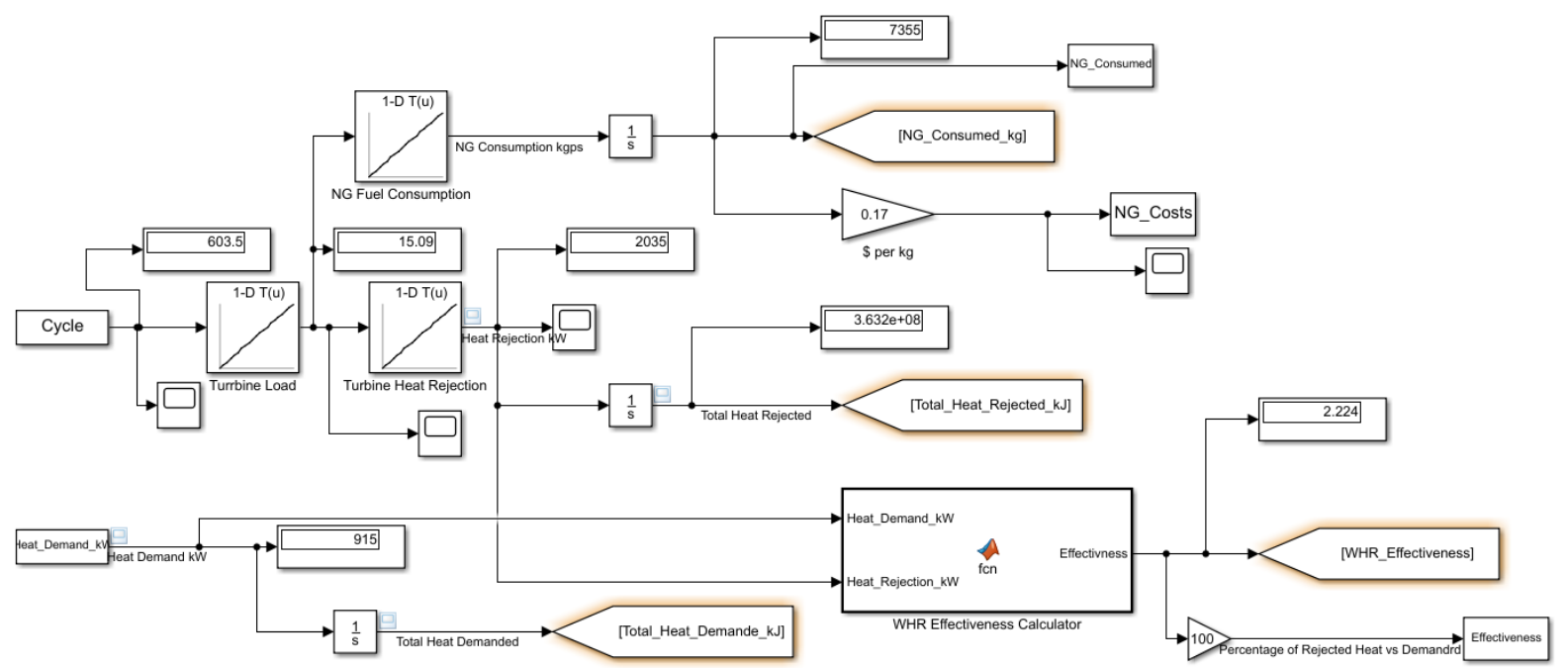

Figure 60. Gas Turbine Powered Drilling Rig SIMULINK Model

After running the four cycles on this model I was found that:

On average the $436.2 \%$ of the demanded heat is rejected by the turbine.

Minimum WHR system effectiveness should always be $58.5 \%$ to exceed instant heat demand for the four cycles. Considering the potential expansion of the gas turbine power generation on the natural gas development industry, a more advanced model based on recorded turbine activity data could be developed as my CHP findings could be combined with gas turbines for further energy savings. 


\section{References}

[1] Energy Information Administration, "eia.gov," 30 October 2020. [Online]. Available: https://www.eia.gov/dnav/ng/hist/n9010us2A.htm. [Accessed 23 November 2020].

[2] P. Kulkarni, "Gas-driven hydraulic fracturing and drilling cut costs, reduce environmental impact," 2013. [Online]. Available:

http://www.gasprocessingnews.com/features/201307/gas-driven-hydraulic-fracturing-anddrilling-cut-costs,-reduce-environmental-impact.aspx. [Accessed 9 March 2021].

[3] J. Mouawad, "Estimate Places Natural Gas Reserves 35\% Higher," 17 June 2009. [Online]. Available: https://www.nytimes.com/2009/06/18/business/energyenvironment/18gas.html. [Accessed 2311 2020].

[4] Energy Information Administration, "eia.gov," 18 December 2019. [Online]. Available: https://www.eia.gov/energyexplained/natural-gas/how-much-gas-is-left.php. [Accessed 23 November 2020].

[5] Energy Information Administration, "eia.gov," 30 October 2020. [Online]. Available: https://www.eia.gov/dnav/ng/hist/n9010us2A.htm. [Accessed 23 November 2020].

[6] Energy Information Administration, "eia.gov," 4 February 2020. [Online]. Available: https://www.eia.gov/tools/faqs/faq.php?id=58\&t=8. [Accessed 23 November 2020].

[7] U.S. Energy Information Administration, "Natural Gas Explained: Where our natural gas comes from," U.S. Energy Information Administration, Washington, DC, 2020.

[8] J. Trieoke, "Well Completion 101 part 3: Well Stimulation," Enverus, Austin, TX, 2014.

[9] J. McFarald, "Oil and Gas Lawyer Blog," 23 July 2012. [Online]. Available: https://www.oilandgaslawyerblog.com/overview-of-shale-development/. [Accessed 23 November 2020].

[10] B. C. P. a. A. V. Richard G. Newwll, "Trophy Hunting vs. Manufacturing Energy: The price-Responsiveness of Shale Gas," Resources For The Future, Washington, DC, 2016.

[11] Eastern Research Group, "2014 Statewide Drilling Rig Emissions Inventory With Updated Trends Inventories," Texas Commission on Environmental Quality, Austin, Texas, 2015.

[12] R. H. A. N. M. D. D. O. Derek Johnson, "Estimated Emissions from the Prime-Movers of Unconventional Natural Gas Well Development Using Recently Collected In-Use Data in the United States," Environmental Science \& Technology, pp. 5499-5508, 2018. 
[13] J. D. a. V. S. C. P. S. I. Memet Bilgin and P.-U. Marcel Snijder, "World's First Hybrid Drilling Rig," Society of Petroleum Engineers, Galveston, Texas, 2020.

[14] D. Helmig, "Air Quality Impacts From Oil And Natural Gas Development In Colorado," 2020.

[15] M. R.-E. Tanja Srebornjak, "Fracking Fumes: Air Pollution From Hydraulic Fracturing Threatens Public Health And Communities," NRDC, no. BRIEF, 2014.

[16] A. Bar-Ilan, J. Grant, R. Parikh, A. Pollack, R. D. Morris and K. Sgamma, "A Comprehensive Emissions Inventory of Upstream Oil and Gas Activities in the Rocky Mountain States," in 19th Annual International Emissions Inventory Conference "Emissions Inventories-informing Emerging Issues, 2010.

[17] C. Moore, B. Zielinska, G. Petron and R. Jackson, "Air Impacts of Increased Natural Gas Acquisition, Processing, and Use: A Critical Review," Environ. Sci. Technol, vol. 48, no. 15, pp. 8349-8359, 2014.

[18] A. Litovitz, A. Curtright, S. Abramzon, N. Burger and C. Samaras, "Estimation of regional air-quality damages from Marcellus Shale natural gas extraction in Pennsylvania," Environ. Res. Lett., vol. 8, no. 1, 2013.

[19] Y. Roohani, A. Roy, J. Heo, A. Robinson and P. Adams, "Impact of natural gas development in the Marcellus and Utica shales on regional ozone and fine particulate matter levels," Atmos. Environ, vol. 155, no. 1, pp. 11-20, 2017.

[20] R. Field, J. Soltis and S. Murphy, "Air quality concerns of unconventional oil and natural gas production.," Environ. Sci. Process Impacts, vol. 16, no. 5, pp. 954-969, 2014.

[21] T. Thompson, D. Shepherd, A. Stacy, M. Barna and B. Schichtel, "Modeling to Evaluate Contribution of Oil and Gas Emissions to Air Pollution," J. Air Waste Manage. Assoc., vol. 67, no. 4, pp. 445-461, 2017.

[22] T. Vinciguerra, S. Yao, J. Dadzie, A. Chittams, T. E. S. Deskins and R. Dickerson, "Regional air quality impacts of hydraulic fracturing and shale natural gas activity: Evidence from ambient VOC observations," Atmos. Environ., vol. 110, no. 1, pp. 144-150, 2015.

[23] United States Environmental Protection Agency, "epa.gov," 22 March 2016. [Online]. Available: https://nepis.epa.gov/Exe/ZyPDF.cgi?Dockey=P100OA05.pdf. [Accessed 24 November 2020].

[24] United States Environmental Protection Agency, "epa.gov," 23 March 2016. [Online]. Available: https://nepis.epa.gov/Exe/ZyPDF.cgi?Dockey=P100OA08.pdf. [Accessed 24 November 2020]. 
[25] Y. L. A. S. Elliot Woolley, "Industrial waste heat recovery: A systematic approach," Sustainable Energy Technologies and Assessments, vol. 29, pp. 50-59, 2018.

[26] A. G. O. Hussam Jouhara, "Industrial waste heat recovery," Energy, vol. 160, pp. 1-2, 2018.

[27] A. J. M. A. R. R. M. W. L.S. Hewawasam, "Waste heat recovery from thermo-electric generators (TEGs)," Energy Reports, vol. 6, no. 2, pp. 474-479, 2020.

[28] H. Jääskeläinen, "DieselNet," 19 December 2019. [Online]. Available: https://dieselnet.com/tech/engine_whr.php. [Accessed 28 Novemeber 2020].

[29] S. B. Shekj Nisar Hossain, "Waste heat recovery from exhaust of a diesel generator set using organic fluids," Procedia Engineering, vol. 90, pp. 439-444, 2014.

[30] e. a. Ho Teng, "Waste Heat Recovery of Heavy-Duty Diesel Engines by Organic Rankine Cycle Part 1: Hybrid Energy System of Diesel and Rankine Engines," SAE Technical Paper, 2007.

[31] CAIN Industries, "Cain," Cain Industries, 28 November 2020. [Online]. Available: http://www.cainind.com/cogeneration-systems.html. [Accessed 28 November 2020].

[32] 3512C Generator Set CAT Engine Specifications. [Performance]. CATERPILLAR, 2013.

[33] Waukesha L7044GSI Specifications. [Performance]. Waukesha, 2010.

[34] M. K. S. Steohenraj. V, "Design and Analysis of Heat Exchanger for Maximum Heat Transfer Rate (Multi Model Optimization Technique)," International Research Journal of Engineering and Technology (IRJET), vol. 5, no. 1, pp. 1421-1426, 2018.

[35] United States Environmental Protection Agency, "epa.gov," December 2012. [Online]. Available: https://www.epa.gov/diesel-fuel-standards/diesel-fuel-standards-andrulemakings\#nonroad-diesel. [Accessed 25 November 2020].

[36] American Boiler Manufacturers Association, "abma.com," [Online]. Available: https://www.abma.com/boiler101\#: :text=Boilers \%20are $\% 20$ used $\% 20$ to $\% 20$ produce,or $\% 20$ from $\% 20$ process $\% 20$ waste $\% 20$ heat.. [Accessed 25 November 2020].

[37] I. Hurst Boiler and Welding Company, Writer, HURST Series 300. [Performance]. Boiler, 2014.

[38] Patterson UTI Drilling, "How much steam does your rig use?," Patterson UTI. 
[39] Bureau of Transportation Statistics, "bts.gov," 5 May 2020. [Online]. Available: https://www.bts.gov/content/gasoline-hybrid-and-electric-vehicle-sales. [Accessed 25 November 2020].

[40] Cummins, "cummins.com," Cummins, [Online]. Available: https://www.cummins.com/electrification/powerdrive-for-electrictrucks\#: :text=The\%20Cummins\%20PowerDrive \%20is\%20an,economics\%20in\%20any $\% 20$ driving\%20situation.. [Accessed 25 November 2020].

[41] Y.-L. W. P.-F. C. M.-C. L. Chao Zhang, "Energy storage system: Current studies on batteries and power condition system," Renewable and Sustainable Energy Reviews, vol. 82, pp. 3091-3106, 2018.

[42] PATTERSON-UTI Drilling Company, LLC, "ECO-CELL."

[43] B. Jabeck, "THE IMPACT OF GENERATOR SET UNDERLOADING," ELECTRIC POWER, Caterpillar Inc, 2014.

[44] CSS Electronics, "CAN ID to J1939 PGN converter," CSS Electronics, [Online]. Available: https://docs.google.com/spreadsheets/d/10f7TFU9oViSQZYGFYVPDia2w1hd5eOPMlgJXmx31Lg/edit?ts=5dffd440\#gid=113091809 2. [Accessed 20 November 2019].

[45] kRAL, "Flowmeters. Highly accurate and robust.," [Online]. Available: https://www.kral.at/fileadmin/data/files/products/KRAL_Flowmeters_Display_and_Proce ssing_Unit.pdf. [Accessed 15 February 2021].

[46] e. a. Derek R. Johnson, "Greenhouse Gas Emissions And Fuel Efficiency Of In-Use High Horsepower Diesel, Dual Fuel, And Natural Gas Engines For Unconventional Well Development," Applied Engineering, vol. 206, no. 0306-2619, pp. 739-750, 2017.

[47] OMEGA, "Revised Thermocouple Reference Tables," [Online]. Available: https://assets.omega.com/resources/thermocouple-ref-tables-k-f.pdf. [Accessed 2104 2021].

[48] W. A. Majewski, "DieselNet," August 2012. [Online]. Available: https://dieselnet.com/tech/emi_intro.php\#: :text=Diesel\%20fuel\%20is\%20a\%20mixture,p ortion\%20of\%20engine\%20charge\%20air.. [Accessed 15 February 2021].

[49] M. A. B. Yunus A. Cengel, Thermodynamics An Engineering Approach, McGraw-Hill Publishing, 2002.

[50] Chemstations, "CHEMCAD Version 7 User Guide," Chemstations, Inc., 2016. 
[51] Tubular Exchanger Manufacturers Association, "Standards of the Tubular Exchanger Manufacturers Association," TUBULAR EXCHANGER MANUFACTURERS ASSOCIATION, INC, Tarrytown, New York 10591, 2007.

[52] L. O. V. a. M. I. Shoesmith, "The Effect Of PHEV And HEV Duty Cycles On Battery And Battery Pack Performance," in Plug-in Highway Electric Vehicle Conference, Canada, 2007.

[53] Energy Information Administration, "Petroleum \& Other Liquids," 22 February 2021. [Online]. Available: https://www.eia.gov/petroleum/gasdiesel/. [Accessed 24 February 2021].

[54] U.S. Energy Information Administration, "Natural Gas Prices," 291 2021. [Online]. Available: https://www.eia.gov/dnav/ng/ng_pri_sum_dcu_nus_m.htm. [Accessed 202124 2].

[55] U.S. Energy Information Administration, "Heat Content of Natural Gas Consumed," 29 January 2021. [Online]. Available:

https://www.eia.gov/dnav/ng/ng_cons_heat_a_EPG0_VGTH_btucf_a.htm. [Accessed 2021 February 2021].

[56] Energy Information Administration, "Utility-scale battery storage costs decreased nearly 70\% between 2015 and 2018," October 2020. [Online]. Available: https://www.eia.gov/todayinenergy/detail.php?id=45596. [Accessed 25 February 2021].

[57] Engineering ToolBox, "Engineering ToolBox," 2003. [Online]. Available: https://www.engineeringtoolbox.com/fuels-higher-calorific-values-d_169.html. [Accessed 17 February 2021].

[58] CATERPILLAR, "G3500 INDUSTRIAL ENGINE PERFORMANCE," CATERPILLAR ENGINE DIVISION, 2000.

[59] M. S. V. Wissenkerke, "Reducing the Environmental Impact of Drilling Operations with Energy Storage," IADC Conferences, pp. 1-14, 2020.

[60] EPA, "Target Setting," [Online]. Available: https://www.epa.gov/climateleadership/targetsetting. [Accessed 9 March 2021].

[61] "SGT-100: Industrial Gas Turbine: Gas Turbines: Manufacturer: Siemens Energy Global," siemens. [Online]. Available: https://www.siemens-energy.com/global/en/offerings/powergeneration/gas-turbines/sgt-100.html. [Accessed: 15-Jun-2021]. 


\section{Appendices}

\subsection{Appendix A: KRAL OEM 20 calibration test.}

KRAL OEM 20 calibration test results obtained at WVU's engine laboratory

\begin{tabular}{|l|r|r|r|r|r|r|}
\hline & \multicolumn{3}{|c|}{ Test 1 } & \multicolumn{3}{c|}{ Test 2 } \\
\hline & Flowmeter A & Flowmeter B & \multicolumn{1}{|c|}{ Scale } & Flowmeter A & Flowmeter B & Scale \\
\hline Average Flow (L/hr) & 485.326 & 484.558 & & 513.468 & 512.577 & \\
\hline Average Flow (L/s) & 0.135 & 0.135 & & 0.143 & 0.142 & 99.000 \\
\hline Time (s) & & & 99.600 & & & 11.612 \\
\hline Mass (kg) & & & 10.932 & & & 13.842 \\
\hline Volume (L) & 13.427 & 13.406 & 13.031 & 14.120 & 14.096 & 1.835 \\
\hline Percent Error (\%) & 3.043 & 2.880 & & 2.012 & \\
\hline
\end{tabular}

\subsection{Appendix B: MATLAB® Codes}

The scripts shown in this section were used for data importation and model development of engine performance.

\section{Natural Gas Fuel Consumption Model Script}

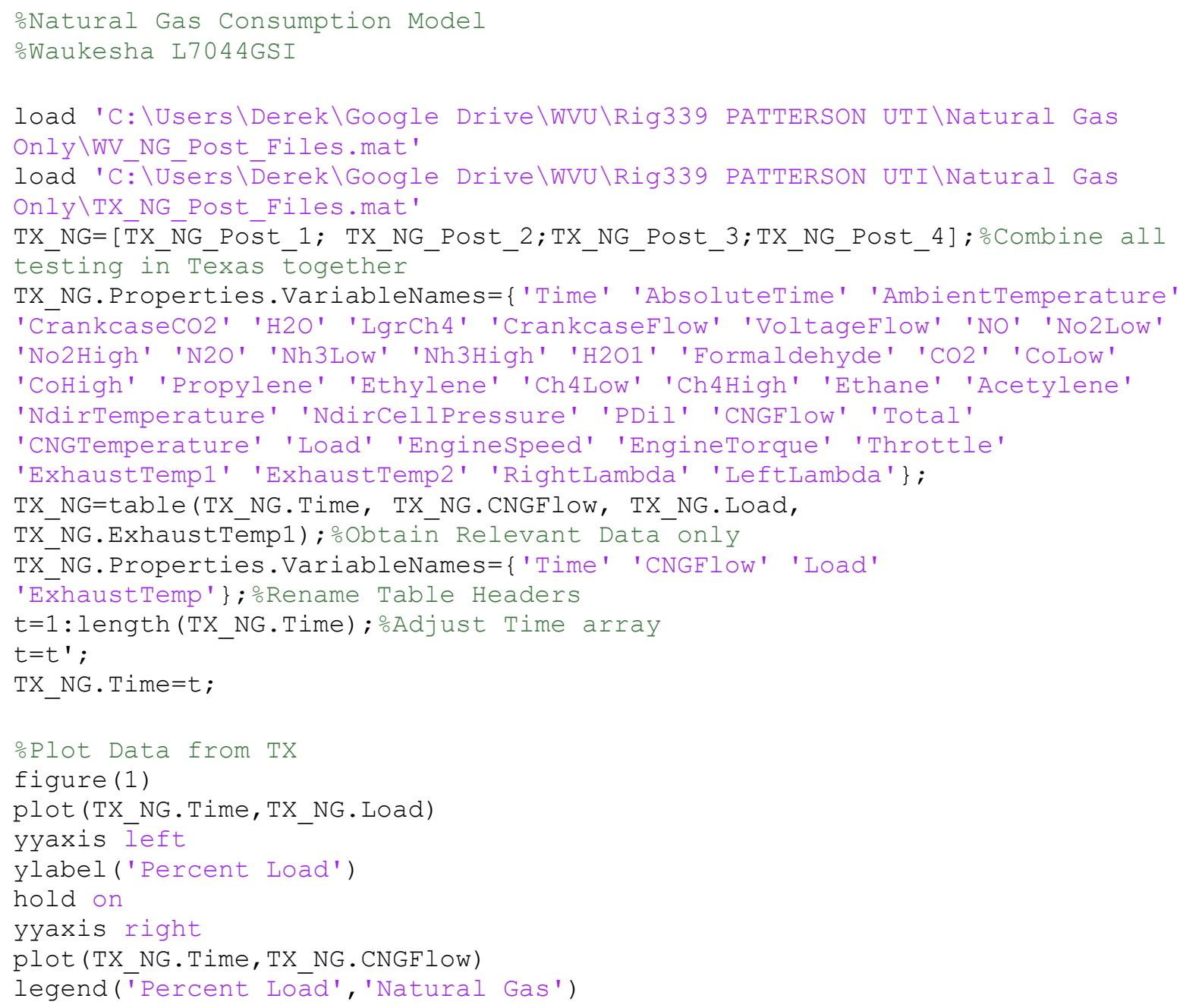




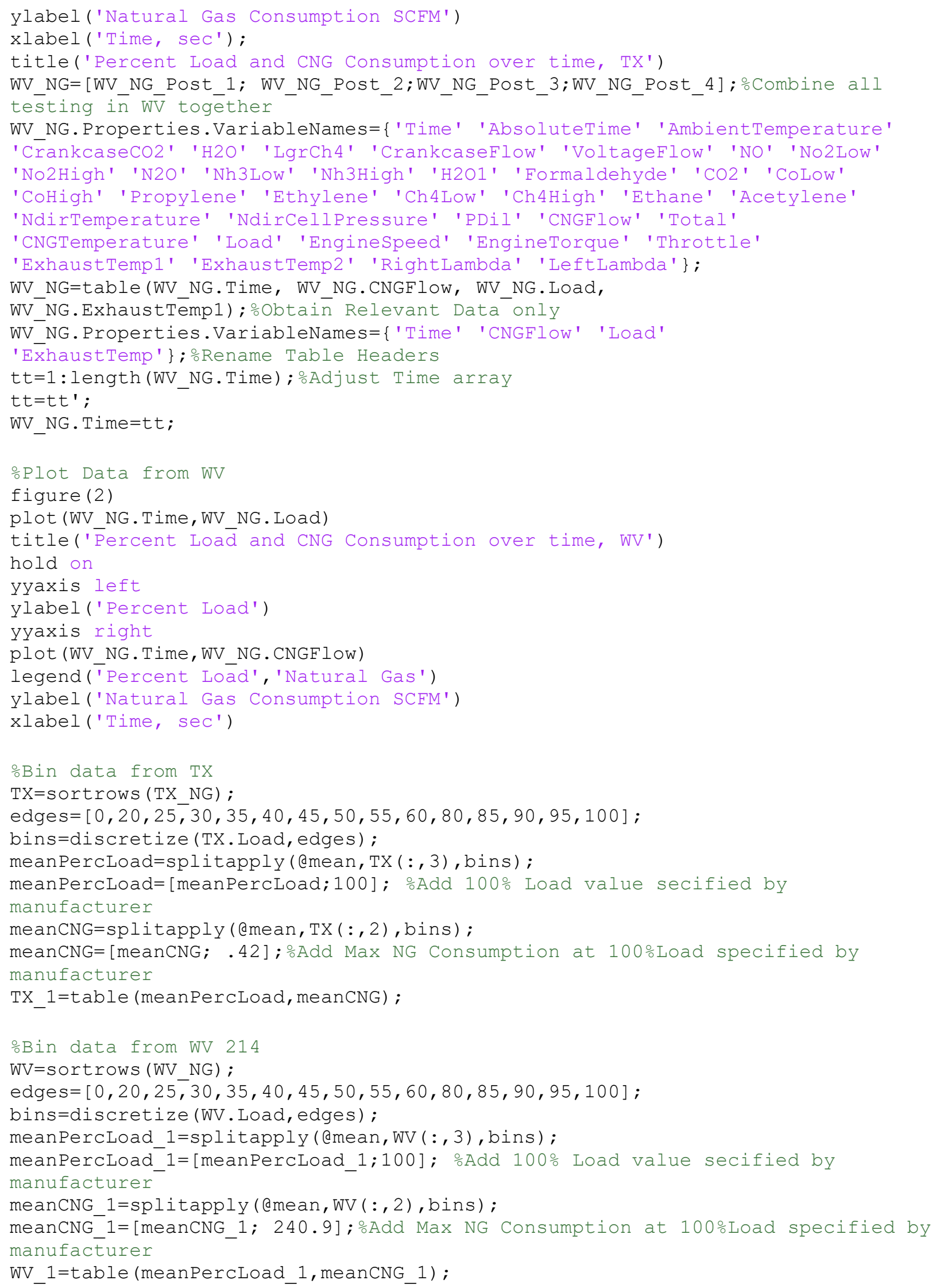




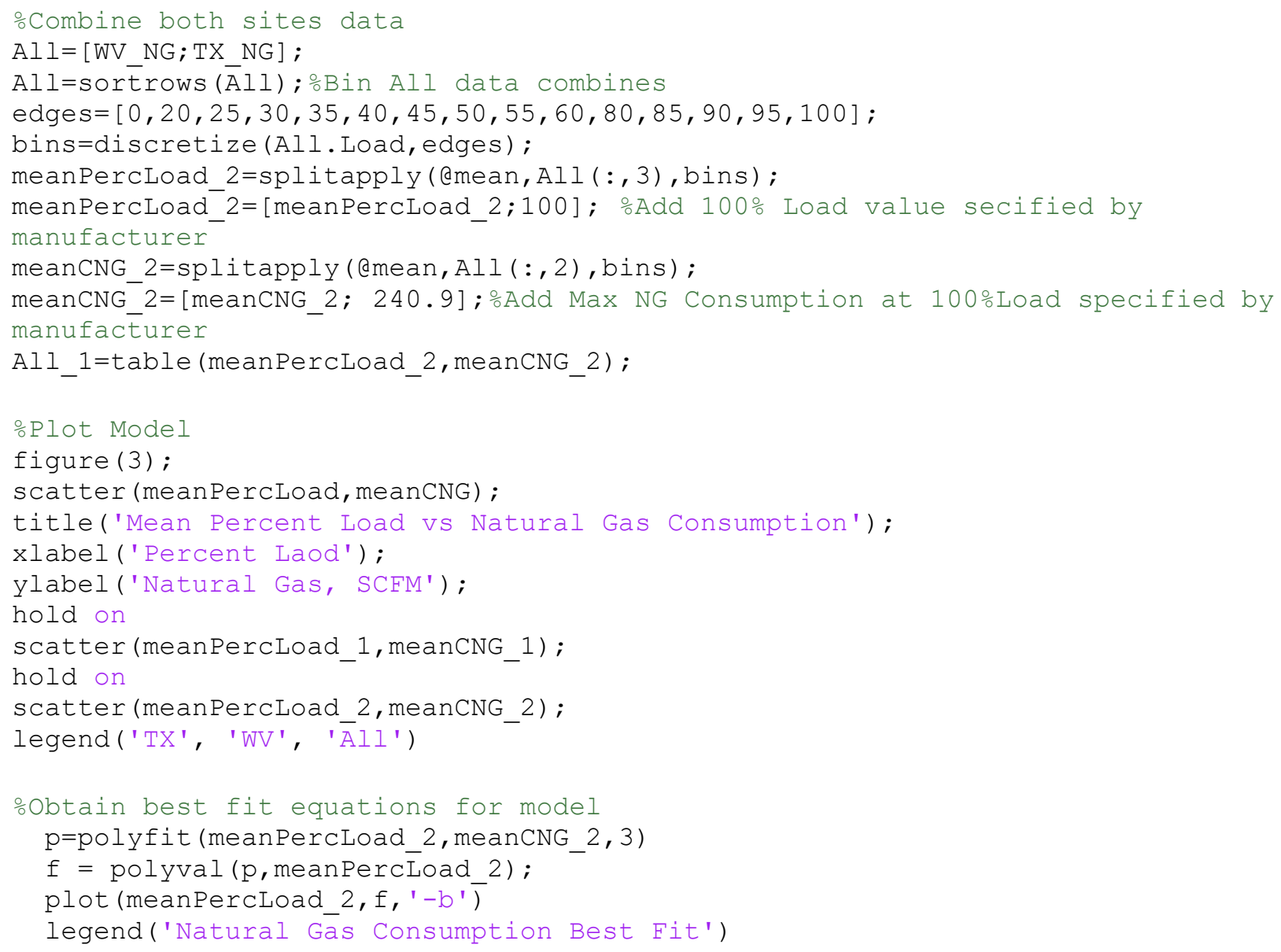




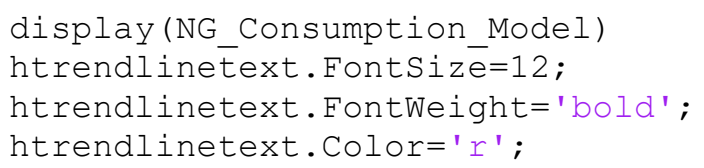

\section{Natural Gas Engine Exhaust Temperature Model}

oWaukeshaL7044GSIEPA Exhaust Heat Rejection Model

Diego Dranuta

$\div 11 / 3 / 2020$

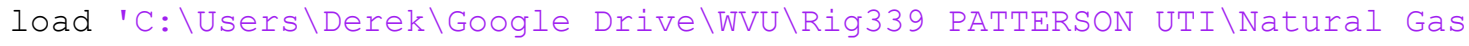

Only\WV_NG_Post_Files.mat'

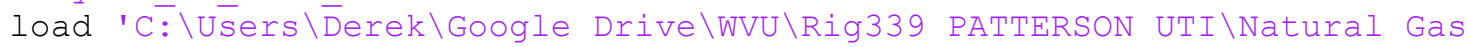

Only $\backslash T X$ NG Post Files.mat'

TX_NG=[TX_NG_Post_1; TX_NG_Post_2;TX_NG_Post_3; TX_NG_Post_4] ;

$t=\overline{1}:$ lengt $\bar{h}\left(T \bar{X} \_N G . \bar{T} i m e\right) ;$

$\mathrm{t}=\mathrm{t}^{\prime}$;

TX NG.Time=t;

figure (1)

plot (TX_NG.Time, TX_NG.Load)

figure $(\overline{2})$

plot (TX_NG.Time, TX_NG.ExhaustTemp1)

WV_NG $=\left[\bar{W} V \_N G \_P o s t \_\overline{1} ;\right.$ WV_NG_Post_2; WV_NG_Post_3; WV_NG_Post_4 $]$;

$t \overline{-}^{-}=1$ : leng $\overline{t h}(\overline{\mathrm{W}} \mathrm{V}$ NG. Time) $\bar{i}$

tt $=$ tt' ;

WV NG. Time=tt;

figure (3)

plot (WV_NG.Time, WV_NG.Load)

figure $(\overline{4})$

plot (WV_NG.Time, WV NG.ExhaustTemp1)

oNote: Use TX DATA ONLY. WV data is TP (Transient)

TX_NG=table (smooth (TX_NG.Load, 1),

smooth ( ( TX_NG.ExhaustTemp1+TX_NG.ExhaustTemp2)./2),1));

TX NG.Properties.VariableNames=\{'Load' 'ExhaustTemp'\};

figure (5)

scatter(TX_NG.Load,TX_NG.ExhaustTemp);

All $1=$ sortrows (TX NG);

edges $=[0,10,15,20,25,30,35,40,45,50,55,60,100]$;

bins=discretize (All_1. Load, edges);

meanPercLoad=splitapply (@mean,All_1 (:, 1), bins);

meanPercLoad_1 $=[$ meanPercLoad; 100$]$;

Add 100\% Looad value

from manufacturer specs

meanExhaustTemp=splitapply (@mean,All_1 (:,2), bins) ;

meanExhaustTemp_1=[meanExhaust Temp; 637] ;

All_2=table (meanPercLoad_1, meanExhaustTemp_1);

figure (6);

scatter (meanPercLoad_1, meanExhaustTemp_1, 'or') ;

title('Mean Percent Load vs Mean Exhaust Temperature in each bin');

xlabel ('Percent Laod');

ylabel('Exhasut Temperature in $\mathrm{C}^{\prime}$ );

hold on

oobtain best fit equations for model

p=polyfit (meanPercLoad, meanExhaust Temp, 3)

$f=\operatorname{polyval}(p$, meanPercLoad);

plot (meanPercLoad, f, '-b')

legend('Dual Fuel Exhasut Temperatre Best Fit') 


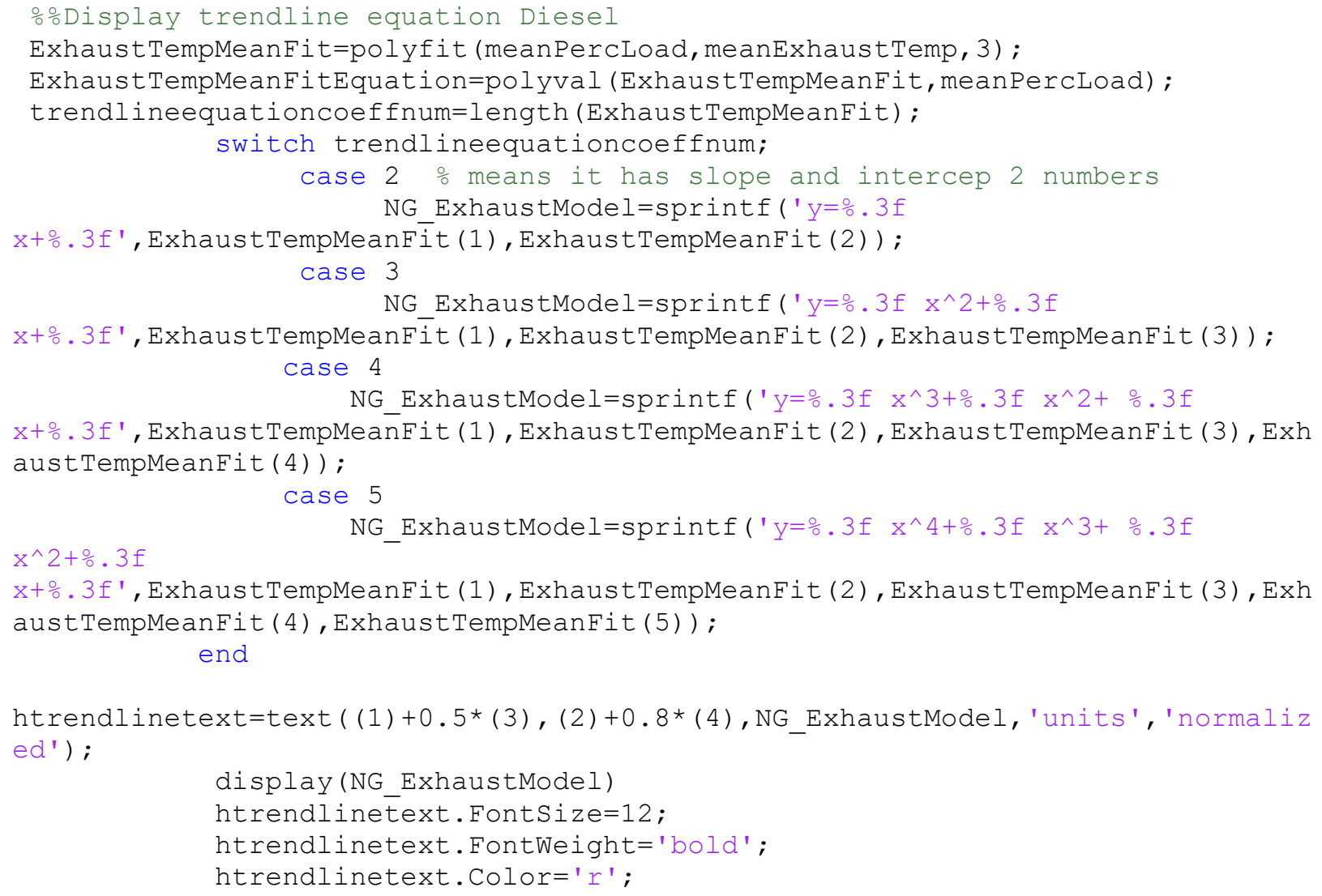

\section{CATERPILLAR 3512C Coolant Temperature Model}

oEngine Coolant Temperature Model

Diego Dranuta

\%WVU

Created on 12/16/2020

Last Updated on 12/16/2020

응응

oLoad cycles, extract percent load and coolant temperature data and cat otogether

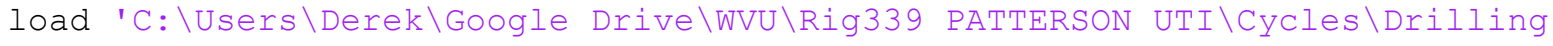
Cycle 1 hour 3 Engines Boiler 
Coolant_1_b=[emissions1.EngineCoolantTemperature]; Coolant ${ }^{-}-\mathrm{b}=$ zeros $(36000,1)$;

Engine_2 $\mathrm{b}$ PercentLoad=[emissions2.EnginePercentLoadAtCurrent Speed]; Coolant $\overline{2} \bar{b}=$ [emissions2.EngineCoolantTemperature];

Engine_ $\overline{3}$ b_ PercentLoad=[emissions3. EnginePercentLoadAtCurrentspeed] ;

Coolant_ $\overline{3}$ _b $=$ [emissions3.EngineCoolantTemperature ];

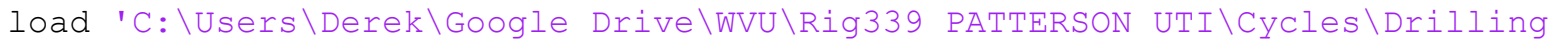
Cycle 24 hours Boiler

On \Drilling_Cycle_24_hours_3_Engines_On_20200229_From_0000am_to_0000am_Boiler on.mat'

Engine_1_c_PercentLoad=[emissions1.EnginePercentLoadAtCurrentSpeed];

Coolant $\overline{1}-\bar{c}=[$ emissions1.EngineCoolantTemperature];

Engine $\overline{2} \bar{c}$ PercentLoad=[emissions2. EnginePercentLoadAtCurrentspeed];

Coolant $\overline{2} \bar{c}=[$ emissions2. EngineCoolantTemperature];

Engine_ $\overline{3}$ c PercentLoad=[emissions3. EnginePercentLoadAtCurrentSpeed] ;

Coolant_ $\overline{3} \_\bar{c}=[$ emissions3.EngineCoolantTemperature ];

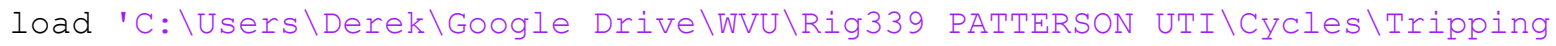

Pipe 1

hour \TP Cycle 1 Hour 3 Engines on 20200229 From 1631 to 1731 Boiler on.mat'

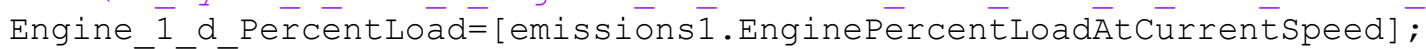

Coolant $\overline{1}-\bar{d}=$ [emissions1.EngineCoolantTemperature];

Engine_$\overline{2}$ _

Coolant $\overline{2}, \bar{d}=[$ emissions2. EngineCoolantTemperature];

Engine_ $\overline{3}$ d__PercentLoad=[emissions3. EnginePercentLoadAtCurrentspeed];

Coolant_ $\overline{3} \_\bar{d}=[$ emissions3.EngineCoolantTemperature ];

Engine_Percent_Load_1=[Engine_1_a_PercentLoad; Engine_1_b_PercentLoad; Engine_1_c_PercentLoad; Engine $\overline{1}$ - d PercentLoad];

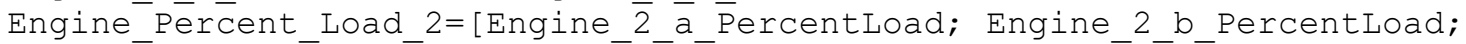

Engine_2_c_PercentLōad; Engine_z $\overline{2}$ d

Engine_Percent_Load_3=[Engine_3_a_PercentLoad; Engine_3_b_PercentLoad;

Engine_3_c_PercentLōad; Engine $\overline{3}$ _ d

Coolant_ $\overline{1}=\overline{[}$ Coolant_1_a; Coolant_$\overline{1} \_\bar{b}$; Coolant_1_c; Coolant_1_d] ;

Coolant 1 (isnan (Coōlānt 1)) =0;

Coolant_2=[Coolant_2_a; Coolant_2_b; Coolant_2_c; Coolant_2_d] ;

Coolant 2 (isnan (Coolant_2)) =0 ;

Coolant_3=[Coolant_3_a; Coolant_3_b; Coolant_3_c; Coolant_3_d] ;

Coolant_3(isnan (Coolant_3)) =0 ;

Engine_1=table (Engine_Percent_Load_1, Coolant_1);

Engine_2=table (Engine_Percent_Load_2, Coolant_2);

Engine_3=table (Engine_Percent_Load_3, Coolant_3);

figure (1)

scatter(Engine_Percent_Load_1, Coolant_1);

figure (2)

scatter(Engine_Percent_Load_2, Coolant_2);

figure (3)

scatter(Engine_Percent_Load_3, Coolant_3);

$\frac{\circ}{\circ} \%$

All_1=sortrows (Engine_1); 


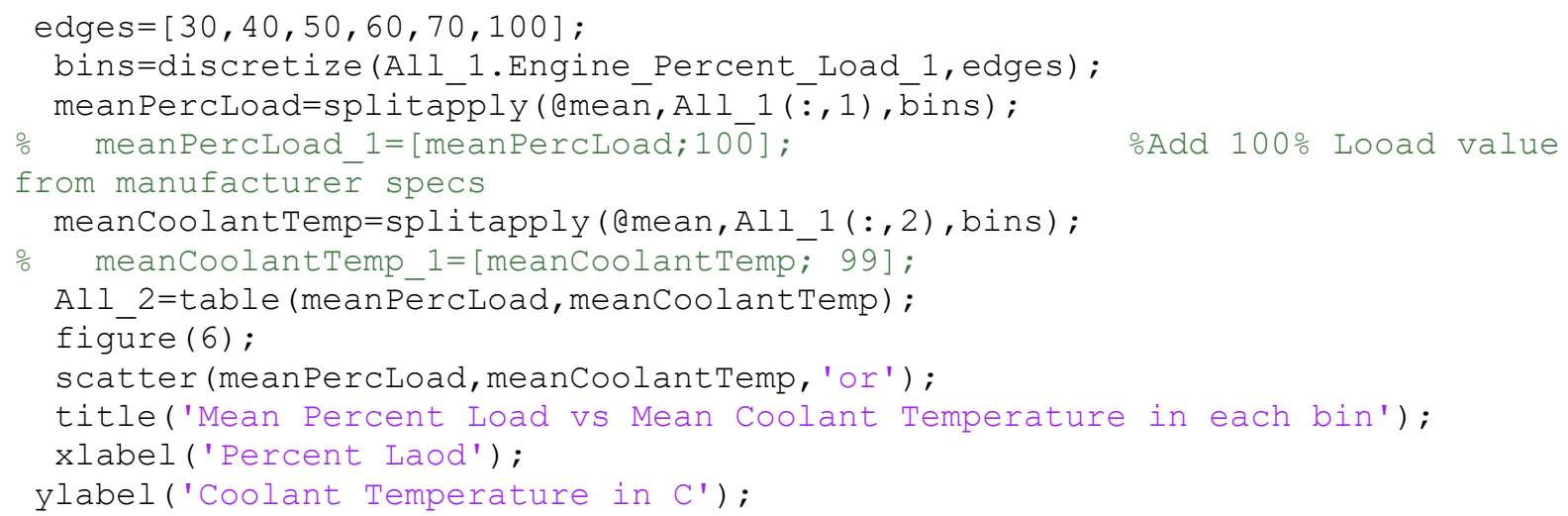

\section{HHPDE CHP Importation Script}

oscript for SimulinkWasteHeatModel

oDiego Dranuta

ㄴast Update 1/14/2021

\% Load TP Cycle

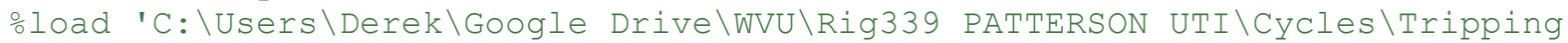

Pipe 1

hour \TP_Cycle_1_Hour_3_Engines_on_20200229_From_1631_to_1731_Boiler_on.mat'

ㄴoad Drilling 2 Engines On

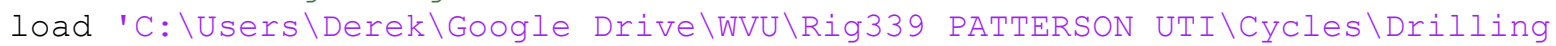
Cycle 2 engines Boiler

On \Drilling_Cycle_1_hour_2_Engines_on_20200228_From_1630pm_to_1730pm_Boiler_o n.mat'

Load Drilling 3 Engines On

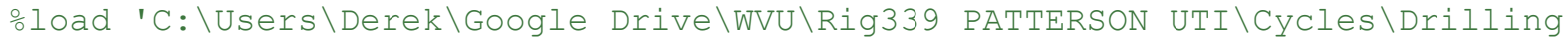
Cycle 1 hour 3 Engines Boiler

On \Drilling_Cycle_1_hour_3_Engines_on_20200229_From_0300_to_0400_Boiler_on.ma $t^{\prime}$

\% Load 24 Hours Cycle

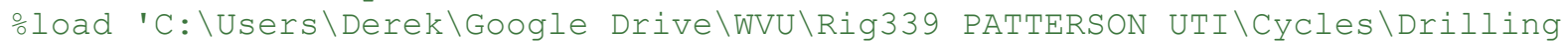
Cycle 24 hours Boiler

On \Drilling_Cycle_24_hours_3_Engines_On_20200229_From_0000am_to_0000am_Boiler -on.mat'

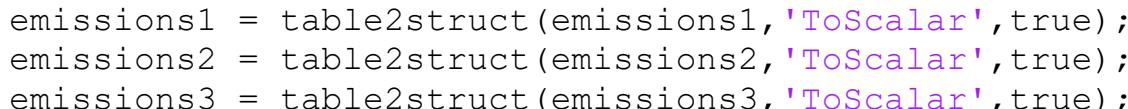

TimeLength1=(emissions1.Time (end, 1)-emissions1.Time $(1,1)$ )

oLoad Tables and correlations

load 'C: \Users \Derek\Desktop \DataCollection \Needed Files (Not Including

Exhaust Model) \TempKvsCpKjpermolK.mat'

KvsCp=table2struct (TempKvsCpKjpermolK, 'ToScalar', true); 


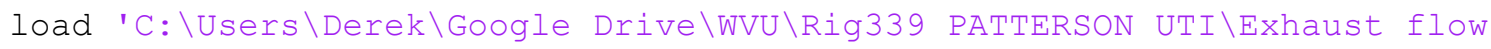
model \Simulink\Exhaust Mass Flow Rate.mat'

Exhaust Mass_Flow Compositiōn_H2 $\overline{\mathrm{O}}=$ table2struct (Superheated_Vapor_Mass_Flow_Ra te_From_Load,' 'To $\bar{S} c a l a r '$, true) ;

Exhaust_Mass_Flow_Composition_Air=table2struct(Air_Mass_Flow_Rate_From_Load, 'Toscalār', Ërue) $\overline{\text {; }}$

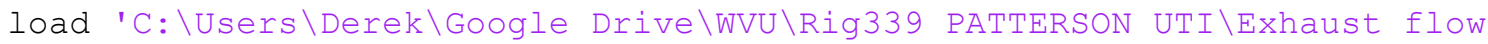
model\Simulink \Superheated_Water_Specific_Enthalpy.mat'

Superheated_Water_Propertiés=table2struct (SuperheatedWaterSpecificEnthalpyTab le, 'Toscalar', trūe);

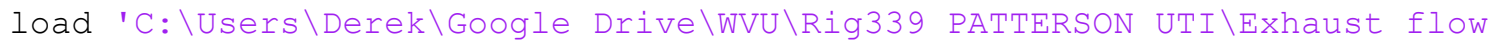
model \Simulink\Cp_Air_K.mat'

CpAirk=table2struct (C̄̄Airk, 'ToScalar', true);

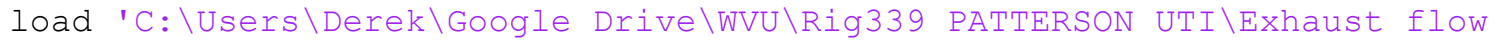
model\Simulink\Ideal_Gas_Properties.mat'

Ideal_Gas_Properties=table2struct (IdealGasPropertiesofgas, 'ToScalar', true) ;

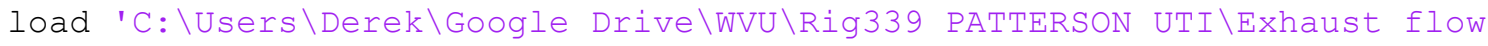
model \Simulink\Cp_Superheated_Steam.mat'

Cp_superheated_Stēam=table2st̄̄uct (CpSuperheatedSteam, 'ToScalar', true) ;

load 'C: \Users \Derek\Desktop \DataCollection \Needed Files (Not Including

Exhaust Model) \TempInCelciousVsGramsPerL.mat'

CvsGramsPerLiter=table2struct (TempInCelciousVsGramsPerL, 'ToScalar', true) ;

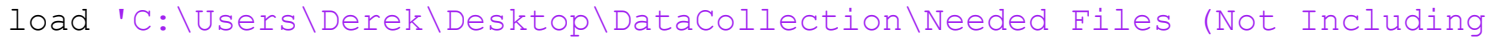

Exhaust Model) \Temperature_K_vs_Cp_Kg_KgK.mat'

KvsCpKjperKgK=table2struct (TémpératureKvsCpKgKgK, 'ToScalar', true);

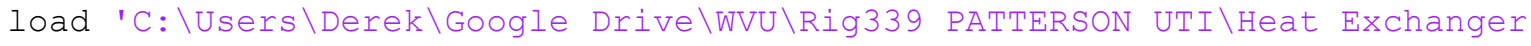
Design and Files\HEX December 2020 Design\HEX_Performance.mat'

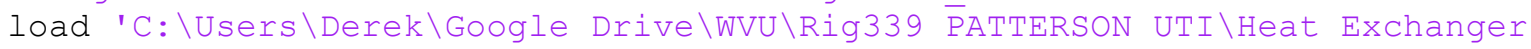
Design and Files \HEX December 2020 Design\HEX Water Mass_Flow_Rate_kgphr.mat'

\%Load CAIN HEX Performance

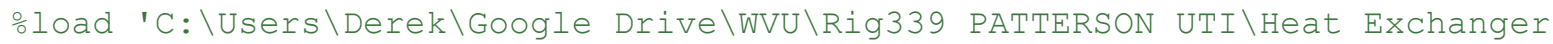
Design and Files\CAIN\ESG1_1_Performance.mat'

load 'C: \Users \Derek\Google $\bar{D} r i v e \backslash W V U \backslash R i g 339$ PATTERSON UTI \Heat Exchanger Design and Files \CAIN $\backslash$ ESG1 2 W EConomizer.mat'

CAIN_Performance=table2struct (ESG1_2_W_Economizer, 'ToScalar', true);

Load JW HEX

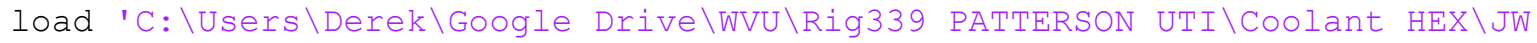
MODEL \JW HEX.mat'

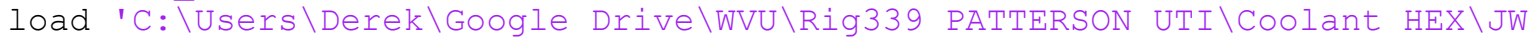
MODEL \JW_Heat_Rejection_Model.mat' 
JW_Heat_Rejection_Model=table2struct(JW_Heat_Rejection_Model, 'ToScalar', true);

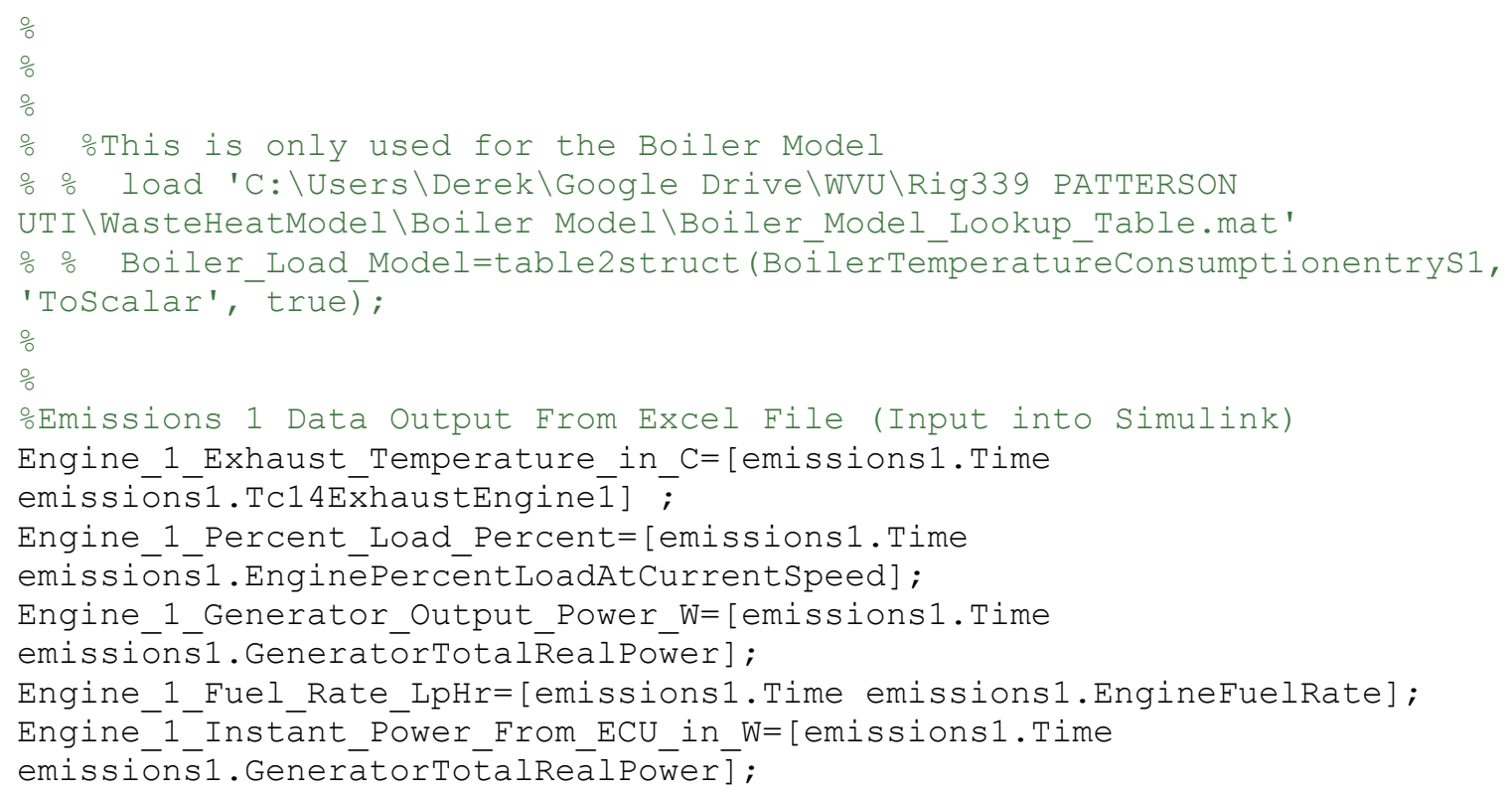


Boiler Data Output From Excel File (Input into Simulink)

Boiler Feed Lperh=[emissions1.Time emissions1.FlowmeterAFeed];

Boiler Return Lperh=[emissions1.Time emissions1.FlowmeterBReturn];

Boiler_Diesel_Feed Temperature C=[emissionsl.Time

emissions1.FlowmetēerAemperature];

Boiler_Diesel_Return_Temperature_C=[emissions1.Time

emissions1.Flowmeter $\bar{B}$ Temperature ];

Boiler Exhaust Temperature C=[emissions1.Time emissions1.Tc8Boiler];

Boiler_Daytank_Temperature_C=[emissions1.Time emissions1.Tc9Daytank];

\section{DNGE CHP Importation Script}

oThis script should be run before running

oSimulinkWasteHeatModel_NaturalGas_Dedicated

Diego Dranuta

Last Update $11 / 6 / 2020$

응 Load Tables

-Load Exhaust Temperature Model

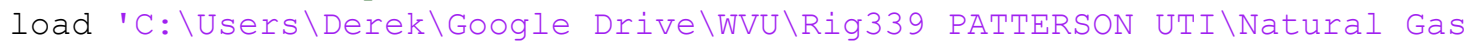
Only \Simuink\Tables For NG Simulink Model.mat'

$\%$ Load Cycles

Load 3 engines 1 Hour Cycle

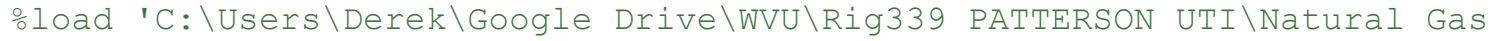

Only\Cycles\Drilling Cycle 1 hour 3 Engines Boiler

on \NG_Drilling_1_Hour_3_Engines.mat'

Load 24 Hours Cȳcle

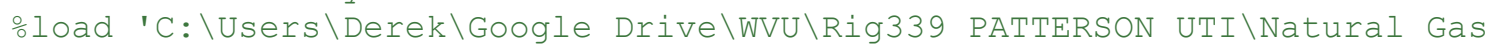

Only \Cycles $\backslash 24$ Hours Boiler On \NG_24_Hours_Cycle.mat'

oLoad 2 Engines 1 Hour Cycle

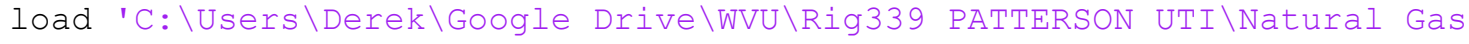

Only\Cycles\Drilling Cycle 1 hour 2 Engines Boiler

on \Drilling_Cycle_2_Engines_1_Hour.mat'

으od Generalizēed Cycle

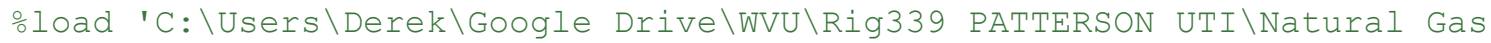

Only\Cycles \Generalized Cycle\Generalized_Cycle_Natural_Gas.mat'

\% $\frac{\circ}{\circ}$ Tad TP 1 Hour Cycle

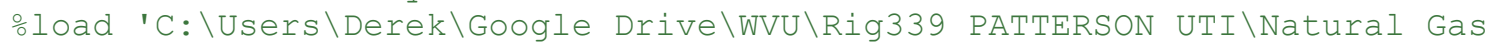

Only\Cycles \Tripping Pipe 1 Hour \NG TP 1 Hour Cycle.mat'

응 Export Simulink Inputs

Engine 1 Percent Load Percent=[Engine_1.Time Engine 1.PercentLoadWaukesha];

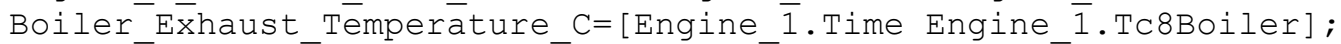

Boiler_Daytank_Temperature_C=[Engine_1.Time Engine_1.Tc9Daytank];

Boiler_Diesel_Eeed_Temperature_C=[Engine_1.Time

Engine $\overline{1}$. FlowmēterATemperature];

Boiler Diesel_Return Temperature_C=[Engine_1.Time

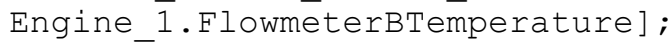

Boiler_Feed_Lperh=[Engine_1.Time Engine_1.FlowmeterAFeed];

Boiler_Return_Lperh=[Engine_1.Time Engine_1.FlowmeterBReturn];

Engine_2_Percēnt_Load_Perceñt=[Engine_2.Tīme Engine_2.PercentLoadWaukesha]; 
Engine_3_Percent_Load_Percent=[Engine_3.Time Engine_3.PercentLoadWaukesha];

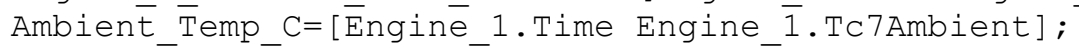

TimeLength1=Engine_1.Time (end, :)

응 Load Heat NG HEX Chart

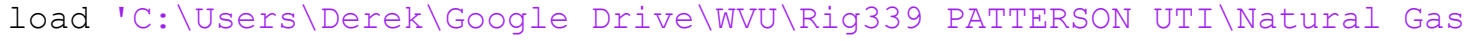

Only \Heat Exchanger Performance \HEX_NG.mat'

응 Load CAIN ESG1 Nat Gas

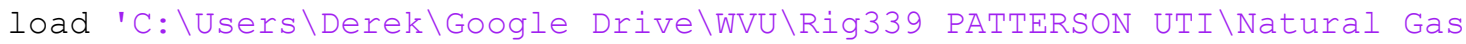

OnIY \CAIN \CAIN ESG1 Performance.mat'

CAIN_ESG1_NG=tāble2struct(CAIN_ESG1_NG_Performance, 'ToScalar', true)

응 Load Boiler Tables

load 'C: \Users \Derek\Desktop \DataCollection \Needed Files (Not Including

Exhaust Model) \TempInCelciousVsGramsPerL.mat'

CvsGramsPerLiter=table2struct (TempInCelciousVsGramsPerL, 'ToScalar', true) ;

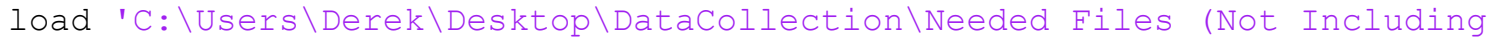

Exhaust Model) \Temperature_K_vs_Cp_Kg_KgK.mat'

KvsCpKjperKgK=table2struct (TemperätureKvsCpKgKgK, 'ToScalar', true) ;

\section{Hybrid Control Script for HHPDE CHP Hybrid System}

oHybrid System Control Design CAT3512C Diesel Engine

oThis code is meant to be used to program ECoCELL on Simulink for its most

officienct performance

응 ㄴoad Cycle

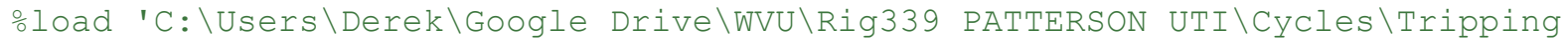

Pipe 1

hour \TP_Cycle_1_Hour_3_Engines_on_20200229_From_1631_to_1731_Boiler_on.mat'

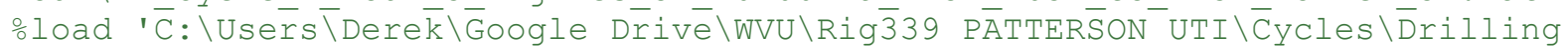

Cycle 2 engines Boiler

On \Drilling_Cycle_1_hour_2_Engines_on_20200228_From_1630pm_to_1730pm_Boiler_o

n.mat'

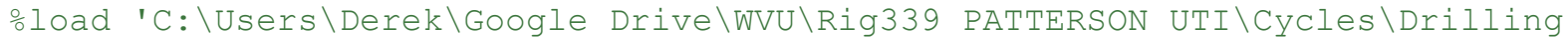

Cycle 1 hour 3 Engines Boiler

On\Drilling_Cycle_1_hour_3_Engines_on_20200229_From_0300_to_0400_Boiler_on.ma $t^{\prime}$

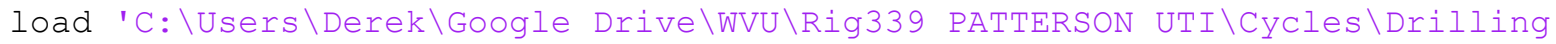

Cycle 24 hours Boiler

On\Drilling_Cycle_24_hours_3_Engines_On_20200229_From_0000am_to_0000am_Boiler on.mat'

emissions1 = table2struct (emissions1, 'ToScalar', true);

emissions2 = table2struct (emissions2,'ToScalar', true);

emissions3 = table2struct (emissions3,'ToScalar', true);

Ambient=[emissions1.Time emissions1.Tc7Ambient] ;

\% Load Load Adjustment Chart from SOC and ROC

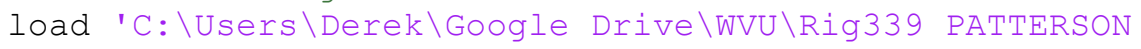

UTI \WasteHeatModel \Hybrid System\Change in Load Chart.mat'

\% Change_in_Load_Chart=table2struct ( Chänge_in_Load_Chart, 'ToScalar', true);

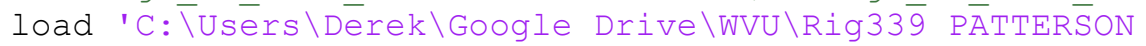

UTI \WasteHeatModel\Hybrid System\Adjustment_in_Load_Rate_of_Charge.mat' 


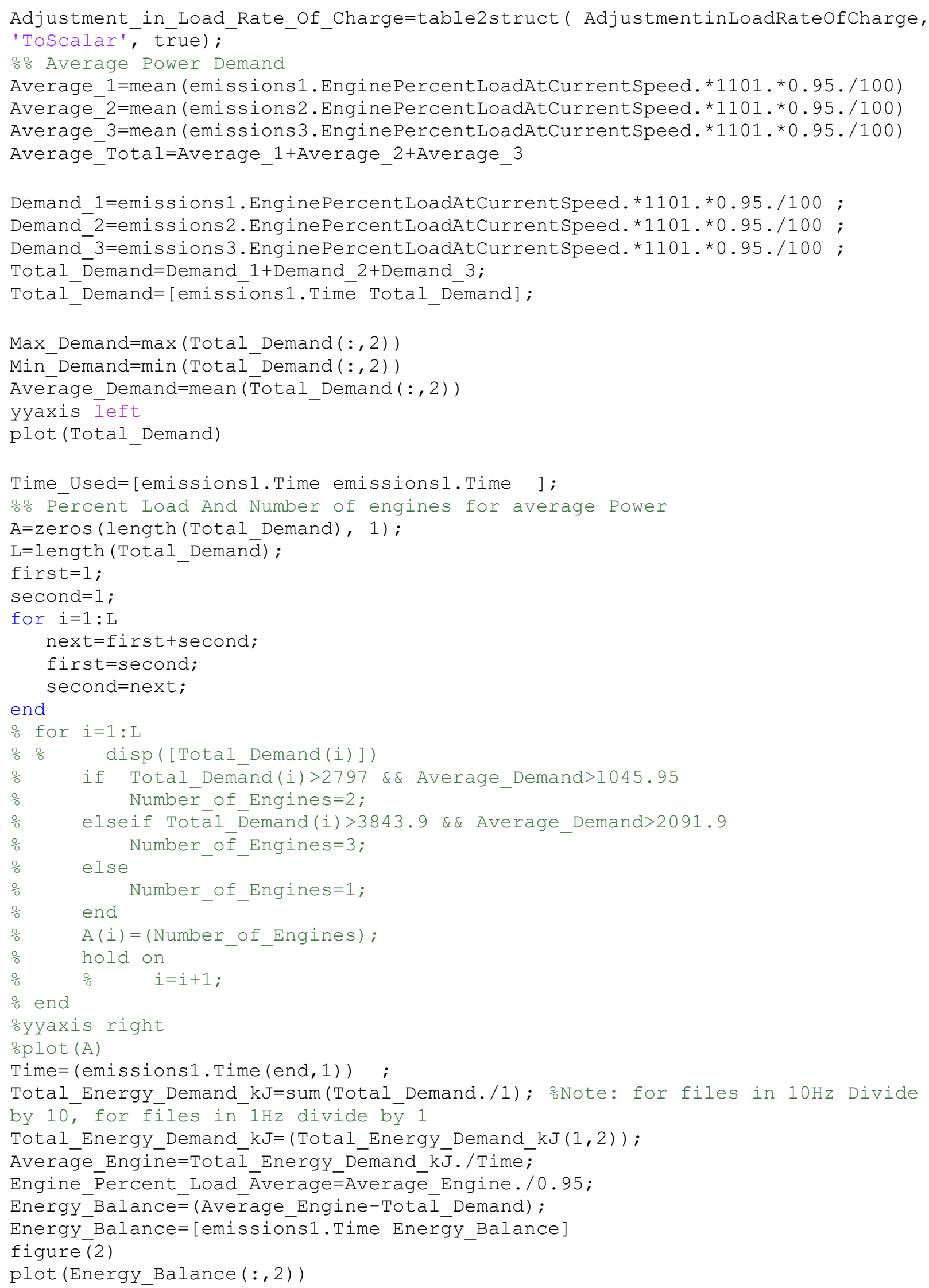




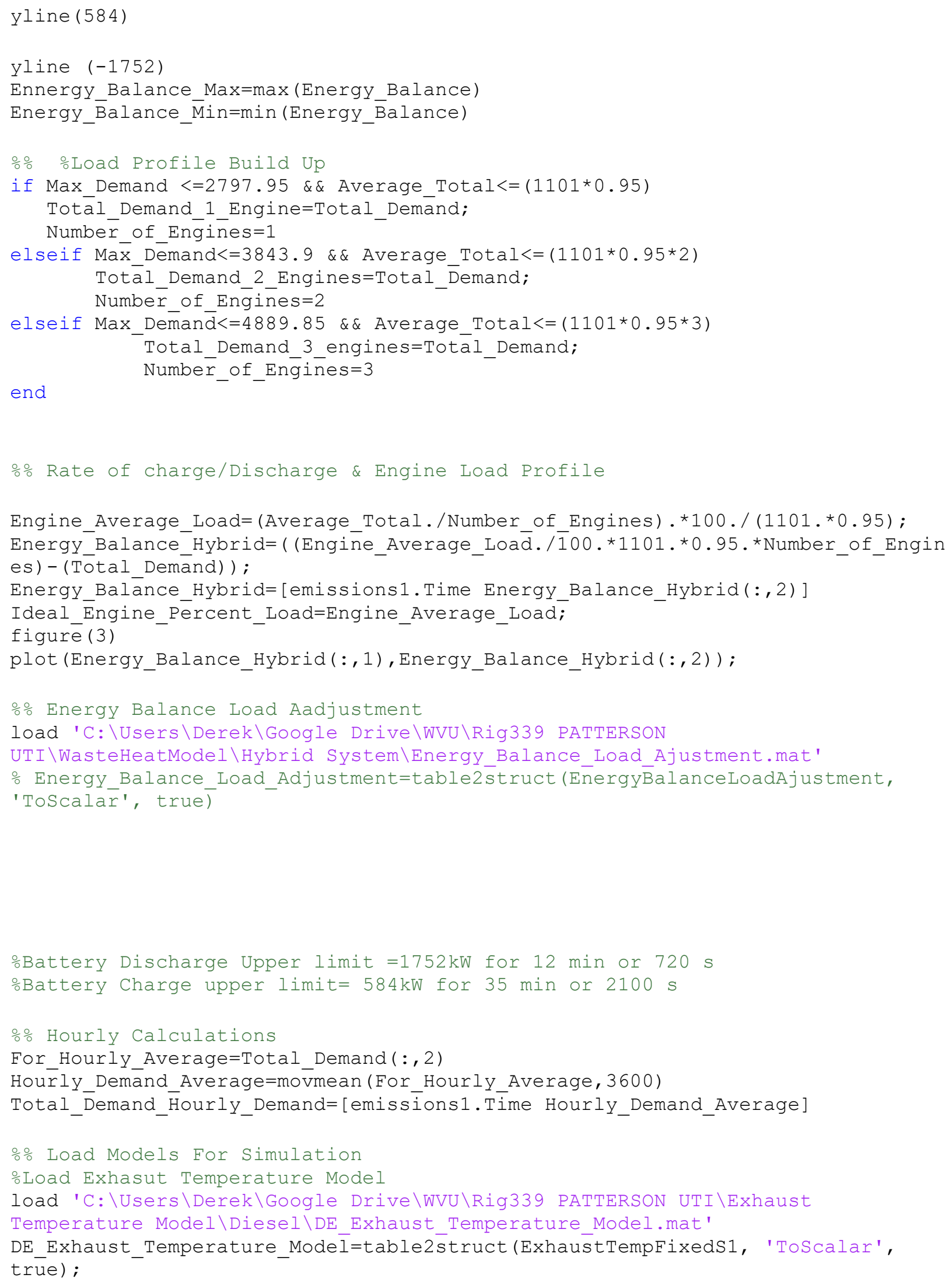


\% Load Fuel Consumption Model

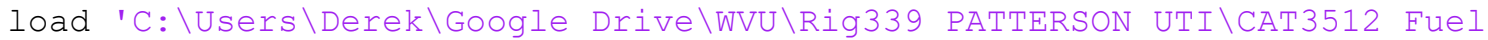

Consumption \CAT3512 Fuel Consumption.mat'

CAT3512_Fuel_Consumption=table2struct (CAT3512FuelModelFromSSS1, 'ToScalar', true);

\section{Hybrid Control Script for DNGE CHP Hybrid System}

oHybrid System Control for Waukesha L7144GSI Dedicated Natural Gas Engine 응응aㅇ Cycle

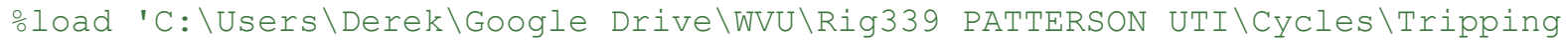
Pipe 1

hour \TP_Cycle_1_Hour_3_Engines_on_20200229_From_1631_to_1731_Boiler_on.mat'

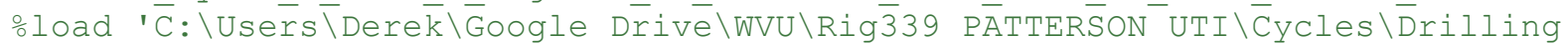
Cycle 2 engines Boiler

On\Drilling_Cycle_1_hour_2_Engines_on_20200228_From_1630pm_to_1730pm_Boiler_o n.mat'

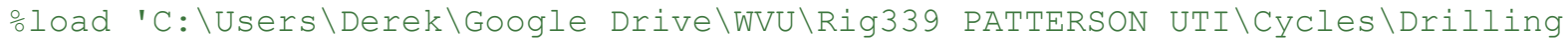
Cycle 1 hour 3 Engines Boiler

On\Drilling_Cycle_1_hour_3_Engines_on_20200229_From_0300_to_0400_Boiler_on.ma $t^{\prime}$

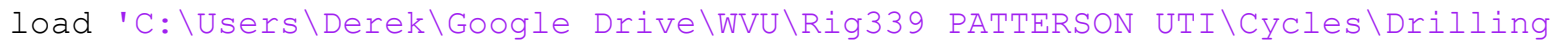
Cycle 24 hours Boiler

On\Drilling_Cycle_24_hours_3_Engines_On_20200229_From_0000am_to_0000am_Boiler on.mat'

émissions1 = table2struct (emissions1, 'Toscalar', true);

emissions2 = table2struct (emissions2,'ToScalar', true);

emissions3 = table2struct(emissions3,'ToScalar', true);

Ambient=[emissions1.Time emissions1.Tc7Ambient];

응 Load Load Adjustment Chart from SOC and ROC

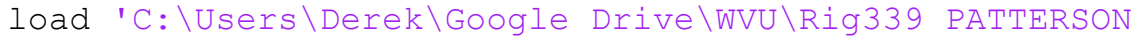

UTI \WasteHeatModeI \Hybrid System\Change_in_Load_Chart.mat'

o Change in Load Chart=table2struct ( Chängè in Load Chart, 'ToScalar', true);

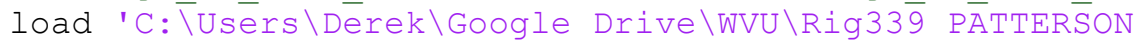

UTI \WasteHeatModeI $\backslash$ Hybrid System \Adjustment_in_Load_Rate_of_Charge.mat' Adjustment_in_Load_Rate_of_Charge=table2struct( AdjüstmentiñLoadRateofCharge, 'ToScalar', true);

음 Average Power Demand

Average_1=mean (emissions1.EnginePercentLoadAtCurrentSpeed.*1101.*0.95./100)

Average $2=$ mean (emissions2. EnginePercentLoadAtCurrentSpeed. $* 1101 . * 0.95 . / 100$ )

Average_3=mean (emissions 3. EnginePercentLoadAtCurrentSpeed.*1101.*0.95./100)

Average_Total=Average_1+Average_2+Average_3

Demand_1=emissions1.EnginePercentLoadAtCurrentSpeed.*1101.*0.95./100;

Demand_2=emissions2.EnginePercentLoadAtCurrentspeed.*1101.*0.95./100;

Demand_3=emissions3. EnginePercentLoadAtCurrentSpeed. *1101.*0.95./100;

Total_Demand=Demand_1+Demand_2+Demand_3;

Total_Demand=[emissions1.Timē Total_Démand] ;

Max_Demand=max (Total_Demand $(:, 2)$ )

Min_Demand=min $($ Total_Demand $(:, 2))$

yyaxis left 


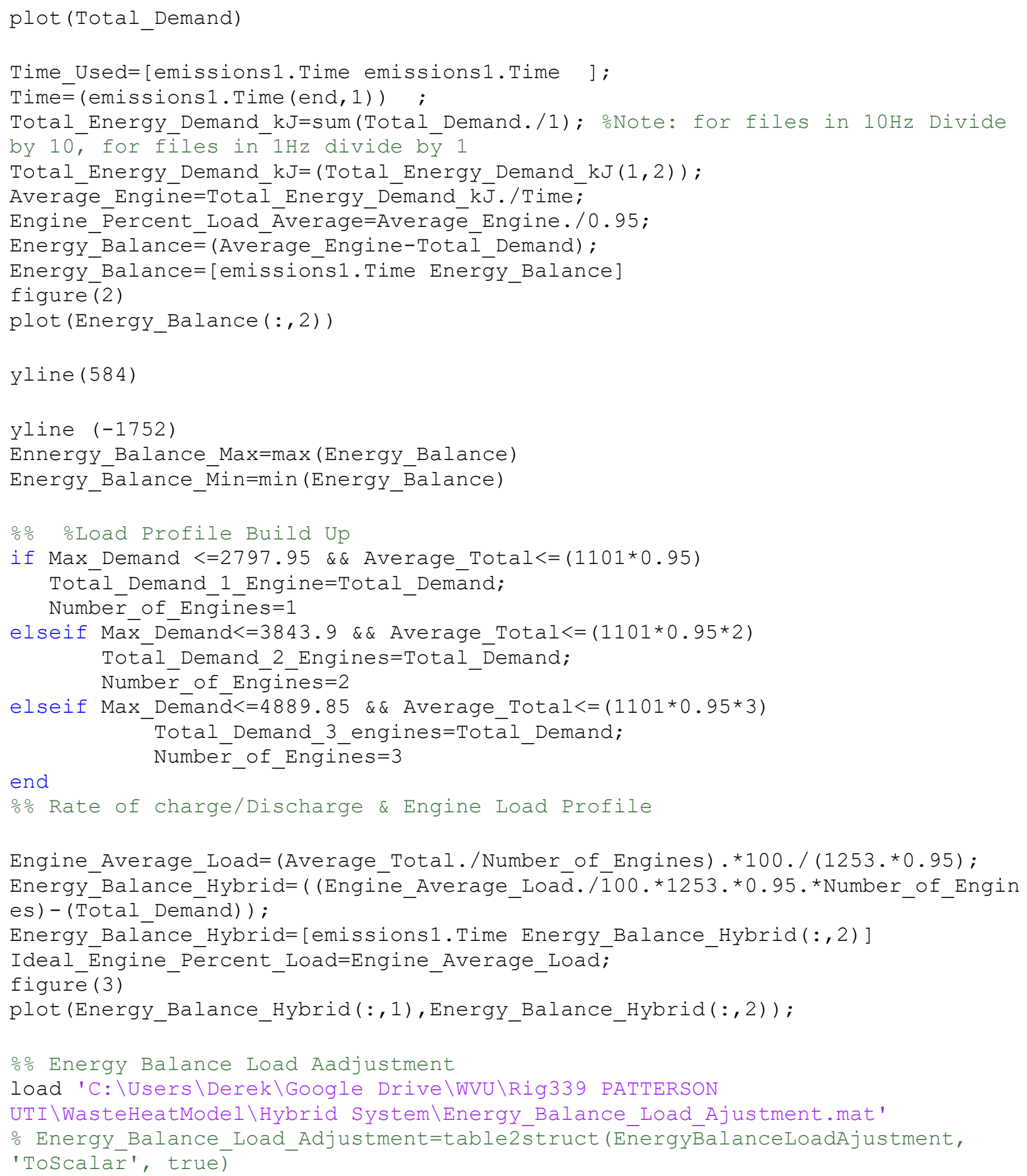


응 Hourly Calculations

For Hourly Average=Total Demand $(:, 2)$

Hourly_Demānd_Average=movimean (For_Hourly_Average, 3600 )

Total_Demand_Hourly_Demand=[emissionsl.Time Hourly_Demand_Average]

\% 


\subsection{Appendix C: CHEMCAD Heat Exchangers TEMA Sheets HHPDE E-HEX TEMA Sheet:}

Simulation: HHPDE E-HEX

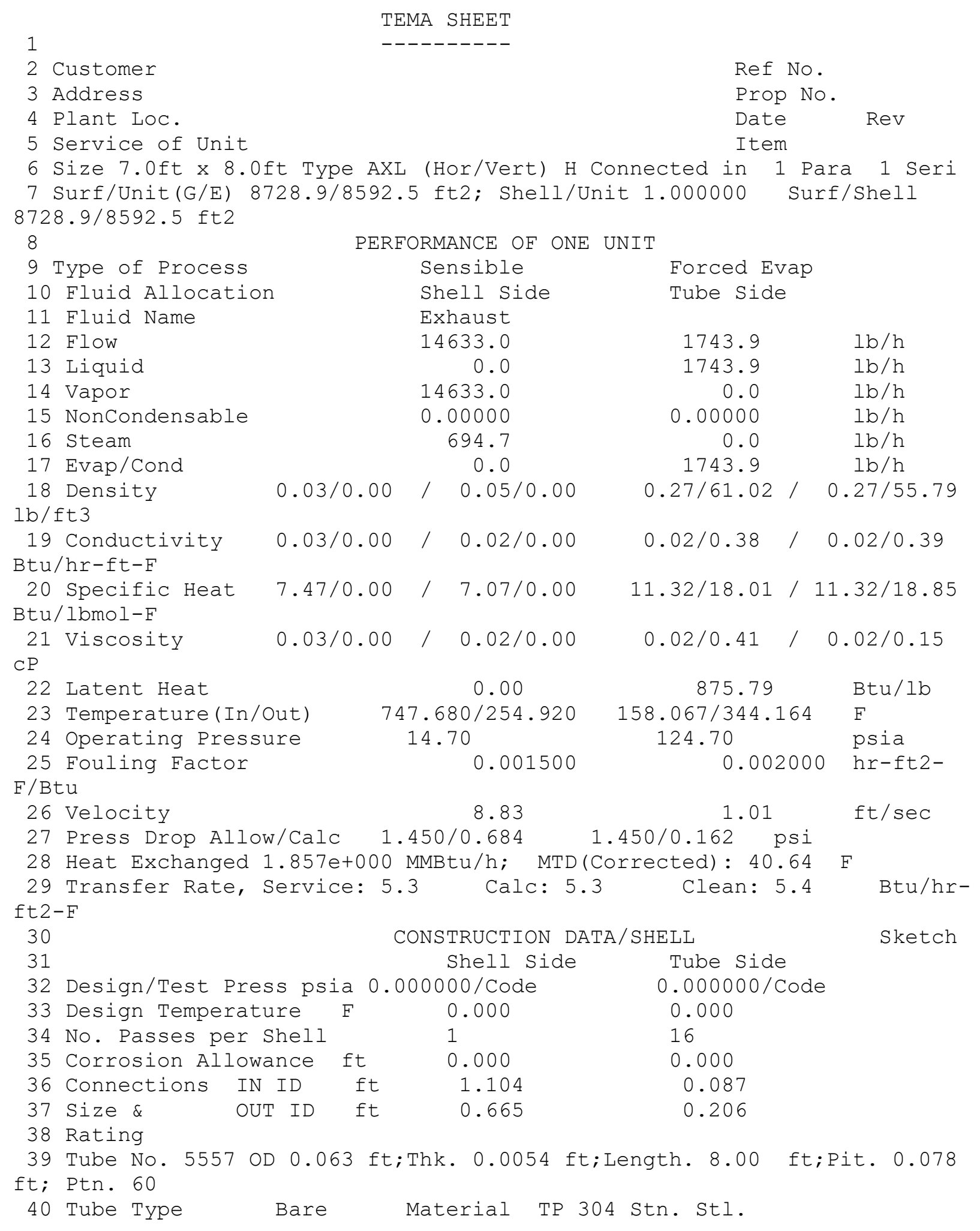




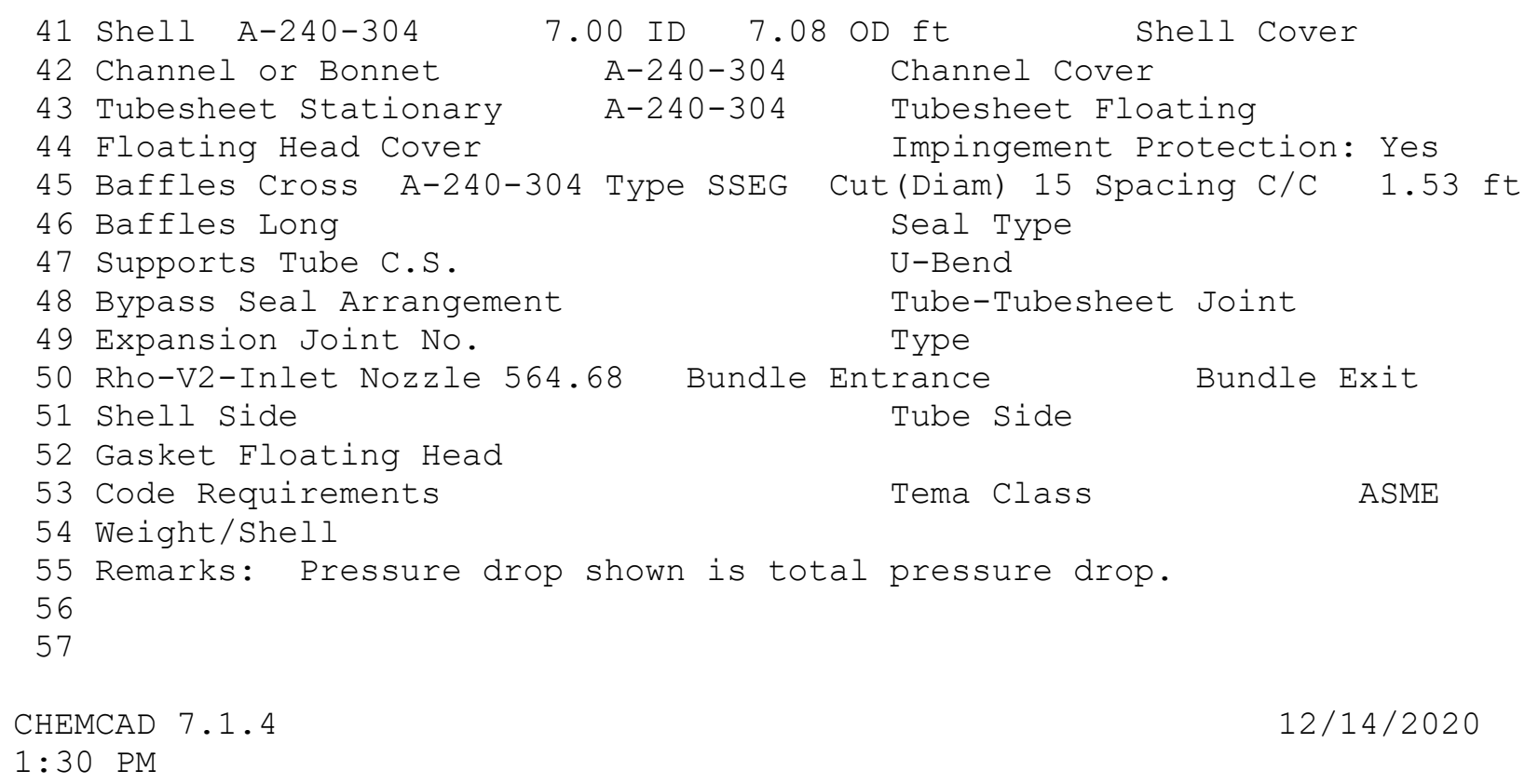

ASME

$12 / 14 / 2020$

DNGE E-HEX TEMA Sheet:

\section{DNGE E-HEX TEMA Sh Simu}

Simulation: DNGE E-HEX

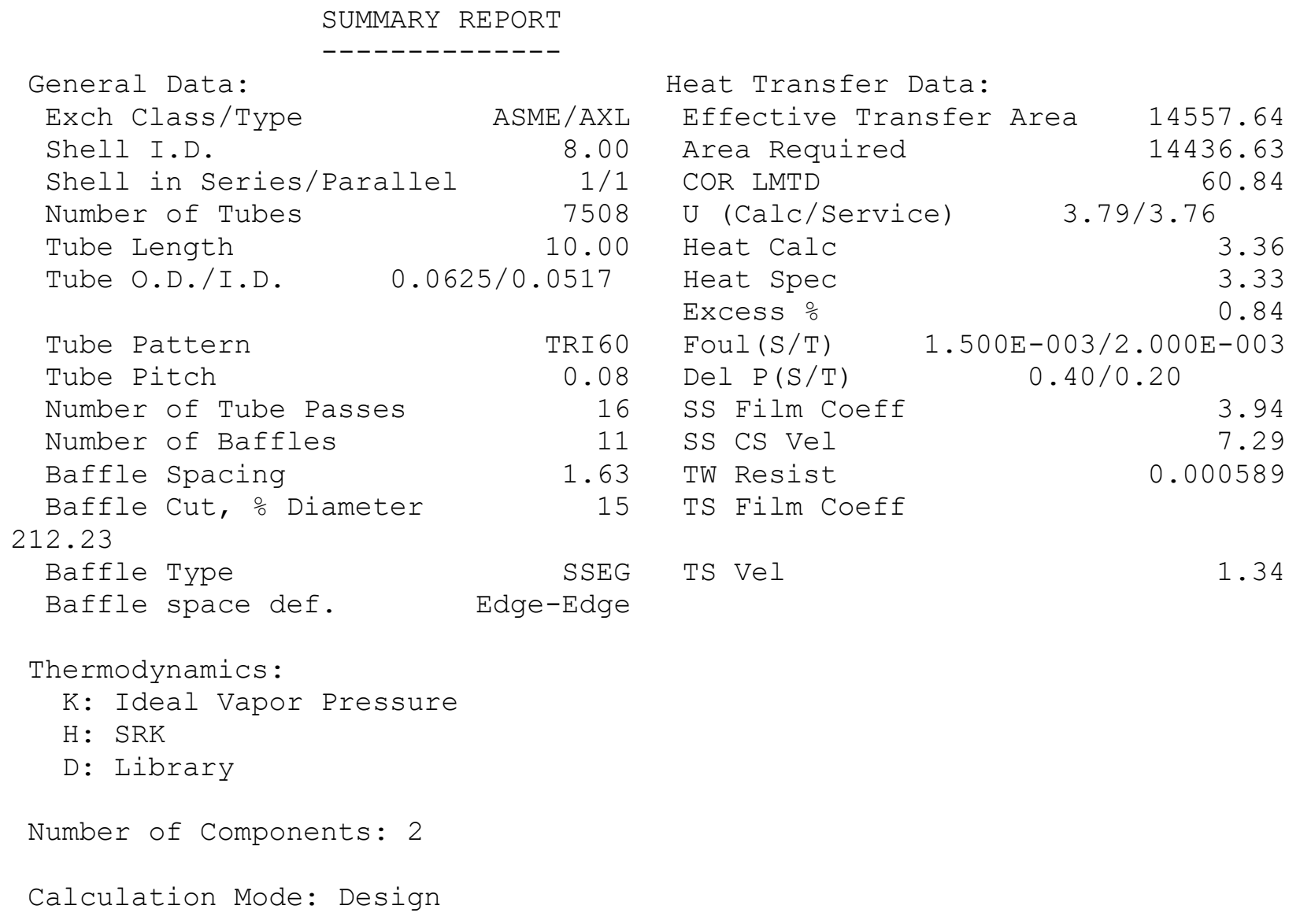




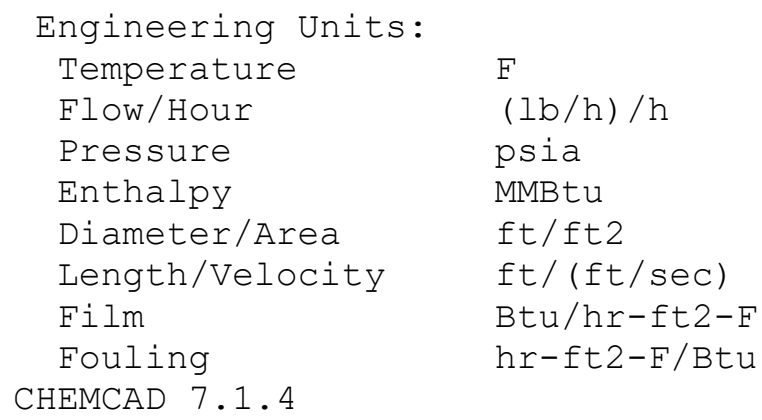

HHPDE JW-HEX TEMA Sheet:

$3 / 27 / 2021$

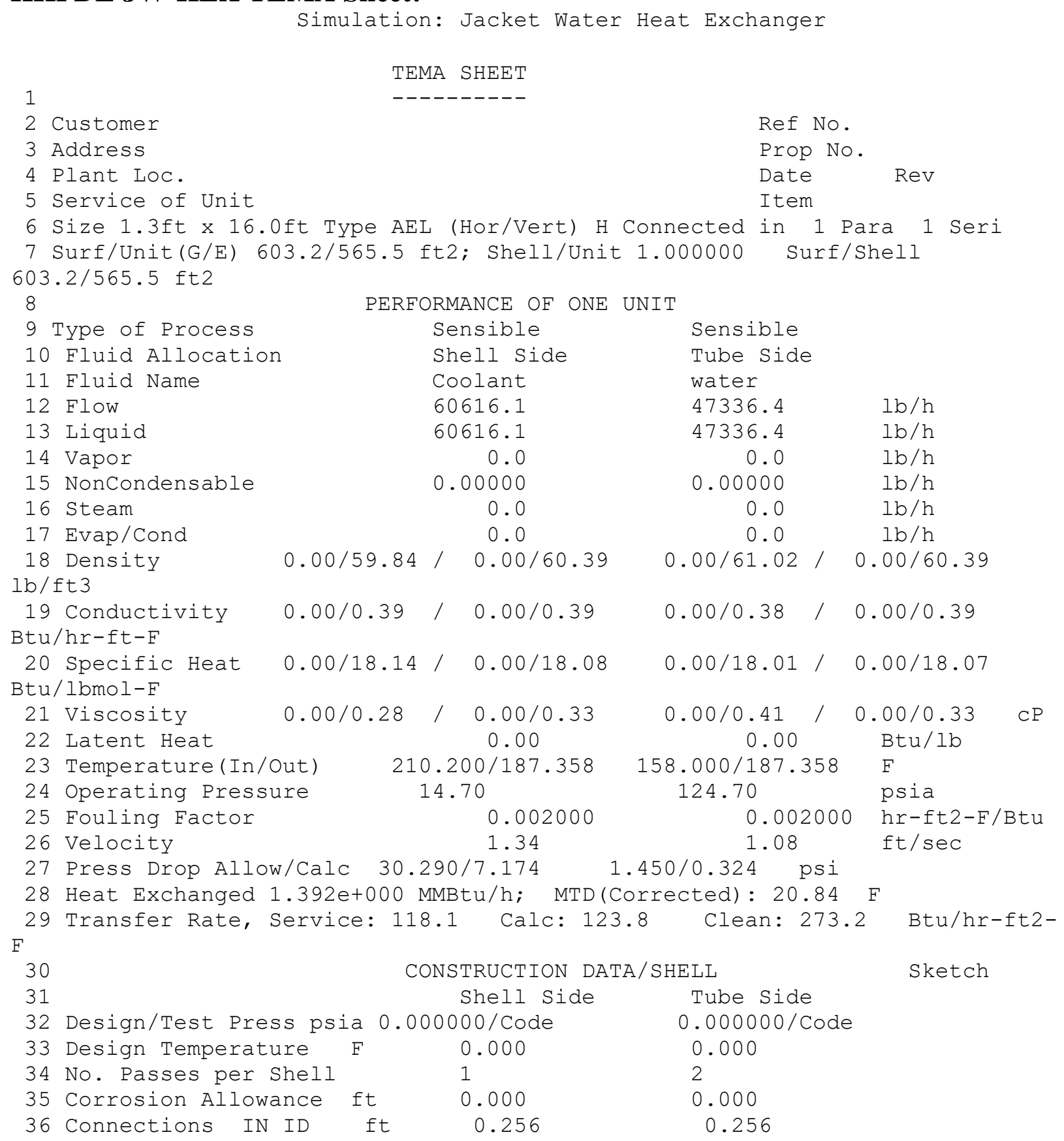




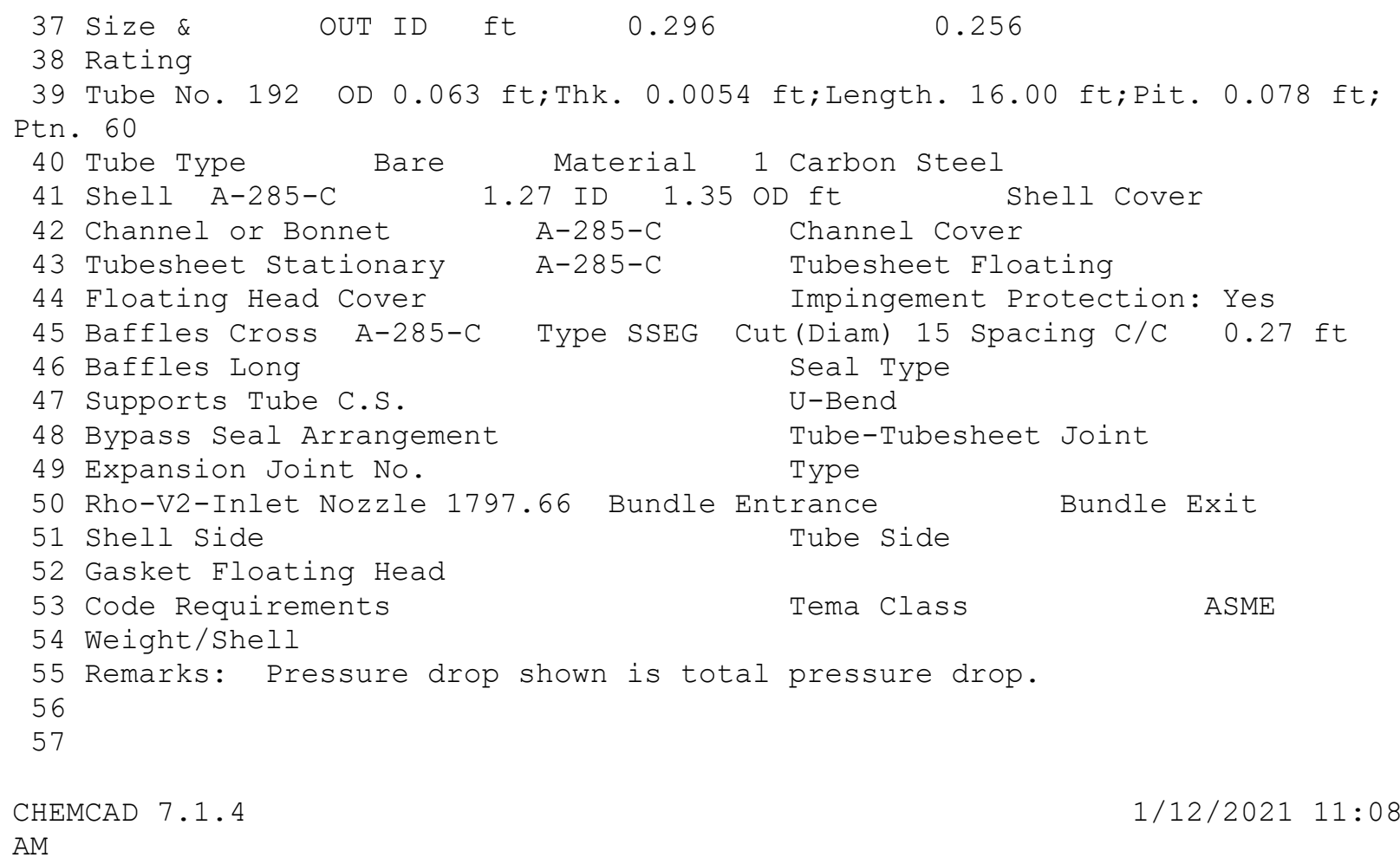




\title{
9.4 Appendix D: Heat Exchanger Quotes
}

\section{CAIN HHPDE ESG Proposal}

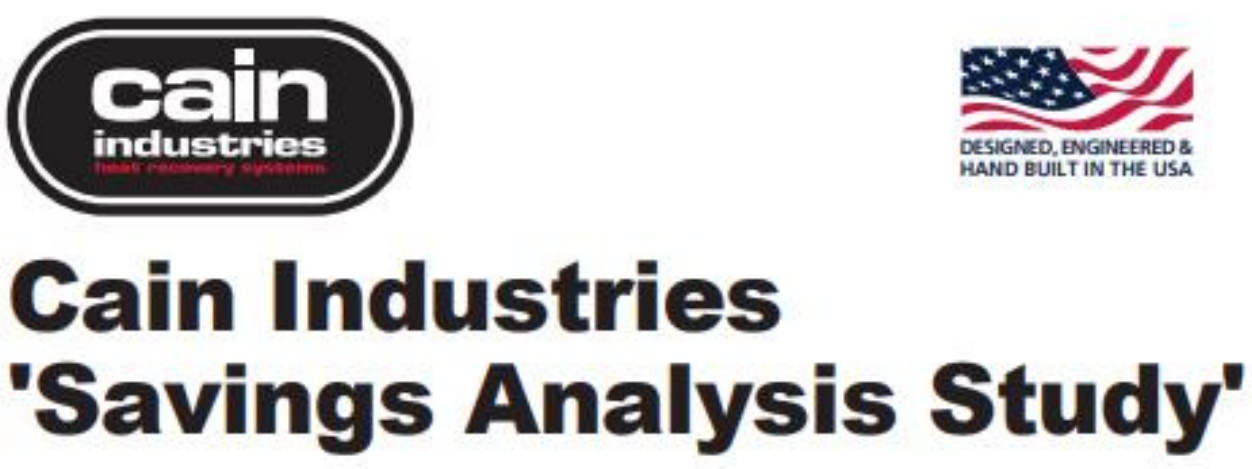

\author{
Caterpillar 3512C Diesel Engine \\ Recovering Exhaust Energy To Generate Steam
}

Exhaust Heat Recovery Proposal

General Submittal Drawing

Terms of Sale and Warranty

Application Data Information

End I lse

West Virginia University

1500 University Ave

Morgantown, WV 26506
From:

Cain Industries, Ine.

W194 N11826 MoCormick Dr.

Germantown, W1 53022 
"Manufacturing Waste Heat Transfer Products To Save Energy"

Boler Economizer Systems - Gas \& Diesel Cogeneration Systems - Fume Incinerafion Systems Exhaust Steam Generators - Finned Tubing

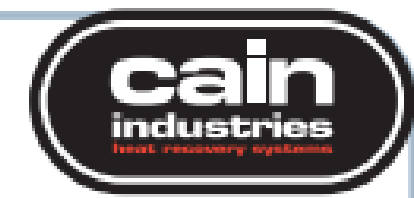

\author{
Caterpillar 3512C Diesel Engine \\ Recovering Exhaust Energy To Generate Steam
}

Ref: 63966

Rep: 24999015

Rev: 1

\section{Engineered For.}

West Virginia University 1500 University Ave. Morgantown, W 26506

\section{End User:}

West Virginia University 1500 University Ave. Morgantown, WV 26506
Date: $12 / 9 / 2020$

Page: 1

\title{
Exhaust Heat Recovery Proposal:
}

Cain Industries is pleased to propose the following ESG1 model heat recovery steam generator to recover exhaust heat from a Caterpillar 3512C Diesel Engine and produce 110 psig steam output. The ESG1 package model comes complete with automatic control for either Supplemental (operating with fired steam boilers) or Primary (standalone) steam output.

- The proposed ESG1 product model will reduce the exhaust temperature gas inlet $747^{\circ} \mathrm{F}$ to $371^{\circ} \mathrm{F}$, with a $27^{\circ} \mathrm{F}$ pinch point @ $344^{\circ} \mathrm{F}$ saturated steam temperature.

- The recovered 1,594,668 BTU/hr to steam output shall produce 1,643 \#/hr operating at 110 psi based@252 $\mathrm{F}$ inlet feedwater temperature.

- See NOTE1 regarding minimum inlet feedwater temperatures and treated water quality requirements.

- The basic ESG1 features a packaged and skid mounted, forced circulation, water tube, heat recovery steam generator.

- The factory tested ESG1 components contain a bypass section, heat exchanger section, and steam flash drum assembly.

- Included as standard is an automatic modulating exhaust gas bypass, controlled by steam pressure, as well as a modulating feedwater water control system.

- The heat transfer tubes are SA178 GrA carbon steel with carbon steel fins.

- Steam output can be produced in 5-10 minutes from a cold start-up.

The heat exchanger section (double seal welded outer shell to $10^{*}$ W.C.) and the steam flash tank assembly are insulated with protective welded carbon steel exteriors. The exhaust gas bypass shall have $3^{\prime \prime}$ thickness insulation and a Stainless Steel protective exterior. After startup/commissoning, the buyer shall be responsible to field insulate the interconnecting piping as deemed necessary.

The Modulating Exhaust Gas Bypass Assembly construction will be designed where all materials in contact with the exhaust gas shall be Stainless Steel.

In the event of loss of electrical power or during an alarm condition, i.e., high water, low water, excess steam pressure, the bypass will be driven to the exhaust bypass position (diverting $99 \%+$ exhaust away from the ESG1).

The steam pressure controller will have Modbus communications for re-transmission of the 


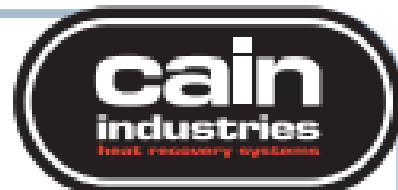

\section{Caterpillar 3512C Diesel Engine \\ Recovering Exhaust Energy To Generate Steam}

Ref: 63966

Rep: 24999015

Rev: 1
Date: $12 / 9 / 2020$

Page: 2

process variable and remote set point capability. The water level controller will also have Modbus communications for re-transmission of the process variable. Contacts will be provided to remotely drive the exhaust gas bypass to the bypass position. The panel is UL approved.

The ESG1 must be installed indoors within a heated/cooled enclosure protected from freezing and/or from excessive heat above $120^{\circ} \mathrm{F}$.

Optional Equipment: Add $\$ 3639$ for auto surface blowdown installed. Add an additional $\$ 1190$ to add MODBUS communications to the auto surface blowdown controller.

All prices are quoted in US currency. The quoted price does not include freight, export crating, any taxes or duties, or start-up services. See the attached "Terms of Sale" bulletin for start-up service requirements and rates, f.o.b. Cain Industries.

NOTE: The ESG1 product line model is typically selected at a feed water temperature of $212^{\circ} \mathrm{F}$ as the recommended minimum inlet temperature for softened and chemical treated boiler water. An optional internal economizer, for higher efficiency and closer approach point, can be used when the available feedwater temperature is above the minimum $150^{\circ} \mathrm{F}$. An optional external feedwater preheater is also available if the feedwater temperature is below $150^{\circ} \mathrm{F}$.

"Upon receipt of written purchase order, Cain Industries shall submit within 7-10 working days, Customer Approval Drawing(s) for review. The product drawing shall be drawn to 'detailed scale' and submitted in the form of AutoCAD .dwg and Adobe .pdf file formats. The submittal drawing shall include various views for plan and elevation customer incorporation into other drawings as required. It is important that these drawing(s) be returned within 60 days from issuance to guarantee quoted price, signed, dated, and marked "Approved for Production" while also forming as a part of the Terms of Sale, and begin the delivery schedule in the proposal. 
"Manufacturing Waste Heat Transfer Products To Save Energy"

Boler Economizer Bystems . Gas \& Diesel Cogeneration Systems - Fume Incinerafion Systems Exhaust Steam Generators - Finned Tubing

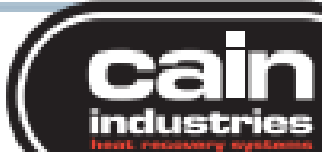

\section{Caterpillar 3512C Diesel Engine}

Recovering Exhaust Energy To Generate Steam

Ref: 63966

Rep: 24999015

Rev: 1

Waste Heat Exhaust:

Primary Fuel Type:

Secondary Fuel Type:

Fual Cost per 100,000 BTU (USD):

Heat Source:

Exhaust Flow Direction:

\section{Model: ESG1-B30B14.5CSS}

Overal Length, inches

Overal Width, inches

Overal Height, inches

Dry Weight, lbs.

Wet Weight ( $6.8 \mathrm{ft} / 43 \mathrm{imp}$ gal), lbs.

Surface Ârea, Ft2

Design Pressure, PSIG

Operating Steam Pressure, PSIG

Hydrostatic Test Pressure, PSIG

fifebesign Temperature, " $\mathrm{F}$

Maximum Entering Temperature, " $\mathrm{F}$

\section{Performance:}

Load of Maximum Output, \%

Exhaust Entering Temp, "F Exhaust Flow Rate, SCFM

Exhaust Leaving Temp, ${ }^{\circ} \mathrm{F}$ Pressure Drop "W.C. Max

*Equivalent Evaporation, lo/hr

Boiler Horsepower, BHP

Boiler Feedwater Flow, GPM

+ Sensible Heat Dry Gas

+ Sensible Heat of $\mathrm{H} 2 \mathrm{O}$ Vapor

+ Latent Heat of Condensation

TT BTU/hr Recovered

("From $251.6^{\circ} \mathrm{F}$ feedwater to 110 PSIG steam)

\section{Savings:}

Therms (100,000 BTU) Saved/Hr

Annual Hours of Operation

Annual Savings Per Load
Date: $12 / 9 / 2020$

Page: 3
\#2 Fuel OI

\#2 Fuel 0

Caterpilar 3512C Diesel Engine Vertical
$18 *$ Dia.

8-18"Dia.

Exhaust Connections

Steam, RF Flange

Boiler Feedwater, NPT

Blowdown Manifold

Steam Safety Valve, NPT

Circulator Motor HP

Voltage

Phase 3

$230 / 460$ 
"Manufacturing Waste Heat Transfer Products To Save Energy"

Boler Economizer Systems - Gas \& Dieset Coganeration Systema - Fume Incinerasion Bystems Exharst Steam Generators - Finned Tubing

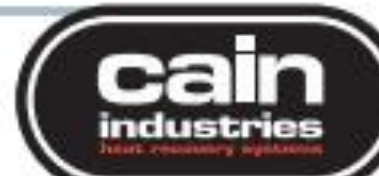

\section{Catterpillar 3512C Diesel Engine \\ Recovering Exhaust Energy To Generate Steam}

Ref: 63966

Rep: 24999015

Rev: 1

\section{Quotation:}

$\begin{array}{ccc}\text { Oly Part } 1 \text { U. } & & \\ & & \\ & & \\ & & \\ & & \\ & & \\ & & \\ & & \\ & 914014 & \\ & 915015 & \\ 2 & 974040 & \text { EACH } \\ & 940060 & \\ 1 & 940065 & \\ 1 & 940070 & \\ 1 & 930040 & \\ & 964025 & \\ 1 & 964770 & \text { EACH } \\ 1 & 967010 & \text { EACH } \\ & 950050 & \\ 4203 & & \end{array}$

Date: $12 / 9 / 2020$

Page: 4

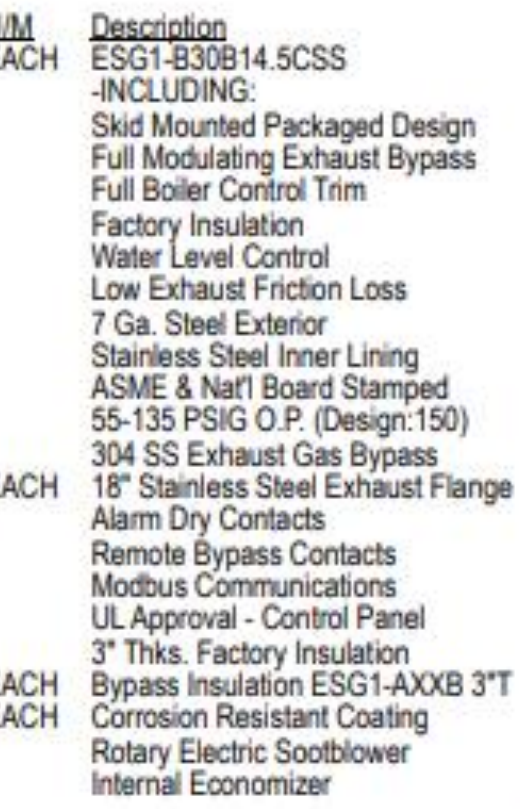

TOTAL PRICE (USD)

\section{Terms of Sale:}

"Estimated Shipping: 14-16 weeks after submittal approval

"Payment Terms: See "Terms of Sale" Bulletin \#25500

" See Bulletin 25500 induding 'Warranty and Performance Guarantee'.

* Savings projections will vary from fluctuating fuel costs, operating hours, \& equipment care

$120890-16.25-0.90$

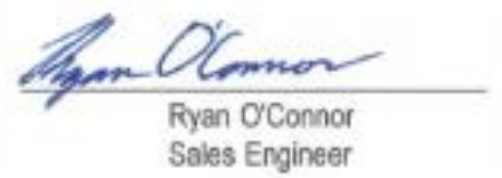


"Manufacturing Waste Heat Transfer Products To Save Energy" Boler Economizer Systems - Gas \& Diesel Cogeneration Systems - Fume Incinerasion Bystems Exhaust Steam Generators - Finned Tubing

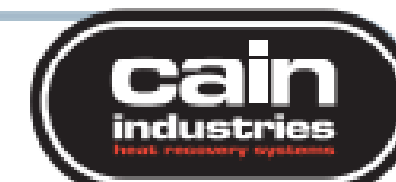

Ref. 63980

Rep: 999

Rev: 0

\section{Caterpillar 3512C Diesel Engine}

\section{Waste Heat Exhaust:}

Primary Fuel Type:

Fuel Cost per 100,000 BTU (USD):

Heat Source:

Exhaust Flow Direction:

Heat Sink:

Liquid Type:

\section{Model: ESGe-220A14.5ALS}

Overal Configuration, inches

Overal Height, inches

Liquid Connection

Exhaust Connection

Dry Weight, lbs.

Wet Weight (0.8 $\mathrm{ft}^{\mathrm{t}} / 5 \mathrm{mp}$ gal), lbs.

Surface Area, Ft2

Design Pressure, PSIG

Hydrostatic Test Pressure, PSIG

@ Design Temperature, " $\mathrm{F}$

Maximum Entering Temperature, ${ }^{\circ} \mathrm{F}$

\section{Performance:}

Load of Maximum Output, \%

Exhaust Entering Temp, ${ }^{\circ} \mathrm{F}$ Exhaust Flow Rate, SCFM Exhaust Leaving Temp, ${ }^{\circ} \mathrm{F}$ Pressure Drop "W.C. Max Liquid Entering Temp, ${ }^{\circ} \mathrm{F}$ Liquid Flow Rate, GPM Liquid Leaving Temp, "F Pressure Drop, PSIG

+ Sensible Heat Dry Gas

+ Sensible Heat of H2O Vapor

+ Latent Heat of Condensation TT BTU/hr Recovered

\section{Savings:}

Therms (100,000 BTU) Saved/Hr

Annual Hours of Operation

Annual Savings Per Load
Date: $12 / 9 / 2020$

Page: 2
Natural Gas

Caterpilar 3512C Diesel Engine

Vertical

Water

$\begin{array}{rrr}24.1 \times 76 & & \\ 8.3 & & \\ 3 / 4^{\circ} \mathrm{NPT} & & \\ 20.9 \times 60.3 & & \\ 230 & & \\ 280 & & \\ 272 & & \\ 250 & & \\ 375 & & \\ 550 & & \\ 900 & & \\ & & \\ \text { Load 1 } & \text { Load 2 } & \text { Load 3 } \\ 100 \% & 75 \% & 50^{\circ} \\ 346^{\circ} & 347 & 345^{\circ} \\ 3,317 & 2,619 & 1,837 \\ 312^{\circ} & 315^{\circ} & 316^{\circ} \\ 0.39 & 0.25 & 0.12 \\ 158.0^{\circ} & 158.0^{\circ} & 158.0^{\circ} \\ 3.3 & 2.5 & 1.9 \\ 237.5^{\circ} & 237.0^{\circ} & 224.8^{\circ} \\ 0.00 & 0.00 & 0.00 \\ 110,117 & 82,935 & 53,336 \\ 20,936 & 15,768 & 10,141 \\ \text { N/A } & \text { N/A } & \text { N/A } \\ 131,054 & 98,703 & 63,477\end{array}$




\section{SUBMITTAL}

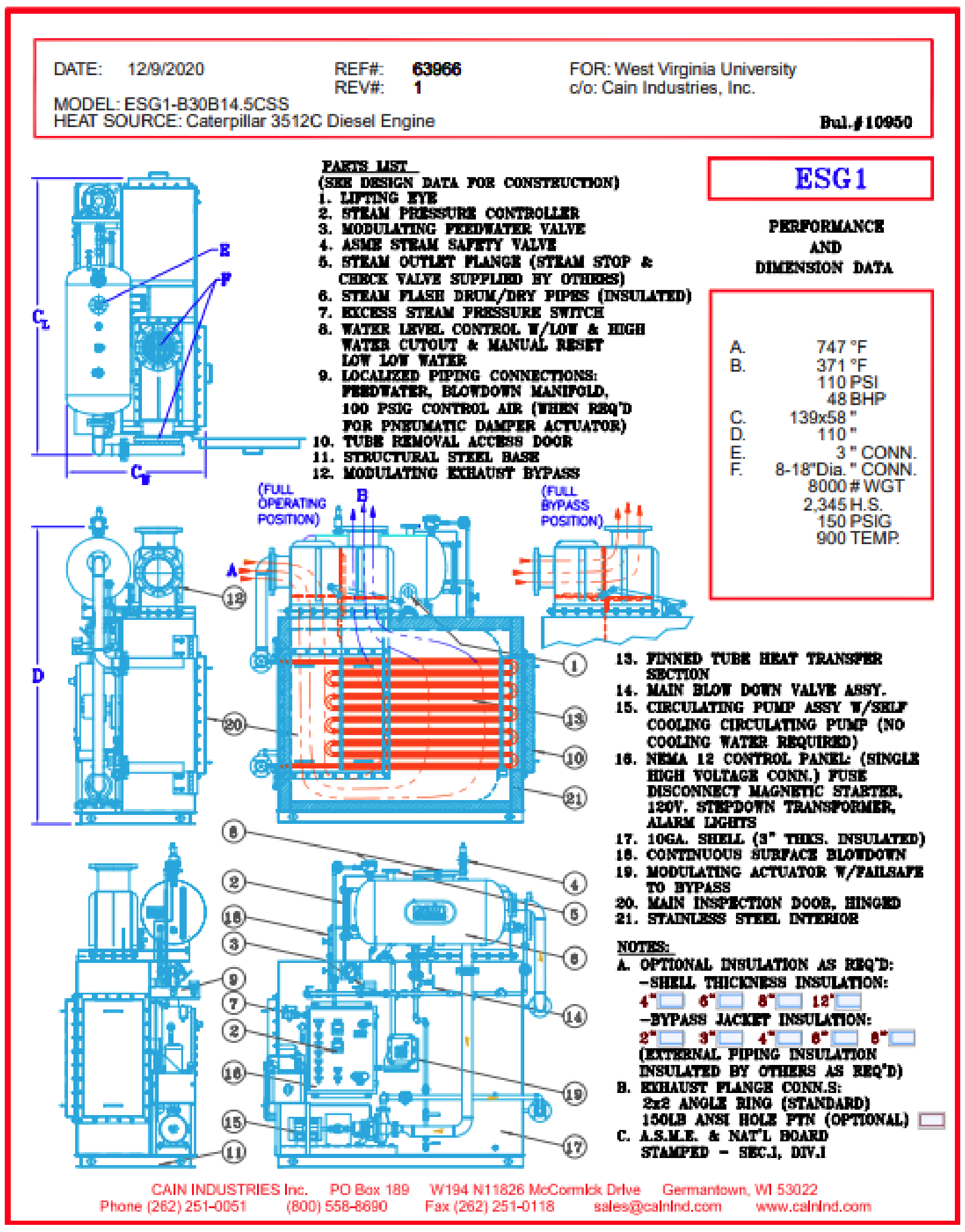




\section{SUBMITTAL}

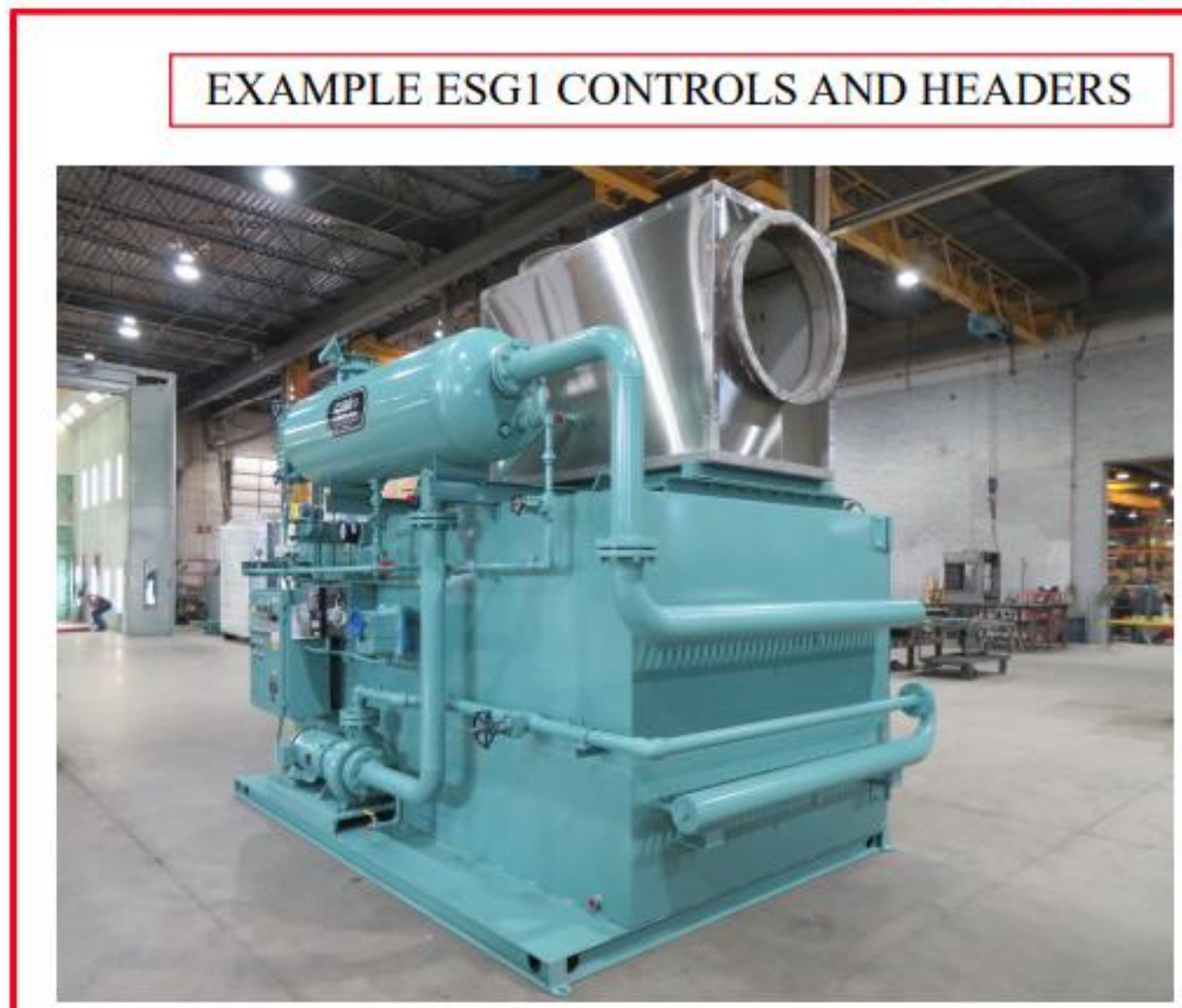




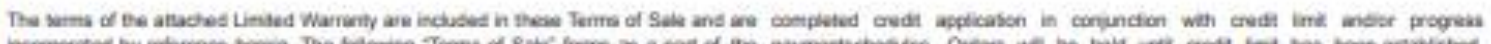

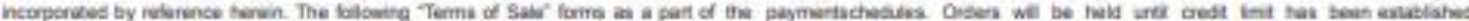

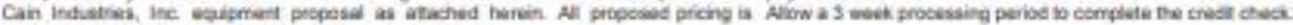

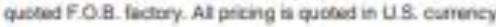

QUOTED DEUVERY TIME

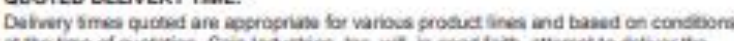

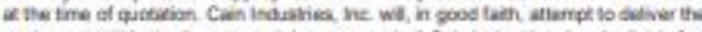

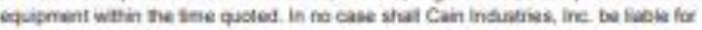

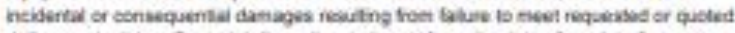

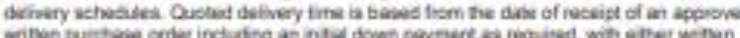

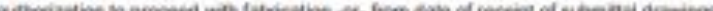
Gass 10 working dapa whan tequired.

\section{OFFER EXPRATION}

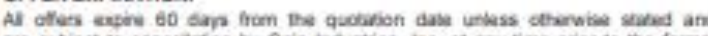

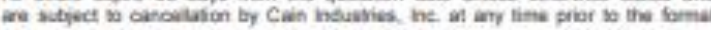
weoptince of but oller to fumih equigmemt quated.

\section{BUBNIT AL DRAWINGS:}

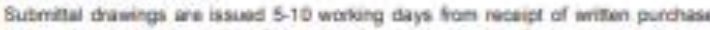

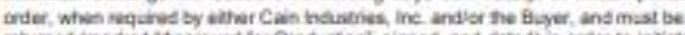

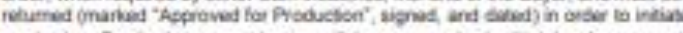

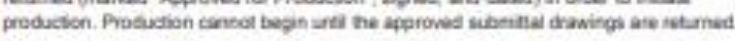

\section{SHPMENT of CoODS:}

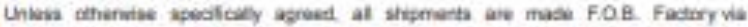

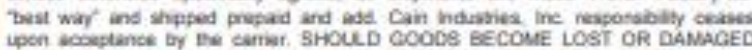
IN SHPWENT, THE PURCHASER OR FECIPENT OF THE COCOS MUST MMEDEATELY NOTFY AND PLACE CLAS WTH THE CAPRUER, ADVISE CAN INDUSTRES, INC OF ANY DASUACE OR DISCREPANCY, AND OETAIN

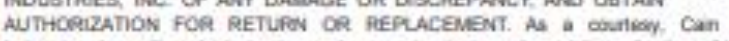

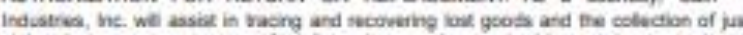

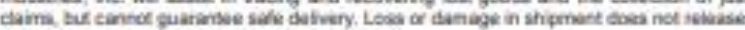
the purchase fom parment of the lobil invoice

\section{PAYMENT-ESTABUSHED ACCOUNTS:}

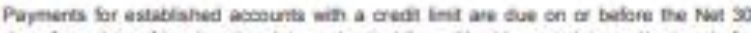

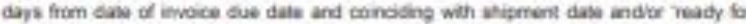
shipmant sure.

\section{Expeorninc:}

Expeding charges may be issued in orser to mperve ealvery depending on the

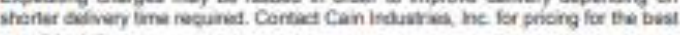
pessible deavery.

\section{STORAGE.}

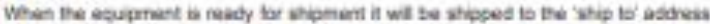

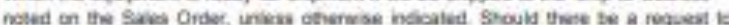

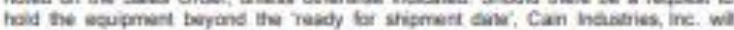

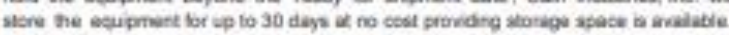

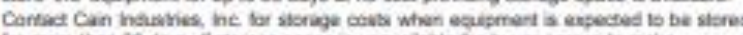

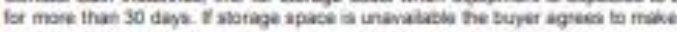

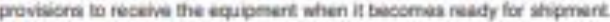

Misinum BLLNe:

The misimum otder is $\$ 10000$, plas shipping costs

\section{CREDI LINIT:}

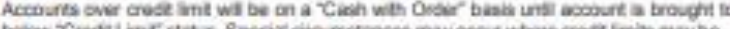

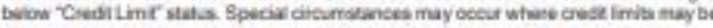

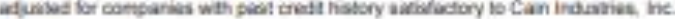

\section{TAXES OR BUIRCHARCES:}

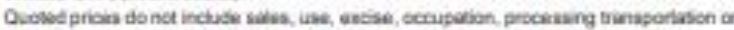

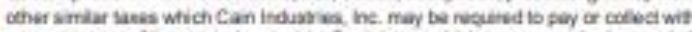

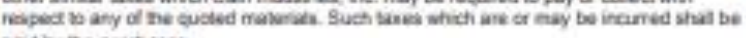
pad by the purchaties

\section{PAYMENT -NEW ACCOUNTS:}

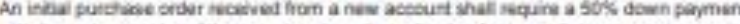

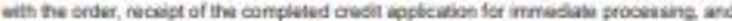

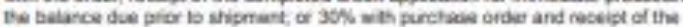

\section{PAYNENT-OFOEFS OUTHSDE THE UMITED STATES.}

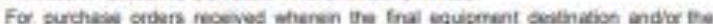

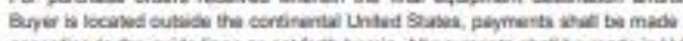

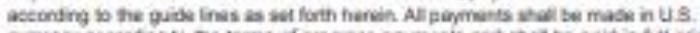

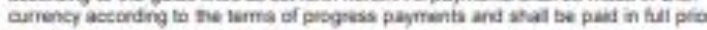

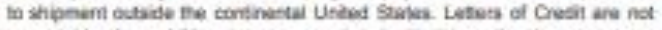

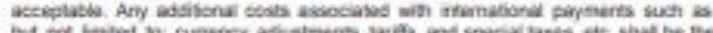

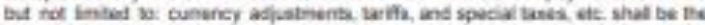
naporabilty of the Buyes.

SERVICE CHARCE:

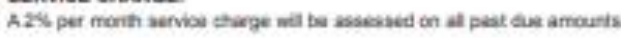

MOCAESS PAYMENT GCHEDULES.

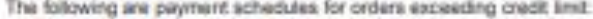

- For parctase inders of $\$ 25,000$ vo $\$ 50$, 000. - $20 \%$ ave whin purchase order

- $30 \%$ awe at 45 caps froen receipt of approval drawngs Baiance due 35 dap from shipenert.

- Over \$SO.050 or regaitad for Be ESO prodact arderx. - 15k aw weth parchase doder

$-15 \%$ ase with sultmial approvid drawnga

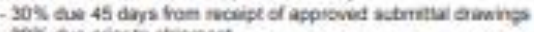

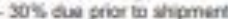

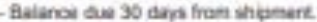

\section{CANCELLATION AND CHANGES:}

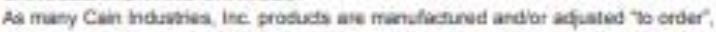

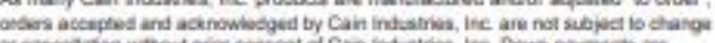

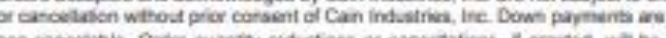

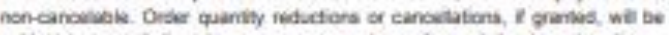

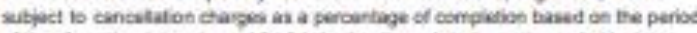

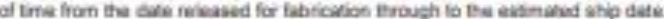

\section{EQUSPMEVT STARTUP S FERVICE.}

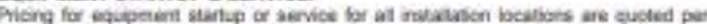

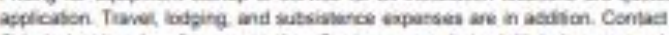

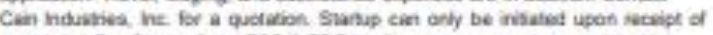
conpleted Pre-Suanp form. ESO S ESC1 beter stethps mun be conplated by

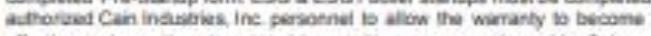

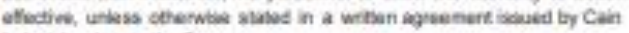
ndestrina, inc bo the Buyet.

\section{RETUPEN OF GOODS FOR WhHRANTY REPAIR}

\section{MEPLACEMENT, OR CREOI:}

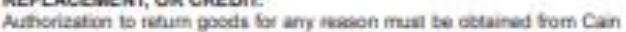
indsiries, inc. prot to the netum of tha stipenem boing made. Al herm

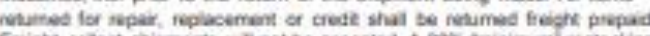

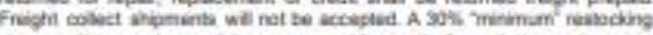

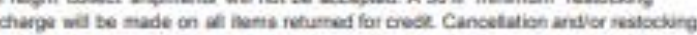
Charpas wet apply 10 the solance of the endef petaling with a manimutt of sors as

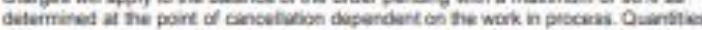

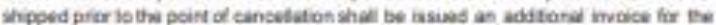
drevence in price treibs tetween the angna quantly ortesed atd be trou shiped up to the port of cancelation.

\section{PacDeETARY DATA:}

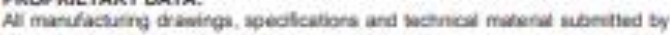
Cain indwaries, he. ane the propaty of Cain industries, he and are bo be

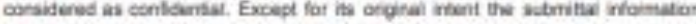

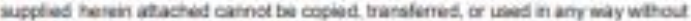

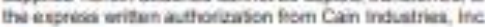

\section{UUTITANON OF REMEDIES:}

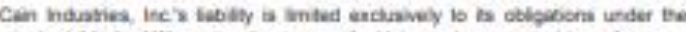

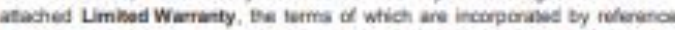

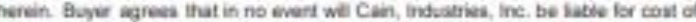

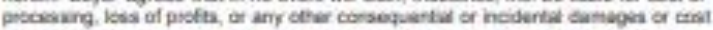

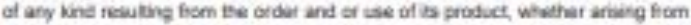

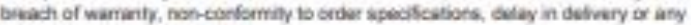
oher bas sustainet by borper. 


\begin{tabular}{|c|c|}
\hline Conpleted Dy: & Diego Dranuta \\
\hline Corpury: & WVu \\
\hline Eral Addone *: & 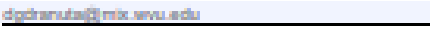 \\
\hline Proposal To: & - Fialds with an asterisk are required \\
\hline Compary Nane: & 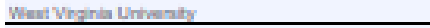 \\
\hline Addrenk & 1356 Evarnadule Dr \\
\hline Can, Sableprovince: & Peral Coste 20005 \\
\hline Coumar & Unbed Shakne- \\
\hline Cortact Nume & Diggo Dranuta \\
\hline Eral Adehear: & 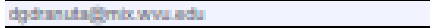 \\
\hline Phane: & 304380 \\
\hline
\end{tabular}

1. Exhaust to Liquid Heating Source:

Oown

Orunase

Ootser

aumer Type:

Qutmoloheric

Orubodarged

3. Design Specifications:

Dexign Phause $110 \quad$ psic

Operating Pranus: 110 psec

Orume incherato

Orines Gas Enoine ODeuel Engine

Qpower Damer Sinunily Mapianed

4. Exhaust Stack Description: ONertal gan flow tinection

Onsiumai gan flow tindien
OTwerral Ovidun Stack Type:

Orectingaler Dinerwion:

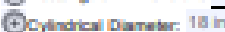

Econamibur space Lintationx CNane ar: $\mathrm{C}$

6. Exhaust Gas Flow Entering: Meinum preware drop a $160 \mathrm{~s}$ lead 40 Terperatus CF?

Oscru ar $\bigcirc$ nсm, a $\mathrm{On}$ Desined Oubat (F) Contert ocs:

$\alpha$ Connert coust.

Cortent Cwoen Arst.

Therrai EFicieng s Lead $\mathrm{X}$ of inat

Moun of Cperzition per Lead

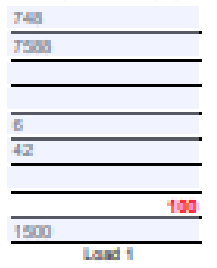

7. Lquid Flow Entering: Manimun pnemure drep a vos las: Terpenanus $\mathrm{CP}$.

Ocan ar Oent

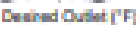

8. Desired BTU / Hr. Recovery:

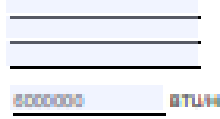

9. Savings Analysis Information:

Fual Cout Pwe soa, doo Des: 51 Tos

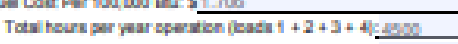
Houn per dis coperation Dapr per ved sperstion: 7 Weeks por year copention:

10. Justification for purchase:

Pyytack (manthey)

Rekum on imatinent [S] :
Initial Inquilry: *

Q2019 pdit emal inquily Qphone mix inquiry. Qmanal mac inquiry

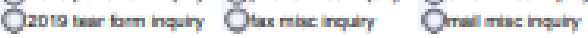

$\square$ Lead

End User: 10 Same As Propeal To

Domgary Narne

Aetran:

Chr Stutu Proince

Courth

Contact Nare:

Erual hatrat:

Phone:

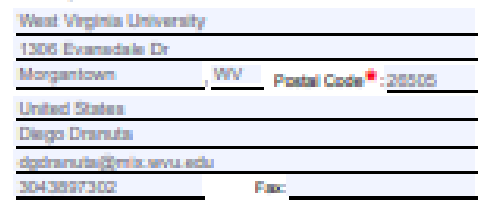

2. Exhaust Source Description: * Onwew o Chatun

Vosuc CAT

Nodes

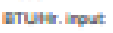

For Depine Eutauet fatrof

swe (unginan:

in' imoineal)

RPQU inginerit?

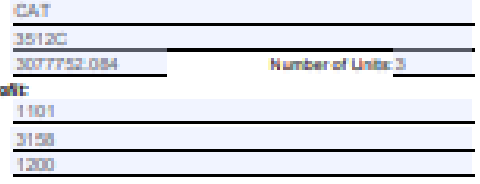

5. Type or Fuel Burned:

Prinary

Onaturatan

Qrapare

Oranua

One, s, efreal cu

Qunetrican

OnbeganDignder Gas

atu/po $13000 \mathrm{~g}$

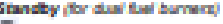
Onatual Gas

\section{Oprapara}

Orantaria

Orex, s, e fuel ou

Qunetican

Qabgubigmer Gan

Whucialion

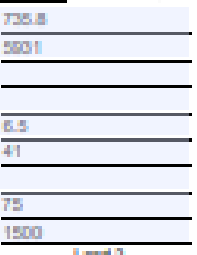
psac)
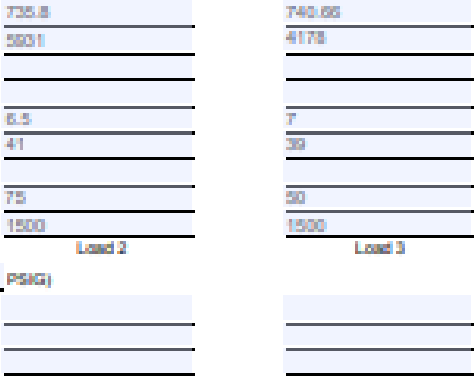

hoses

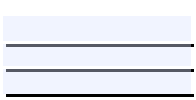

Attachments:

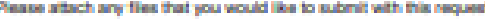

Notes:

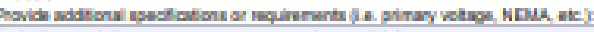

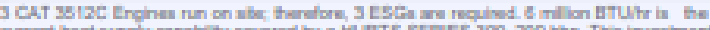

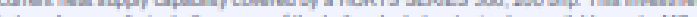

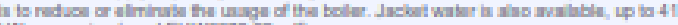

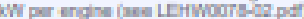

Attention:

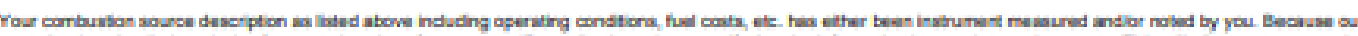

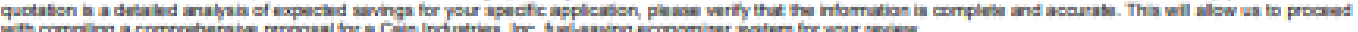

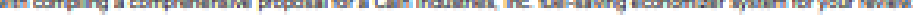

Verified $B y^{*}:$,

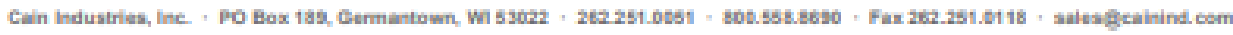
o 20 s Cuin indurrea, ine 


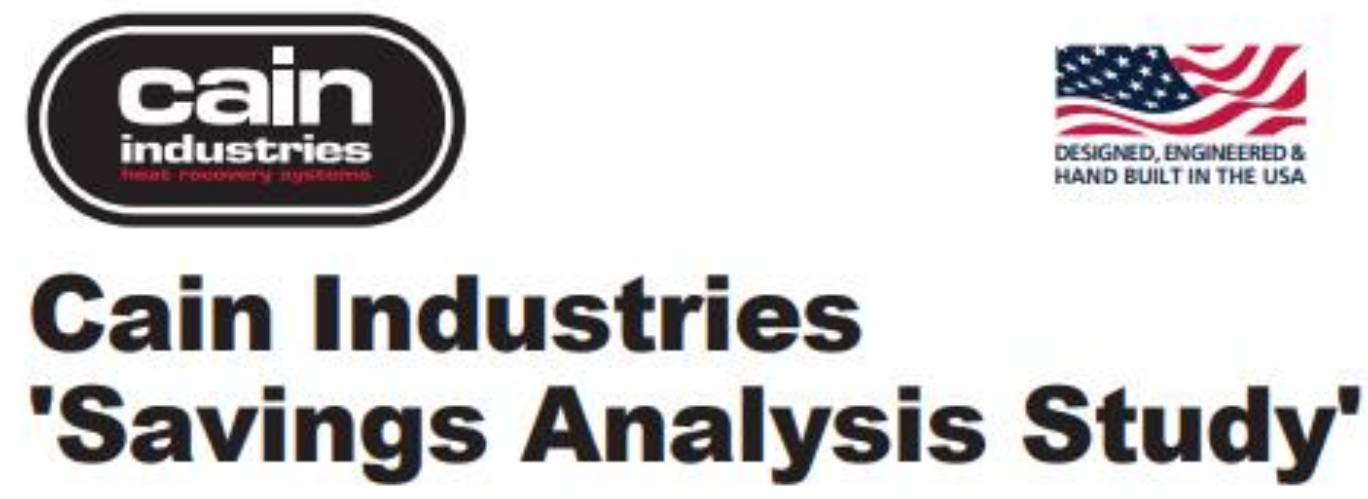

\author{
Waukesha L7044GSI Natural Gas Engine \\ Recovering Exhaust Energy To Generate Steam
}

Exhaust Heat Recovery Proposal

General Submittal Drawing

Terms of Sale and Warranty

Application Data Information

End User

West Virginia University

1500 University Ave.

Morgantown, WV 26506
From.

Cain Industries, Inc.

W194 N11826 McCormick Dr.

Germantown, W1 53022

Ryan O'Connex

Sales Engineer

262-415-7875

yan.oconor geainind.com 


\section{"Manufacturing Waste Heat Transfer Products To Save Energy" \\ Boller Economizer Systems . Gas \& Diesel Cogeneration Systems - Fume Incinerafion Systems Exhaust Steam Generators - Finned Tubing}

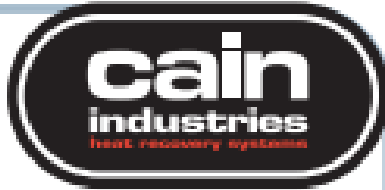

Waukesha L7044GSI Natural Gas Engine

Recovering Exhaust Energy To Generate Steam

Ref: 64070

Rep: 24999015

Rev: 0

\section{Engineered For.}

West Virginia University

1500 University Ave.

Morgantown, WV 26506

\section{End User.}

West Virginia University 1500 University Ave.

Morgantown, WV 26506
Date: $1 / 20 / 2021$

Page: 1

Altn: Diego Dranuta

Ph: $\quad 304-389-7302$

Attn: Diego Dranuta

Ph: $\quad 304-389-7302$

\section{Exhaust Heat Recovery Proposal:}

Cain Industries is pleased to propose the following ESG1 model heat recovery steam generator to recover exhaust heat from a Waukesha L7044GSI Natural Gas Engine and produce 110 psig steam output. The ESG1 package model comes complete with automatic control for either Supplemental (operating with fired steam boilers) or Primary (standalone) steam output.

- The proposed ESG1 product model will reduce the exhaust temperature gas inlet $1,098^{\circ} \mathrm{F}$ to $412^{\circ} \mathrm{F}$, with a $68^{\circ} \mathrm{F}$ pinch point @ $344^{\circ} \mathrm{F}$ saturated steam temperature.

- The recovered $2,200,310 \mathrm{BTU} / \mathrm{hr}$ to steam output shall produce 2,375 \#/hr operating at 110 psi based @ 295 $\mathrm{F}$ inlet feedwater temperature.

- See NOTE1 regarding minimum inlet feedwater temperatures and treated water quality requirements.

- The basic ESG1 features a packaged and skid mounted, forced circulation, water tube, heat recovery steam generator.

- The factory tested ESG1 components contain a bypass section, heat exchanger section, and steam flash drum assembly.

- Included as standard is an automatic modulating exhaust gas bypass, controlled by steam pressure, as well as a modulating feedwater water control system.

- The heat transfer tubes are SA178 GrA carbon steel with carbon steel fins.

- Steam output can be produced in 5-10 minutes from a cold start-up.

The heat exchanger section (double seal welded outer shell to $10^{*}$ W.C.) and the steam flash tank assembly are insulated with protective welded carbon steel exteriors. The exhaust gas bypass shall have 6" thickness insulation and a Stainless Steel protective exterior. After startup/commissoning, the buyer shall be responsible to field insulate the interconnecting piping as deemed necessary.

The Modulating Exhaust Gas Bypass Assembly construction will be designed where all materials in contact with the exhaust gas shall be Stainless Steel.

In the event of loss of electrical power or during an alarm condition, i.e., high water, low water, excess steam pressure, the bypass will be driven to the exhaust bypass position (diverting $99 \%+$ exhaust away from the ESG1).

The steam pressure controller will have Modbus communications for re-transmission of the 
"Manufacturing Waste Heat Transfer Products To Save Energy"

Boiler Economizer Systems - Gas \& Dieset Cogeneration Systems - Fume Incinerafon Systems Exhaust Steam Generators - Finned Tubing

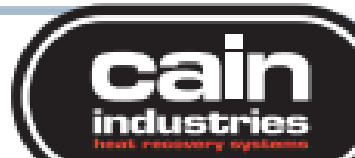

\section{Waukesha L7044GSI Natural Gas Engine}

Recovering Exhaust Energy To Generate Steam

Ref: 64070

Rep: 24999015

Rev: 0
Date: $1 / 20 / 2021$

Page: 2

process variable and remote set point capability. The water level controller will also have Modbus communications for re-transmission of the process variable. Contacts will be provided to remotely drive the exhaust gas bypass to the bypass position. The panel is UL approved.

The ESG1 must be installed indoors within a heated/cooled enclosure protected from freezing and/or from excessive heat above $120^{\circ} \mathrm{F}$.

Optional Equipment: Add $\$ 3639$ for auto surface blowdown installed. Add an additional $\$ 1190$ to add MODBUS communications to the auto surface blowdown controller.

All prices are quoted in US currency. The quoted price does not include freight, export crating, any taxes or duties, or start-up services. See the attached "Terms of Sale" bulletin for start-up service requirements and rates, f.o.b. Cain Industries.

NOTE: The ESG1 product line model is typically selected at a feed water temperature of $212^{\circ} \mathrm{F}$ as the recommended minimum inlet temperature for softened and chemical treated boiler water. The included internal economizer, for higher efficiency and closer approach point, can be used when the available feedwater temperature is above the minimum $150^{\circ} \mathrm{F}$. An optional external feedwater preheater is also available if the feedwater temperature is below $150^{\circ} \mathrm{F}$.

*Upon receipt of written purchase order, Cain Industries shall submit within 7-10 working days, Customer Approval Drawing(s) for review. The product drawing shall be drawn to 'detailed scale' and submitted in the form of AutoCAD .dwg and Adobe .pdf file formats. The submittal drawing shall include various views for plan and elevation customer incorporation into other drawings as required. It is important that these drawing(s) be returned within 60 days from issuance to guarantee quoted price, signed, dated, and marked "Approved for Production" while also forming as a part of the Terms of Sale, and begin the delivery schedule in the proposal. 
"Manufacturing Waste Heat Transfer Products To Save Energy" Boiler Economizer Systems. Gas \& Diesel Cogeneration Systems - Fume Incinerafion Systems Exhaust Steam Generators - Finned Tubing

Waukesha L7044GSI Natural Gas Engine

Recovering Exhaust Energy To Generate Steam

Ref: 64070

Rep: 24999015

Rev: 0

\section{Waste Heat Exhaust:}

Primary Fuel Type:

Fual Cost per 100,000 BTU (USD):

Heat Source:

Exhaust Flow Direction:

Model: ESG1-824816CSS

Overal Length, inches

Overal Widith, inches

Overal Height, inches

Dry Weight, Ibs.

Wet Weight ( $4.8 \mathrm{ft}^{2} / 30 \mathrm{imp}$ gal), lbs.

Surface Area, Ft2

Design Pressure, PSIG

Operating Steam Pressure, PSIG

Hydrostatic Test Pressure, PSIG

@ Design Temperature, " $\mathrm{F}$

Maximum Entering Temperature, " $\mathrm{F}$

Performance:

Load of Maximum Output, \%

Exhaust Entering Temp, " $\mathrm{F}$

Exhaust Flow Rate, SCFM

Exhaust Leaving Temp, "F

Pressure Drop "W.C. Max

"Equivalent Evaporation, lo/hr

Boiler Horsepower, BHP

Boler Feedwater Flow, GPM

+ Sensible Heat Dry Gas

+ Sensible Heat of H2O Vapor

+ Latent Heat of Condensation

TT BTU/hr Recovered

("From $294.8^{\circ} \mathrm{F}$ feedwater to $110 \mathrm{PSIG}$ steam)

\section{Savings:}

Therms (100,000 BTU) Saved/Hr

Annual Hours of Operation.

Annual Savings Per Load
Date: $1 / 20 / 2021$

Page: 3

Natural Gas

Waukesha L7044GSI Natural Gas Engine

Vertical

\begin{tabular}{|c|c|c|c|}
\hline $\begin{array}{r}121 \\
58 \\
110 \\
0000 \\
8300 \\
615 \\
150 \\
110 \\
225 \\
550\end{array}$ & \multicolumn{2}{|c|}{$\begin{array}{l}\text { Customer Connections: } \\
\text { Exhaust Connections } \\
\text { Steam, RF Flange } \\
\text { Boiler Feedwater, NPT } \\
\text { Blowdown Manifold } \\
\text { Steam Safety Valve, NPT } \\
\text { Circulator Motor HP } \\
\text { Voltage }\end{array}$} & $\begin{array}{r}18^{*} \text { Dia. } \\
8-18^{\circ} \text { Dia. } \\
3 \\
3 / 4 \\
1 \\
1-1 / 4 \\
3 \\
230 / 460 \\
60\end{array}$ \\
\hline $\begin{array}{c}\text { Load } 1 \\
100 \% \\
1096^{\circ} \\
2,553 \\
412 \\
1.43 \\
2375 \\
66 \\
5.2 \\
1,848,805 \\
351,505 \\
\text { N/A } \\
2,200,310\end{array}$ & $\begin{array}{r}\text { Load 2 } \\
76 \% \\
1156^{\circ} \\
2,258 \\
406^{\circ} \\
1.20 \\
2305 \\
64 \\
5.0 \\
1,794,465 \\
341,174 \\
\text { NAA } \\
2,135,639\end{array}$ & $\begin{array}{r}\text { Load 3 } \\
52 \% \\
1185^{\circ} \\
1,775 \\
390^{\circ} \\
0.81 \\
1922 \\
53 \\
42 \\
1,496,736 \\
284,568 \\
\text { N/A } \\
1,781,304\end{array}$ & $\begin{array}{r}\text { Load 4 } \\
28 \% \\
1179^{\circ} \\
1,126 \\
367^{\circ} \\
0.38 \\
1243 \\
34 \\
2.7 \\
967,716 \\
183,988 \\
\text { N/A } \\
1,151,704\end{array}$ \\
\hline 22.003 & 21.356 & 17.813 & 11.517 \\
\hline
\end{tabular}


"Manufacturing Waste Heat Transfer Products To Save Energy" Boiler Economizer Systems - Gas \& Diesel Cogeneration Systems - Fume Incinerafion Systems

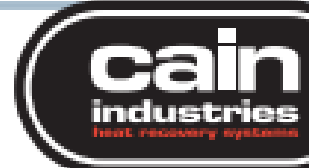

Waukesha L7044GSI Natural Gas Engine

Recovering Exhaust Energy To Generate Steam

Ref: 64070

Rep: 24999015

Date: $1 / 20 / 2021$

Rev: 0

Page: 4

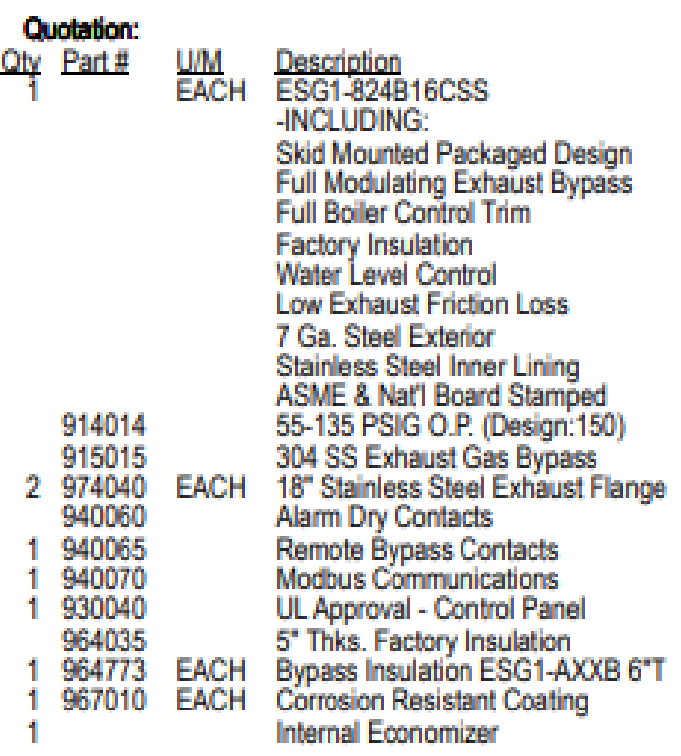

TOTAL PRICE (USD)

Terms of Sale:

*Estimated Shipping: 14-16 weeks after submittal approval

* Payment Terms: See "Terms of Sale" Bulletin \#25500

* See Bulletin 25500 induding 'Warranty and Performance Guarantee'.

* Savings projections will vary from fluctuating fuel costs, operating hours, \& equipment care

$012021-0844-0.90$

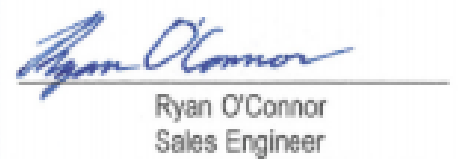


"Manufacturing Waste Heat Transfer Products To Save Energy"

Boler Economizer Systems . Gas \& Dieset Cogeneration Systems - Fume Incinerafion Systems Exhaust Steam Generators - Finned Tubing

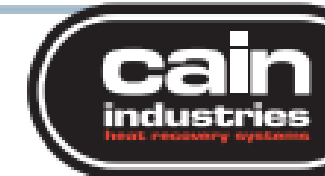

\section{Economizer Performance}

Ref: 64071

Rep: 999

Rev: 0

Waste Heat Exhaust:

Primary Fuel Type:

Fual Cost per 100,000 BTU (USD):

Heat Source:

Exhaust Flow Direction:

Heat Sink:

Liquid Type:

\section{Model: ESGe-224A16ALS}

Overal Configuration, inches

Overal Height, inches

Liquid Connection

Exhaust Connection

Dry Weight, lbs.

Wet Weight (0.9 $\mathrm{ft}^{\mathrm{t}} / 5 \mathrm{imp}$ gal), lbs.

Surface Area, Ft2

Design Pressure, PSIG

Hydrostatic Test Pressure, PSIG

@ Design Temperature, " $\mathrm{F}$

Maximum Entering Temperature, " $\mathrm{F}$

\section{Performance:}

Load of Maximum Output, \%

Exhaust Entering Temp, " $\mathrm{F}$ Exhaust Flow Rate, SCFM Exhaust Leaving Temp, 'F Pressure Drop "W.C. Max Liquid Entering Temp, "F Liquid Flow Rate, GPM Liquid Leaving Temp, "F

Pressure Drop, PSIG

+ Sensible Heat Dry Gas

+ Sensible Heat of H2O Vapor

+ Latent Heat of Condensation

TT BTU/hr Recovered

\section{Savings:}

Therms (100,000 BTU) Saved/Hr

Annual Hours of Operation

Annual Savings Per Load
Date: 1/19/2021

Page: 2

Natural Gas

Waukesha L7044GSI Natural Gas Engine Vertical

Water 


\section{SUBMITTAL}

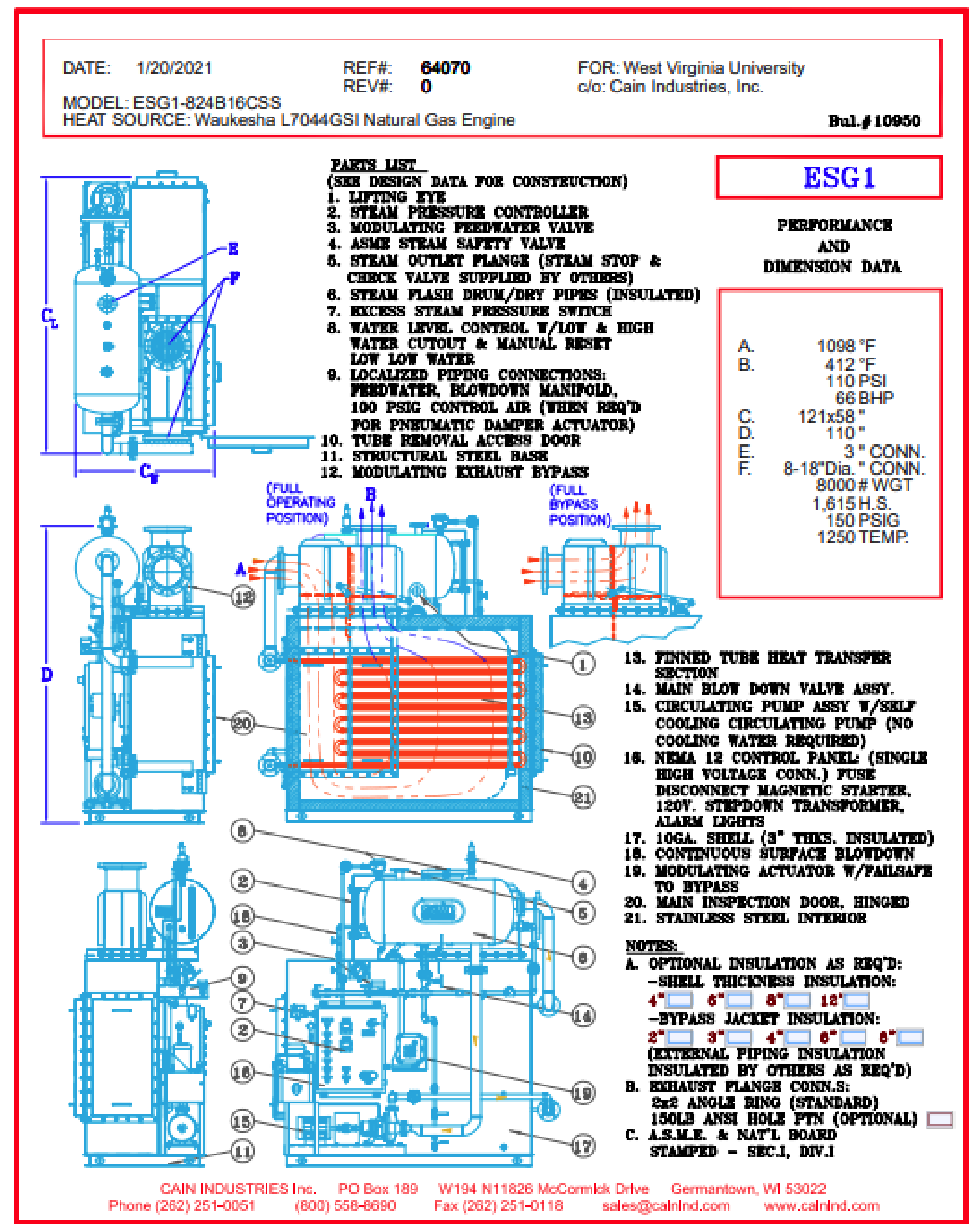




\section{Jacket Water Heat Exchanger Quote}

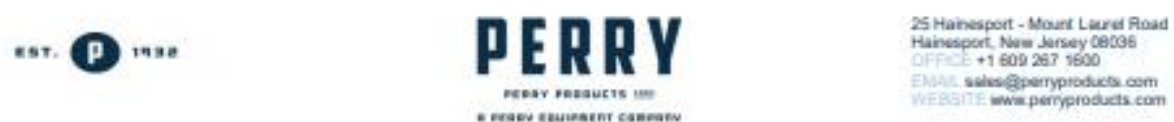

Company: West Virginia University

Attn: Diego Dranuta

Email: dgdranuta@mix.wvu.edu
Date: $3 / 1 / 2021$

Perry Ref: 21-064

Revision: 0

Option 1: Jacket Water Heat Exchanger - Per Customer Data Sheet

Description: AEL-16-192 (16" Diameter Shell / 192' Long Tubes)

Approx Sq Ft: $603 \mathrm{ft2}$ (each)

Materials: C/S Shellside, C/S Tubeside

Tubes: (192) 3/4" OD X 16 GA (MW) X 192" LG X SA-214 Welded Tubes

Design: TEMA Class C / Type: AEL

Code: Construction is per ASME VIII/D1. Exchanger will be ASME stamped and NB registered.

Notes: Exchanger includes supports for horizontal operation. Tubes to be rolled and expanded into a double grooved tubesheet. External carbon steel to be sandblasted and coated with standard shop primer.

\begin{tabular}{|r|l|l|}
\hline \multicolumn{1}{|c|}{ DESIGN } & Shell Side (1-Pass) & Tube Side (2-Pass) \\
\hline PRESSURE: & $150 \mathrm{PSI}$ & $150 \mathrm{PSI}$ \\
\hline TEMPERATURE: & $250^{\circ} \mathrm{F}$ & $250^{\circ} \mathrm{F}$ \\
\hline MATERIAL: & $\mathrm{C} / \mathrm{S}$ & $\mathrm{C} / \mathrm{S}$ \\
\hline CONNECTIONS: & $(2) 3^{\circ} 150 \#$ RFSO & $(2) 3^{\circ} 150 \#$ RFSO \\
\hline & & \\
\hline CORR ALLOW: & $0.0625^{\circ}$ & $0.0625^{\circ}$ \\
\hline RADIOGRAPH: & None & None \\
\hline EX JT: & None & \\
\hline
\end{tabular}

\section{MATERIALS OF CONSTRUCTION:}

Tubes: SA-214 Carbon Steel

Tubesheets: SA-516-70

Baffles: C/S

Shell/ Channel Cylinders: SA-53 E/B

Shell / Channel Nozzles: SA-106B / SA-105

Channel Covers: SA-516-70

Body Flanges: SA-105

Gaskets: Klingersil C4430

Bolting: SA-193-B7 / SA-194-2H (Coated)

\section{Price Qty (3): $\$ 82,100$}

Shipment: (6) to (8) weeks after receipt of approval drawings and release for shop fabrication

Drawings: (1) to (2) weeks after receipt of order

All prices are ExWorks, Hainesport, NJ.

Perry Products Proposal 


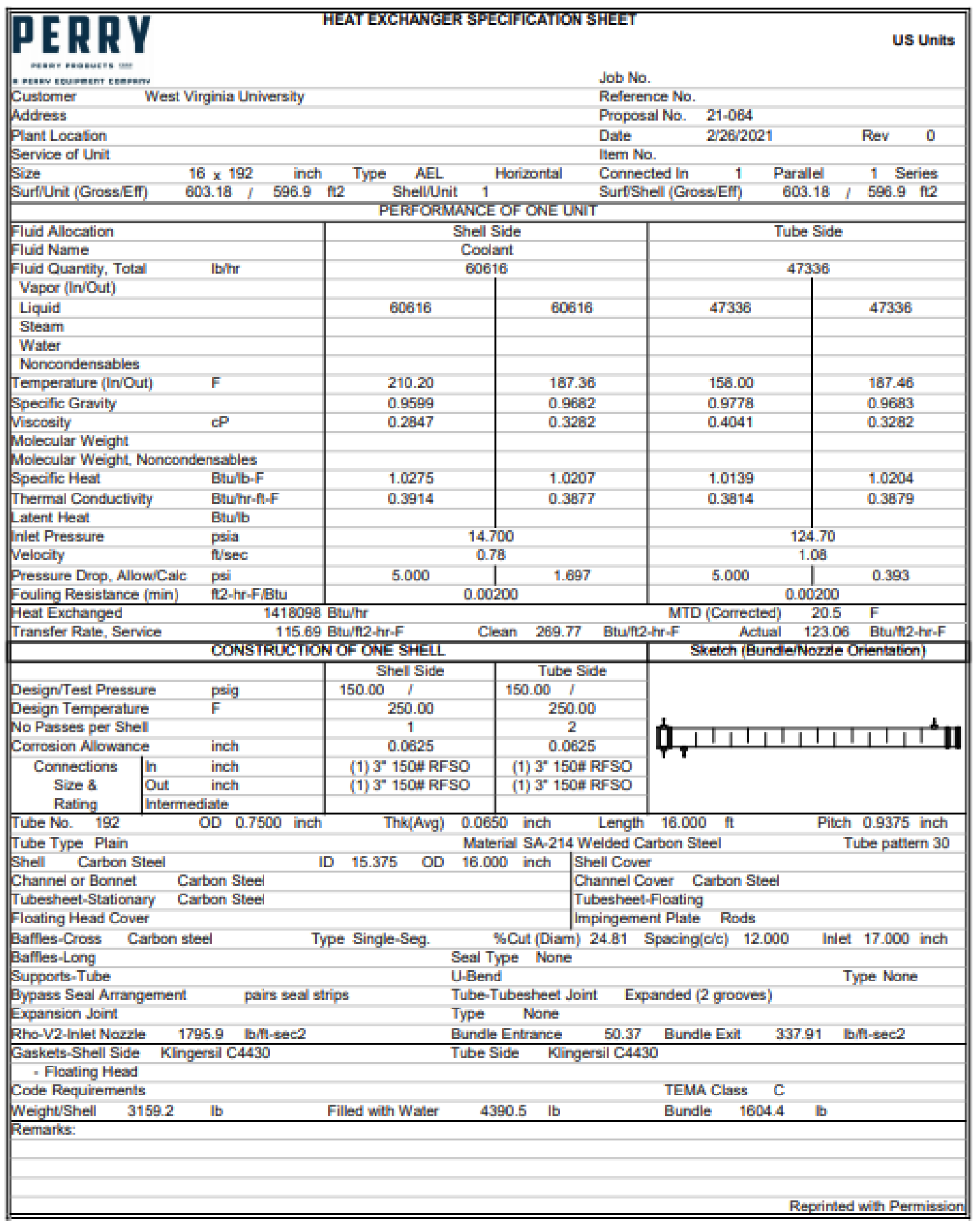




\subsection{Appendix E: SIMULINK® 0-D Models. HHPDE CHP System}

HHPDE CHP system engine, E-HEX, and JW-HEX sub model SIMULNK® Environment

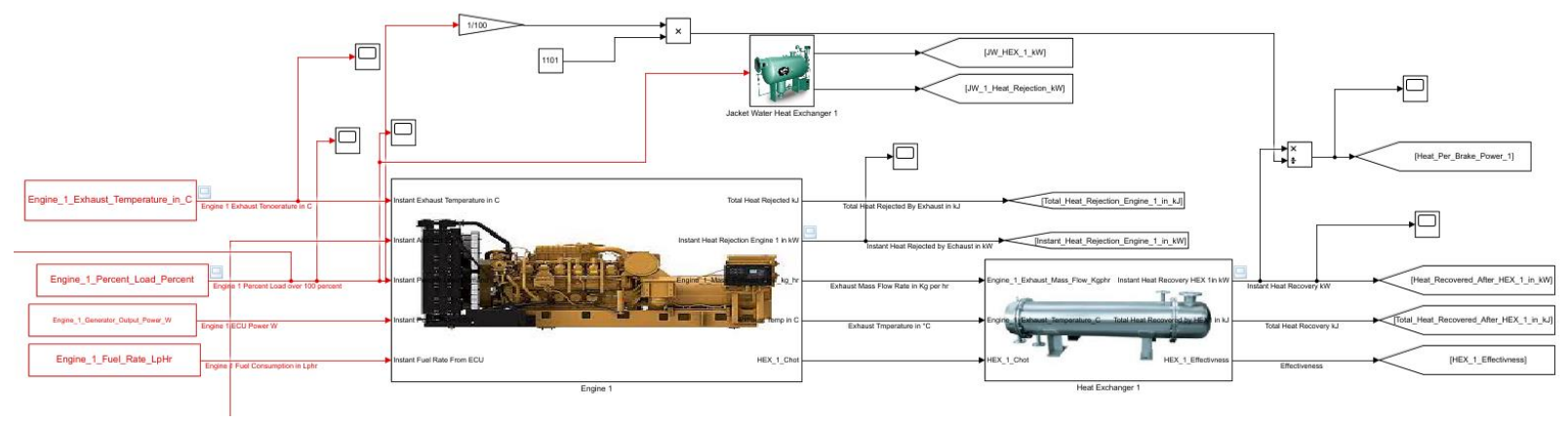

Where engine subsystem inputs were:

- Exhaust temperature

- Engine load

- Genset instant power output

- Engine fuel consumption

Engine Subsystem outputs were:

- Total exhaust heat rejection

- Instant exhaust heat rejection

- Exhaust mass flow rate (dry air and water vapor combined)

- Exhaust temperature

CAT 3512C engine calculations based on Equation 2 are shown in the figures below 
HHPDE CHP system engine sub model calculations based on Equation 2.

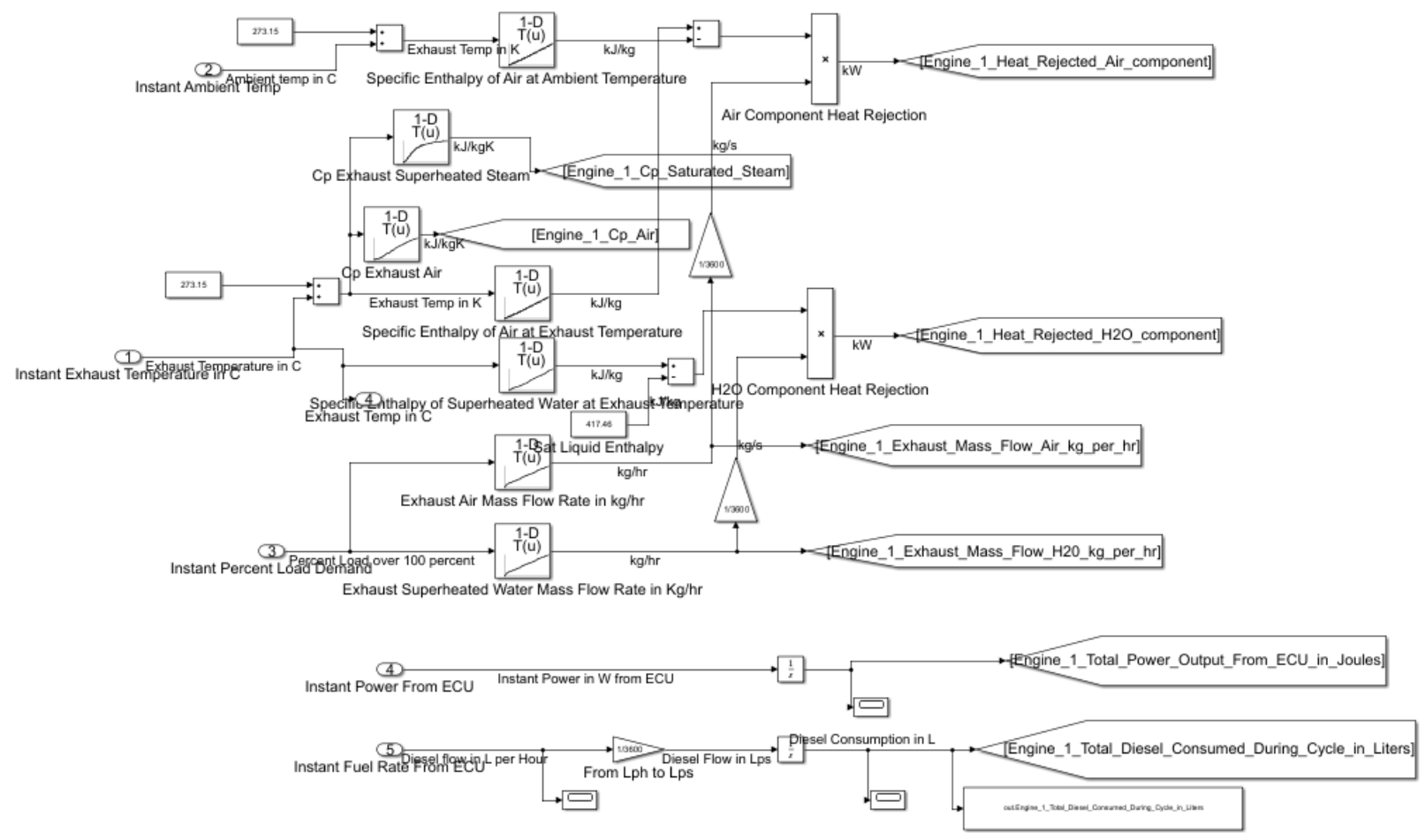


HHPDE exhaust flow dry air and water vapor mass flow rates modeled used on Equation 2 for heat rejection calculations.

\begin{tabular}{|c|c|c|}
\hline Engine Load & Mass Exhaust Flow rate air & $\mathrm{H}_{2} \mathrm{O}$ Mass Exhaust Flow rate \\
\hline$\%$ & $\mathrm{~kg} / \mathrm{hr}$ & $\mathrm{kg} / \mathrm{hr}$ \\
\hline 0 & 0.0 & 0.0 \\
\hline 5 & 889.9 & 44.4 \\
\hline 10 & 1176.2 & 58.6 \\
\hline 15 & 1462.5 & 72.9 \\
\hline 20 & 1748.7 & 87.2 \\
\hline 25 & 2035.0 & 101.4 \\
\hline 30 & 2321.3 & 115.7 \\
\hline 35 & 2607.6 & 130.0 \\
\hline 40 & 2893.9 & 144.2 \\
\hline 45 & 3180.2 & 158.5 \\
\hline 50 & 3459.5 & 172.4 \\
\hline 55 & 3752.7 & 187.0 \\
\hline 60 & 4039.0 & 201.3 \\
\hline 65 & 4325.3 & 215.6 \\
\hline 70 & 4611.6 & 229.8 \\
\hline 75 & 4911.7 & 244.8 \\
\hline 80 & 5184.1 & 258.4 \\
\hline 85 & 5470.4 & 272.6 \\
\hline 90 & 5756.7 & 286.9 \\
\hline 95 & 6043.0 & 301.2 \\
\hline 100 & 6322.3 & 315.1 \\
\hline
\end{tabular}


HHPDE engine sub system SIMULINK® environment outputs.
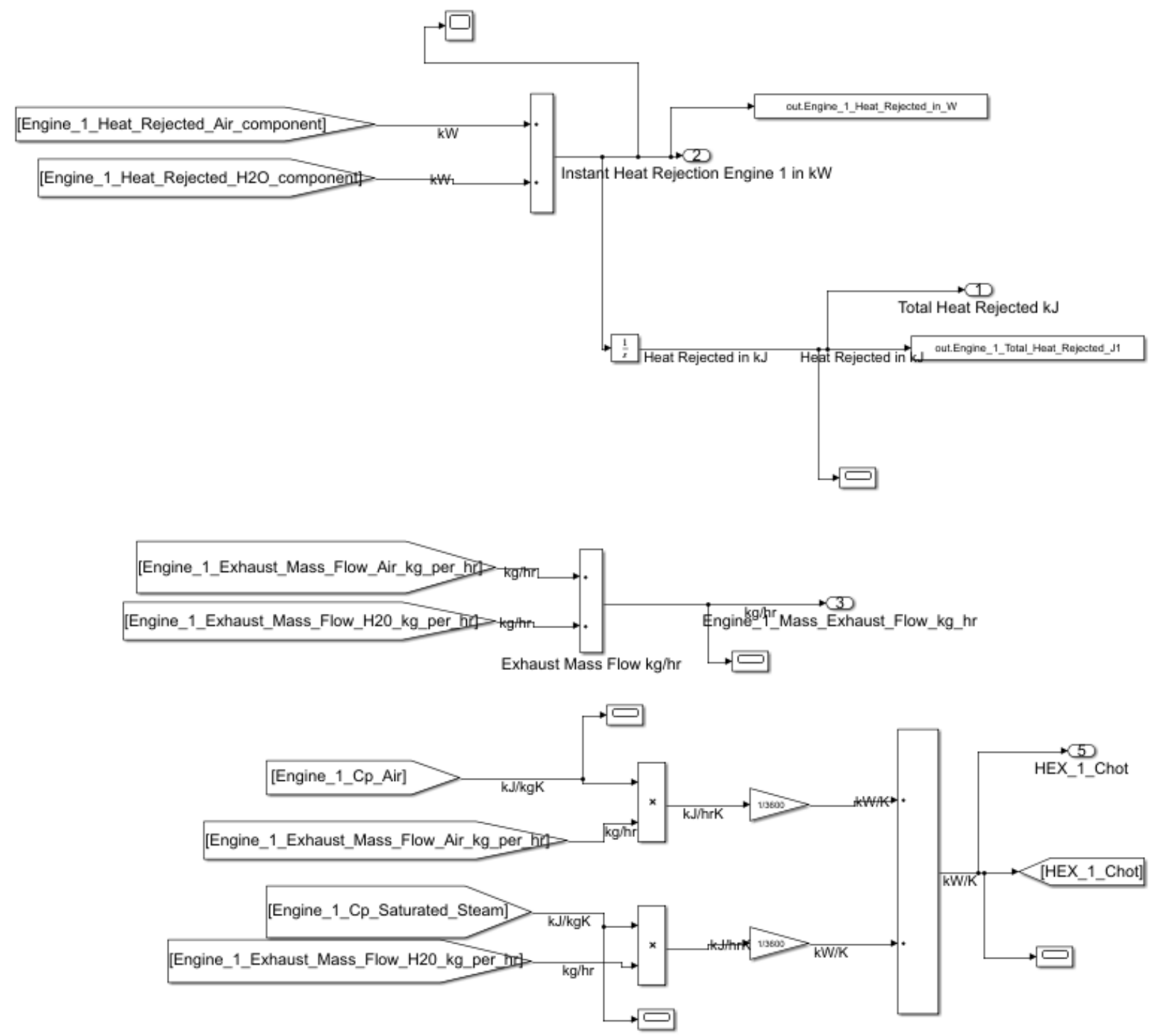

HHPDE E-HEX subsystem inputs were:

- Exhaust mass flow rate (dry air and water vapor combined)

- Exhaust temperature

HHPDE E-HEX subsystem outputs were:

- Instant heat recovery

- Total heat recovery 
HHPDE E-HEX calculations are presented in the figures below, along with the two-entry table used for heat recovery calculations and HHPDE E-HEX water flow rate.

HHPDE E-HEX calculations HHPDE exhaust composition model and variable exhaust gas temperatures.

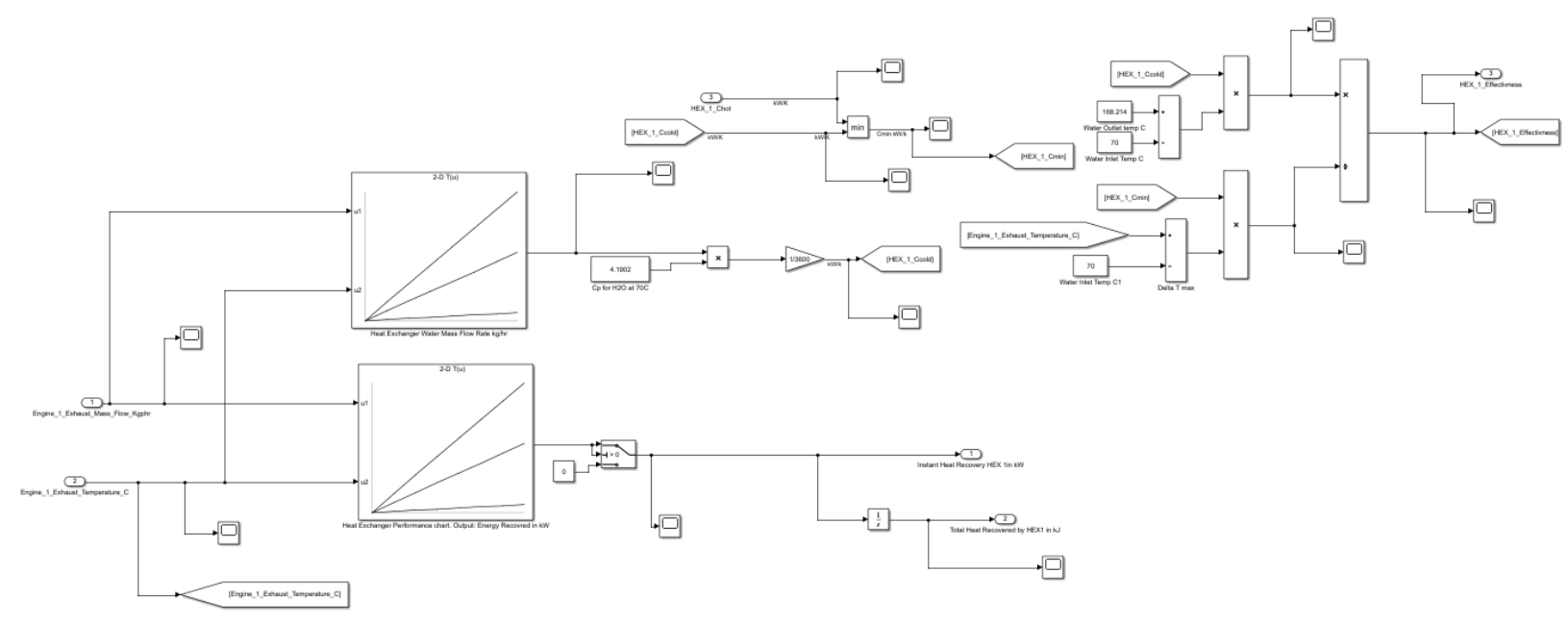

HHPDE E-HEX heat recovery two-entry table based on CHEMCAD® simulated scenarios for modeled exhaust gas composition and variable exhaust gas temperatures.

\begin{tabular}{|c|c|c|c|}
\hline \multicolumn{4}{|c|}{ HEX Energy Performance $\mathrm{kW}$} \\
\hline Exhaust & Engine Exhaust Temperature $\left({ }^{\circ} \mathrm{C}\right)$ \\
\hline Exhaust Flow $(\mathrm{kg} / \mathrm{hr})$ & 200 & 400 & 600 \\
\hline 0 & 0.0 & 0.0 & 0.0 \\
\hline 1000 & 9.6 & 84.7 & 162.5 \\
\hline 2000 & 19.3 & 169.3 & 323.6 \\
\hline 3000 & 28.9 & 254.7 & 483.3 \\
\hline 4000 & 38.6 & 339.4 & 643.0 \\
\hline 5000 & 48.2 & 424.1 & 801.3 \\
\hline 6000 & 58.5 & 509.4 & 959.0 \\
\hline 7000 & 68.2 & 593.4 & 1115.2 \\
\hline
\end{tabular}


HHPDE E-HEX water flow rate two-entry table based on CHEMCAD® simulated scenarios and variable exhaust gas temperatures.

\begin{tabular}{|c|c|c|c|}
\hline \multicolumn{4}{|c|}{ HEX WATER SIDE MASS FLOW RATE KG/HR } \\
\hline Exhaust & \multicolumn{3}{|c|}{ Temperature $\left({ }^{\circ} \mathrm{C}\right)$} \\
\hline Exhaust Flow $(\mathrm{kg} / \mathrm{hr})$ & 200 & 400 & 600 \\
\hline 0 & 0 & 0 & 0 \\
\hline 1000 & 14 & 123 & 236 \\
\hline 2000 & 28 & 246 & 470 \\
\hline 3000 & 42 & 370 & 702 \\
\hline 4000 & 56 & 493 & 934 \\
\hline 5000 & 70 & 616 & 1164 \\
\hline 6000 & 85 & 740 & 1393 \\
\hline 7000 & 99 & 862 & 1620 \\
\hline
\end{tabular}

HHPDE JW-HEX subsystem input was:

- Engine load

HHPDE JW-HEX subsystem outputs were:

- Instant Heat rejection to JW

- Instant heat recovery

The figures below present the models used for the instant heat rejection to JW and instant heat recovery via JW-HEX utilized in the 0-D SIMULINK model. 
HHPDE heat rejected to the coolant based modeled JW temperature and mass flow rates as a function of engine load.

\begin{tabular}{|c|c|}
\hline \multicolumn{2}{|c|}{ HHPDE JW-HEX Heat Rejection Model } \\
\hline Engine Load (\%) & Heat Rejection (kW) \\
\hline 0 & 0.0 \\
\hline 5 & 30.6 \\
\hline 10 & 60.1 \\
\hline 15 & 88.5 \\
\hline 20 & 115.9 \\
\hline 25 & 142.2 \\
\hline 30 & 167.5 \\
\hline 35 & 191.7 \\
\hline 40 & 214.8 \\
\hline 45 & 236.9 \\
\hline 50 & 257.9 \\
\hline 55 & 277.9 \\
\hline 60 & 296.8 \\
\hline 65 & 314.7 \\
\hline 70 & 331.4 \\
\hline 75 & 347.2 \\
\hline 80 & 361.8 \\
\hline 85 & 375.4 \\
\hline 90 & 388.0 \\
\hline 95 & 399.5 \\
\hline 100 & 409.9 \\
\hline
\end{tabular}


HHPDE JW-HEX performance based on CHEMCAD® simulated scenarios, modeled exhaust gas composition and exhaust gas temperatures.

\begin{tabular}{|c|c|}
\hline Engine Load & Heat Recovered \\
\hline$\%$ & $\mathrm{~kW}$ \\
\hline 0 & 0 \\
\hline 10 & 49.61 \\
\hline 20 & 100.87 \\
\hline 30 & 152.41 \\
\hline 40 & 202.89 \\
\hline 50 & 250.96 \\
\hline 60 & 295.94 \\
\hline 70 & 334.47 \\
\hline 75 & 351.74 \\
\hline 80 & 367.2 \\
\hline 90 & 392.1 \\
\hline 100 & 407.84 \\
\hline
\end{tabular}

HHPDE ESG subsystem input was:

- Engine load

HHPDE ESG subsystem outputs were:

- Instant heat recovery

- Total heat recovery

The HHPDE ESG subsystem included calculations for the three engines ESGs. Figures below present the HHPDE ESG subsystem and its heat recovery model. 
HHPDE ESG SIMULINK® subsystem containing the three ESG (one per genset).

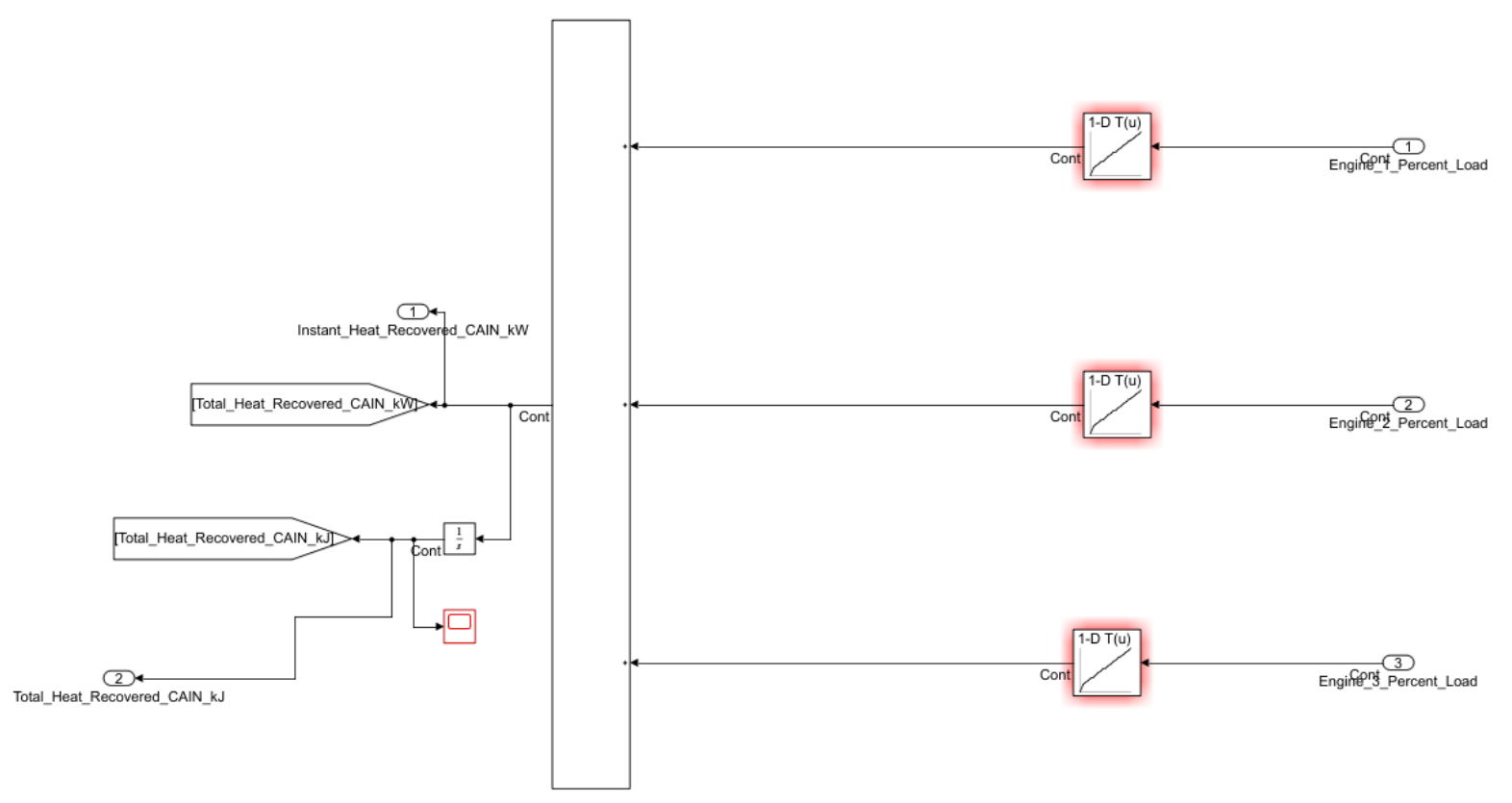


HHPDE ESG heat recovery model based on data provided by CAIN Industries which is attached in Appendix D.

\begin{tabular}{|c|c|}
\hline Engine Laod & Heat Recovery \\
\hline$\%$ & $\mathrm{~kW}$ \\
\hline 0 & 0.0 \\
\hline 5 & 86.8 \\
\hline 10 & 108.7 \\
\hline 15 & 130.6 \\
\hline 20 & 152.5 \\
\hline 25 & 174.4 \\
\hline 30 & 196.3 \\
\hline 35 & 218.1 \\
\hline 40 & 240.0 \\
\hline 45 & 261.9 \\
\hline 50 & 283.8 \\
\hline 55 & 305.7 \\
\hline 60 & 327.6 \\
\hline 65 & 349.5 \\
\hline 70 & 371.4 \\
\hline 75 & 393.3 \\
\hline 80 & 415.2 \\
\hline 85 & 437.1 \\
\hline 90 & 459.0 \\
\hline 95 & 480.9 \\
\hline 100 & 502.8 \\
\hline
\end{tabular}

\section{HHPDE CHP hybrid System}

The HHPDE CHP hybrid system included the same subsystems as the HHPDE CHP system plus the HEMS subsystem. The figures below show the HEMS subsystem and its respective sub models. 
HEMS SIMULINK® subsystem used for both HHPDE CHP hybrid and DNGE CHP hybrid models

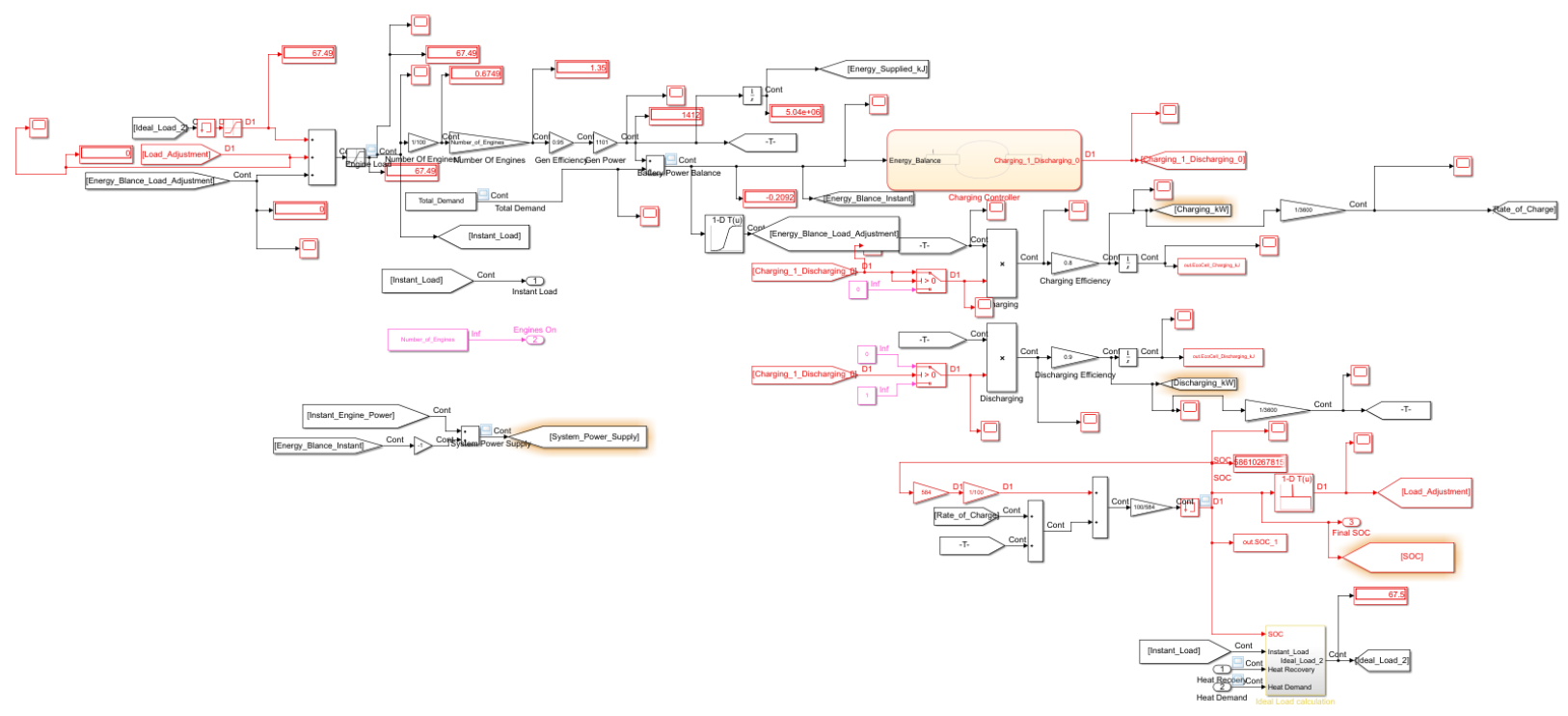

Where the main components of this subsystem were:

- Power demand

- Imported from recorded cycles

- Energy balance (charging/discharging control)

○ Determined when the HEMS was charging or discharging given power demand and power supply

- Power demand

- Power produced by gensets

- Power supplied by or to the HEMS

- HEMS control system

○ Ideal load control system

- Utilized the previous 60 seconds of SOC to adjust the load to an ideal steady load to meet cycle power demands

○ Energy balance engine load adjustment control

- Prevented the HEMS from exceeding charging and discharging rates

○ SOC engine load adjustment control

- Maintained the HEMS within the SOC operational range (40\% to $100 \%$ )

○ Heat balance control 
- Adjusted engine load to meet instant power demands if the energy balance engine load adjustment control and the SOC engine load adjustment control allowed it.

The HEMS sub models of the subsystem are presented in the figures below.

HEMS charging/discharging control system modeled.

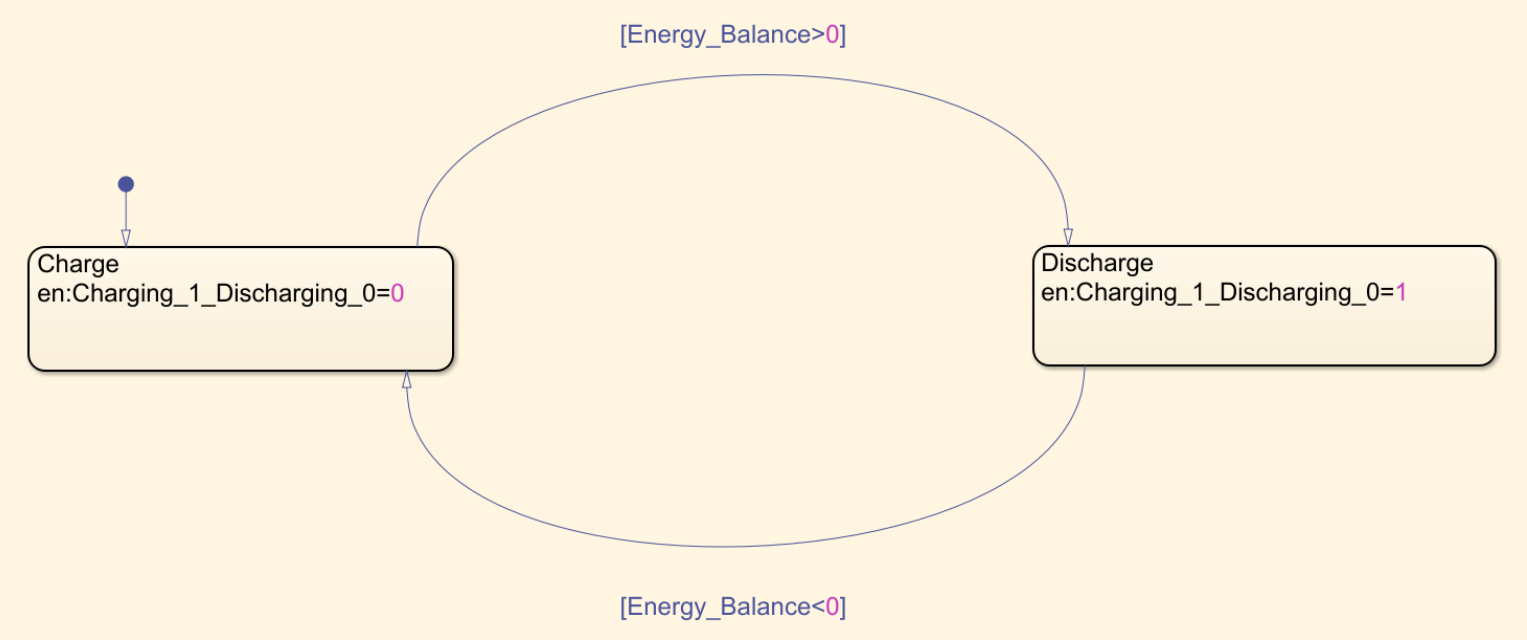

HEMS energy balance engine load adjustment control and SOC engine load adjustment control designed for complying with the HEMS technical specifications.

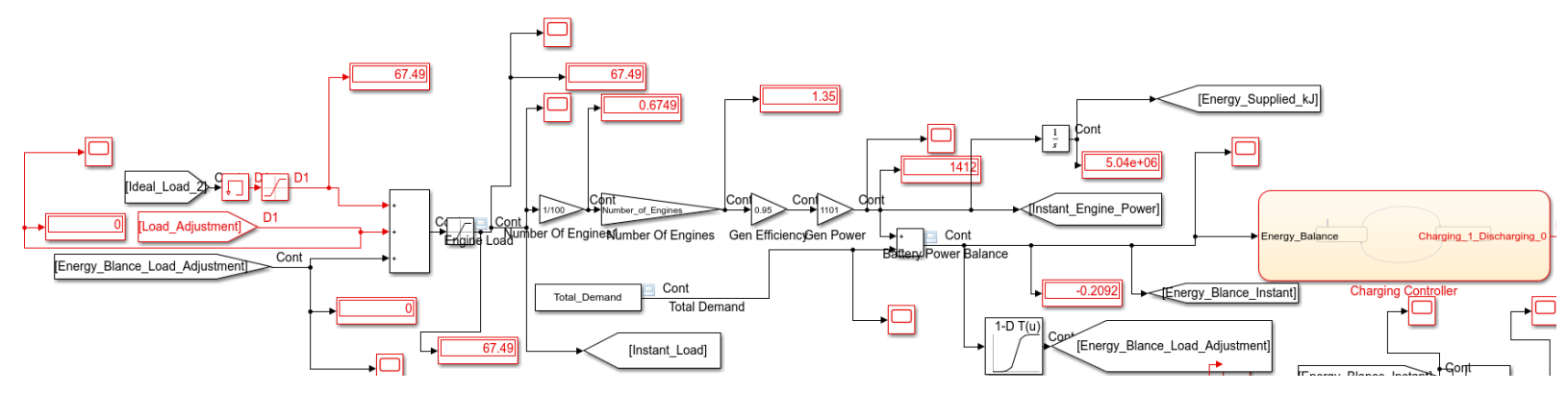


HEMS heat control balance.

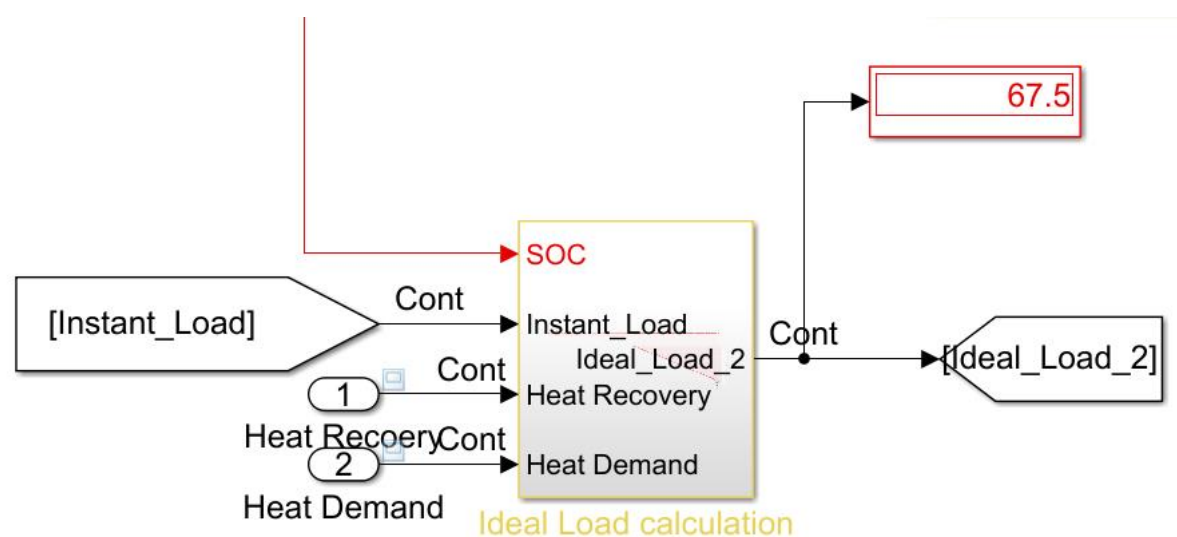

\section{DNGE CHP System}

DNGE CHP system engine and E-HEX sub models SIMULNK@ Environment

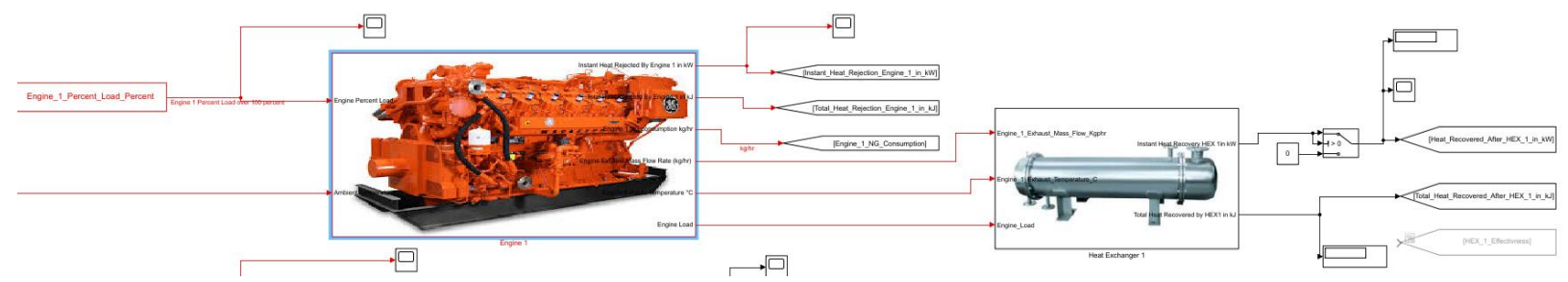

Where engine subsystem inputs were:

- Engine load

Engine Subsystem outputs were:

- Total exhaust heat rejection

- Instant exhaust heat rejection

- Exhaust mass flow rate (dry air and water vapor combined)

- Exhaust temperature

- Engine load

- Natural gas consumption 
Waukesha L7044GSI engine calculations based on Equation 2 are shown in the figures below.

DNGE CHP system engine sub model calculations based on Equation 2.
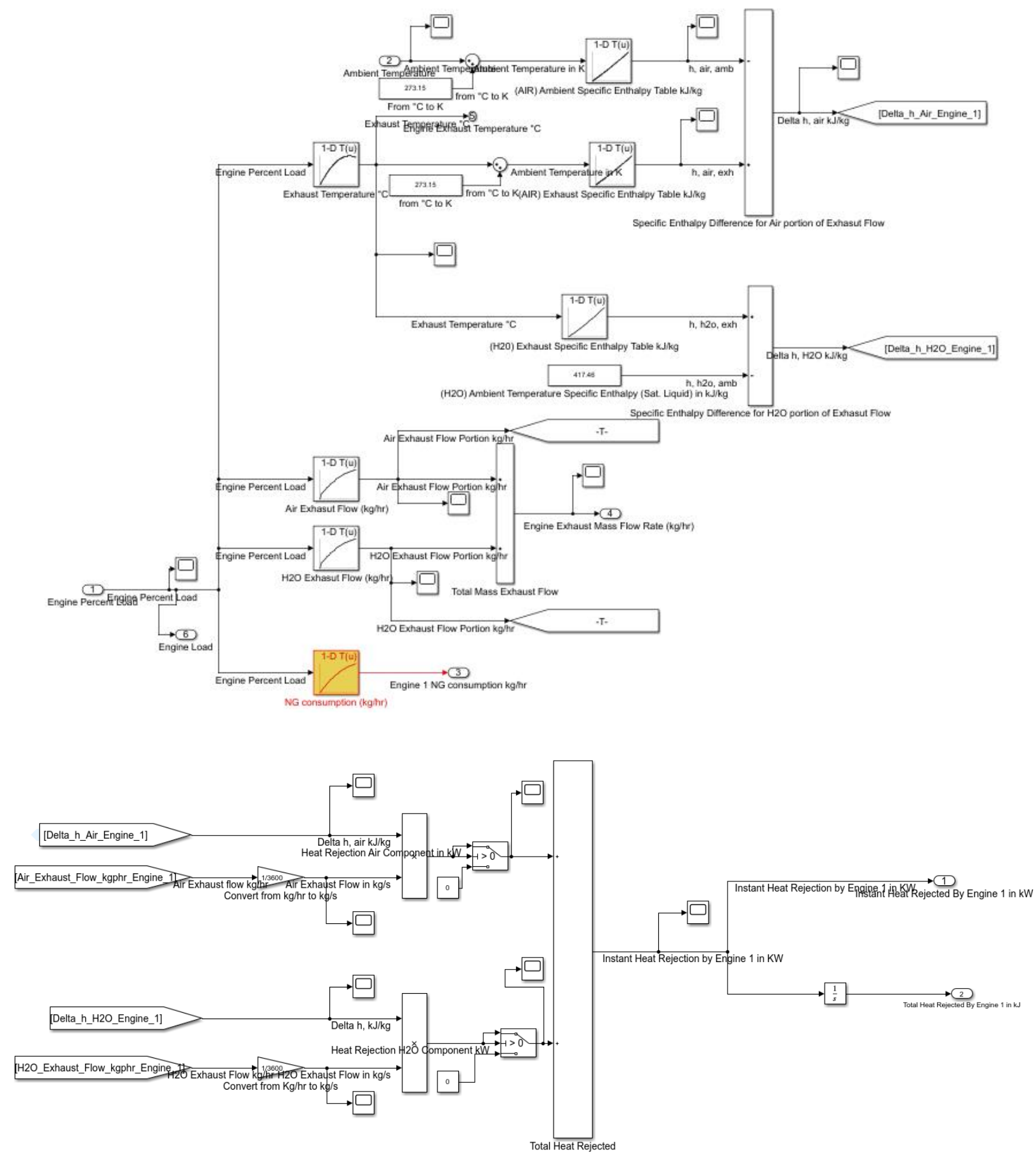
DNGE E-HEX subsystem inputs were:

- Exhaust mass flow rate (dry air and water vapor combined)

- Exhaust temperature

- Engine Load

HHPDE E-HEX subsystem outputs were:

- Instant heat recovery

- Total heat recovery

HHPDE E-HEX calculations are presented in the figures below, along with the two-entry table used for heat recovery calculations and HHPDE E-HEX water flow rate.

DNGE CHP system E-HEX sub model based on engine laod.

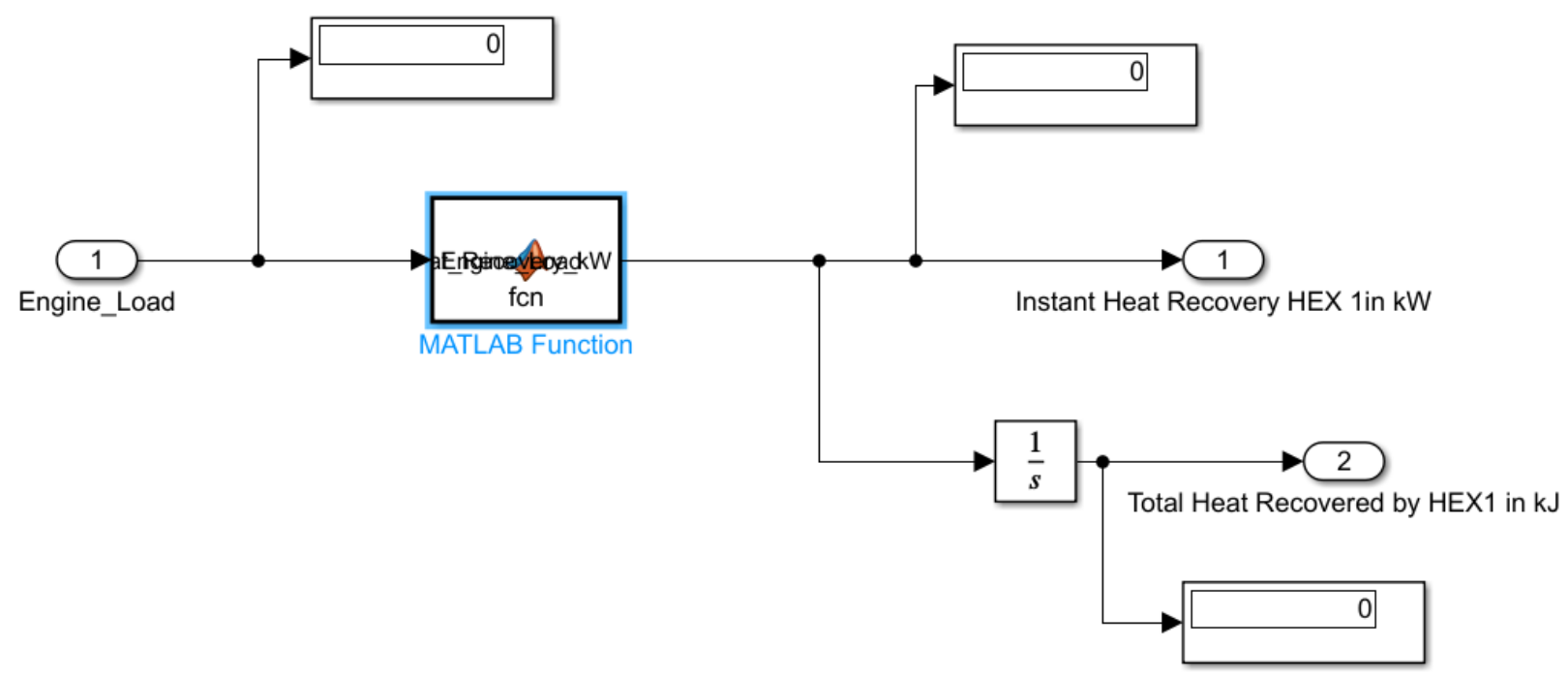

Where the DNGE E-HEX model was included in the MATLAB® function block and presented below.

function Heat_Recovery_kW = fcn(Engine_Load)

Heat_Recovery_kW $=9.9 \overline{2} 51 .{ }^{\star}$ Engine_Load;

DNGE boiler subsystem inputs were: 
- Boiler diesel fuel feed

- Boiler diesel fuel return

DNGE boiler subsystem inputs were:

- Instant heat output

○ Total heat output

○ Natural gas fuel consumption (converted utilizing Equation 1)

- Total natural gas fuel consumption

The figures below show the natural gas powered boiler model

DNGE CHP system boiler sub model calculations based on Equation 1.

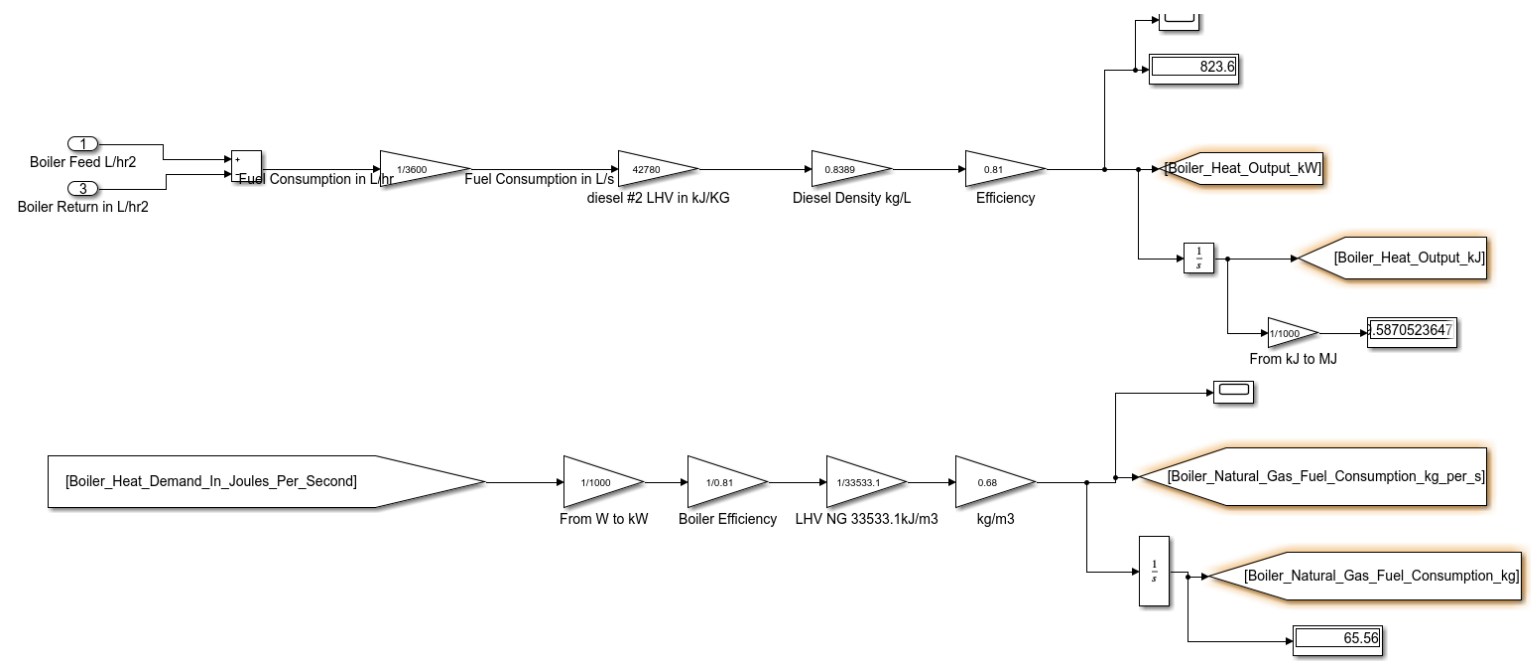

DNGE ESG subsystem input was:

- Engine load

DNGE ESG subsystem outputs were:

- DNGE ESG instant recovered heat

- DNGE ESG total recovered heat

The figures below present the DNGE ESG subsystem, which includes the three ESG (one per genset). 
DNGE CHP system SIMULINK® ESG sub model.

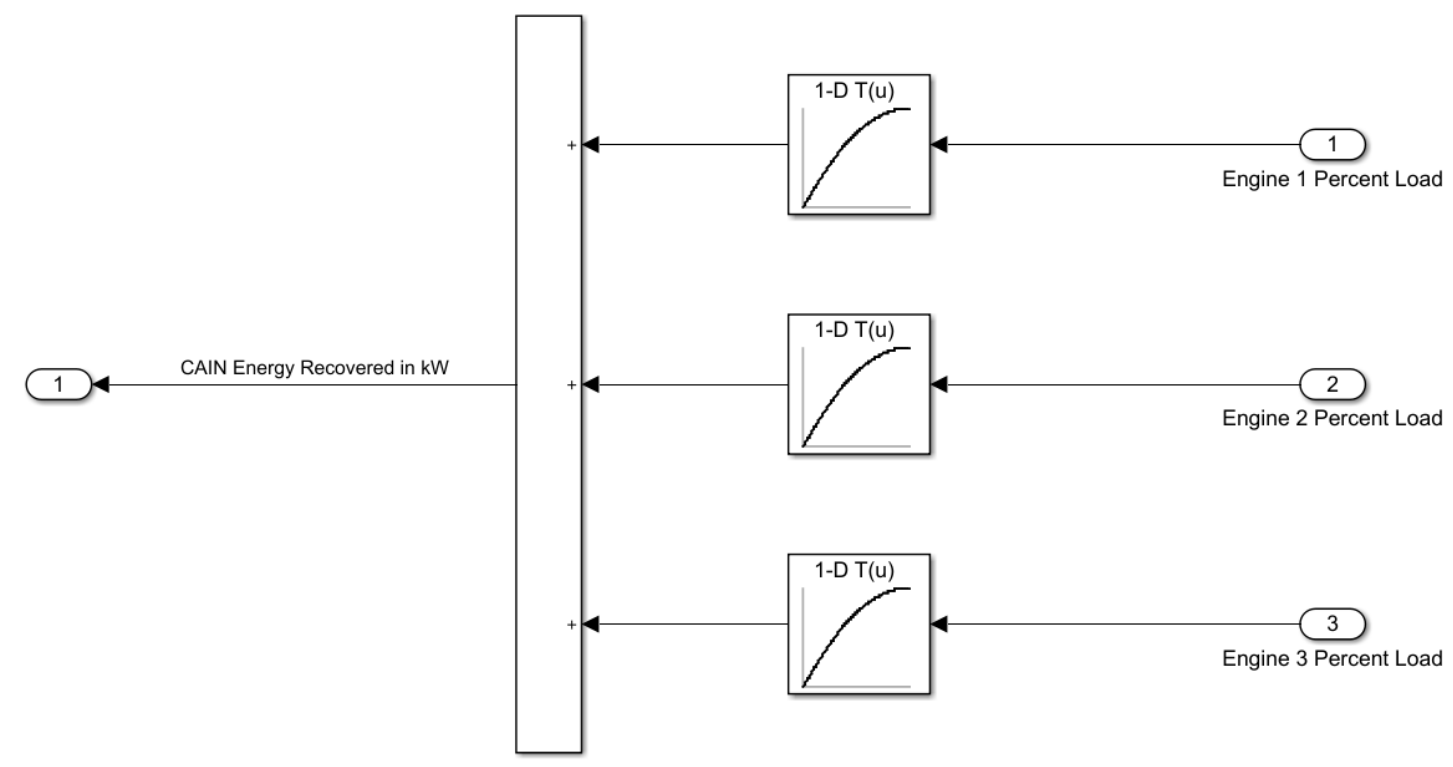

DNGE CHP system ESG sub model calculations based on engine load and ESG performance supplied by CAIN Industries as specified in Appendix D

\begin{tabular}{|c|c|}
\hline Engine Load & Heat Recovery \\
\hline$\%$ & $\mathrm{~kW}$ \\
\hline 0 & 0 \\
\hline 10 & 131.6 \\
\hline 20 & 249.16 \\
\hline 30 & 352.68 \\
\hline 40 & 442.16 \\
\hline 50 & 517.6 \\
\hline 60 & 579 \\
\hline 70 & 626.36 \\
\hline 80 & 659.68 \\
\hline 90 & 678.96 \\
\hline 100 & 684.2 \\
\hline
\end{tabular}




\section{DNGE CHP Hybrid System}

The DNGE CHP hybrid system added the same HEMS system utilized for the HHPDE CHP hybrid system to the DNGE CHP system. Same subsystems and blocks were copied and implemented into a new SIMULINK $®$ environment model. 


\subsection{Appendix F: Boiler Rental Pricing}

\section{Rental Quote}

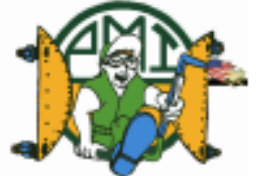

Bill To

Diego Dranuta

WVU

Morgantown, WV

Phone: (304) 389-7302

\section{Booking Number BK0007064 \\ Booking Date 4/16/2021 \\ PO Number}

Power Mechanical, Inc. 4811 Commerce Drive Newport News, VA 23607

\section{Rental Location}

Diego Dranuta

WVU

Morgantown, WV

Phone: (304) 389-7302

Customer Name WVI

Payment Terms

Power Mechanical, Inc. proposes to provide the following rental equipment for your project:

Description 200 HP Steam Boiler, 110 PSI, \#2 Oil Or Gas, 480V

Rental Rate $\$ 7,500.00$ per MONTH

Price is based on a 1 month minimum rental.

Please note that all units are subject to availability at the time of order

Miscellaneous Charges $\quad$ Quantity U of M Unit Price Line Total

TRUCKING CHARGE Round Trip Freight Charge $\quad 1.00 \quad$ EACH $3,950.00 \quad 3,950.00$

START UP T/M Start up: Billed on a T\&M basis. This service is required to be performed by a PMI technician.

By my signature below, I certify that I have read and agree to the provisions set forthe in this Rental Agreement and in the General Terms and Conditions and Equipment Terms and Conditions posted at www.PMITerms.com. I understand that a copy of the Terms and Conditions can be sent to me at my request.

Customer Signature:

PO\#:
Date:

Expected Date of Delivery: 